Universidade de São Paulo

Faculdade de Filosofia, Ciências e Letras de Ribeirão Preto Departamento de Química

Programa de Pós-Graduação em Química

\title{
Síntese do Aripuanin
}

\section{Aline Fernanda Nascimento}

\section{Orientador: Paulo Marcos Donate}

\begin{abstract}
Dissertação apresentada à Faculdade de Filosofia, Ciências e Letras de Ribeirão Preto da Universidade de São Paulo, como parte das exigências para a obtenção do título de Mestre em Ciências, Área: Química
\end{abstract}

RIBEIRÃO PRETO -SP 
Dedico esta dissertação à minha mãe Maria Luiza e ao meu pai José Lino, pelo amor e carinho de sempre. E com muito esforço deram condições para que eu pudesse estudar. Obrigada. 


\section{Agradecimentos}

- Ao Prof. Dr. Paulo Marcos Donate, pela orientação, confiança e paciência.

- Ao Prof. Dr. Maurício Gomes Constantino e ao Prof. Dr. Gil Valdo José da Silva, pela colaboração e amizade.

- Ao Djalma, Mércia e Virgínia pelas respectivas análises realizadas: IV, HPLC e RMN e além de tudo pela amizade.

- Aos amigos do laboratório: Álvaro, Chico, Cláudio, Daiane, Érica, Felipe, Luíz (Jamanta), Luís Felipe (Magrelo), Marcel, Marco (Boi), Mirela, Miro, Paulo, Rodrigo (Pena), Rosangela, Susimaire, Valdemar, Valquíria, Walter, Vinícius.

- Em especial, agradeço à Ana Lucia, Daniel, Kleber e Ricardo (PSTU), pelo auxílio prestado no dia a dia do laboratório e principalmente pelas orientações e sugestões ao meu trabalho.

- À Adriana, Andreza, Anderson, Carla, Cristina, Elen, Eliana, Josi, Mariza, Miriam e Rosane pela amizade e incentivo.

- À todas às pessoas que de alguma forma contribuíram para a realização deste trabalho.

- À Capes pela ajuda financeira. 


\section{ÍNDICE}

$\begin{array}{ll}\text { ABREVIAÇÕES } & \text { ii }\end{array}$

RESUMO $\quad$ iii

SUMMARY iv

$\begin{array}{ll}\text { 1. INTRODUÇÃO } & 01\end{array}$

1.1. Plantas do gênero Fícus $\quad 02$

1.2. Os carotenóides $\quad 04$

1.3. Metabólitos de carotenóides cíclicos $\quad 07$

$\begin{array}{ll}\text { 1.4. O Aripuanin } & 13\end{array}$

2. OBJETIVO 15

3. DISCUSÃO DOS RESULTADOS 17

4. CONCLUSÃO 38

5. PARTE EXPERIMENTAL $\quad 40$

5.1. Índice de Compostos e Reações Descritas 43

$\begin{array}{ll}\text { 5.2. Procedimento Experimental } & 47\end{array}$

$\begin{array}{ll}\text { 6. SEÇÃO DE ESPECTROS } & 79\end{array}$

6.1. ${ }^{1} \mathrm{H}-\mathrm{RMN},{ }^{13} \mathrm{C}-\mathrm{RMN}, \mathrm{IV} \quad 81$

7. REFERÊNCIAS BIBLIOGRÁFICAS 178 


\section{ABREVIAÇÕES}

Bn: grupo benzila

COSY: correlation spectroscopy

CTAB: brometo de cetiltrimetilamônio

DMAP: 4-N,N-dimetil-aminopiridina

DPEA: N,N,N-diisopropiletilamina

HMQC: heteronuclear multiple-quantum correlation

HPLC: high performance liquid chromatography

IV: infravermelho

MOM: grupo metoximetila

NOE: nuclear Overhauser effect

PPTS: para-toluenossulfonato de piridínio

RMN: ressonância magnética nuclear

Red-Al ${ }^{\circledR}$ : bis (2-metoxi-etoxi)-hidreto de alumínio e sódio

TBDMS: grupo terc-butildimetilsilila

THF: tetra-hidrofurano

TMS: tetrametilsilano 


\section{RESUMO}

As plantas do gênero Ficus são conhecidas popularmente por figueiras e foram as primeiras plantas cultivadas pelo homem, os quais utilizavam os frutos para alimentação, as folhas na medicina e o caule na indústria.

Recentemente, um novo produto natural denominado Aripuanin (30), o nor-

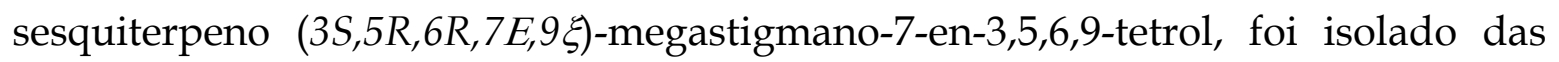
folhas da espécie Ficus aripuanensis C.C. Berg, da família Moraceae, uma das principais famílias presentes na floresta amazônica. A síntese do composto 30 ainda não foi descrita na literatura.

Apesar de não haver indícios do uso da Ficus aripuanensis na medicina tradicional, várias espécies do gênero Ficus são muito utilizadas na medicina popular como agente anti-helmíntico, anti-reumático, antifúngico, antibacteriano, antiinflamatório, antiulcerativo e ainda no tratamento de leucorréia e lepra.

$\mathrm{O}$ produto natural 30 possui uma grande semelhança estrutural com compostos derivados dos megastigmanos, que são considerados substâncias derivadas dos carotenóides por clivagem oxidativa da cadeia poliênica conjugada. Esses compostos têm sido continuamente isolados de diferentes espécies de plantas e apresentam grande importância comercial devido as suas propriedades aromatizantes.

Neste trabalho, foi realizada a primeira síntese total do Aripuanin (30), num total de nove etapas sintéticas, partindo-se da isoforona (34) comercial, com um rendimento global de $4,8 \%$.

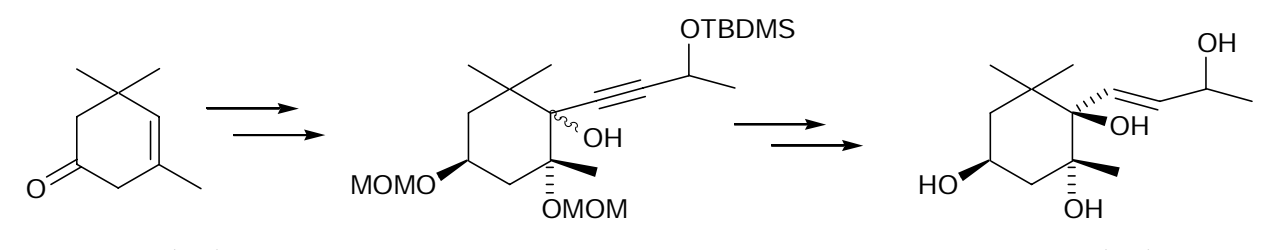

I soforona (34)

Aripuanin (30) 


\section{SUMMARY}

The plants of the Ficus genus, known as fig trees, were the first plants cultivated by the men, which make use of their fruits in the alimentation, their leaves in the medicine and the stalk in the industry.

Recently, a new natural product denominated Aripuanin (30), the norsesquiterpene (3S,5R,6R,7E,9S)-megastigmane-7-ene-3,5,6,9-tetrol, was isolated from the leaves of Ficus aripuanensis C.C. Berg (Moraceae), one of the main families of the Amazonian forest. The synthesis of compound $\mathbf{3 0}$ was not described in the literature yet.

In spite of no use in traditional medicine has been described for Ficus Aripuanensis, some species of the Ficus genus are used in folk medicine for their anthelmintic, antirheumatic, antifungal, antimicrobial, antibacterial, antiulcer and anti-inflammatory properties, in leucorrhea and leprosy.

The natural product 30 is structurally similar to the megastigmane derivatives, which are considered to be substances derived from carotenoids by oxidative cleavage of conjugated double bonds. These compounds have been isolated continuously from different species of plants, and have commercial importance due their flavoring properties.

In this work, was performed the first total synthesis of Aripuanin (30), in nine synthetic steps, starting from readily available isophorone (34), in $4.8 \%$ total yield.

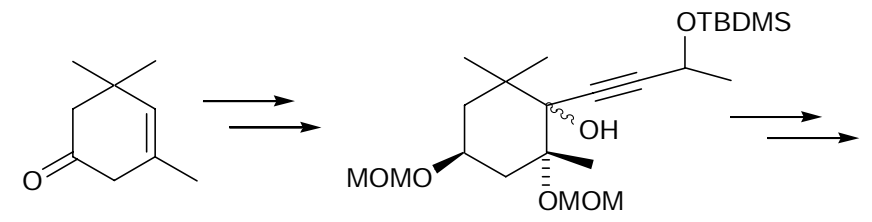

I sophorone (34)

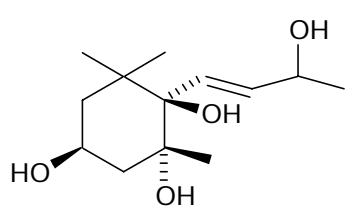

Aripuanin (30) 


\section{INTRODUÇÃO}




\subsection{Plantas do gênero Ficus}

O Brasil possui um rico território, cortado por grandes rios e com um vasto reino vegetal e animal. Sua flora é a mais magnífica que se conhece. Há plantas medicinais de alto valor terapêutico, algumas delas sem similares estrangeiras. Possui também as melhores madeiras florestais, servindo às construções civil e naval, à marcenaria e à escultura. Para a arborização de ruas e jardins a flora brasileira ostenta inúmeras espécies de grande beleza, com o colorido das flores e a suavidade de seus perfumes. ${ }^{1}$

As figueiras foram às primeiras plantas cultivadas pelo homem. Gregos, romanos e outros povos da antiguidade utilizavam fartamente os figos na alimentação, as folhas na medicina e o caule na indústria. Essas plantas pertencem ao gênero Ficus, o mais importante da família Moraceae. Existem cerca de 1.000 espécies, localizadas principalmente nas áreas tropicais e subtropicais. ${ }^{2}$

As figueiras ou gameleiras, nomes vulgares pelos quais as plantas do gênero Ficus são conhecidas, são facilmente aclimatáveis nas condições mais diversas, desde à beira-mar, nas dunas quentes da Líbia, ou até nas planícies frias dos Andes. ${ }^{3}$

No Brasil existem 59 espécies do gênero Ficus. A maior parte é encontrada na floresta amazônica, sendo riquíssimos em espécies os Estados do Amazonas e do Acre. Na região Norte crescem 48 espécies, no Centro Oeste 27, no Nordeste 20, no Sudeste 19 e no Sul 12 espécies. Nas florestas do sul da Bahia, no Espírito Santo, em Minas Gerais e no Rio de Janeiro, o número de espécies tem aumentado, mas no sul do país esse número vem decrescendo. A maior parte das plantas do gênero Ficus são encontradas principalmente em lugares úmidos, daí a abundância de espécies nas regiões amazônicas e litorâneas do Brasil. ${ }^{2}$

Essas plantas se destacam pela sua importância nos ecossistemas tropicais, pois apresentam frutos comestíveis, suas folhas e látex possuem propriedades medicinais e o caule é utilizado tanto na indústria quanto no paisagismo. 
O sistema radicular de suas raízes é tão extenso que chega a formar um emaranhado capaz de fixar o solo e impedir a erosão. Embora muitas espécies possam fixar encostas e conter até imensos rochedos, algumas delas não possuem esse tipo de raiz. O caule estrutural das figueiras as torna indispensável em parques e jardins de grandes dimensões, além da enorme sombra que propiciam.

Os frutos (figos) servem de alimentos para a maioria dos animais silvestres. Sendo que a espécie Ficus carica apresenta frutos que podem ser comidos crus pelo homem. 2,3

O suco leitoso que verte do caule e das folhas é muito utilizado na região amazônica no combate a vermes, tais como o Ancilostomo duodenalis e o Ascaris lumbricoides. ${ }^{4}$

De modo geral, as plantas do gênero Ficus têm sido muito utilizadas na medicina popular como agente anti-helmíntico, anti-reumático, antifúngico, antibacteriano, antiulcerativo, antiinflamatório e, ainda, no tratamento de leucorréia e lepra. .-8 $^{5-8}$ 


\subsection{Os Carotenóides}

Os carotenóides são pigmentos naturais sintetizados pelas plantas e alguns microorganismos. ${ }^{9}$

Em geral, a estrutura dos carotenóides é formada por oito resíduos de isopreno, sendo também conhecidos como tetraterpenóides (40 C). Possuem uma cadeia poliênica ramificada central, podendo apresentar nas extremidades grupos lineares como no licopeno (1) ou grupos cíclicos como no $\beta$-caroteno (2).

Os carotenóides podem ser divididos em dois grupos: o grupo dos hidrocarbonetos, também chamado de carotenos e o grupo das xantofilas que apresentam funções oxigenadas, como a zeaxantina (3) e a rodoxantina (4).

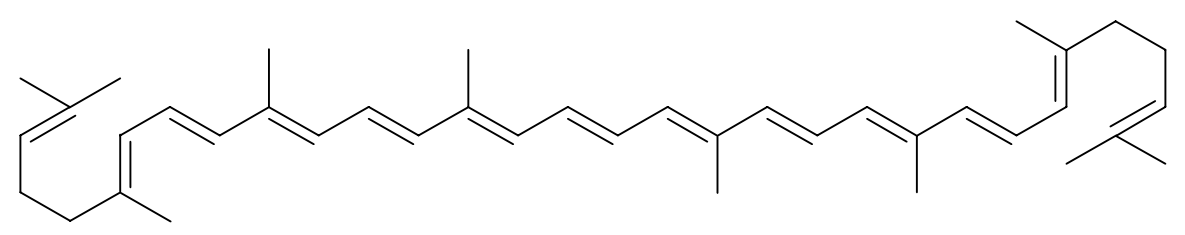

Licopeno (1)

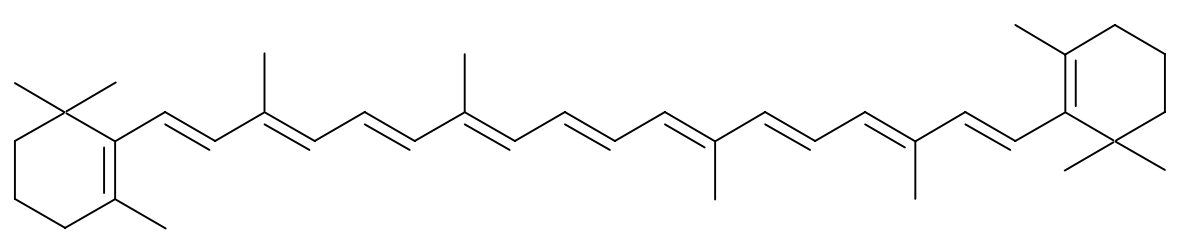

$\beta$-Caroteno (2)

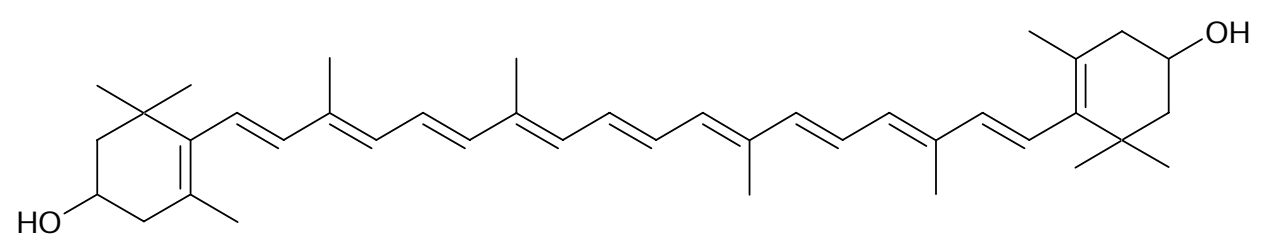

Zeaxantina (3) 


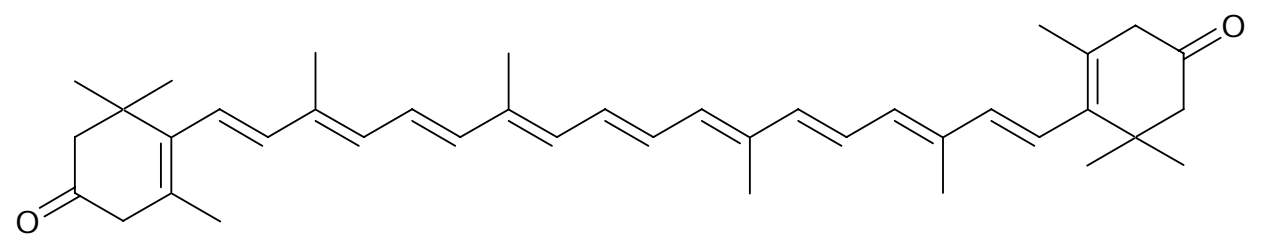

Rodoxantina (4)

A combinação deste sistema conjugado com os grupos terminais funcionalizados, formam a estrutura característica desta classe de produtos naturais. 9,10

Nos animais, os carotenóides encontram-se dissolvidos em gorduras ou combinados com proteínas na fase aquosa. Nos vegetais, são encontrados junto à clorofila, além de serem os constituintes principais das cores de algumas flores. ${ }^{9}$

Os carotenóides possuem importantes funções. Nos vegetais, atuam como protetores de sistemas sensíveis à luz e também como pigmentos auxiliares na absorção da luz durante a fotossíntese. ${ }^{11,12}$

Os carotenóides absorvem a luz em comprimentos de onda diferentes daqueles absorvidos pela clorofila e, portanto, são receptores suplementares de luz, capacitando as plantas a captarem a maior parte da energia disponível na luz solar. A variação nas proporções destes pigmentos auxiliares é responsável pela diversidade das cores dos organismos fotossintetizadores.

Nos animais, o $\beta$-caroteno em especial, atua como precursor da vitamina $\mathrm{A}$ (5), também chamada de Retinol, e de seus derivados como o Retinal (6) e o Ácido Retinóico (7). ${ }^{11,12}$

O Retinal (6), ou Retinaldeído, encontra-se reversivelmente associado às proteínas visuais. Quando a luz atinge a retina, ocorre uma série de reações fotoquímicas, gerando um impulso nervoso que é a base da transdução visual. O Retinol (5) e o Ácido Retinóico (7) agem como hormônios esteroidais, atuando na regulação do crescimento e na diferenciação celular. ${ }^{13}$ 


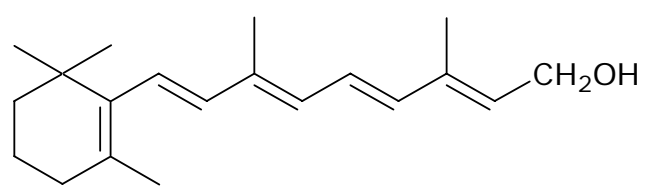

Vitamina A (5)

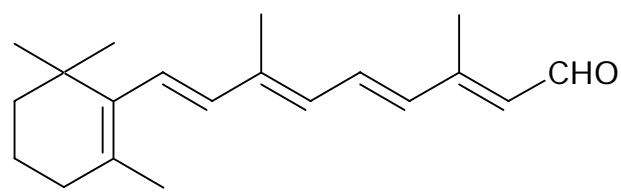

Retinal (6)

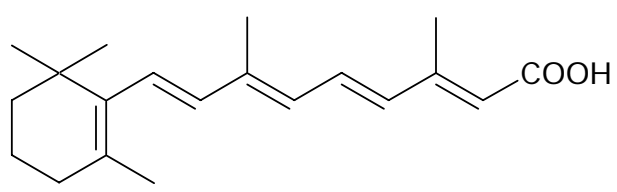

Ácido Retinóico (7)

Além disso, os carotenóides, de modo geral, possuem um importante papel como antioxidante, no combate contra os radicais livres, que pode reduzir os riscos de vários tipos de câncer, a progressão de doenças neurodegenerativas e até mesmo doenças do coração.11-14 Dessa forma, o aumento no consumo de alimentos ricos em carotenóides (frutas e legumes), propicia um aumento na proteção contra vários tipos de doenças. 


\subsection{Metabólitos de carotenóides cíclicos}

Os carotenos (40 C) podem sofrer clivagem oxidativa da cadeia poliênica, dando origem a produtos com menor número de átomos de carbono. Vários trabalhos têm sido publicados na literatura, mostrando como reações deste tipo podem ocorrer nas plantas. ${ }^{15}$

As ligações mais comumente fragmentadas são aquelas entre os átomos de carbono 9 e 10, 8 e 9, 7 e 8, 6 e 7; conforme demonstrado a seguir:

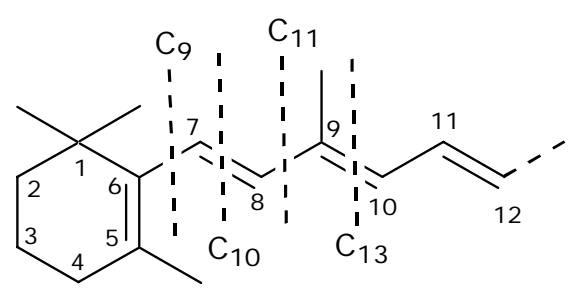

O oxigênio singlete é conhecido pela sua propriedade efetiva na clivagem oxidativa de duplas ligações conjugadas, podendo ser gerado sob irradiação na região do infravermelho próximo. Dessa forma, vários pesquisadores ${ }^{15}$ propuseram que oxidações semelhantes, envolvendo intermediários de vida curta, como A, B ou C, mostrados no esquema 1, também podem ocorrer em sistemas biológicos. 


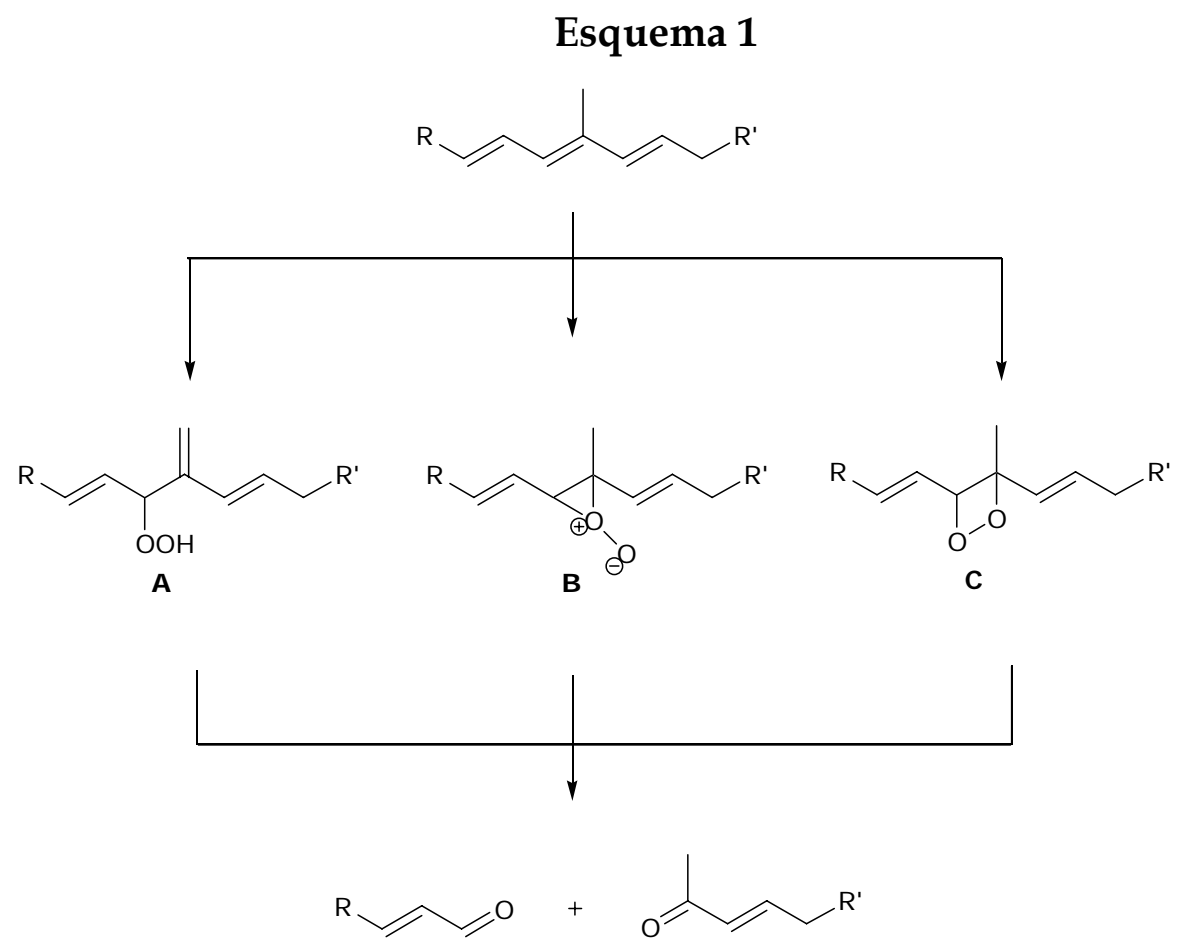

Steven ${ }^{16}$ mostrou que carotenóides do tomate são rapidamente degradados por enzimas e que há uma grande correlação entre a concentração de certos produtos de degradação e a do seu provável carotenóide precursor. Sanderson e colaboradores ${ }^{17}$ também demonstraram que o $\beta$-caroteno (2) presente nas folhas do chá preto é degradado enzimaticamente, tendo a $\beta$-ionona (8) como principal produto, além de várias outras substâncias voláteis não identificadas, algumas das quais devem ser derivadas exclusivamente da parte central da cadeia poliênica.

Através de experimentos de laboratório, ${ }^{18}$ pode-se observar que a fotooxigenação exaustiva do $\beta$-caroteno (2) gerou vários produtos, tais como: $\beta$-ionona (8), desoxixantoxina (9), dihidroactinidiolida (10), 6-hidroxi-2,2,6trimetilciclohexanona (11) e ácido gerônico (12). Enquanto que o seu correspondente hidroxi-derivado, a zeaxantina (3), quando submetida a este mesmo tratamento, forneceu: 3-hidroxi-5,6-epóxido- $\beta$-ionona (13), loliolida (14), 2,4-hidroxi-2,6,6-trimetilciclohexanona (15), ácido hidroxigerônico (16), 3-hidroxi- 
$\beta$-ciclocitral (17) e isololiolida (18). As estruturas de todos esses compostos são mostradas na figura 1.

\section{Figura 1}
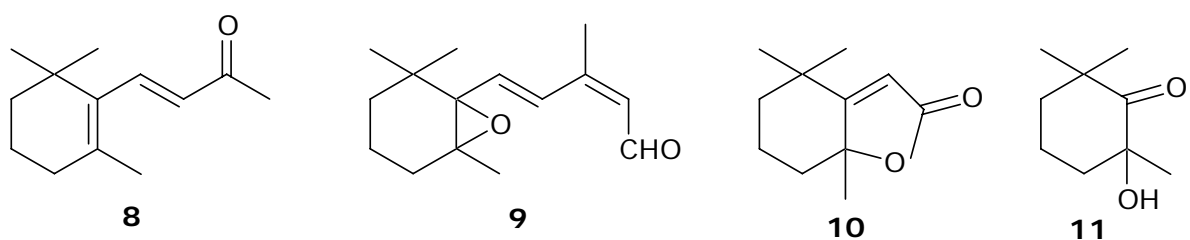

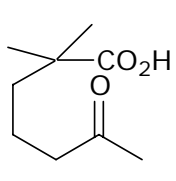

12<smiles>CC(=O)/C=C/C12OC1(C)CC(O)CC2(C)C</smiles>

13
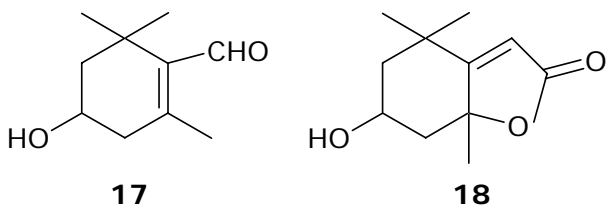

14

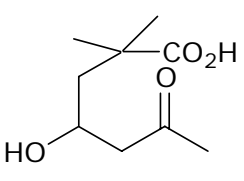

16

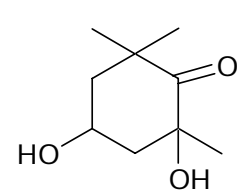

15

Após diversos estudos, ${ }^{15}$ pesquisadores confirmaram que os carotenóides são os únicos precursores de compostos oxigenados contendo de 9 a 15 átomos de carbono e que esses compostos são produzidos em sistemas biológicos por mecanismos análogos ao da foto-oxigenação.

Existe um grande número de compostos considerados como produtos de degradação primária dos carotenóides por clivagem oxidativa da cadeia poliênica. Esses produtos naturais são vastamente encontrados em óleos essenciais, chás, tabaco etc, e possuem uma grande importância comercial devido as suas propriedades aromatizantes. ${ }^{19-23}$

Flavorizantes são substâncias que conferem ou intensificam o sabor e o aroma de alimentos e bebidas. Os flavorizantes, em especial os aromatizantes, são responsáveis pelo reconhecimento, seleção e pela aceitação dos alimentos. 
A quantidade e a qualidade dos aromatizantes produzidos pelos vegetais depende de fatores genéticos e são influenciados pela forma de amadurecimento e de armazenamento do vegetal. O processo realizado depois da colheita também é de vital importância. ${ }^{23}$

O poder flavorizante de derivados de sesquiterpenos (15 C) contendo oxigênio é considerado relativamente pequeno ou quase nulo. A situação é diferente para os nor-compostos contendo de 1 a 3 átomos de carbono a menos, que ocorrem como metabólitos de sesquiterpenos e são geralmente caracterizados pelo seu forte aroma.

Na figura 2 são mostrados alguns exemplos desses produtos naturais com propriedades aromatizantes, encontrados no reino vegetal, tais como: megastigmano-4,6,8-trien-3-ona (19), 3-hidroxi- $\beta$-ionol (20), 3-hidroxi- $\beta$-ionona (21), 5,6-epoxi-3-hidroxi- $\beta$-ionol (22), 3-oxo- $\alpha$-ionol (23), 3-oxo- $\alpha$-damascona (24), 3-hidroxi-7,8-dehidro- $\beta$-ionol $\quad$ (25), $\quad 3$-oxo-7,8-dihidro- $\alpha$-ionol $\quad$ (26), $\quad 3,6-$ dihidroximegastigmano-7-en-9-ona (27), blumenol-A (28), damascenona (29), aripuanin (30). 


\section{Figura 2}<smiles>CC=CC=C1C(C)=CC(=O)CC1(C)C</smiles>

19<smiles>CC(O)C=CC12OC1(C)CC(O)CC2(C)C</smiles>

22<smiles>CC1=C(C#CC(C)O)C(C)(C)CC(O)C1</smiles>

25<smiles>CC1=CC(=O)CC(C)(C)C1(O)/C=C/C(C)O</smiles>

28<smiles>CC1=C(/C=C/C(C)O)C(C)(C)CC(=O)C1</smiles>

20<smiles>CC1=CC(=O)CC(C)(C)C1/C=C/C(C)O</smiles>

23<smiles>CC1=CC(=O)CC(C)(C)C1CCC(C)O</smiles>

26<smiles>C/C=C/C(=O)C1=C(C)C=CCC1(C)C</smiles>

29<smiles>CC(=O)/C=C/C1=C(C)CC(O)CC1(C)C</smiles>

21<smiles>C/C=C/C(=O)C1C(C)=CC(=O)CC1(C)C</smiles>

24<smiles>CC(=O)/C=C/C1(O)C(C)CC(O)CC1(C)C</smiles>

27<smiles>CC(O)/C=C/C1(O)C(C)(C)CC(O)CC1(C)O</smiles>

30

Embora esses compostos sejam considerados como produtos de degradação primária dos carotenóides, eles também podem ser interconvertidos a uma série de outros compostos correlatos, através de simples reações como redução de dupla ligação, desidratação, redução de grupos carbonílicos etc. Como por exemplo, a 3-hidroxi- $\beta$-ionona (21) que pode dar origem as outras cetonas tais como: megastigmano-3,5,7-trien-9-ona (31), 3-oxo-megastigmano-7-en-9-ona (32), megastigmano-5,7-dien-3-ona (33), mostradas na figura 3. 


\section{Figura 3}<smiles>CC(=O)/C=C/C1=C(C)C=CCC1(C)C</smiles>

31<smiles>CC(=O)/C=C/C1C(C)CC(=O)CC1(C)C</smiles>

32<smiles>CCC=CC1=C(C)CC(=O)CC1(C)C</smiles>

33 


\subsection{O Aripuanin}

Aripuanin é o nome usual do $(3 S, 5 R, 6 R, 7 E, 9 \xi)$-megastigmano-7-en-3,5,6,9tetrol (30), um produto natural recentemente isolado das folhas da espécie Ficus aripuanensis existente na floresta Amazônica.5,24

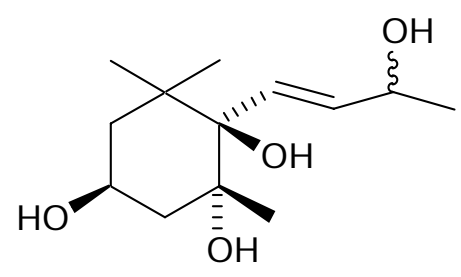

30

Apesar do uso da Ficus aripuanensis não ser descrito na medicina tradicional, várias espécies do gênero Ficus têm sido vastamente utilizadas na medicina popular da região amazônica, já comentado anteriormente.,2,5

O produto natural 30 é um nor-sesquiterpeno, composto por 13 átomos de carbono. É derivado dos megastigmanos, os quais possuem uma grande semelhança estrutural com alguns produtos de degradação primária dos carotenóides, com propriedades aromatizantes, mostrados nas páginas 9 e 11.

A síntese do Aripuanin (30) ainda não foi descrita na literatura até o momento. De acordo com os resultados de estudos realizados anteriormente, visando a síntese do ácido abscísico e de compostos análogos, ${ }^{25}$ verificou-se que o produto natural 30 poderia ser sintetizado a partir do produto comercial isoforona (34).

A estratégia proposta para realizar a síntese do Aripuanin (30) utiliza-se de reações clássicas da química orgânica, conforme mostrado no esquema 2. Uma abordagem mais detalhada dessas reações será feita a seguir, onde se discutirá os resultados obtidos nesta síntese. 


\section{Esquema 2}<smiles>CC1=CC(C)(C)CC(O)C1</smiles><smiles>[R]OC1CC(C)=CC(C)(C)C1</smiles><smiles>[R]OC1CC(C)(C)C(=O)C(C)(C)C1</smiles>

38

$\stackrel{\mathrm{LiAlH}_{4}}{\longrightarrow}$<smiles>[R20]C(C)/C=C/[C@@]1(O)C(C)(C)C[C@@H]([R20])C[C@]1(C)O</smiles>

40

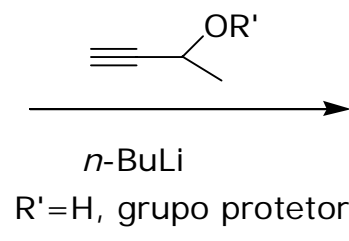

$\stackrel{\text { hidrólise } \rightarrow}{\longrightarrow}$

Aripuanin 
2. OBJETIVO 
O objetivo deste trabalho é realizar a síntese racêmica do produto natural (3S,5R,6R,7E,9 $)$-megastigmano-7-en-3,5,6,9-tetrol, também chamado de Aripuanin (30), cuja síntese ainda não foi descrita na literatura.

A rota sintética proposta para a realização da síntese do produto natural 30 pode ser visualizada no esquema 2, da página 14.

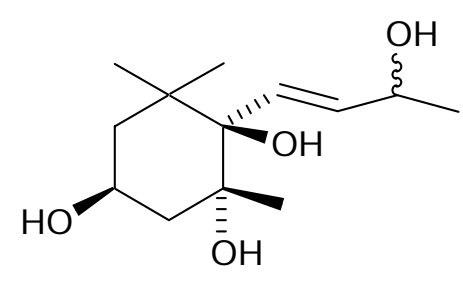

Aripuanin (30) 
3. DISCUSSÃO DOS RESULTADOS 
Para iniciar o estudo da síntese do Aripuanin (30) partiu-se de um produto comercial, a isoforona (34), que foi tratada com brometo de metil-magnésio $\left(\mathrm{CH}_{3} \mathrm{MgBr}\right)$ e quantidades catalíticas de cloreto férrico, de acordo com o método de Kharasch e Tawney, ${ }^{26}$ fornecendo a cetona desconjugada 35, conforme mostrado no esquema 3.

O brometo de metila usado na preparação do $\mathrm{CH}_{3} \mathrm{MgBr}$ foi obtido do formicida Bromex®. Nessa reação, o $\mathrm{CH}_{3} \mathrm{MgBr}$ atua como base, abstraindo o próton da posição $\gamma$ em relação à carbonila e o $\mathrm{FeCl}_{3}$ atua como ácido de Lewis, formando uma ligação com o oxigênio da carbonila, evitando a adição do grupo metila do reagente de Grignard nessa posição.

\section{Esquema 3}

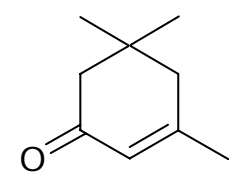

34

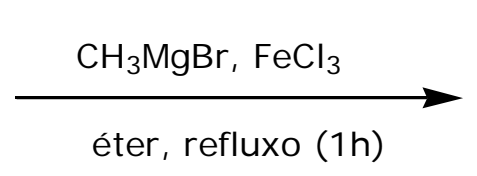

$72 \%$

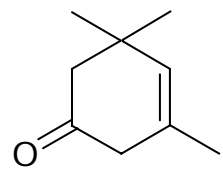

35

A isoforona desconjugada 35 obtida foi purificada por destilação sob pressão reduzida ( $2 \mathrm{mmHg}$ ), resultando num óleo amarelo claro, com $72 \%$ de rendimento, o qual foi devidamente caracterizado através de métodos espectroscópicos. Este produto não deve ser armazenado por um tempo prolongado, pois reverte ao material de partida, a isoforona (34), que é termodinamicamente mais estável.

Em seguida, o grupo carbonílico do composto 35 foi reduzido por tratamento com hidreto de alumínio e lítio, ${ }^{27}$ usando éter etílico anidro como solvente, obtendo-se o álcool racêmico 36, conforme mostrado no esquema 4. A purificação do produto bruto obtido foi realizada por destilação horizontal sob pressão reduzida (2 mmHg), fornecendo um óleo incolor, com $80 \%$ de rendimento, que foi devidamente caracterizado por análises espectroscópicas. 


\section{Esquema 4}<smiles>CC1=CC(C)(C)CC(=O)C1</smiles>

35

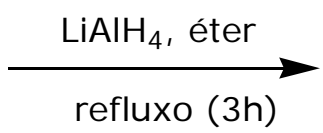

$80 \%$

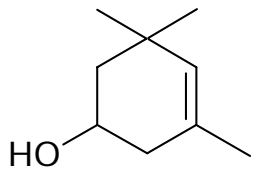

36

A função hidroxila do composto 36 foi protegida na forma de éter de tercbutildimetilsilano, utilizando NaH como base, THF anidro como solvente e cloreto de terc-butildimetilsilila (TBDMSCl), sob refluxo de 24 horas. ${ }^{28} \mathrm{O}$ produto obtido foi purificado por cromatografia em coluna de sílica gel, utilizando como eluente uma mistura de n-hexano:acetato de etila (9:1), resultando num óleo amarelo claro, com $71 \%$ de rendimento, que foi caracterizado por métodos espectroscópicos como sendo o composto 41, conforme mostrado no esquema 5.

\section{Esquema 5}

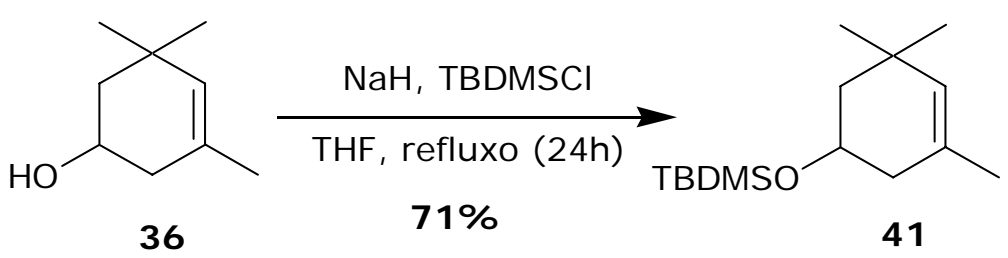

Dando seqüência a rota sintética proposta inicialmente, foi realizada a reação de oxidação da dupla ligação do composto 41, utilizando solução aquosa de permanganato de potássio $\left(\mathrm{KMnO}_{4}\right)^{25 \mathrm{~b}}$ em meio neutro, ${ }^{29}$ cujo $\mathrm{pH}$ foi controlado por adição de sulfato de magnésio $\left(\mathrm{MgSO}_{4}\right)$ ao meio reacional. Em presença de $\mathrm{MgSO}_{4}$ os íons hidróxidos gerados no meio reacional são capturados e precipitados como hidróxido de magnésio. ${ }^{29}$

Em virtude dessa reação ter sido realizada em meio aquoso muito diluído, ocorreram vários problemas durante a fase de extração. Depois de 15 horas de 
reação (quando todo o $\mathrm{MnO}_{4}^{-}$tinha sido reduzido), tentou-se extrair o resíduo da fase aquosa através de métodos convencionais, porém sem nenhum sucesso. Utilizou-se também um extrator contínuo líquido-líquido, durante vários dias, utilizando éter etílico e acetato de etila como solventes. Entretanto, mais uma vez, não se obteve sucesso nos processos de extração, o que não permitiu a identificação dos possíveis produtos formados ou mesmo da recuperação do material de partida (composto 41).

A oxidação de olefinas por $\mathrm{KMnO}_{4}{ }^{30}$ envolve a formação de um éster cíclico de manganês 42. Sob condições alcalinas (devido a geração de íons hidróxidos no meio reacional), a subseqüente decomposição do composto 42 gera o glicol cis 44, produzido pelo ataque do hidróxido ao manganês do composto 43.

Já em condições reacionais neutras, decorrentes da adição de $\mathrm{MgSO}_{4}$ ao meio reacional, a oxidação resulta na formação de uma hidroxi-cetona 46. Nestas condições o composto 43 é oxidado por $\mathrm{MnO}_{4}^{-}$para formar o composto 45 . Em seguida, a hidrólise aquosa gera a cetona 46, antes que o hidróxido presente em menor quantidade possa atacar o manganês, gerando o glicol 44. Desse modo parece que o permanganato e o íon hidróxido competem entre si para reagir com um intermediário comum 43, conforme mostrado no esquema 6. 


\section{Esquema 6}

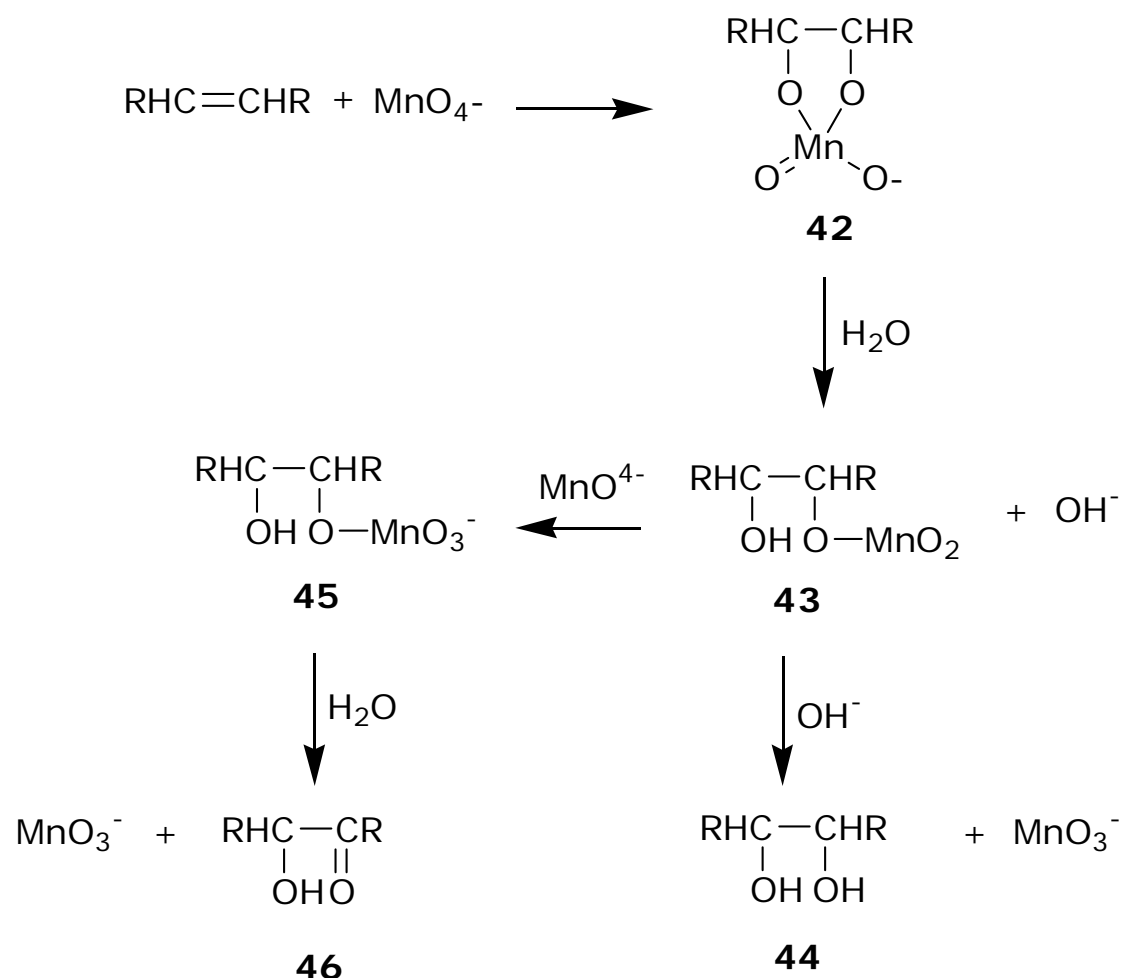

Realizou-se uma nova tentativa de oxidação do composto 41 utilizando-se brometo de cetiltrimetilamônio $(\mathrm{CTAB})^{31}$ como catalisador de transferência de fase. Adicionaram-se cristais de $\mathrm{KMnO}_{4}$ (1,5 equivalente) em uma mistura de diclorometano (2 mL), solução aquosa de $\mathrm{NaOH}$ a 40\% (2 mL) e 0,1 equivalente de CTAB. Após 23 horas de reação, foi obtido um sólido branco que após as devidas análises espectroscópicas ( $\left.{ }^{1} \mathrm{H}-\mathrm{RMN},{ }^{13} \mathrm{C}-\mathrm{RMN}, \mathrm{IV}\right)$ verificou-se não se tratar do produto oxidado de interesse, mas sim do próprio catalisador de transferência de fase (CTAB) utilizado na reação. Além disso, a presença do catalisador de transferência de fase dificultou o processo de extração da reação devido a formação de emulsão.

Diante das dificuldades encontradas na etapa de oxidação da dupla ligação, resolveu-se então proteger a hidroxila do composto 36 com diferentes grupos 
protetores para, em seguida, testar novamente a reação com $\mathrm{KMnO}_{4}$, para dar seqüência à síntese proposta.

Assim, a hidroxila do composto 36 foi protegida com o grupo benzila através da reação com cloreto de benzila $(\mathrm{BnCl})^{32}$ usando $\mathrm{NaH}$ como base, sob refluxo de THF anidro durante 25 horas, conforme mostrado no esquema 7. O produto obtido foi purificado por cromatografia em coluna de sílica gel, utilizando como eluente uma mistura de n-hexano:acetato de etila (9:1), resultando na obtenção de um óleo incolor, com $63 \%$ de rendimento, que foi caracterizado como sendo o composto 47 desejado.

\section{Esquema 7}

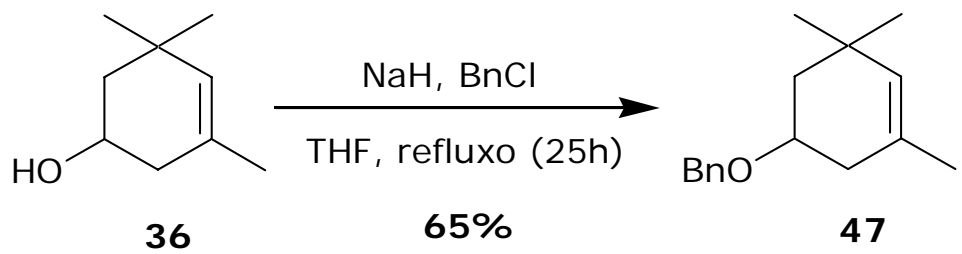

O composto 36 também teve a sua hidroxila protegida na forma de metoximetil-éter, pelo tratamento do álcool 36 com a base $\mathrm{N}, \mathrm{N}$-diisopropiletilamina (DPEA) seguido de reação com clorometil-metil-éter (MOMCl), 33 conforme mostrado no esquema 8. O composto 48 obtido foi purificado por destilação horizontal sob pressão reduzida (2 mmHg), fornecendo um óleo incolor, com 91\% de rendimento, que foi devidamente caracterizado por análises espectroscópicas.

\section{Esquema 8}

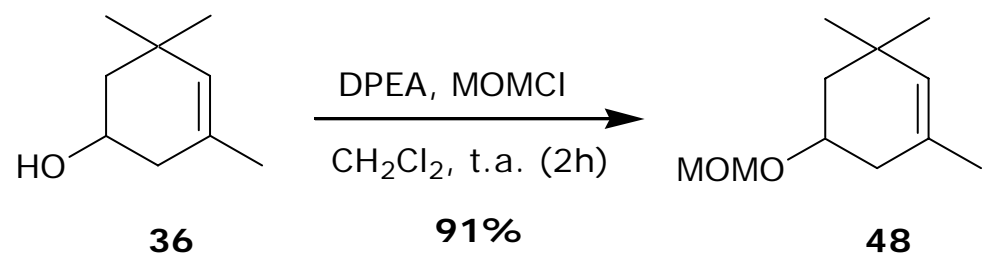


O álcool 36 também foi tratado com trietilamina $\left(\mathrm{Et}_{3} \mathrm{~N}\right)$, anidrido acético $\left(\mathrm{Ac}_{2} \mathrm{O}\right)$ e 4-N,N-dimetil-aminopiridina (DMAP), ${ }^{34}$ conforme mostrado no esquema 9. Obteve-se o acetato 49 desejado, na forma de óleo incolor, com $90 \%$ de rendimento, após purificação por cromatografia em coluna de sílica gel, utilizando como eluente uma mistura de $n$-hexano:acetato de etila (9:1).

\section{Esquema 9}

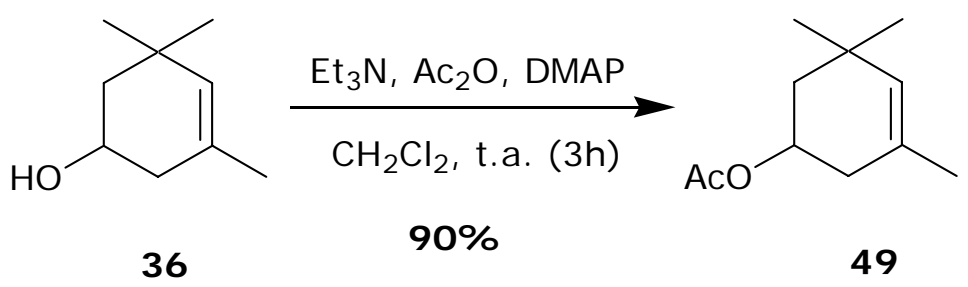

Dando seqüência à rota sintética proposta, as reações de oxidação das duplas ligações dos compostos 47, 48 e 49 foram realizadas com solução aquosa de $\mathrm{KMnO}_{4}{ }^{25 \mathrm{~b}}$

No caso dos compostos 47 e 48, protegidos respectivamente com os grupos benzila $(\mathrm{Bn})$ e metoximetila $(\mathrm{MOM})$, não foi possível realizar a extração do produto da solução aquosa, mesmo variando-se o tipo de solvente orgânico utilizado na extração e utilizando-se um extrator contínuo líquido-líquido durante vários dias. É provável que tenham ocorrido reações paralelas, com a formação de subprodutos que tenham forte interação com a água.

Por outro lado, no caso da reação de oxidação do composto 49 foi possível extrair o produto formado utilizando éter etílico como solvente. O produto obtido foi purificado por cromatografia em coluna de sílica gel, utilizando como eluente uma mistura de $n$-hexano:acetato de etila (1:1), resultando num óleo incolor, com $83 \%$ de rendimento, que foi caracterizado como sendo a hidroxi-cetona 50 de interesse, conforme mostrado no esquema 10. 


\section{Esquema 10}

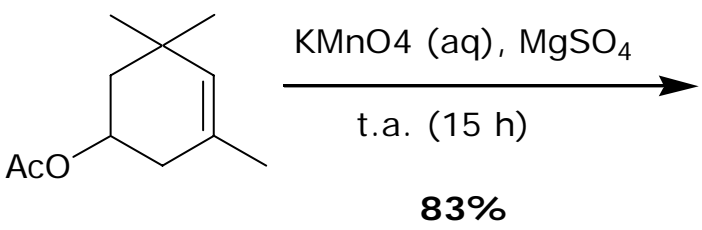

49

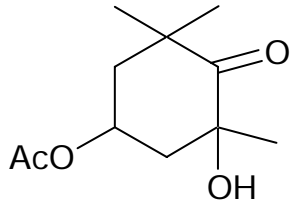

50

Como na reação de oxidação da dupla ligação do composto 49 foi gerado um novo centro quiral na molécula, obteve-se, então, a formação de quatro diasteroisômeros do composto 50, o que dificultou bastante as análises espectroscópicas. Os sinais dos deslocamentos químicos presentes no espectro de ${ }^{1} \mathrm{H}-\mathrm{RMN}$ da mistura estavam todos duplicados. Através da integral relativa dos sinais pôde-se determinar que a proporção entre os dois diasteroisômeros 50a (3S, $5 R)$ e $50 \mathrm{~b}(3 S, 5 S)$ é de $1: 1$, sendo os outros dois diasteroisômeros os seus respectivos enantiômeros.

Os estereoisômeros 50a $(3 S, 5 R)$ e $50 \mathrm{~b}(3 S, 5 S)$ foram então separados por HPLC, utilizando como fase móvel uma mistura de $n$-hexano:isopropanol (95:5) e uma coluna Shimadzu Shim-pack CLC-CN(M). Após a separação, o composto 50a $(3 S, 5 R)$ cristalizou-se na forma de um pó branco cristalino $\left(P F=52-53^{\circ} \mathrm{C}\right)$, enquanto que o $50 \mathrm{~b}(3 S, 5 S)$ permaneceu na forma de um óleo incolor.

A estereoquímica relativa entre os substituintes desses dois estereoisômeros foi determinada através de experimentos de diferença de NOE, os quais demonstraram que a relação entre os grupos acetila e hidroxila no composto 50a $(3 S, 5 R)$ é trans, enquanto que no composto $50 \mathrm{~b}(3 S, 5 S)$ é cis, conforme pode ser visualizado na figura 4.

\section{Figura 4}

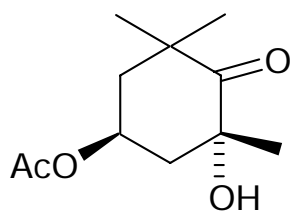

$50 a$

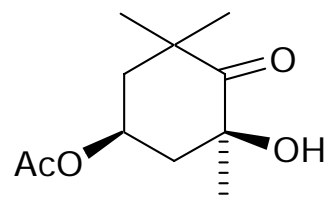

50b 
Uma vez obtida a hidroxi-cetona 50, deu-se seqüência a rota sintética proposta no esquema 2 (página 14), passando-se a estudar a reação de adição do acetileto metálico $25 \mathrm{a}, 35$ derivado do 3-butin-2-ol à carbonila do composto 50 (utilizado como mistura dos diasteroisômeros 50a e 50b).

Inicialmente, foi preparado o diânion do 3-butin-2-ol, utilizando n-BuLi como base e THF anidro como solvente, à temperatura de $-78^{\circ} \mathrm{C}$, adicionando em seguida o composto 50 diluído em THF anidro. A mistura reacional foi mantida sob agitação à $-78^{\circ} \mathrm{C}$ durante cinco horas. Porém, os resultados obtidos não foram satisfatórios devido a ocorrência da eliminação do grupo acetato, dando origem ao diol correspondente (composto 51), além da degradação do material de partida.

Por causa disso, realizou-se uma reação de hidrólise ${ }^{36}$ da hidroxi-cetona 50 (mistura de diasteroisômeros) com uma solução aquosa de $\mathrm{K}_{2} \mathrm{CO}_{3}$ a $10 \%$, obtendose o diol 51, conforme mostrado no esquema 11. O composto 51 obtido foi purificado por cromatografia em coluna de sílica gel, utilizando como eluente uma mistura de $n$-hexano:acetato de etila (1:9), resultando num óleo incolor, com 90\% de rendimento.

\section{Esquema 11}

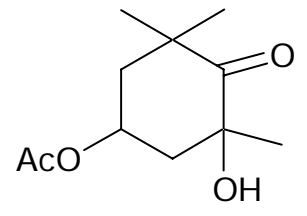

50

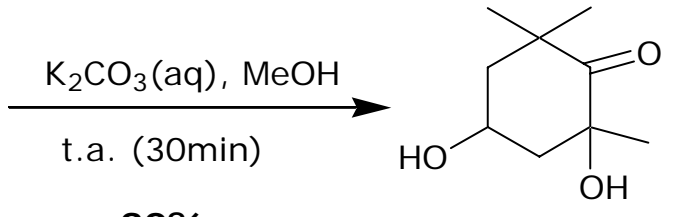

51

Como o composto 51 também existe na forma de quatro diasteroisômeros, houve uma certa dificuldade nas análises espectroscópicas. Os sinais do espectro de ${ }^{1} \mathrm{H}-\mathrm{RMN}$ da mistura estavam todos duplicados e pôde-se determinar que a proporção entre os diasteroisômeros 51 a $(3 S, 5 R)$ e 51 b $(3 S, 5 S)$ manteve-se em 1:1, sendo os outros dois diasteroisômeros os seus respectivos enantiômeros.

A separação desses dois diasteroisômeros foi realizada por cromatografia em coluna de sílica gel, utilizando como eluente uma mistura de $n$-hexano:acetato 
de etila (1:1). Essa separação também foi 100\% quantitativa, como já havia ocorrido na separação dos compostos 50a e 50b, embora o tempo decorrido para essa separação tenha sido muito maior do que o tempo gasto na separação dos diasteroisômeros 50a e 50b por HPLC. Após a separação, os dois diasteroisômeros cristalizaram-se na forma de sólidos incolores (composto 51a: $(3 S, 5 R)$ : PF = 86$87^{\circ} \mathrm{C}$, composto $\left.51 \mathrm{~b}(3 S, 5 S): \mathrm{PF}=63-64^{\circ} \mathrm{C}\right)$.

Com o uso de experimentos de diferença de NOE pôde-se verificar a estereoquímica entre esses dois compostos. Conforme pode ser visualizado no na figura 5, a relação entre as duas hidroxilas no composto 51 a $(3 S, 5 R)$ é trans, enquanto que em $\mathbf{5 1 b}(3 S, 5 S)$ é cis.

\section{Figura 5}

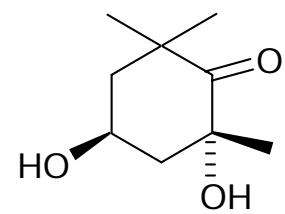

$51 \mathbf{a}$

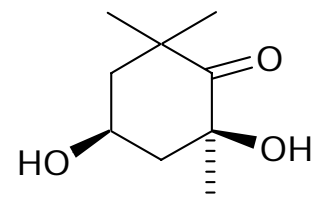

51b

Como a separação da mistura dos diasteroisômeros 51a e 51 b pode ser realizada por cromatografia líquida convencional, optou-se então por realizar primeiramente a reação de hidrólise do grupo acetato da mistura de diasteroisômeros 50a e 50b para somente depois realizar a separação dos diasteroisômeros 51a e 51b. Dessa maneira, pode-se prosseguir a rota sintética apenas com o diasteroisômero trans (51a) e assim facilitar as análises espectroscópicas das reações subseqüentes.

Algumas tentativas de adição do diânion do 3-butin-2-ol25a à carbonila do diol 51a foram realizadas, utilizando o mesmo procedimento já citado anteriormente na página 24 para a mistura de diasteroisômeros 50a e 50b, porém, não houve sucesso nessas reações, devido a decomposição do material de partida (composto 51a), que pôde ser observado por cromatografia em camada delgada 
(ccd). As análises dos espectros de ${ }^{1} \mathrm{H}-\mathrm{RMN}$ dos materiais. brutos obtidos confirmaram ter havido decomposição do composto $\mathbf{5 1 a . ~}$

Por causa desses resultados indesejados, foi necessário acrescentar duas novas etapas na rota sintética, realizando-se primeiramente a clivagem do grupo acetato do composto 50 e, em seguida, realizando a proteção das duas hidroxilas do composto 51a com um grupo que não fosse sensível ao ânion do acetileto.

Assim, optou-se por proteger as hidroxilas do composto 51a na forma de metoxi-metil-éter, ${ }^{33}$ conforme mostrado no esquema 12 , cuja reação deu origem a dois produtos, o composto dissubstituído 53, majoritário, com 75\% de rendimento e o composto monossubstituído 52, minoritário, com $20 \%$ de rendimento. Esses dois compostos foram separados por cromatografia em coluna de sílica gel, utilizando uma mistura de n-hexano:acetato de etila (8:2) como eluente, ambos resultando num óleo incolor, com um rendimento total de 95\%.

\section{Esquema 12}

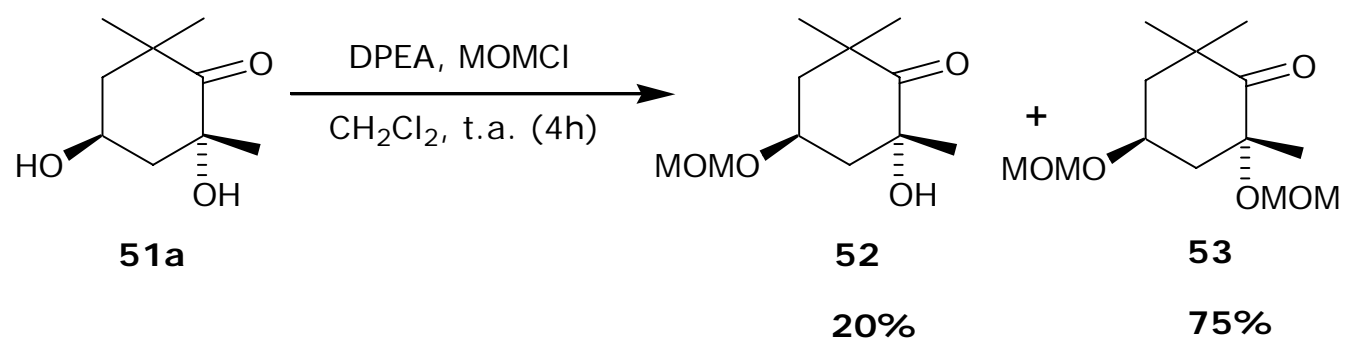

Novas tentativas de adição do diânion do 3-butin-2-ol25a,35 à carbonila dos compostos 52 e 53 foram realizadas separadamente, utilizando o mesmo procedimento anterior, porém, mais uma vez, resultaram na decomposição de ambos os materiais de partida 52 e 53.

Diante da dificuldade de se realizar a adição desse diânion, decidiu-se proteger a hidroxila do 3-butin-2-ol (54) com cloreto de terc-butildimetilsilila (TBDMSCl), ${ }^{37}$ utilizando imidazol como base e THF anidro como solvente, produzindo o composto 55, com um rendimento de $92 \%$, conforme mostrado no esquema 13. 


\section{Esquema 13}

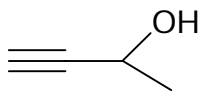

54

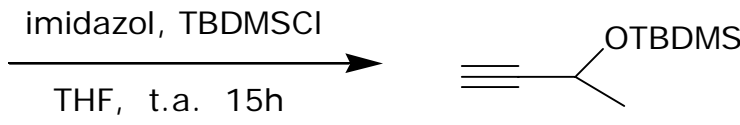

$92 \%$
55

Em seguida, foi realizada a reação de adição do monoacetileto do composto 55 à carbonila dos compostos 52 e 53 . No caso do composto 53, ocorreu a formação do produto 56 desejado, com $85 \%$ de rendimento, após purificação por cromatografia em coluna de sílica gel, conforme mostrado no esquema 14. Porém, no caso do composto 52 monoprotegido ocorreu a decomposição do material de partida, o que demonstra que a presença da hidroxila livre na molécula do composto 52 atrapalha o ataque do ânion acetileto à carbonila.

\section{Esquema 14}

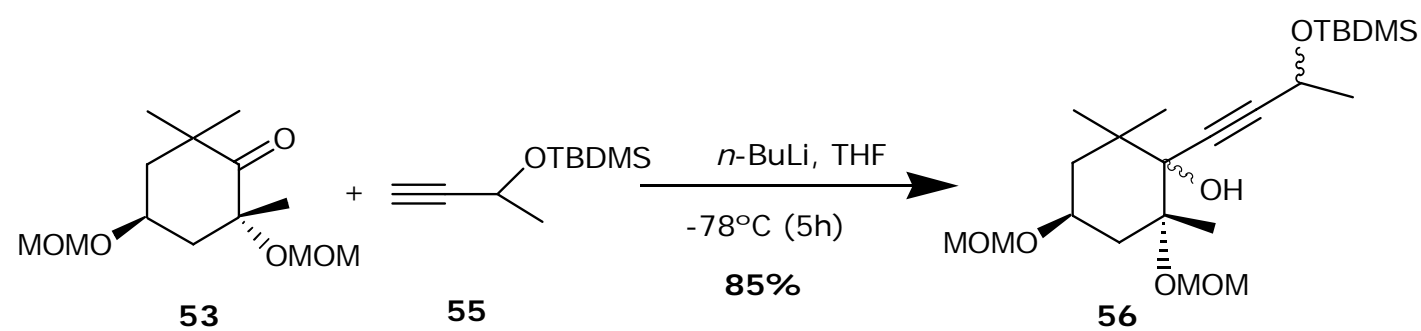

Nesta reação de adição foram gerados dois novos centros quirais na molécula e, conseqüentemente, foi produzido quatro novos pares de diasteroisômeros do composto 56, numa proporção de 1:1:1:1. Os sinais do espectro de ${ }^{1} \mathrm{H}-\mathrm{RMN}$ da mistura estavam todos sobrepostos, indicando que os deslocamentos químicos desses estereoisômeros são muito semelhantes. Os estereoisômeros do composto 56 não puderam ser separados e, por causa disso, não tiveram a relação estereoquímica entre eles definida.

Tentativas de efetuar a redução parcial da tripla ligação ${ }^{38}$ do composto 56 (mistura de diasteroisômeros) utilizando $\mathrm{LiAlH}_{4}$ não resultaram na formação do produto desejado, mas sim na degradação do material de partida. 
Em uma nova tentativa de realizar a redução da tripla ligação do composto 56, utilizando-se como agente redutor uma solução a 70\% de Red-Al® [Bis(2metoxi-etoxi)-hidreto de alumínio e sódio] em tolueno, ${ }^{39}$ foi obtido o produto 57 desejado com $73 \%$ de rendimento, após purificação em coluna de sílica gel, conforme pode ser visualizado no esquema 15.

\section{Esquema 15}

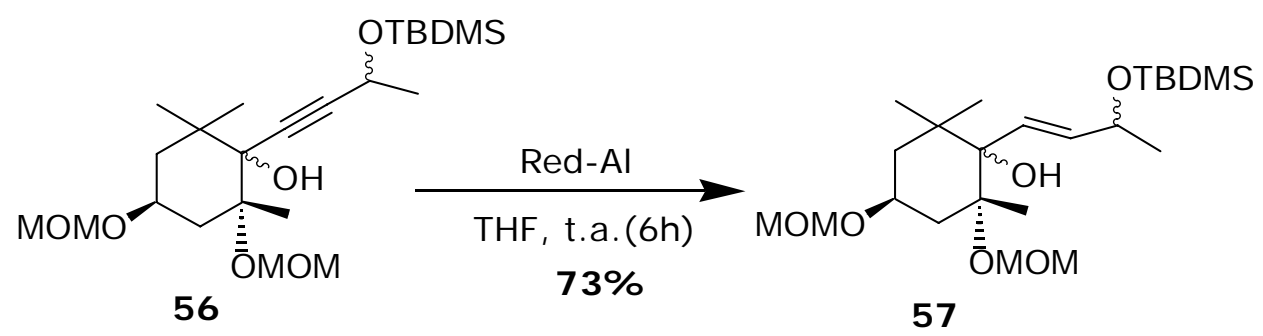

O composto 57 também foi obtido na forma de quatro pares de diasteroisômeros, numa proporção de 1:1:1:1, determinada através dos valores das integrais do espectro de ${ }^{1} \mathrm{H}-\mathrm{RMN}$ da mistura. Neste caso, nem todos os sinais apareceram sobrepostos (alguns deles estavam duplicados). Esses estereoisômeros também não puderam ser separados e, por causa disso, também não tiveram a relação estereoquímica entre eles definida.

Para finalizar a rota sintética inicialmente proposta neste trabalho, restava apenas realizar a hidrólise dos grupos protetores do composto 57 obtido.

Sabe-se que o grupo TBDMS é sensível em meio levemente ácido e que o grupo MOM pode ser hidrolisado sob condições ácidas em $\mathrm{pH}$ inferiores a 3. Dessa forma, várias tentativas de realizar a clivagem simultânea desses grupos protetores presentes no composto 57 foram realizadas.

De maneira geral, essas reações de clivagem resultaram principalmente na obtenção de dois produtos: o composto 58 decorrente da hidrólise parcial do material de partida 57 e o produto natural 30 de interesse. Em apenas uma das condições reacionais testadas foi formada também um terceiro composto, o 
produto 59, resultante do ataque do solvente usado (metanol) a uma das hidroxilas desprotegidas, conforme mostrado no esquema 16.

\section{Esquema 16}<smiles>CO[C@H](C)/C=C/[C@]1(O)[C@H](OC)C[C@@H](OC(C)C)CC1(C)C</smiles>

Um resumo dos resultados obtidos nas tentativas de realização da hidrólise simultânea dos grupos protetores do composto 57 é mostrado na Tabela 1 abaixo.

Tabela 1 - Reações de hidrólise dos grupos TBDMS e MOM do composto 57.

\begin{tabular}{ccccccc}
\hline Ácido & Solvente & T $\left({ }^{\circ} \mathrm{C}\right)$ & Tempo de & \multicolumn{3}{c}{ Rendimento } \\
\cline { 5 - 7 } utilizado & utilizado & & reação (h) & $(58)$ & $(59)$ & $(30)$ \\
\hline HCl (2 mol/L) & $\mathrm{MeOH}$ & t. a. & 22 & $46 \%$ & - & - \\
PPTS (1eq) & $\mathrm{MeOH}$ & 50 & 21 & $37 \%$ & - & $22 \%$ \\
PPTS (2eq) & $\mathrm{MeOH}$ & 50 & 42 & $42 \%$ & - & $37 \%$ \\
PPTS (2eq)* & $\mathrm{MeOH}$ & 50 & 48 & $30 \%$ & - & $50 \%$ \\
PPTS (2eq) & $\mathrm{MeOH}$ & 65 & 21 & - & $73 \%$ & - \\
PPTS (10eq) & $t$-BuOH & 83 & 04 & - & - & $13 \%$ \\
PPTS (10eq) & $t$ - $\mathrm{BuOH}$ & 83 & 06 & - & - & $9 \%$ \\
PPTS (10eq) & $t$-BuOH & 50 & 48 & $47 \%$ & - & - \\
PPTS (2eq)* & $i$-PrOH & 50 & 48 & $27 \%$ & - & $53 \%$ \\
\hline
\end{tabular}

* melhores resultados obtidos 
Primeiramente, a hidrólise do composto 57 (mistura de diasteroisômeros) foi realizada utilizando 3 gotas de $\mathrm{HCl}$ (2 mol/L) dissolvido em metanol28,40 $(\mathrm{pH}=3)$, que, após 22 horas de reação à temperatura ambiente, forneceu o composto 58, decorrente da hidrólise parcial dos grupos protetores, com $46 \%$ de rendimento, conforme mostrado no esquema 17, além de produtos de decomposição. Notou-se que, nessas condições, com o aumento do tempo reacional, como tentativa de hidrolisar o grupo MOM ainda remanescente no composto 58, ocorreu a decomposição do produto formado. O composto 58 demonstrou ser muito instável, decompondo-se facilmente quando armazenado ou até mesmo quando diluído em solvente deuterado.

\section{Esquema 17}

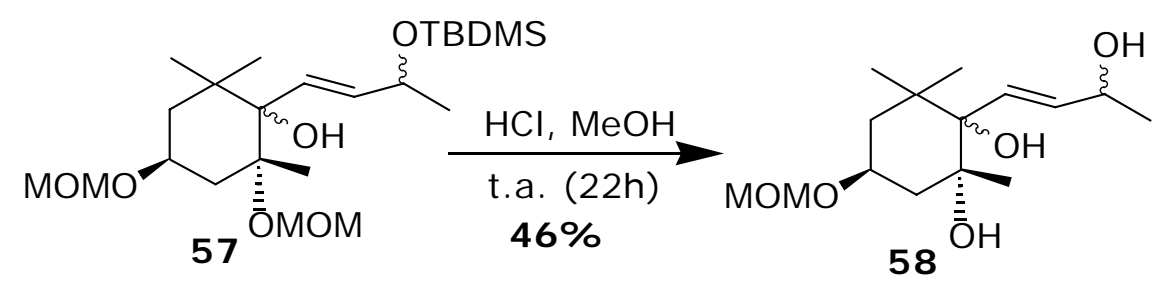

Em seguida, testou-se realizar a reação de hidrólise utilizando um sal ácido mais fraco, o para-toluenossulfonato de piridínio (PPTS), ${ }^{28,41}$ que é muito utilizado na hidrólise de éteres presentes em moléculas sensíveis a meio fortemente ácido.

Na primeira tentativa de hidrólise do composto 57 utilizou-se 1 equivalente de PPTS 40,41 dissolvido em metanol. A reação foi iniciada a temperatura ambiente, mas, decorridas algumas horas, como a hidrólise não estava se processando, a temperatura reacional foi aumentada para $50^{\circ} \mathrm{C}$ e, após 21 horas de reação, obtevese o produto natural 30 desejado, com rendimento de $22 \%$, juntamente com cerca de $37 \%$ do composto 58 . Os dois produtos obtidos foram separados e purificados por cromatografia em coluna de sílica gel, utilizando como eluente uma mistura de n-hexano:acetato de etila (1:1). 
Essa reação foi repetida, utilizando 2 equivalentes de PPTS e variando o tempo reacional (mantendo a temperatura a $50^{\circ} \mathrm{C}$ ). Após 42 horas de reação, nessas condições reacionais, obteve-se o composto 58 com $42 \%$ de rendimento e o produto natural 30 com 37\% de rendimento. Após com 48 horas de reação, mantendo-se essas condições reacionais, o rendimento do composto 58 diminuiu de $42 \%$ para $30 \%$ e o rendimento do produto natural 30 aumentou de $37 \%$ para $50 \%$, conforme pode ser visualizado no esquema 18. Porém, com o aumento suplementar do tempo reacional (acima de 48 horas), verificou-se, por cromatografia em camada delgada, que ocorria a decomposição dos produtos formados.

\section{Esquema 18}

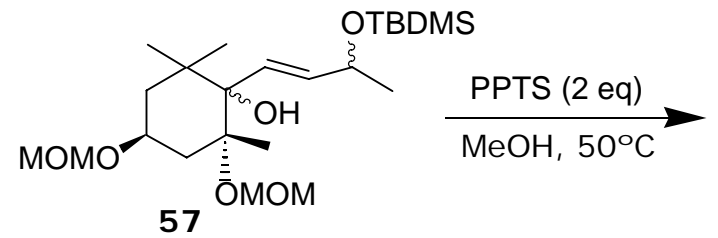

(42 h)

(48 h)

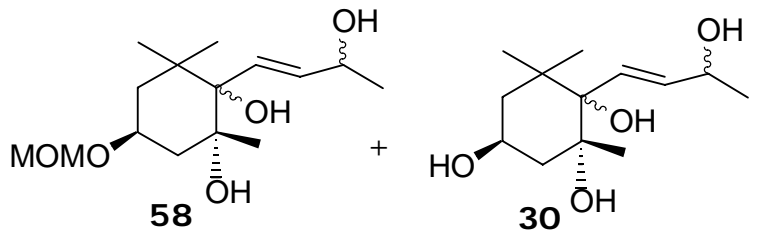

$42 \%$

$37 \%$

$50 \%$

Um novo teste de hidrólise do composto 57 foi realizado utilizando novamente 2 equivalentes de PPTS e metanol como solvente, mas, como tentativa de se diminuir o tempo de reação e melhorar o rendimento do produto 30, a temperatura da mistura reacional foi aumentada de $50^{\circ} \mathrm{C}$ para $65^{\circ} \mathrm{C}$ (temperatura de refluxo do metanol). Porém, após 21 horas de reação nessas novas condições, ocorreu a formação do composto 59, com rendimento de 73\%, originário da adição do solvente em uma das hidroxilas, conforme mostrado no esquema 19. O composto 59 foi purificado por cromatografia em coluna de sílica gel, utilizando como eluente uma mistura de $n$-hexano:acetato de etila (2:8). 


\section{Esquema 19}

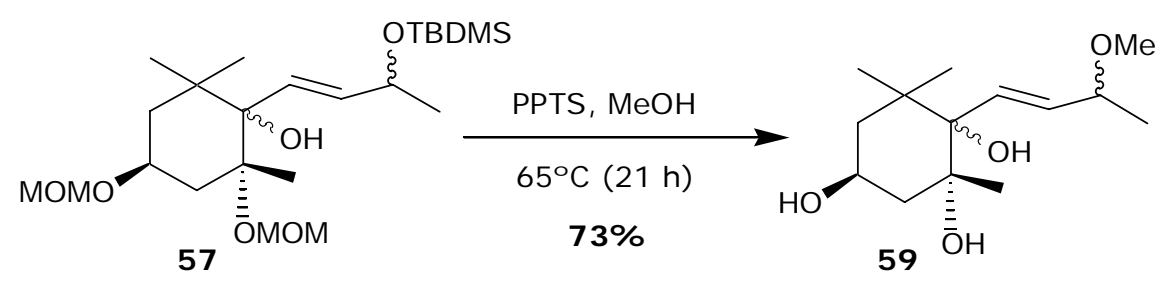

Pelo espectro de ${ }^{1} \mathrm{H}-\mathrm{RMN}$ da mistura dos quatro pares de diasteroisômeros do composto 59 formados, verificou-se que os sinais dos deslocamentos químicos estavam duplicados e pôde-se determinar que a proporção entre eles é de 1:1:1:1.

Para fins analíticos, uma pequena quantidade dos dois pares de diasteroisômeros do composto 59 foi separada por cromatografia em coluna de sílica gel, utilizando como eluente uma mistura de n-hexano:acetato de etila (2:8). Ambos estereoisômeros permaneceram na forma de óleo amarelo claro.

Através da técnica de NOE-diff, pôde-se verificar que a estereoquímica relativa entre as duas hidroxilas vizinhas no composto 59a $(3 S, 5 R, 6 S)$ é cis, enquanto que no composto $59 \mathrm{~b}(3 S, 5 R, 6 R)$ é trans, conforme pode ser visualizado na figura 6. Isso demonstra claramente que o centro assimétrico do carbono metoxilado não interfere significativamente no deslocamento químico desses diastereoisômeros.

\section{Figura 6}

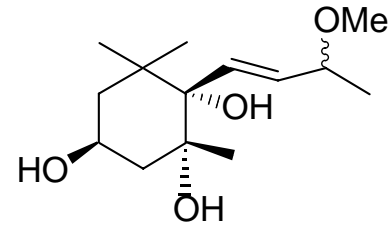

$59 a$<smiles>COC(C)/C=C/[C@@]1(O)C(C)(C)C[C@@H](O)C[C@]1(C)O</smiles>

59b

Uma nova tentativa de hidrólise do composto 57 foi realizada, utilizando dessa vez um solvente mais impedido estericamente e que não fosse capaz de se 
adicionar a nenhuma das hidroxilas. Dessa forma, o terc-butanol foi testado inicialmente como solvente, utilizando-se nessa reação 10 equivalantes de PPTS ${ }^{42}$ e, após 4 horas de reação à $83^{\circ} \mathrm{C}$ (temperatura de refluxo do $t$-BuOH), obteve-se o produto natural 30, porém, com um rendimento de apenas $13 \%$, além de produtos de decomposição. Notou-se que após 6 horas de reação, nessas mesmas condições reacionais, começou a ocorrer decomposição do produto natural 30 formado (o rendimento caiu de $13 \%$ para $9 \%$ ), o que demonstra que o produto natural 30 de interesse não resiste a temperaturas elevadas.

Essa reação foi então repetida, utilizando $t$-BuOH como solvente e 10 equivalentes de PPTS, mas a temperatura reacional foi mantida a $50^{\circ} \mathrm{C}$. Neste caso, após 48 horas de reação, ocorreu apenas a formação do composto 58, decorrente da hidrólise parcial dos grupos protetores, com $47 \%$ de rendimento.

Diante desses resultados, testou-se um terceiro e último solvente para a reação de hidrólise do composto 57, nas mesmas condições reacionais do melhor resultado obtido até então. Nessa reação utilizou-se o isopropanol como solvente, 2 equivalentes de PPTS e manteve-se a temperatura reacional a $50^{\circ} \mathrm{C}$. Depois de 48 horas nessas condições, o produto natural 30 foi obtido com 53\% de rendimento, juntamente com o composto 58 que foi também obtido com rendimento de $27 \%$, conforme mostrado no esquema 20.

\section{Esquema 20}

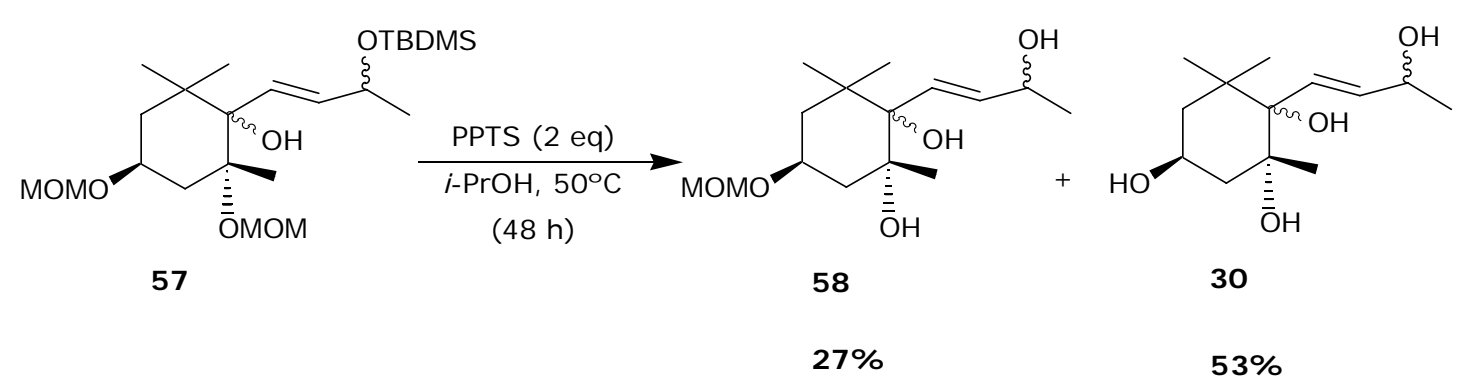

Essa última reação de hidrólise testada (2 eq. de $\mathrm{PPTS}, i-\operatorname{PrOH}, 50^{\circ} \mathrm{C}$ ) produziu o melhor resultado dentre todas as reações realizadas (cf. resultados mostrados na tabela 1 da página 30), embora o rendimento do produto natural 30 
tenha sido bastante próximo do resultado da reação realizada com 2 eq. de PPTS, $\mathrm{MeOH}, 50^{\circ} \mathrm{C}$.

Como o produto natural 30 obtido encontra-se na forma de quatro pares de diasteroisômeros, a análise de seus espectros de ${ }^{1} \mathrm{H}-\mathrm{RMN}$ e ${ }^{13} \mathrm{C}-\mathrm{RMN}$ foram bastante dificultadas devido a sobreposição dos sinais. Porém, pela análise do espectro de ${ }^{1} \mathrm{H}-\mathrm{RMN}$ da mistura pôde-se determinar que a proporção entre esses diasteroisômeros é de 1:1:1:1.

Para fins analíticos, uma pequena quantidade de dois pares dos diasteroisômeros do produto natural $\mathbf{3 0}$ foi separada por cromatografia em coluna de sílica gel, utilizando como eluente uma mistura de n-hexano:acetato de etila (2:8). Ambos estereoisômeros permaneceram na forma de óleo incolor.

Através do experimento de diferença de NOE, pôde-se verificar que a estereoquímica relativa entre as duas hidroxilas vizinhas no composto $30 a(3 S, 5 R$, $6 S)$ é cis, enquanto que no composto $30 \mathrm{~b}(3 S, 5 R, 6 R)$ é trans; conforme pode ser visualizado na figura 7. Neste caso, também se pôde verificar que o centro assimétrico referente ao carbono da cadeia lateral não influenciou no deslocamento químico desses diasteroisômeros.

\section{Figura 7}

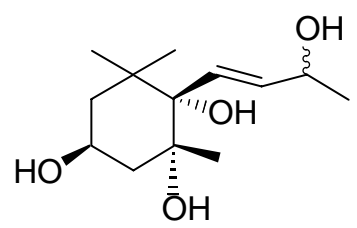

$30 a$

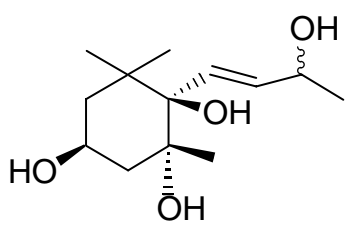

30b

Em resumo, a rota sintética proposta inicialmente no esquema 2 (página 14) pôde ser concretizada com sucesso com algumas modificações. Devido aos problemas encontrados durante a realização da reação de oxidação da dupla ligação dos compostos 41,47-49 e também na reação de adição dos derivados de 3butin-2-ol (54) à carbonila do composto 50, tornou-se necessário incluir uma nova etapa de desproteção do acetato 50 e uma nova etapa de proteção das hidroxilas do 
diol 51a utilizando o $\mathrm{MOMCl}$, conforme pode ser visualizado no esquema 21 que resume todas as reações realizadas. As novas reações acrescentadas nessa nova estratégia sintética, apesar de haver aumentado o número de etapas reacionais, forneceram bons resultados.

A reação final de hidrólise do composto 57 também se mostrou um pouco problemática. Foram testados dois reagentes ( $\mathrm{HCl}$ e PPTS) que são muito usados em reações de hidrólise do grupo protetor MOM e também foram utilizados diferentes solventes e temperaturas reacionais, na tentativa de melhorar o rendimento do produto natural 30. O melhor resultado na reação de hidrólise do composto 57 foi obtido com o uso de 2 equivalentes de PPTS, isopropanol como solvente e $50^{\circ} \mathrm{C}$ de temperatura reacional que, após 48 horas, produziu um rendimento de $53 \%$ do produto natural 30 de interesse.

Como resultado global, o produto natural Aripuanin (30) foi obtido em sua forma racêmica a partir da isoforona comercial (34), com um rendimento total de $4,8 \%$ após 9 etapas sintéticas, o que pode ser considerado satisfatório, tendo em vista que essa é a primeira síntese realizada desse produto natural. 


\section{Esquema 21}
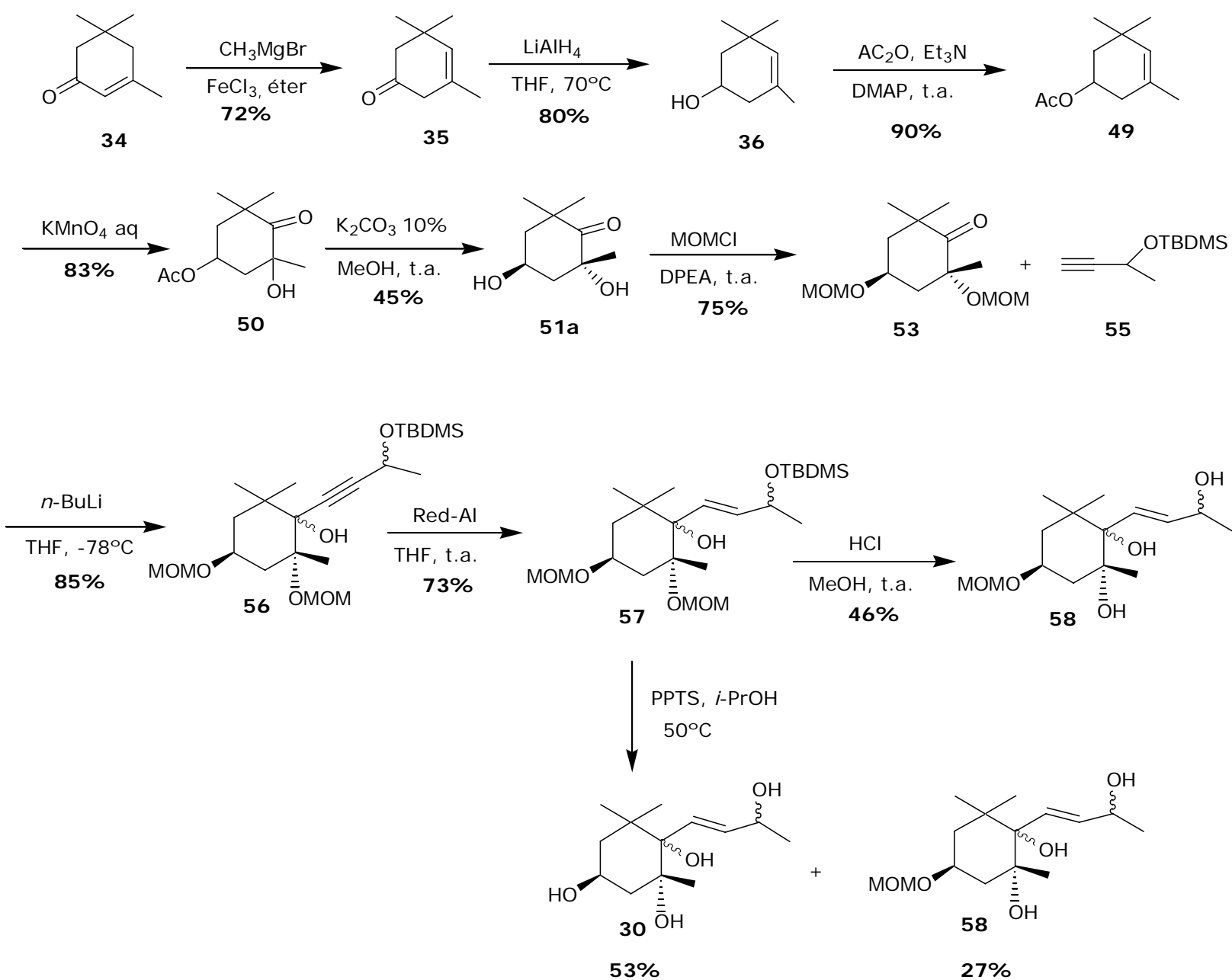
4. CONCLUSÃO 
Os resultados obtidos neste trabalho, demonstraram a viabilidade da rota sintética proposta inicialmente. O produto natural 30 desejado foi obtido, em sua forma racêmica, a partir da isoforona (34) comercial, com um rendimento total de 4,8\%, após nove etapas sintéticas.

A realização dessa primeira síntese total do Aripuanin (30), baseou-se em reações tradicionais de relativa simplicidade, como as reações de redução, oxidação, proteção de grupos funcionais, dentre outras.

Nesta síntese em especial, a utilização dos grupos protetores foi muito importante para que a reação de oxidação da dupla ligação do composto 49 com $\mathrm{KMnO}_{4}$ e a adição do acetileto metálico à carbonila do composto 53 fossem realizadas com sucesso. Embora os grupos protetores utilizados, MOM e TBDMS, geralmente sejam de fácil hidrólise, no caso do composto 57 esses grupos não puderam ser facilmente removidos, o que demonstra a dificuldade de se trabalhar com compostos polifuncionais e também a importância da escolha apropriada e do uso de grupos protetores em síntese orgânica.

Os rendimentos isolados de cada intermediário reacional tiveram valores bastante significativos, variando de $72 \%$ a $90 \%$. Entretanto, na reação final de hidrólise dos grupos protetores do composto 57 obteve-se um rendimento de apenas $53 \%$.

No decorrer do desenvolvimento da parte experimental, foi necessário separar os dois diasteroisômeros da hidroxi-cetona 51 para possibilitar uma adequada análise espectroscópica dos compostos obtidos. A partir dessa etapa, optou-se por seguir a rota sintética utilizando apenas um desses diasteroisômeros a fim de facilitar as análises espectroscópicas dos produtos obtidos nas reações subseqüentes.

O produto natural final e seus principais intermediários sintéticos deverão ser submetidos a ensaios biológicos, a serem realizados por pesquisadores da FCFRP-USP. 
5. PARTE EXPERIMENTAL 
Nesta seção, os compostos foram nomeados conforme recomendações oficiais da International Union of Pure and Applied Chemistry (IUPAC) para nomenclatura de compostos orgânicos.

Os espectros de ressonância magnética nuclear de próton (1 $\left.{ }^{1} \mathrm{H}-\mathrm{RMN}\right)$ foram registrados a $400 \mathrm{MHz}$ e a $500 \mathrm{MHz}$ em um espectrômetro Bruker DRX-400 e Bruker DRX-500, respectivamente.

Os deslocamentos químicos $(\delta)$ estão relatados em parte por milhão (ppm) em relação ao tetrametilsilano (TMS), utilizado como padrão interno, colocando-se entre parênteses a multiplicidade $(s=$ singleto, $s \mathrm{l}=$ singleto largo, $\mathrm{d}=\mathrm{dubleto,t}=$ tripleto, $\mathrm{q}=$ quadrupleto, quin= quintupleto, $\mathrm{dd}=$ duplo dubleto, $\mathrm{dt}=$ duplo tripleto, $\mathrm{ddd}=$ duplo duplo dubleto, $\mathrm{ddt}=$ duplo duplo tripleto, $\mathrm{ddq}=$ duplo duplo quadrupleto, dddd= duplo duplo duplo dubleto, qd = quadruplo dubleto, qdd= quaduplo duplo dubleto, $\mathrm{m}=$ multipleto), a constante de acoplamento $(J)$ em Hertz (Hz) e o número de hidrogênios deduzidos da integral relativa.

Os espectros de ressonância magnética de carbono-13 $\left({ }^{13} \mathrm{C}-\mathrm{RMN}\right)$ foram registrados a $100 \mathrm{MHz}$ e a $125 \mathrm{MHZ}$ em um espectrômetro Bruker Avance DRX400 e Bruker Avance DRX-500, respectivamente, e foram traçados de acordo com a conveniência, utilizando-se as seguintes técnicas:

${ }^{13} \mathrm{C}\left\{{ }^{1} \mathrm{H}\right\}$ - Carbono Totalmente Desacoplado de Hidrogênio;

DEPT - Distortionless Enhancement by Polarization Transfer.

Os experimentos de correlação ${ }^{1} \mathrm{H} \times{ }^{1} \mathrm{H}(\mathrm{COSY})$ e ${ }^{13} \mathrm{C} \times{ }^{1} \mathrm{H}(\mathrm{HMQC})$ e o experimento de NOE-diff foram obtidos no espectrômetro Bruker DRX-500.

Os espectros de absorção no infravermelho (IV) foram registrados em um espectrofotômetro Perkin-Elmer Spectrum RX IFTIR System, em celas de KBr para líquidos (filme) ou em pastilhas de KBr para sólidos.

Os espectros de massas (EM) de baixa resolução não puderam ser obtidos devido a problemas técnicos no espectrômetro HP GC/MS SYSTEM 5988-A do Departamento de Química da FFCLRP-USP, que permaneceu indisponível para análises durante um longo tempo. 
Os pontos de fusão foram determinados em uma placa de aquecimento Kofler com um termômetro não aferido, instalada em um microscópico modelo Bristoline.

Para a realização de destilação horizontal, empregou-se um aparelho de destilação evaporativa horizontal Kugelrohrofen, marca Büchi modelo GKR-50. As temperaturas registradas referem-se a temperatura do forno.

Para concentrar as soluções foram utilizados evaporadores rotatórios do tipo Buchler e Büchi, operando sob pressão reduzida de aproximadamente 30 mmHg.

As cromatografias em camada delgada (ccd) foram realizadas utilizando-se placas de sílica gel 60 da Merck $®$. Os solventes e reagentes comerciais foram convenientemente purificados conforme métodos usuais. ${ }^{43}$ 


\section{1. Índice de Compostos e Reações Descritas}

1) 3,5,5-Trimetil-3-ciclo-hexen-1-ona (35)

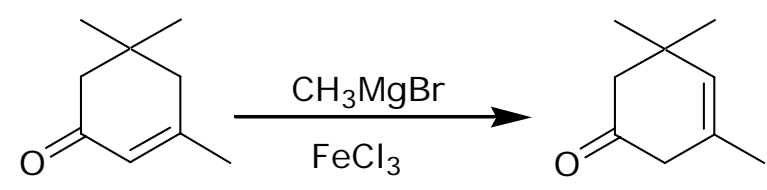

34

35

2) 3,5,5-Trimetil-3-ciclo-hexen-1-ol (36)

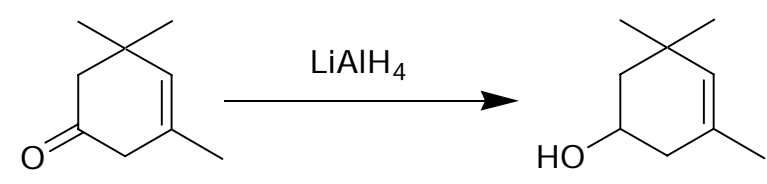

35

36

3) terc-Butil-dimetil-(3,3,5-trimetil-ciclo-hexiloxi)-silano (41)

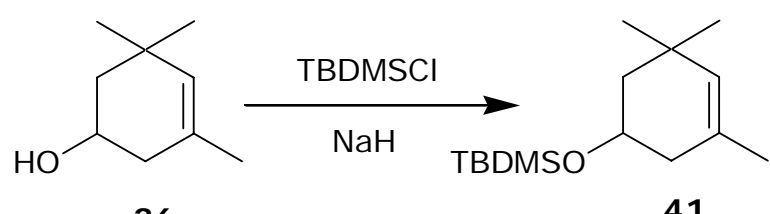

36

41

4) (3,5,5-Trimetil-ciclo-hex-3-eniloximetil)-benzeno (47)<smiles>CC1=CC(C)(C)CC(OCc2ccccc2Br)C1</smiles> 
5) 5-Metoximetoxi-1,3,3-trimetil-ciclo-hexeno (48)<smiles>COC1CC(C)=CC(C)(C)C1</smiles>

6) Acetato de 3,5,5-trimetil-ciclo-hex-3-enil (49)<smiles>CCN(CC)C(=O)OC1CC(C)=CC(C)(C)C1</smiles>

7) Acetato de 3-hidroxi-3,5,5-trimetil-4-oxo-ciclo-hexil (50a e 50b)<smiles>CC(=O)OC1CC(C)=CC(C)(C)C1</smiles>

8) 2,4-Di-hidroxi-2,6,6-trimetil-ciclo-hexanona (51a e 51b)

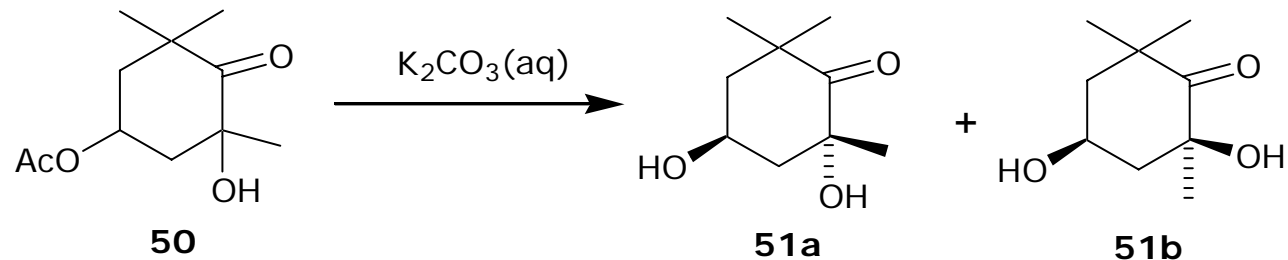


9) 2-Hidroxi-4-metoximetoxi-2,6,6-trimetil-ciclo-hexanona (52) e 2,4-bis-metoximetoxi-2,6,6-trimetil-ciclo-hexanona (53)

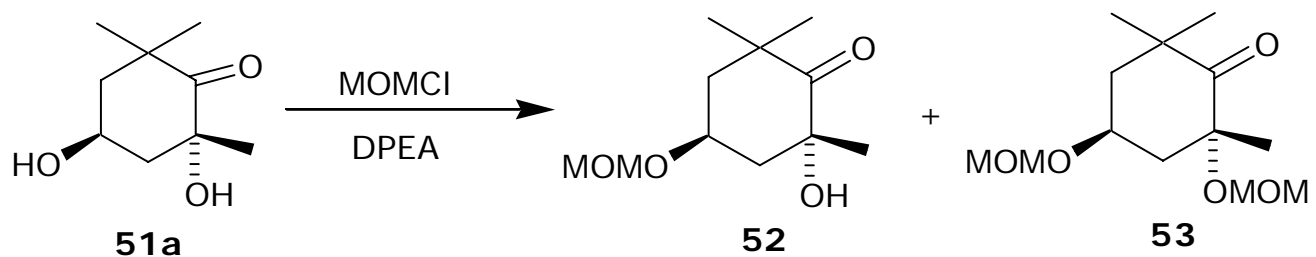

10) terc-Butil-dimetil-(1-metil-prop-2-iniloxi)-silano (55)

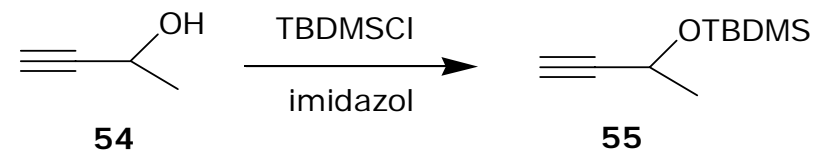

11) 1-[3-(terc-Butil-dimetil-silaniloxi)-but-1-inil]-2,4-bis-metoximetoxi-2,6,6trimetil-ciclo-hexanol (56)

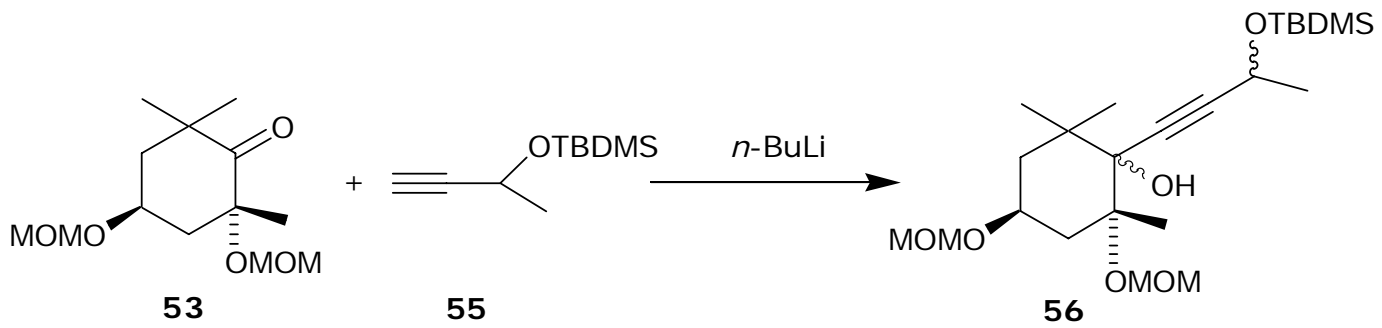

12) 1-[3-(terc-Butil-dimetil-silaniloxi)-but-1-enil]-2,4-bis-metoximetoxi-2,6,6trimetil-ciclo-hexanol (57)

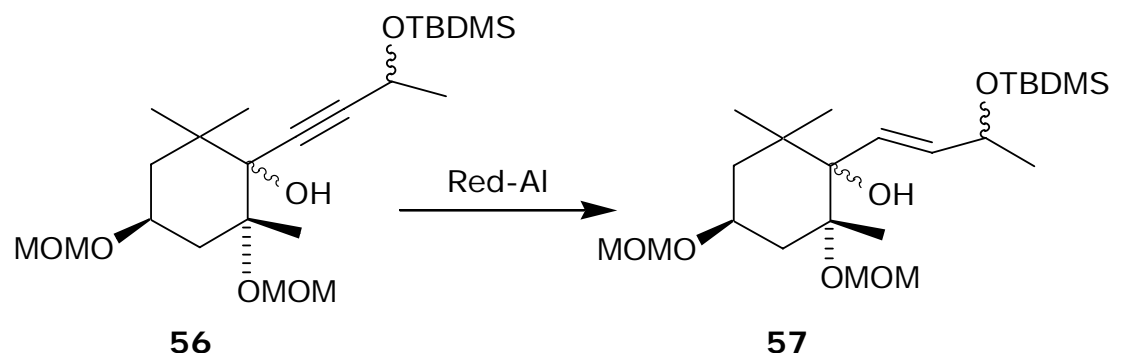


13) 2-(3-Hidroxi-but-1-enil)-5-metoximetoxi-1,3,3-trimetil-ciclo-hexano-1,2-diol (58)

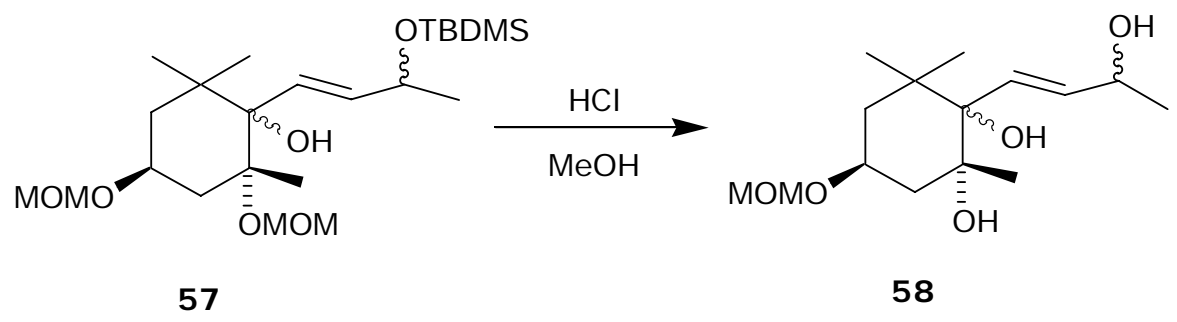

14) 1-(3-Hidroxi-but-1-enil)-2,6,6-trimetil-ciclo-hexano-1,2,4-triol (30a e 30b)

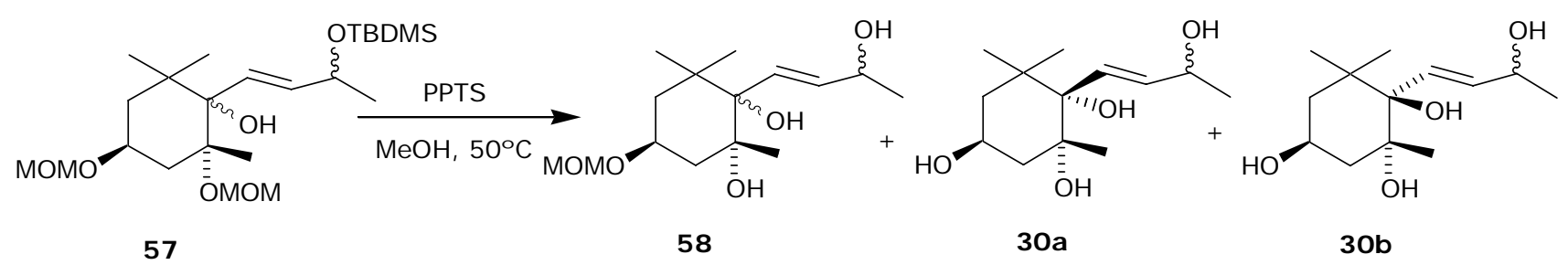

15) 1-(3-Metoxi-but-1-enil)-2,6,6-trimetil-ciclo-hexano-1,2,4-triol (59a e 59b)

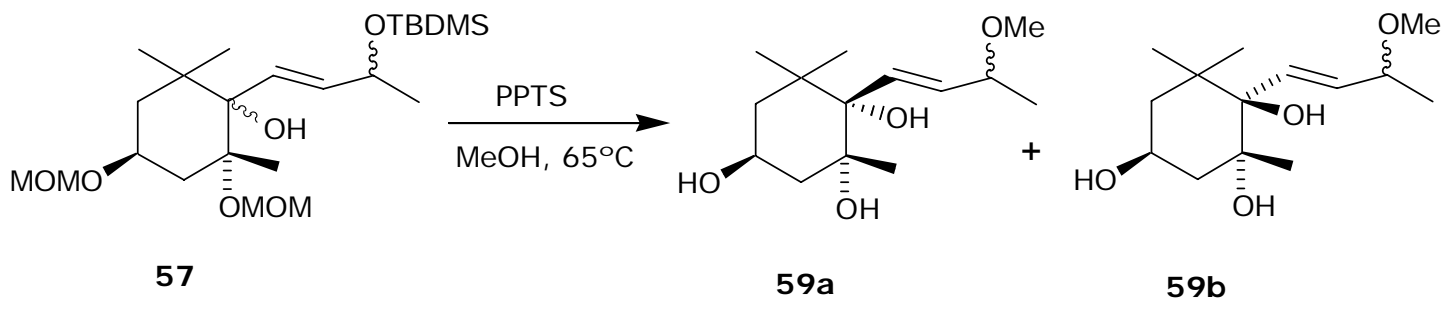




\subsection{Procedimento Experimental}

1) Preparação do 3,5,5-trimetil-3-ciclo-hexen-1-ona (35):

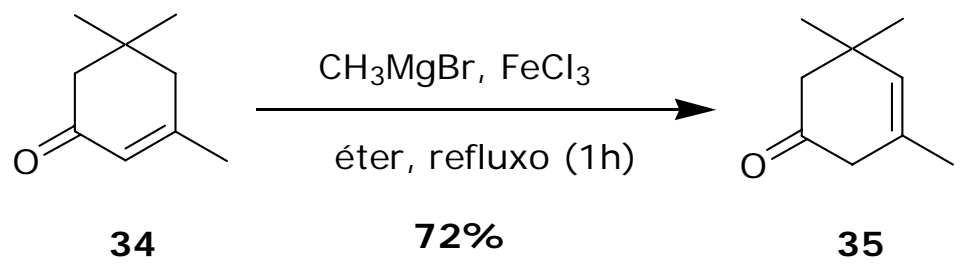

Em um balão de $250 \mathrm{~mL}$ de 3 bocas, provido de agitação magnética, condensador de refluxo, funil de adição e tubo para entrada de gás, mantido sob atmosfera inerte, adicionou-se magnésio metálico $(2,0631$ g; 84,9 mmol) e um cristal de iodo. Em seguida, o sistema foi aquecido com um secador até sublimar o iodo.

Adicionou-se $25 \mathrm{~mL}$ de éter etílico anidro e borbulhou-se o $\mathrm{CH}_{3} \mathrm{Br}$. A velocidade de borbulhamento foi controlada para manter um refluxo brando do solvente. Com o passar do tempo, a mistura reacional adquiriu uma coloração escura. Após o consumo de todo o magnésio, foram adicionados mais $60 \mathrm{~mL}$ de éter etílico anidro e o tubo de entrada de gás foi retirado.

A mistura foi resfriada à $0^{\circ} \mathrm{C}$ e adicionou-se $\mathrm{FeCl}_{3}(0,3175 \mathrm{~g} ; 1,96 \mathrm{mmol})$ dissolvido em $3 \mathrm{~mL}$ éter etílico anidro. Adicionou-se, lentamente, a isoforona (34) (9,0113 g; 65,3 mmol) dissolvida em $15 \mathrm{~mL}$ éter etílico anidro, mantendo-se a mistura reacional abaixo de $10^{\circ} \mathrm{C}$. Terminada a adição, deixou-se a mistura reacional sob refluxo durante uma hora.

Depois disso, resfriou-se a mistura reacional à $0^{\circ} \mathrm{C}$ e adicionou-se uma mistura de ácido acético glacial (5 mL) e gelo moído (50 g), formando um sólido que dificultou a agitação. Separou-se a fase orgânica e extraiu-se a fase aquosa com éter etílico. Os extratos orgânicos foram combinados e lavados com solução saturada de $\mathrm{NaHCO}_{3}$, água, solução saturada de $\mathrm{NaCl}$ e secados com $\mathrm{MgSO}_{4}$ anidro. 
Após a evaporação do solvente, o resíduo foi destilado sob pressão reduzida (temperatura $48^{\circ} \mathrm{C}$, pressão $1 \mathrm{mmHg}$ ), resultando num óleo amarelo claro, com rendimento de $72 \%$, que foi caracterizado como sendo o composto 35 desejado.

Rendimento: 6,4879 g (47,0 mmol; 72\%)

Dados espectroscópicos do composto 35:

${ }^{1} \mathrm{H}-\mathrm{RMN}\left(\mathrm{CDCl}_{3}, 400 \mathrm{MHz}\right) \delta(\mathrm{ppm}): 5,50(1 \mathrm{H}, \mathrm{s}) ; 2,72(2 \mathrm{H}, \mathrm{s}) ; 2,32(2 \mathrm{H}, \mathrm{s})$; $1,71(3 \mathrm{H}, \mathrm{s}) ; 1,04(6 \mathrm{H}, \mathrm{s})$.

${ }^{13} \mathrm{C}-\mathrm{RMN}\left(\mathrm{CDCl}_{3}, 100 \mathrm{MHz}\right) \delta$ (ppm): 212,1 (C=O); 133,6 (=CH); 130,1 (C); $53,8\left(\mathrm{CH}_{2}\right) ; 44,2\left(\mathrm{CH}_{2}\right) ; 36,9(\mathrm{C}) ; 30,1\left(2 \mathrm{CH}_{3}\right) ; 23,0\left(\mathrm{CH}_{3}\right)$. 


\section{2) Preparação do 3,5,5-trimetil-3-ciclo-hexen-1-ol (36):}

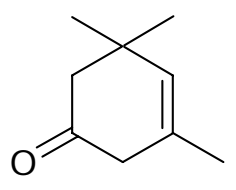

35

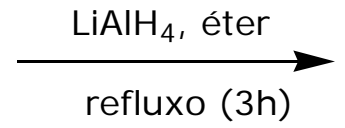

$80 \%$

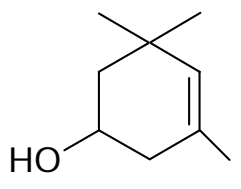

36

Em um balão de $250 \mathrm{~mL}$ de 3 bocas, provido de agitação magnética, funil de adição e condensador de refluxo, mantido sob atmosfera inerte, adicionou-se hidreto de lítio e alumínio (1,4094 g; 37,1 mmol) e $75 \mathrm{~mL}$ de éter etílico anidro.

$\mathrm{O}$ sistema reacional foi resfriado à $0^{\circ} \mathrm{C}$ e adicionou-se lentamente $\mathrm{o}$ composto 35 (5,6911 g; 41,2 mmol), dissolvido em $15 \mathrm{~mL}$ de éter etílico anidro. Após a adição, agitou-se a mistura reacional durante 30 minutos a temperatura ambiente e deixou-se sob refluxo durante 3 horas.

Em seguida, a mistura reacional foi resfriada à $0^{\circ} \mathrm{C}$ e adicionou-se na seqüência, água gelada $(1,5 \mathrm{~mL})$, solução de $\mathrm{NaOH}$ a $15 \%$ (1,5 mL) e novamente água $(4,5 \mathrm{~mL})$. Filtrou-se o sólido branco formado, o qual foi lavado várias vezes com éter etílico. As soluções etéreas foram juntadas, secadas com $\mathrm{MgSO}_{4}$ anidro e o solvente foi evaporado sob pressão reduzida.

O resíduo foi purificado por destilação horizontal a $50^{\circ} \mathrm{C}(2 \mathrm{mmHg})$, obtendo-se um óleo incolor, com rendimento de $80 \%$, o qual foi caracterizado como sendo o composto 36 desejado.

Rendimento: 4,6174 g (32,98 mmol; 80\%)

\section{Dados espectroscópicos do composto 36:}

${ }^{1} \mathrm{H}-\mathrm{RMN}\left(\mathrm{CDCl}_{3}, 400 \mathrm{MHz}\right) \delta(\mathrm{ppm}): 5,10(1 \mathrm{H}, \mathrm{s}) ; 4,00\left(1 \mathrm{H}, \mathrm{dddd}, J_{1}=11,9\right.$ $\left.\mathrm{Hz}, J_{2}=9,3 \mathrm{~Hz}, J_{3}=5,6 \mathrm{~Hz}, J_{4}=3,5\right) ; 2,22\left(1 \mathrm{H}, \mathrm{dd}, J_{1}=16,4 \mathrm{~Hz}, J_{2}=5,6 \mathrm{~Hz}\right) ; 1,87(1 \mathrm{H}$, ddq, $\left.J_{1}=16,4 \mathrm{~Hz}, J_{2}=9,3 \mathrm{~Hz}, J_{3}=1,3 \mathrm{~Hz}\right) ; 1,72\left(1 \mathrm{H}, \mathrm{ddt}, J_{1}=11,9 \mathrm{~Hz}, J_{2}=3,5 \mathrm{~Hz}, J_{3}=\right.$ 1,3 Hz); 1,65 (3H, s); 1,52 (OH, sl); 1,32 (1H, t, J= 11,9 Hz); 1,00 (3H, s); 0,98 (3H, s). 
${ }^{13} \mathrm{C}-\mathrm{RMN}\left(\mathrm{CDCl}_{3}, 100 \mathrm{MHz}\right) \delta$ (ppm): 131,5 (=CH); 128,5 (=C); 65,5 (CH$\mathrm{OH}) ; 45,9\left(\mathrm{CH}_{2}\right) ; 39,6\left(\mathrm{CH}_{2}\right) ; 33,9(\mathrm{C}) ; 31,4\left(\mathrm{CH}_{3}\right) ; 29,5\left(\mathrm{CH}_{3}\right) ; 23,2\left(\mathrm{CH}_{3}\right)$.

IV (cm-1): $3338(\mathrm{OH}) ; 1669$ (C=C); $1360(\mathrm{OH}) ; 1050(\mathrm{C}-\mathrm{O}) ; 835(\mathrm{C}-\mathrm{H})$ dupla ligação. 


\section{3) Preparação do terc-butil-dimetil-(3,3,5-trimetil-ciclo-hexiloxi)-silila (41):}

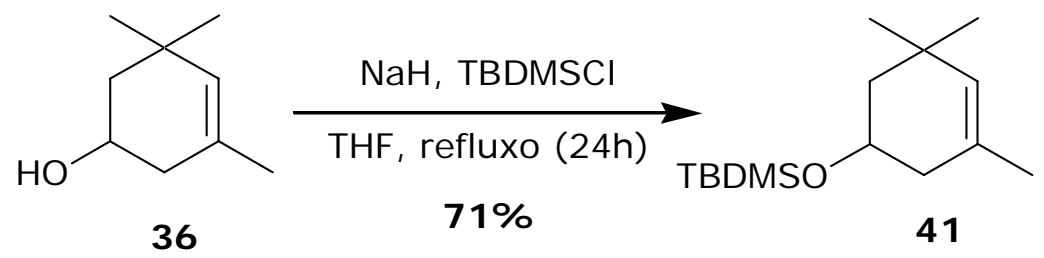

Em um balão de $50 \mathrm{~mL}$ de 3 bocas, equipado com condensador de refluxo, sob atmosfera inerte, adicionou-se hidreto de sódio (0,2610 g; 10,9 mmol), o qual foi lavado duas vezes com $n$-hexano anidro para eliminar o óleo mineral.

Adicionou-se $10 \mathrm{~mL}$ de THF anidro e uma solução do composto 36 (0,1930 g; 1,38 mmol) em $2 \mathrm{~mL}$ de THF anidro. Aqueceu-se a mistura reacional sob refluxo durante 3 horas.

Em seguida, a mistura reacional foi resfriada a temperatura ambiente e adicionou-se 0,2261 g (1,50 mmol) de TBDMSCl (cloreto de terc-butildimetilsilila) dissolvido em $2 \mathrm{~mL}$ de THF anidro. Aqueceu-se novamente a mistura sob refluxo por mais 21 horas e, depois disso, resfriou-se a mistura reacional com banho de gelo e adicionou-se gelo picado à solução até que não ocorresse mais evolução de gás.

As fases foram separadas e a fase aquosa foi extraída com éter etílico. Os extratos orgânicos foram combinados, lavados com água, com solução saturada de $\mathrm{NaCl}$ e secados com $\mathrm{MgSO}_{4}$ anidro. Após filtração, o solvente foi evaporado sob pressão reduzida.

O resíduo foi purificado por cromatografia em coluna de sílica gel, eluindose com uma mistura de $n$-hexano:acetato de etila (9:1). Obteve-se um óleo amarelo claro com $71 \%$ de rendimento, o qual foi caracterizado como sendo o composto $\mathbf{4 1}$ desejado.

Rendimento: 0,2485 g (0,98 mmol; 71\%). 


\section{Dados espectroscópicos do composto 41:}

${ }^{1} \mathbf{H}-\mathbf{R M N}\left(\mathrm{CDCl}_{3}\right) \delta$ (ppm): 5,03 (1H, s); 3,92 (1H, dddd, $J_{1}=12,0 \mathrm{~Hz}, J_{2}=9,3$ $\left.\mathrm{Hz}, J_{3}=5,5 \mathrm{~Hz}, J_{4}=3,6 \mathrm{~Hz}\right) ; 2,04\left(1 \mathrm{H}, \mathrm{dd}, J_{1}=16,6 \mathrm{~Hz} ; J_{2}=5,5 \mathrm{~Hz}\right) ; 1,87\left(1 \mathrm{H}, \mathrm{ddq}, J_{1}=\right.$ $\left.16,6 \mathrm{~Hz}, J_{2}=9,3 \mathrm{~Hz}, J_{3}=1,3 \mathrm{~Hz}\right) ; 1,61(3 \mathrm{H}, \mathrm{s}) ; 1,58\left(1 \mathrm{H}, \mathrm{ddt}, J_{1}=12,0 \mathrm{~Hz}, J_{2}=3,6 \mathrm{~Hz}\right.$, $\left.J_{3}=1,3 \mathrm{~Hz}\right) ; 1,32(1 \mathrm{H}, \mathrm{t}, J=12,0 \mathrm{~Hz}) ; 0,97(3 \mathrm{H}, \mathrm{s}) ; 0,95(3 \mathrm{H}, \mathrm{s}) ; 0,88(9 \mathrm{H}, \mathrm{s}) ; 0,06(6 \mathrm{H}$, s).

${ }^{13} \mathrm{C}-\mathrm{RMN}\left(\mathrm{CDCl}_{3}\right) \delta$ (ppm): 131,4 (=CH); 128,8 (=C); 66,6 (CH-O); 46,4 ( $\left.\mathrm{CH}_{2}\right)$; 40,2 ( $\left.\mathrm{CH}_{2}\right) ; 33,9(\mathrm{C}) ; 31,4\left(\mathrm{CH}_{3}\right) ; 29,5\left(\mathrm{CH}_{3}\right) ; 25,8\left(3 \mathrm{CH}_{3}\right) ; 23,3\left(\mathrm{CH}_{3}\right) ; 18,1(\mathrm{C}) ;-4,6(2$ $\left.\mathrm{CH}_{3}-\mathrm{Si}\right)$.

IV (cm-1): $1675(\mathrm{C}=\mathrm{C}) ; 1256\left(\mathrm{Si}_{-} \mathrm{CH}_{3}\right) ; 1082(\mathrm{Si}-\mathrm{C}-\mathrm{O})$ sim; 835 (C-H) dupla ligação. 


\section{4) Preparação do (3,5,5-trimetil-ciclo-hex-3-eniloximetil)-benzeno (47):}

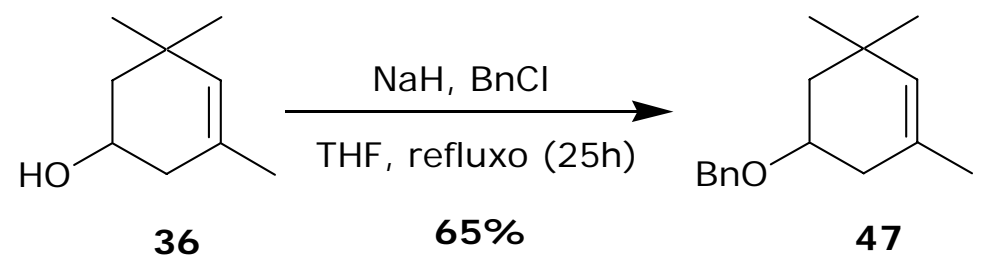

Em um balão de $25 \mathrm{~mL}$ com 3 bocas, equipado com condensador de refluxo e sob atmosfera inerte, adicionou-se hidreto de sódio (0,1210 g; 5,04 mmol), o qual foi lavado duas vezes com $n$-hexano anidro para retirar o óleo mineral.

Adicionou-se $8 \mathrm{~mL}$ de THF anidro e uma solução do composto 36 (0,1536 g; 1,09 mmol) em 1,5 mL de THF anidro. Aqueceu-se a mistura reacional sob refluxo durante 4 horas.

Em seguida, a mistura reacional foi resfriada à temperatura ambiente e adicionou-se o 0,17 $\mathrm{mL}(0,1899 \mathrm{~g} ; 1,50 \mathrm{mmol})$ de $\mathrm{BnCl}$ (cloreto de benzila). Aqueceu-se novamente a mistura sob refluxo por mais 21 horas e, depois disso, resfriou-se a mistura reacional com um banho de gelo e adicionou-se gelo picado à solução até que não ocorresse mais evolução de gás.

As fases foram separadas e a fase aquosa foi extraída com éter etílico. Os extratos orgânicos foram combinados, lavados com água, solução saturada de $\mathrm{NaCl}$ e secados com $\mathrm{MgSO}_{4}$ anidro. Após filtração, o solvente foi evaporado sob pressão reduzida e o resíduo foi purificado por cromatografia em coluna de sílica gel, eluindo-se com uma mistura de $n$-hexano:acetato de etila (9:1).

Obteve-se um óleo incolor com $65 \%$ de rendimento, o qual foi caracterizado como sendo o composto 47 desejado.

Rendimento: 0,1893 g (0,71 mmol; 65\%). 


\section{Dados espectroscópicos do composto 47:}

${ }^{1} \mathrm{H}-\mathrm{RMN}\left(\mathrm{CDCl}_{3}\right) \boldsymbol{\delta}$ (ppm): 7,36 (5Harom, m); 5,10 (1H, s); 4,58 (2H, s); 3,73 $\left(1 \mathrm{H}, \mathrm{dddd}, J_{1}=11,9 \mathrm{~Hz}, J_{2}=9,4 \mathrm{~Hz}, J_{3}=5,6 \mathrm{~Hz}, J_{4}=3,3 \mathrm{~Hz}\right) ; 2,27\left(1 \mathrm{H}, \mathrm{dd}, J_{1}=16,4 \mathrm{~Hz}\right.$, $\left.J_{2}=5,6 \mathrm{~Hz}\right) ; 1,96\left(1 \mathrm{H}, \mathrm{ddq}, J_{1}=16,4 \mathrm{~Hz}, J_{2}=9,4 \mathrm{~Hz}, J_{3}=1,5 \mathrm{~Hz}\right) ; 1,84\left(1 \mathrm{H}, \mathrm{ddt}, J_{1}=11,9\right.$ $\left.\mathrm{Hz}, J_{2}=3,3 \mathrm{~Hz}, J_{3}=1,5 \mathrm{~Hz}\right) ; 1,64(3 \mathrm{H}, \mathrm{s}) ; 1,36(1 \mathrm{H}, \mathrm{t}, J=11,9 \mathrm{~Hz}) ; 1,01(3 \mathrm{H}, \mathrm{s}) ; 0,95$ $(3 \mathrm{H}, \mathrm{s})$.

${ }^{13} \mathrm{C}-\mathrm{RMN}\left(\mathrm{CDCl}_{3}\right) \delta$ (ppm): 139,4 (C) arom; 132,1 (=CH); 129,1 (=C); 128,7 (2 $\mathrm{CH})$ arom; $128,0(2 \mathrm{CH})$ arom; 127,8 $(\mathrm{CH})$ arom; 73,5 $\left(\mathrm{CH}_{2}-\mathrm{O}\right) ; 70,4(\mathrm{CH}-\mathrm{O}) ; 42,9\left(\mathrm{CH}_{2}\right)$; $37,3\left(\mathrm{CH}_{2}\right) ; 34,2(\mathrm{C}) ; 31,8\left(\mathrm{CH}_{3}\right) ; 29,9\left(\mathrm{CH}_{3}\right) ; 23,8\left(\mathrm{CH}_{3}\right)$.

IV (cm-1): $1496(\mathrm{C}=\mathrm{C})$ arom; $1099(\mathrm{C}-\mathrm{O}-\mathrm{C})_{\text {assim; }} 1072(\mathrm{C}-\mathrm{O}-\mathrm{C})_{\text {sim }} ; 734(\mathrm{C}-\mathrm{H})$ arom; $696(\mathrm{C}-\mathrm{H})$ arom. 
5) Preparação do 5-metoximetoxi-1,3,3-trimetil-ciclo-hexeno (48):

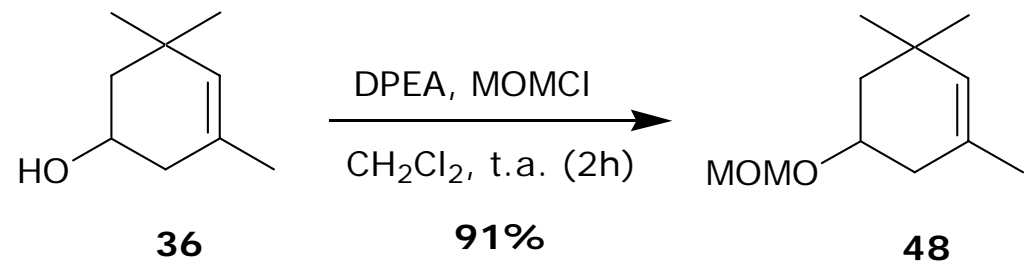

Em um balão de $15 \mathrm{~mL}$ de 2 bocas, mantido sob atmosfera inerte, adicionouse $0,2042 \mathrm{~g}(1,46 \mathrm{mmol})$ do composto 36 e $2 \mathrm{~mL}$ de $\mathrm{CH}_{2} \mathrm{Cl}_{2}$ anidro. Resfriou-se a $0^{\circ} \mathrm{C}$, adicionou-se 0,35 $\mathrm{mL} \quad(0,2585 \mathrm{~g} ; 2,0 \mathrm{mmol})$ de DPEA (N,N diisopropiletilamina) e, em seguida, adicionou-se lentamente 0,12 mL (0,1288 g; 1,6 $\mathrm{mmol}$ ) de $\mathrm{MOMCl}$ (clorometil-metil-éter). Manteve-se a mistura reacional sob agitação a temperatura ambiente durante 2 horas.

Passado esse tempo, adicionou-se à mistura reacional uma solução aquosa saturada de $\mathrm{NaHCO}_{3}$ e separou-se as fases. A fase aquosa foi extraída com $\mathrm{CH}_{2} \mathrm{Cl}_{2}$, lavada com solução aquosa a 10\% de $\mathrm{CuSO}_{4}$, água e, por último, com uma solução saturada de $\mathrm{NaCl}$. Combinaram-se os extratos orgânicos, secou-se com $\mathrm{MgSO}_{4}$ anidro, filtrou-se e concentrou-se sob pressão reduzida.

$\mathrm{O}$ resíduo foi purificado por destilação horizontal à $60^{\circ} \mathrm{C}$ sob pressão reduzida (2 mmHg), obtendo-se um óleo incolor, com rendimento de $91 \%$, o qual foi caracterizado como sendo o composto 48 desejado.

Rendimento: 0,2442 g (1,33 mmol; 91\%). 


\section{Dados espectroscópicos do composto 48:}

${ }^{1} \mathrm{H}-\mathrm{RMN}\left(\mathrm{CDCl}_{3}\right) \delta$ (ppm): 5,10 (1H, s); 4,73 (1H, d, J=6,8 Hz); 4,70 (1H, d, $J=6,8 \mathrm{~Hz}) ; 3,88\left(1 \mathrm{H}, \mathrm{dddd}, J_{1}=12,1 \mathrm{~Hz}, J_{2}=9,5 \mathrm{~Hz}, J_{3}=5,6 \mathrm{~Hz}, J_{4}=3,5 \mathrm{~Hz}\right) ; 3,39(3 \mathrm{H}$, s); $2,24\left(1 \mathrm{H}, \mathrm{dd}, J_{1}=16,4 \mathrm{~Hz}, J_{2}=5,6 \mathrm{~Hz}\right), 1,93\left(1 \mathrm{H}, \mathrm{ddq}, J_{1}=16,4 \mathrm{~Hz}, J_{2}=9,5 \mathrm{~Hz}\right.$, $\left.J_{3}=1,3 \mathrm{~Hz}\right) ; 1,76\left(1 \mathrm{H}, \mathrm{ddt}, J_{1}=12,1 \mathrm{~Hz}, J_{2}=3,5 \mathrm{~Hz}, J_{3}=1,3 \mathrm{~Hz}\right) ; 1,64(3 \mathrm{H}, \mathrm{s}) ; 1,35(1 \mathrm{H}$, $\mathrm{t}, \mathrm{J}=12,1 \mathrm{~Hz}) ; 1,00(3 \mathrm{H}, \mathrm{s}) ; 0,98(3 \mathrm{H}, \mathrm{s})$.

${ }^{13} \mathrm{C}-\mathrm{RMN}\left(\mathrm{CDCl}_{3}\right) \delta$ (ppm): 131,7 (=CH); 128,7 (=C); 94,9 (CH $\left.2-\mathrm{O}\right) ; 71,7(\mathrm{CH}-$ O); 55,2 ( $\left.\mathrm{CH}_{3}-\mathrm{O}\right) ; 43,2\left(\mathrm{CH}_{2}\right) ; 37,3\left(\mathrm{CH}_{2}\right) ; 33,8(\mathrm{C}) ; 31,4\left(\mathrm{CH}_{3}\right) ; 29,5\left(\mathrm{CH}_{3}\right) ; 23,3\left(\mathrm{CH}_{3}\right)$.

IV (cm-1): 1675 (C=C); 1104 (C-O-C) assim; 1048 (C-O-C) sim; 917 (C-H) dupla ligação. 
6) Preparação do acetato de 3,5,5-trimetil-ciclo-hex-3-enil (49):

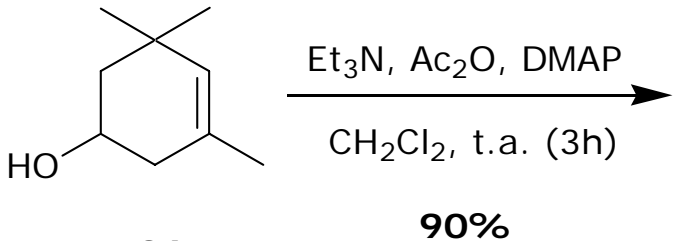

36

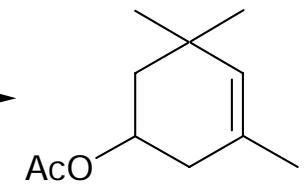

49

Em um balão de $25 \mathrm{~mL}$ de 2 bocas, mantido sob atmosfera inerte, adicionouse o composto 36 (1,0015 g; 7,15 mmol), 2,0 mL de $\mathrm{CH}_{2} \mathrm{Cl}_{2}$ anidro, 1,2 $\mathrm{mL}(0,8640 \mathrm{~g}$; 8,54 mmol) de Et $3 \mathrm{~N}$ (trietilamina), 0,8 $\mathrm{ml}(0,8640 \mathrm{~g} ; 8,46 \mathrm{mmol})$ de anidrido acético $\left(\mathrm{Ac}_{2} \mathrm{O}\right)$ e quantidades catalíticas $(0,0872 \mathrm{~g} ; 0,71 \mathrm{mmol})$ de DMAP (4-N,Ndimetilaminopiridina).

Agitou-se a mistura reacional a temperatura ambiente durante 3 horas. Após esse período, adicionou-se éter etílico, lavou-se com uma solução de $\mathrm{HCl} 2$ mol/L, com solução saturada de $\mathrm{NaHCO}_{3}$ e secou-se com $\mathrm{MgSO}_{4}$ anidro, filtrou-se e evaporou-se o solvente sob pressão reduzida.

O resíduo foi purificado através de cromatografia em coluna de sílica gel, eluindo-se com uma mistura de $n$-hexano:acetato de etila (9:1), obtendo-se um óleo incolor com $90 \%$ de rendimento, o qual foi caracterizado como sendo o composto 49 desejado.

Rendimento: 1,1773 g (6,47 mmol; 90\%).

\section{Dados espectroscópicos do composto 49:}

${ }^{1} \mathbf{H}-\mathbf{R M N}\left(\mathrm{CDCl}_{3}\right) \delta$ (ppm): 5,12 $(1 \mathrm{H}, \mathrm{s}) ; 5,07\left(1 \mathrm{H}, \mathrm{dddd}, J_{1}=11,9 \mathrm{~Hz}, J_{2}=9,1\right.$ $\left.\mathrm{Hz} ; J_{3}=5,8 \mathrm{~Hz}, J_{4}=3,8 \mathrm{~Hz}\right) ; 2,28\left(1 \mathrm{H}, \mathrm{dd}, J_{1}=16,4 \mathrm{~Hz}, J_{2}=5,8 \mathrm{~Hz}\right) ; 2,04(3 \mathrm{H}, \mathrm{s}) ; 1,93$ $\left(1 \mathrm{H}, \mathrm{ddq}, J_{1}=16,4 \mathrm{~Hz}, J_{2}=9,1 \mathrm{~Hz}, J_{3}=1,3 \mathrm{~Hz}\right) ; 1,72\left(1 \mathrm{H}, \mathrm{ddt}, J_{1}=11,9 \mathrm{~Hz}, J_{2}=3,8 \mathrm{~Hz}\right.$, $\left.J_{3}=1,3 \mathrm{~Hz}\right) ; 1,64(3 \mathrm{H}, \mathrm{s}) ; 1,44(1 \mathrm{H}, \mathrm{t}, J=11,9 \mathrm{~Hz}) ; 1,01(6 \mathrm{H}, \mathrm{s})$. 
${ }^{13} \mathrm{C}-\mathrm{RMN}\left(\mathrm{CDCl}_{3}\right) \delta$ (ppm): 170,8 (C=O); 131,7 (=CH); 128,2 (=C); 69,4 (CH$\mathrm{O}) ; 41,8\left(\mathrm{CH}_{2}\right) ; 35,8\left(\mathrm{CH}_{2}\right) ; 33,7\left(\mathrm{CH}_{3}\right) ; 31,1\left(\mathrm{CH}_{3}\right) ; 29,4(\mathrm{C}) ; 23,2\left(\mathrm{CH}_{3}\right) ; 21,4\left(\mathrm{CH}_{3}\right)$.

IV (cm-1): 1733 (C=O); 1240 (C-C-(=O)-O) assim; 1034 (C-H) dupla ligação. 
7) Preparação do acetato de 3-hidroxi-3,5,5-trimetil-4-oxo-ciclo-hexil (50a e 50b):<smiles>CC(=O)OC1CC(C)=CC(C)(C)C1</smiles>

49
$\mathrm{KMnO}_{4}(\mathrm{aq}), \mathrm{MgSO}_{4}$

t.a. $(15 \mathrm{~h})$

$83 \%$

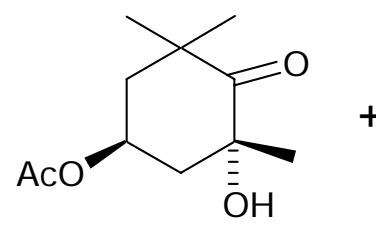

$50 a$

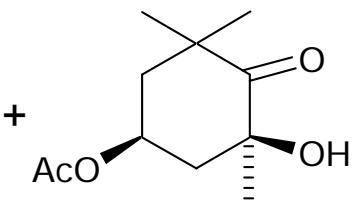

$50 b$

Em um balão de $250 \mathrm{~mL}$, provido de agitação magnética, foi adicionado o composto 49 (0,2146 g; 1,17 mmol), $110 \mathrm{~mL}$ de água e $\mathrm{MgSO}_{4}(0,5275 \mathrm{~g} ; 4,38 \mathrm{mmol})$ para manter o $\mathrm{pH}$ neutro. Resfriou-se a mistura reacional a $0^{\circ} \mathrm{C}$ e adicionou-se lentamente uma solução de $\mathrm{KMnO}_{4}(0,2242 \mathrm{~g} ; 1,42 \mathrm{mmol})$ em água (70 mL), mantendo-se a temperatura abaixo de $6^{\circ} \mathrm{C}$.

Depois de 15 horas de reação a temperatura ambiente, filtrou-se o $\mathrm{MnO}_{2}$ formado e extraiu-se a fase aquosa com éter etílico. A solução etérea resultante foi secada com $\mathrm{MgSO}_{4}$ anidro e evaporada sob pressão reduzida.

O resíduo foi purificado através de cromatografia em coluna de sílica gel, eluindo-se com uma mistura de $n$-hexano:acetato de etila (1:1). Obteve-se um óleo incolor com $83 \%$ de rendimento, o qual foi caracterizado como sendo o composto 50 desejado.

Como o composto 50 obtido possui dois centros assimétricos, formou-se quatro diasteroisômeros do composto 50, o que dificultou as análises espectroscópicas. Os sinais dos deslocamentos químicos presentes no espectro de ${ }^{1} \mathrm{H}-\mathrm{RMN}$ da mistura estavam todos duplicados. Através da integral relativa dos sinais pôde-se determinar que a proporção entre os dois diasteroisômeros 50a (3S, $5 R)$ e $50 \mathrm{~b}(3 S, 5 S)$ é de $1: 1$, sendo os outros dois diasteroisômeros os seus respectivos enantiômeros.

Por causa disso, estes diasteroisômeros 50a $(3 S, 5 R)$ e $50 \mathrm{~b}(3 S, 5 S)$ foram separados por HPLC, utilizando como fase móvel uma mistura de nhexano:isopropanol (95:5) em uma coluna Shimadzu Shim-pack CLC-CN(M). 
Após a separaçao, o esteroisômero 50a $(3 S, 5 R)$ cristalizou na forma de um sólido branco cristalino com $\mathrm{PF}=52-53^{\circ} \mathrm{C}$, enquanto que o esteroisômero $50 \mathrm{~b}$ (3S, 5S) permaneceu na forma de um óleo incolor.

A estereoquímica relativa entre esses dois compostos foi, determinada com uso da técnica de NOE-diff, sendo que a relação entre os grupos substituintes acetila e hidroxila no composto 50 a $(3 S, 5 R)$ é trans, enquanto que no composto $50 \mathrm{~b}(3 S, 5 S)$ é cis.

Rendimento: 0,2096 g (0,98 mmol; 83\%).

Dados espectroscópicos do diasteroisômero 50a $(3 S, 5 R)$ :

${ }^{1} \mathrm{H}-\mathrm{RMN}\left(\mathrm{CDCl}_{3}\right) \delta$ (ppm): 5,26 (1H, ddt, $\left.J_{1}=7,8 \mathrm{~Hz}, J_{2}=6,6 \mathrm{~Hz}, J_{3}=4,8 \mathrm{~Hz}\right)$; 2,22 (1H, ddd, $\left.J_{1}=14,4 \mathrm{~Hz}, J_{2}=4,8 \mathrm{~Hz}, J_{3}=1,5 \mathrm{~Hz}\right) ; 2,11-2,05(2 \mathrm{H}, \mathrm{m}) ; 2,01(3 \mathrm{H}, \mathrm{s})$; $1,86\left(1 \mathrm{H}, \mathrm{dd}, J_{1}=13,9 \mathrm{~Hz}, J_{2}=7,8 \mathrm{~Hz}\right) ; 1,38(3 \mathrm{H}, \mathrm{s}) ; 1,21(3 \mathrm{H}, \mathrm{s}) ; 1,17(3 \mathrm{H}, \mathrm{s})$.

${ }^{13} \mathrm{C}-\mathrm{RMN}\left(\mathrm{CDCl}_{3}\right) \delta$ (ppm): 215,8 (C=O) cet; 170,3 (C=O) éster; 74,5 (C-OH); 66,7 (CH-O); 43,1 ( $\left.\mathrm{CH}_{2}\right) ; 43,1\left(\mathrm{CH}_{2}\right) ; 43,1(\mathrm{C}) ; 27,6\left(\mathrm{CH}_{3}\right) ; 27,5\left(\mathrm{CH}_{3}\right) ; 27,4\left(\mathrm{CH}_{3}\right) ; 21,3$ $\left(\mathrm{CH}_{3}\right)$.

IV (cm-1): $3447(\mathrm{OH}) ; 1745(\mathrm{C}=\mathrm{O})$ éster;1718 (C=O) cetona; $1368(\mathrm{OH}) ; 1247$ (C$\mathrm{C}(=\mathrm{O})-\mathrm{O})_{\text {assim; }} 1167$ (O-C-C) assim; 1030 (C-O) álcool.

Dados espectroscópicos do diasteroisômero $50 \mathrm{~b}(3 S, 5 S)$ :

${ }^{1} \mathrm{H}-\mathrm{RMN}\left(\mathrm{CDCl}_{3}\right) \delta$ (ppm): 5,27 (1H, tt, J $\left.=11,6 \mathrm{~Hz}, \mathrm{~J}_{2}=4,2 \mathrm{~Hz}\right) ; 2,43(1 \mathrm{H}$, ddd, $\left.\mathrm{J}_{1}=12,3 \mathrm{~Hz}, \mathrm{~J}_{2}=4,2 \mathrm{~Hz}, \mathrm{~J}_{3}=3,3 \mathrm{~Hz}\right) ; 2,12\left(1 \mathrm{H}, \mathrm{ddd}, \mathrm{J}_{1}=13,1 \mathrm{~Hz}, \mathrm{~J}_{2}=4,2 \mathrm{~Hz}, \mathrm{~J}_{3}=\right.$ $3,3 \mathrm{~Hz}) ; 2,07(3 \mathrm{H}, \mathrm{s}) ; 1,89\left(1 \mathrm{H}, \mathrm{dd}, \mathrm{J}_{1}=12,3 \mathrm{~Hz}, \mathrm{~J}_{2}=11,6 \mathrm{~Hz}\right) ; 1,74\left(1 \mathrm{H}, \mathrm{dd}, \mathrm{J}_{1}=13,1\right.$ $\left.\mathrm{Hz}, \mathrm{J}_{2}=11,6 \mathrm{~Hz}\right) ; 1,47(3 \mathrm{H}, \mathrm{s}) ; 1,29(3 \mathrm{H}, \mathrm{s}) ; 1,19(3 \mathrm{H}, \mathrm{s})$. 
${ }^{13} \mathrm{C}-\mathrm{RMN}\left(\mathrm{CDCl}_{3}\right) \delta$ (ppm): 217,2 (C=O) cetona; 170,8 (C=O) éster; 75,1 (C-OH); 66,5 (CH-O); 45,0 ( $\left.\mathrm{CH}_{2}\right) ; 44,9\left(\mathrm{CH}_{2}\right) ; 43,3(\mathrm{C}) ; 28,7\left(\mathrm{CH}_{3}\right) ; 27,8\left(\mathrm{CH}_{3}\right) ; 26,8\left(\mathrm{CH}_{3}\right) ; 21,6$ $\left(\mathrm{CH}_{3}\right)$.

IV (cm-1): $3488(\mathrm{OH}) ; 1740(\mathrm{C}=\mathrm{O})$ éster;1703 (C=O) cetona; $1368(\mathrm{OH}) ; 1250$ (C-C(=O)-O) assim; 1163 (O-C-C)assim; 1031 (C-O) álcool. 


\section{8) Preparação do 2,4-dihidroxi-2,6,6-trimetil-ciclo-hexanona (51a e 51b):}<smiles>CC(=O)OC1CC(C)(C)C(=O)C(C)(O)C1</smiles>

50

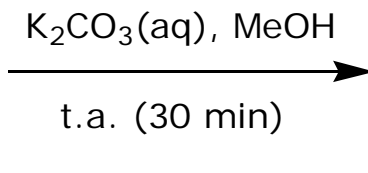

$90 \%$

Em um balão de $15 \mathrm{~mL}$, munido de agitação magnética, foi adicionado 0,6046 g (2,83 mmol) do composto 50 (mistura de diasteroisômeros), $4 \mathrm{~mL}$ de metanol e $4 \mathrm{~mL}$ de solução aquosa a $10 \%$ de $\mathrm{K}_{2} \mathrm{CO}_{3}$. Agitou-se a mistura reacional a temperatura ambiente durante 30 minutos e, em seguida, o metanol foi evaporado sob pressão reduzida. Extraiu-se a fase aquosa com éter etílico, lavou-se com água, com solução saturada de $\mathrm{NaCl}$, filtrou-se e eliminou-se o solvente sob pressão reduzida.

O resíduo foi purificado através de cromatografia em coluna de sílica gel, utilizando como eluente uma mistura de $n$-hexano:acetato de etila (1:9), obtendo-se um óleo incolor, com $90 \%$ de rendimento, que foi caracterizado como sendo o composto 51 de interesse.

Como o composto 51 também existe na forma de quatro diasteroisômeros, houve uma certa dificuldade nas análises espectroscópicas. Os sinais do espectro de ${ }^{1} \mathrm{H}-\mathrm{RMN}$ da mistura estavam todos duplicados e pôde-se determinar que a proporção entre os diasteroisômeros 51 a $(3 S, 5 R)$ e 51 b $(3 S, 5 S)$ manteve-se em 1:1, sendo os outros dois diasteroisômeros os seus respectivos enantiômeros.

Os diasteroisômeros $51 \mathrm{a}(3 S, 5 R)$ e $51 \mathrm{~b}(3 S, 5 S)$ gerados foram separados por cromatografia em coluna de sílica gel, utilizando como eluente uma mistura de nhexano:acetato de etila (1:1). O estereoisômero 51a $(3 S, 5 R)$ cristalizou na forma de sólido branco cristalino com $\mathrm{PF}=86-87^{\circ} \mathrm{C}$ e o estereoisômero $51 \mathrm{~b}(3 S, 5 S)$ também se cristalizou na forma de sólido branco cristalino com $\mathrm{PF}=63-64^{\circ} \mathrm{C}$. 
Através da técnica de NOE-diff, pôde-se verificar que a estereoquímica relativa entre as duas hidroxilas no composto $51 a(3 S, 5 R)$ é trans, enquanto que no composto $51 b(3 S, 5 S)$ é cis.

Rendimento: $0,4373 \mathrm{~g}(2,54 \mathrm{mmol} ; 90 \%)$.

Dados espectroscópicos do diasteroisômero 51a $(3 S, 5 R)$ :

1H-RMN ( $\left.\mathrm{CDCl}_{3}\right) \delta$ (ppm): 4,38 (1H, ddt, $\left.J_{1}=9,1 \mathrm{~Hz}, J_{2}=7,8 \mathrm{~Hz}, J_{3}=4,7 \mathrm{~Hz}\right)$; 2,28 $\left(1 \mathrm{H}, \mathrm{ddd}, J_{1}=14,0 \mathrm{~Hz}, J_{2}=4,7 \mathrm{~Hz}, J_{3}=2,3 \mathrm{~Hz}\right) ; 2,01\left(1 \mathrm{H}, \mathrm{ddd}, J_{1}=13,6 \mathrm{~Hz}, J_{2}=4,7\right.$ $\left.\mathrm{Hz}, J_{3}=2,3 \mathrm{~Hz}\right) ; 1,96\left(1 \mathrm{H}, \mathrm{dd}, J_{1}=14,0 \mathrm{~Hz}, J_{2}=7,8 \mathrm{~Hz}\right) ; 1,84\left(1 \mathrm{H}, \mathrm{dd}, J_{1}=13,6 \mathrm{~Hz}, J_{2}=\right.$ 9,1 Hz); 1,64 (OH, sl); 1,44 (3H, s); 1,27 (3H, s); 1,24 (3H, s).

${ }^{13} \mathrm{C}-\mathrm{RMN}\left(\mathrm{CDCl}_{3}\right) \delta$ (ppm): 216,5 (C=O); 75,1 (C-OH); 63,8 (CH-OH); 47,5 $\left(\mathrm{CH}_{2}\right) ; 47,4\left(\mathrm{CH}_{2}\right) ; 43,6(\mathrm{C}) ; 28,2\left(\mathrm{CH}_{3}\right) ; 28,1\left(\mathrm{CH}_{3}\right) ; 27,8\left(\mathrm{CH}_{3}\right)$.

IV (cm-1): 3393 (OH); 1708 (C=O); $1374(\mathrm{OH}) ; 1044$ (C-O) álcool.

\section{Dados espectroscópicos do diasteroisômero 51b $(3 S, 5 S)$ :}

${ }^{1} \mathrm{H}-\mathrm{RMN}\left(\mathrm{CDCl}_{3}\right) \delta$ (ppm): 4,26 (1H, tt, $\left.J_{1}=10,6 \mathrm{~Hz}, J_{2}=4,0 \mathrm{~Hz}\right) ; 2,62(\mathrm{OH}, \mathrm{sl})$; $2,40\left(1 \mathrm{H}, \mathrm{ddd}, J_{1}=12,6 \mathrm{~Hz}, J_{2}=4,0 \mathrm{~Hz}, J_{3}=3,3 \mathrm{~Hz}\right) ; 2,08\left(1 \mathrm{H}, \mathrm{ddd}, J_{1}=13,1 \mathrm{~Hz}, J_{2}=4,0\right.$ $\left.\mathrm{Hz}, J_{3}=3,3 \mathrm{~Hz}\right) ; 1,87\left(1 \mathrm{H}, \mathrm{dd}, J_{1}=12,6 \mathrm{~Hz}, J_{2}=10,6 \mathrm{~Hz}\right) ; 1,72\left(1 \mathrm{H}, \mathrm{dd}, J_{1}=13,1 \mathrm{~Hz}, J_{2}=\right.$ 10,6 Hz); 1,42 (3H, s); 1,25 (3H, s); 1,20 (3H, s).

${ }^{13} \mathrm{C}-\mathrm{RMN}\left(\mathrm{CDCl}_{3}\right) \delta$ (ppm): 217,3 (C=O); 74,8 (C-OH); 63,9 (CH-OH); 48,6 $\left(\mathrm{CH}_{2}\right) ; 48,1\left(\mathrm{CH}_{2}\right) ; 42,9(\mathrm{C}) ; 28,3\left(\mathrm{CH}_{3}\right) ; 27,6\left(\mathrm{CH}_{3}\right) ; 26,8\left(\mathrm{CH}_{3}\right)$.

IV (cm-1): 3391 (OH); 1705 (C=O); 1367 (OH); 1049 (C-O) álcool. 
9) Preparação do 2-hidroxi-4-metoximetoxi-2,6,6-trimetil-ciclo-hexanona (52) e 2,4-bis-metoximetoxi-2,6,6-trimetil-ciclo-hexanona (53):

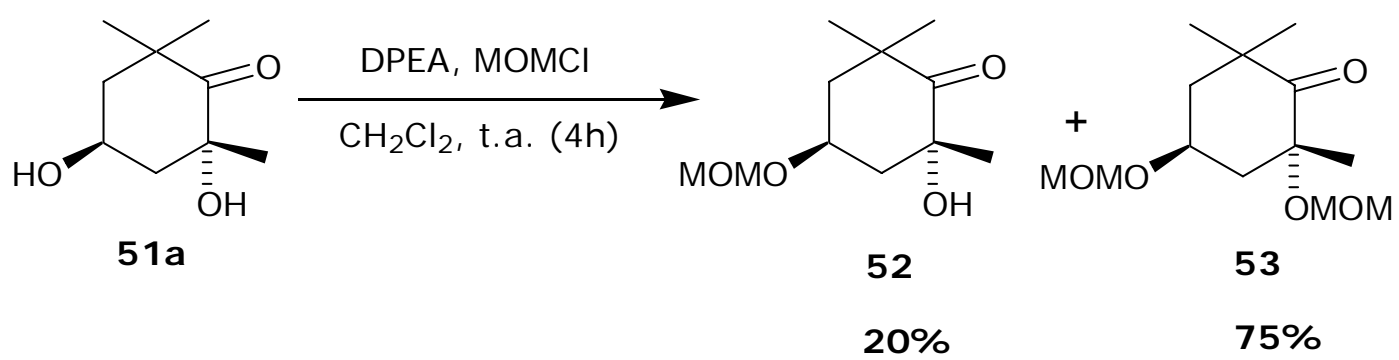

Em um balão de $25 \mathrm{~mL}$ de 2 bocas, equipado com agitação magnética e mantido sob atmosfera inerte, foi adicionado $0,1247 \mathrm{~g}(0,72 \mathrm{mmol})$ do composto 51a dissolvido em $2 \mathrm{~mL}$ de $\mathrm{CH}_{2} \mathrm{Cl}_{2}$ anidro, 0,38 mL (0,2792 g; 2,16 mmol) de DPEA (N,N-diisopropiletilamina) e, em seguida, adicionou-se lentamente 0,22 mL (0,2318 g; 2,88 mmol) de $\mathrm{MOMCl}$ (clorometil-metil-éter). Deixou-se a mistura reacional sob agitação durante 4 horas a temperatura ambiente.

Passado esse tempo, adicionou-se solução aquosa saturada de $\mathrm{NaHCO}_{3}$ e separaram-se as fases. Extraiu-se a fase aquosa com $\mathrm{CH}_{2} \mathrm{Cl}_{2}$, lavou-se o extrato orgânico com água destilada, solução saturada de $\mathrm{NaCl}$, secou-se com $\mathrm{MgSO}_{4}$ anidro, filtrou-se e concentrou-se sob pressão reduzida.

Os compostos 52 e 53 obtidos foram separados por cromatografia em coluna de sílica gel, utilizando como eluente uma mistura de $n$-hexano:acetato de etila (8:2). Ambos foram obtidos na forma de óleo incolor, o composto 52 com $20 \%$ de rendimento e o composto 53 com $75 \%$ de rendimento.

Rendimento (composto 52): 0,0313 g (0,14 mmol; 20\%).

Rendimento (composto 53): 0,1414 g (0,54 mmol; 75\%).

Rendimento total: $95 \%$ 


\section{Dados espectroscópicos do composto 52:}

${ }^{1} \mathrm{H}-\mathrm{RMN}\left(\mathrm{CDCl}_{3}\right) \delta$ (ppm): 4,70 (2H, s); 4,18 (1H, ddt, $J_{1}=8,3 \mathrm{~Hz}, J_{2}=7,1 \mathrm{~Hz}$, $\left.J_{3}=4,8 \mathrm{~Hz}\right) ; 3,40(3 \mathrm{H}, \mathrm{s}) ; 2,77(\mathrm{OH}, \mathrm{sl}) ; 2,24\left(1 \mathrm{H}, \mathrm{ddd}, J_{1}=14,2 \mathrm{~Hz}, J_{2}=4,8 \mathrm{~Hz}, J_{3}=1,8\right.$ $\mathrm{Hz}) ; 2,04\left(1 \mathrm{H}, \mathrm{dd}, J_{1}=14,2 \mathrm{~Hz}, J_{2}=7,1 \mathrm{~Hz}\right) ; 2,01\left(1 \mathrm{H}, \mathrm{ddd}, J_{1}=13,9 \mathrm{~Hz}, J_{2}=4,8 \mathrm{~Hz}, J_{3}=\right.$ $1,8 \mathrm{~Hz}) ; 1,88\left(1 \mathrm{H}, \mathrm{dd}, J_{1}=13,9 \mathrm{~Hz}, J_{2}=8,3 \mathrm{HZ}\right) ; 1,43(3 \mathrm{H}, \mathrm{s}) ; 1,25(3 \mathrm{H}, \mathrm{s}) ; 1,23(3 \mathrm{H}, \mathrm{s})$.

${ }^{13} \mathrm{C}-\mathrm{RMN}\left(\mathrm{CDCl}_{3}\right) \delta$ (ppm): 216,7(C=O); 94,9 ( $\left.\mathrm{CH}_{2}-\mathrm{O}\right) ; 74,7$ (C-OH); 68,8 (CH-O); 55,4 (CH3); 44,3 ( $\left(\mathrm{CH}_{2}\right) ; 44,0\left(\mathrm{CH}_{2}\right) ; 43,1(\mathrm{C}) ; 27,8\left(\mathrm{CH}_{3}\right) ; 27,7\left(\mathrm{CH}_{3}\right) ; 27,5$ $\left(\mathrm{CH}_{3}\right)$.

IV (cm-1): $3423(\mathrm{OH}) ; 1709(\mathrm{C}=\mathrm{O}) ; 1374(\mathrm{OH}) ; 1103$ (C-O-C)assim; 1042 $(\mathrm{C}-\mathrm{O}-\mathrm{C})_{\text {sim }}$.

\section{Dados espectroscópicos do composto 53:}

${ }^{1} \mathrm{H}-\mathrm{RMN}\left(\mathrm{CDCl}_{3}\right) \delta$ (ppm): 4,72 (1H, d, J1= 7,1 Hz); 4,70 (1H, d, J1= 7,1 Hz); 4,59 (1H, d, $\left.J_{1}=7,1 \mathrm{~Hz}\right) ; 4,45\left(1 \mathrm{H}, \mathrm{d}, J_{1}=7,1 \mathrm{~Hz}\right) ; 4,33\left(1 \mathrm{H}, \mathrm{tt}, J_{1}=11,1 \mathrm{~Hz}, J_{2}=4,3 \mathrm{~Hz}\right)$; 3,40 (3H, s); 3,36 (3H, s); 2,55 (1H, ddd, $\left.J_{1}=13,9 \mathrm{~Hz}, J_{2}=4,3 \mathrm{~Hz}, J_{3}=3,5 \mathrm{~Hz}\right) ; 2,10(1 \mathrm{H}$, ddd, $\left.J_{1}=13,1 \mathrm{~Hz}, J_{2}=4,3 \mathrm{~Hz}, J_{3}=3,5 \mathrm{~Hz}\right) ; 1,63\left(1 \mathrm{H}, \mathrm{dd}, J_{1}=13,1 \mathrm{~Hz}, J_{2}=11,1 \mathrm{~Hz}\right) ; 1,62$ $\left(1 \mathrm{H}, \mathrm{dd}, J_{1}=13,9 \mathrm{~Hz}, J_{2}=11,1 \mathrm{~Hz}\right) ; 1,31(3 \mathrm{H}, \mathrm{s}) ; 1,29(3 \mathrm{H}, \mathrm{s}) ; 1,11(3 \mathrm{H}, \mathrm{s})$.

${ }^{13} \mathrm{C}-\mathrm{RMN}\left(\mathrm{CDCl}_{3}\right) \delta$ (ppm): 211,4 (C=O); 95,2 ( $\left.\mathrm{CH}_{2}-\mathrm{O}\right) ; 92,0\left(\mathrm{CH}_{2}-\mathrm{O}\right) ; 79,6$ (C$\mathrm{O}) ; 68,3$ (CH-O); 55,7 ( $\left.\mathrm{CH}_{3}-\mathrm{O}\right) ; 55,3\left(\mathrm{CH}_{3}-\mathrm{O}\right) ; 46,1\left(\mathrm{CH}_{2}\right) ; 46,0\left(\mathrm{CH}_{2}\right) ; 44,0$ (C); 27,5 $\left(\mathrm{CH}_{3}\right) ; 27,2\left(\mathrm{CH}_{3}\right) ; 21,6\left(\mathrm{CH}_{3}\right)$.

IV (cm-1): 1708 (C=O); 1149 (C-O-C) assim; 1102 (C-O-C) assim; 1044 (C-O-C) sim. 


\section{0) Preparação do terc-butil-dimetil-(1-metil-prop-2-iniloxi)-silano (55):}

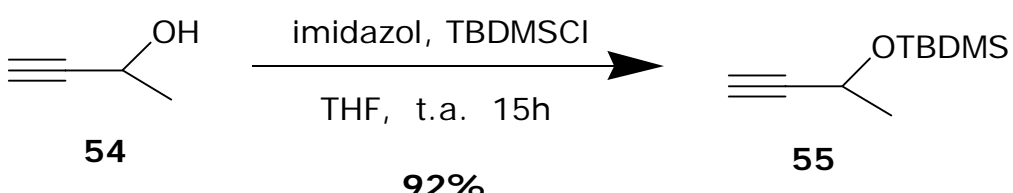

Em um balão de $50 \mathrm{~mL}$ de 2 bocas, munido de agitação magnética e sob atmosfera de $\mathrm{N}_{2}$, adicionou-se 0,4254 g (0,47 mL; 6,0 mmol) de 3-butin-2-ol (54) dissolvido em $7 \mathrm{~mL}$ de THF anidro e 0,4085 g $(6,0 \mathrm{mmol})$ de imidazol dissolvido em $7 \mathrm{~mL}$ de THF anidro.

Deixou-se a mistura reacional sob agitação a temperatura ambiente durante 30 minutos. Resfriou-se a mistura reacional a $0^{\circ} \mathrm{C}$ e, em seguida, adicionou-se 1,0551 g (7,0 mmol) de cloreto de terc-butildimetilsilila (TBDMSCl) dissolvido em 7 $\mathrm{mL}$ de THF anidro.

A reação foi deixada sob agitação durante 15 horas a temperatura ambiente. Depois disso, adicionou-se água e separaram-se as fases. Extraiu-se a fase aquosa com éter etílico, lavou-se o extrato orgânico com água destilada, solução saturada de $\mathrm{NaCl}$, secou-se com $\mathrm{MgSO}_{4}$ anidro, filtrou-se e evaporou-se o solvente sob pressão reduzida.

$\mathrm{O}$ resíduo foi purificado por destilação horizontal $\left(30 \mathrm{mmHg} ; 50^{\circ} \mathrm{C}\right)$, obtendo-se um óleo incolor com rendimento de $92 \%$, que foi caracterizado como sendo o composto 55 desejado.

Rendimento: 1,0212 g (5,5 mmol; 92\%).

Dados espectroscópicos do composto 55:

${ }^{1} \mathrm{H}-\mathrm{RMN}\left(\mathrm{CDCl}_{3}, 400 \mathrm{MHz}\right) \delta(\mathrm{ppm}): 4,50\left(1 \mathrm{H}, \mathrm{qd}, J_{1}=6,6 \mathrm{~Hz}, J_{2}=2,0 \mathrm{~Hz}\right)$; 2,36 (1H, d, J= 2,0 Hz); 1,41 (3H, d, J= 6,6 Hz); 0,89 (9H, s); 0,12 (3H, s); 0,10 (3H, s). 
${ }^{13} \mathrm{C}-\mathrm{RMN}\left(\mathrm{CDCl}_{3}, 100 \mathrm{MHz}\right) \delta$ (ppm): 86,4 (C) tripla; 71,1 (C-H) tripla; 58,7 (CH$\mathrm{O}) ; 25,7\left(3 \mathrm{CH}_{3}\right) ; 25,3\left(\mathrm{CH}_{3}\right) ; 18,2(\mathrm{C}) ;-5,0\left(\mathrm{CH}_{3}-\mathrm{Si}\right) ;-4,7\left(\mathrm{CH}_{3}-\mathrm{Si}\right)$.

IV (cm-1): 3313 (C) tripla; $1258\left(\mathrm{Si}^{-\mathrm{CH}_{3}}\right)_{\text {sim; }} 1104$ (Si-O-C) assim; 1052 (Si-O-C) sim; $778(\mathrm{C}-\mathrm{H})$ tripla ligação. 


\section{1) Preparação do 1-[3-(terc-butil-dimetil-silaniloxi)-but-1-inil]-2,4-bis-metoxi-} metoxi-2,6,6-trimetil-ciclo-hexanol (56):

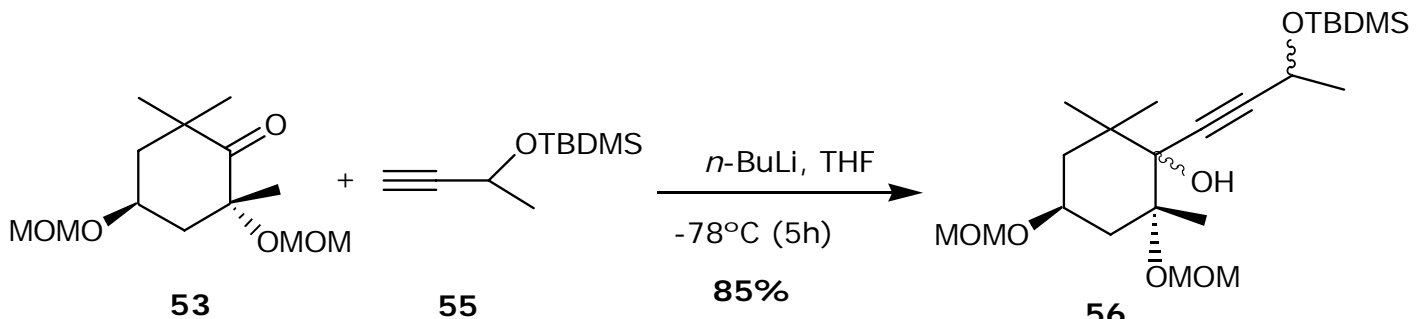

Em um balão de $25 \mathrm{~mL}$ de 2 bocas, munido de agitação magnética e sob atmosfera de $\mathrm{N}_{2}$, adicionou-se 0,3864 g (2,10 mmol) do composto 55 dissolvido em $4 \mathrm{~mL}$ de THF anidro. Resfriou-se a solução a $-78^{\circ} \mathrm{C}$ e, em seguida, adicionou-se 1,8 $\mathrm{mL}(2,34 \mathrm{mmol})$ de uma solução de $n$-BuLi em $n$-hexano (1,3 mol/L), deixando-se a mistura reacional sob agitação a $-78^{\circ} \mathrm{C}$ durante 40 minutos.

Passado esse tempo, adicionou-se 0,2188 g $(0,84 \mathrm{mmol})$ da cetona 53 dissolvida em $1 \mathrm{~mL}$ de THF anidro. A mistura reacional permaneceu sob agitação durante 5 horas nessa mesma temperatura.

Em seguida, adicionou-se solução saturada de cloreto de amônio, separaram-se as fases e a fase aquosa foi extraída com éter etílico. A fase etérea foi lavada com solução saturada de cloreto de sódio, secada com $\mathrm{MgSO}_{4}$ anidro, filtrada e concentrada sob pressão reduzida.

O resíduo obtido foi purificado por cromatografia em coluna de sílica gel, utilizando como eluente uma mistura de n-hexano:acetato de etila (8:2), produzindo o composto 56 com rendimento de $85 \%$.

Nesta reação de adição foram gerados dois novos centros quirais na molécula e, conseqüentemente, foi produzido quatro novos pares de diasteroisômeros do composto 56, numa proporção de 1:1:1:1. Os sinais do espectro de ${ }^{1} \mathrm{H}-\mathrm{RMN}$ da mistura estavam todos sobrepostos, indicando que os deslocamentos químicos desses estereoisômeros são muito semelhantes. 
Os estereoisômeros do composto 56 não puderam ser separados e, por causa disso, não tiveram a relação estereoquímica entre eles definida.

Rendimento: 0,3163 g (0,71 mmol; 85\%).

Dados espectroscópicos da mistura dos diasteroisômeros do composto 56:

${ }^{1} \mathrm{H}-\mathrm{RMN}\left(\mathrm{CDCl}_{3}, 400 \mathrm{MHz}\right) \delta$ (ppm): 4,81 (1H, d, J= 7,3 Hz); 4,69 (1H, d, J= 7,3 Hz); 4,65 (1H, d, J=6,8 Hz); 4,62 (1H, d, J=6,8 Hz); 4,54 (1H, q, J=6,6 Hz); 4,53 $(1 \mathrm{H}, \mathrm{q}, \mathrm{J}=6,6 \mathrm{~Hz}) ; 3,91\left(1 \mathrm{H}, \mathrm{tt}, J_{1}=11,1 \mathrm{~Hz}, J_{2}=4,3 \mathrm{~Hz}\right) ; 3,39(3 \mathrm{H}, \mathrm{s}) ; 3,34(3 \mathrm{H}, \mathrm{s}) ; 2,20$ $\left(1 \mathrm{H}, \mathrm{ddd}, J_{1}=13,9 \mathrm{~Hz}, J_{2}=4,3 \mathrm{~Hz}, J_{3}=2,3 \mathrm{~Hz}\right) ; 1,82-1,63(3 \mathrm{H}, \mathrm{m}) ; 1,47(3 \mathrm{H}, \mathrm{s}) ; 1,40$ $(3 \mathrm{H}, \mathrm{d}, J=6,5 \mathrm{~Hz}) ; 1,39(3 \mathrm{H}, \mathrm{d}, J=6,5 \mathrm{~Hz}) ; 1,14(3 \mathrm{H}, \mathrm{s}) ; 1,12(3 \mathrm{H}, \mathrm{s}) ; 0,86(9 \mathrm{H}, \mathrm{s}) ; 0,08$ $(3 \mathrm{H}, \mathrm{s}) ; 0,07(3 \mathrm{H}, \mathrm{s})$.

${ }^{13} \mathrm{C}-\mathrm{RMN}\left(\mathrm{CDCl}_{3}, 100 \mathrm{MHz}\right) \delta$ (ppm): 94,9 (CH$) ; 91,6\left(\mathrm{CH}_{2}\right) ; 89,3(\mathrm{C}-\mathrm{OH})$; 83,7 (C) tripla; 82,9 (C) tripla; 77,8 (C-O); 69,6 (CH-O); 58,9 (CH-OSi); 56,3 (CH $)$; 55,1 $\left(\mathrm{CH}_{3}\right) ; 43,7\left(\mathrm{CH}_{2}\right) ; 43,6\left(\mathrm{CH}_{2}\right) ; 41,2\left(\mathrm{CH}_{2}\right) ; 41,1\left(\mathrm{CH}_{2}\right) ; 40,3(\mathrm{C}) ; 29,3\left(\mathrm{CH}_{3}\right) ; 25,7$ (3 $\left.\mathrm{CH}_{3}\right) ; 25,3\left(\mathrm{CH}_{3}\right) ; 25,2\left(\mathrm{CH}_{3}\right) ; 23,1\left(\mathrm{CH}_{3}\right) ; 21,7\left(\mathrm{CH}_{3}\right) ; 18,1(\mathrm{C}) ;-5,1\left(\mathrm{CH}_{3}-\mathrm{Si}\right) ;-4,7\left(\mathrm{CH}_{3}-\right.$ $\mathrm{Si)}$.

IV (cm-1): $3442(\mathrm{OH}) ; 1252\left(\mathrm{Si}_{-} \mathrm{CH}_{3}\right) ; 1145$ (C-O-C) assim; 1101 (Si-O-C) assim; 1048 (C-O) álcool; $778(\mathrm{OH})$. 


\section{2) Preparação do 1-[3-(terc-butil-dimetil-silaniloxi)-but-1-enil]-2,4-bis-} metoximetoxi-2,6,6-trimetil-ciclo-hexanol (57):

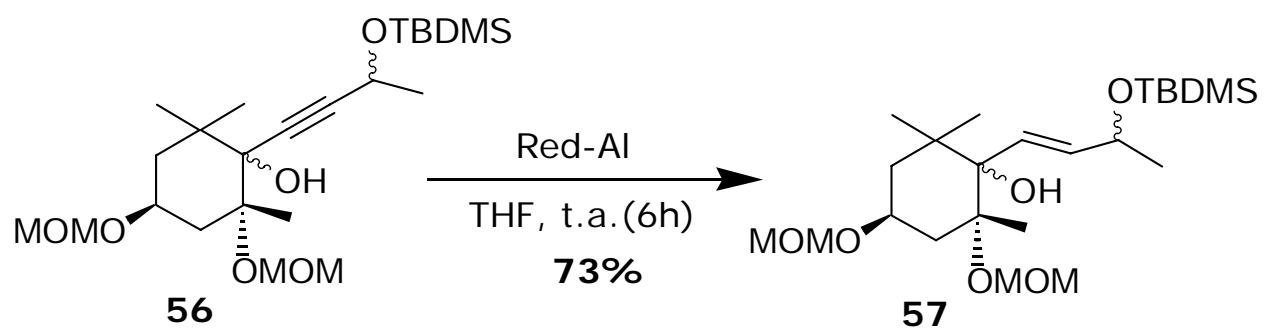

Em um balão de $25 \mathrm{~mL}$ de 2 bocas, munido de agitação magnética e sob atmosfera de $\mathrm{N}_{2}$, foi adicionada 0,0411 $\mathrm{g}(0,09 \mathrm{mmol})$ do composto 56 e $2 \mathrm{~mL}$ de THF anidro. Resfriou-se a solução à $0^{\circ} \mathrm{C}$ e adicionou-se gota a gota $0,15 \mathrm{~mL}(0,54$ mmol) de uma solução 70\% de bis(2-metoxi-etoxi)-hidreto de alumínio e sódio (Red-Al®) em tolueno. Manteve-se a mistura reacional sob agitação durante 6 horas a temperatura ambiente.

Em seguida, resfriou-se a mistura à $0^{\circ} \mathrm{C}$ e adicionou-se água lentamente, formando-se um sólido branco, o qual foi filtrado e lavado várias vezes com éter etílico. O extrato orgânico foi secado com $\mathrm{MgSO}_{4}$ anidro, filtrado e o solvente foi removido sob pressão reduzida.

O resíduo foi purificado por cromatografia em coluna de sílica gel, utilizando como eluente uma mistura de $n$-hexano:acetato de etila (8:2), obtendo-se o composto 57 com rendimento de $73 \%$.

O composto 57 também foi obtido na forma de quatro pares de diasteroisômeros, numa proporção de 1:1:1:1, determinada através dos valores das integrais do espectro de ${ }^{1} \mathrm{H}-\mathrm{RMN}$ da mistura. Neste caso, nem todos os sinais apareceram sobrepostos (alguns deles estavam duplicados). Esses estereoisômeros também não puderam ser separados e, por causa disso, também não tiveram a relação estereoquímica entre eles definida.

Rendimento: 0,0301 g (0,067 mmol; 73\%). 


\section{Dados espectroscópicos da mistura dos diasteroisômeros do composto 57:}

${ }^{1} \mathrm{H}-\mathrm{RMN}\left(\mathrm{CDCl}_{3}\right) \delta$ (ppm): 5,83 (1H, dd, $\left.J_{1}=15,2 \mathrm{~Hz}, J_{2}=4,5 \mathrm{~Hz}\right) ; 5,82(1 \mathrm{H}$, $\left.\mathrm{dd}, J_{1}=15,2 \mathrm{~Hz}, J_{2}=4,5 \mathrm{~Hz}\right) ; 5,71\left(1 \mathrm{H}, \mathrm{dd}, J_{1}=15,2 \mathrm{~Hz}, J_{2}=3,0 \mathrm{~Hz}\right) ; 5,70\left(1 \mathrm{H}, \mathrm{dd}, J_{1}=\right.$ $\left.15,2 \mathrm{~Hz}, J_{2}=3,0 \mathrm{~Hz}\right) ; 4,80\left(1 \mathrm{H}, \mathrm{d}, J_{1}=7,3 \mathrm{~Hz}\right) ; 4,73(1 \mathrm{H}, \mathrm{d}, J=7,3 \mathrm{~Hz}) ; 4,68(1 \mathrm{H}, \mathrm{d}, J=$ $6,8 \mathrm{~Hz}) ; 4,65(1 \mathrm{H}, \mathrm{d}, J=6,8 \mathrm{~Hz}) ; 4,30\left(1 \mathrm{H}, \mathrm{qdd}, J_{1}=6,5 \mathrm{~Hz}, J_{2}=4,5 \mathrm{~Hz}, J_{3}=3,0 \mathrm{~Hz}\right) ; 4,29$ $\left(1 \mathrm{H}, \mathrm{qdd}, J_{1}=6,5 \mathrm{~Hz}, J_{2}=4,5 \mathrm{~Hz}, J_{3}=3,0 \mathrm{~Hz}\right) ; 3,99\left(1 \mathrm{H}, \mathrm{tt}, J_{1}=11,6 \mathrm{~Hz}, J_{2}=4,5 \mathrm{~Hz}\right) ; 3,42$ $(3 \mathrm{H}, \mathrm{s}) ; 3,36(3 \mathrm{H}, \mathrm{s}) ; 2,26\left(1 \mathrm{H}, \mathrm{ddd}, J_{1}=13,9 \mathrm{~Hz}, J_{2}=4,5 \mathrm{~Hz}, J_{3}=2,8 \mathrm{~Hz}\right) ; 1,77(1 \mathrm{H}, \mathrm{ddd}$, $\left.J_{1}=13,4 \mathrm{~Hz}, J_{2}=4,5 \mathrm{~Hz}, J_{3}=2,8 \mathrm{~Hz}\right) ; 1,76\left(1 \mathrm{H}, \mathrm{ddd}, J_{1}=13,4 \mathrm{~Hz}, J_{2}=4,5 \mathrm{~Hz}, J_{3}=2,8 \mathrm{~Hz}\right)$; 1,49-1,37 (2H, m); 1,16 (3H, s); 1,14 (3H, d, J J = 6,5 Hz); 1,10 (3H, s); 1,05 (3H, s); 0,89 $(9 \mathrm{H}, \mathrm{s}) ; 0,83(3 \mathrm{H}, \mathrm{s}) ; 0,79(3 \mathrm{H}, \mathrm{s}) ; 0,05(3 \mathrm{H}, \mathrm{s}) ; 0,04(3 \mathrm{H}, \mathrm{s}) ; 0,03(3 \mathrm{H}, \mathrm{s})$.

${ }^{13} \mathrm{C}-\mathrm{RMN}\left(\mathrm{CDCl}_{3}\right) \delta$ (ppm): 133,4 (HC=); 126,8 (=CH); 126,6 (=CH); 94,3 $\left(\mathrm{CH}_{2}\right) ;$ 90,6 ( $\left.\mathrm{CH}_{2}\right) ;$ 82,1 (C-OH); 77,8 (C-O); 69,2 (C-O); 68,2 (CH-OSi); 68,1 (CH-OSi); 55,8 (CH$) ; 54,5\left(\mathrm{CH}_{3}\right) ; 43,7\left(\mathrm{CH}_{2}\right) ; 40,7\left(\mathrm{CH}_{2}\right) ; 40,6\left(\mathrm{CH}_{2}\right) ; 38,8(\mathrm{C}) ; 28,3\left(\mathrm{CH}_{3}\right) ; 28,2$ $\left(\mathrm{CH}_{3}\right) ; 25,7\left(3 \mathrm{CH}_{3}\right) ; 24,2\left(\mathrm{CH}_{3}\right) ; 24,0\left(\mathrm{CH}_{3}\right) ; 20,8\left(\mathrm{CH}_{3}\right) ; 20,7\left(\mathrm{CH}_{3}\right) ; 17,6(\mathrm{C}) ;-5,4$ $\left(\mathrm{CH}_{3}-\mathrm{Si}\right) ;-5,3\left(\mathrm{CH}_{3}-\mathrm{Si}\right)$.

IV (cm-1): $3561(\mathrm{OH}) ; 1250\left(\mathrm{Si}_{-} \mathrm{CH}_{3}\right) ; 1147$ (C-O-C) assim; 1099 (Si-O-C) assim; 1051 (C-O) álcool; 835 (C-H) dupla; $775(\mathrm{OH})$. 


\section{3) Preparação do 2-(3-hidroxi-but-1-enil)-5-metoximetoxi-1,3,3-trimetil-ciclo-} hexano-1,2-diol (58):

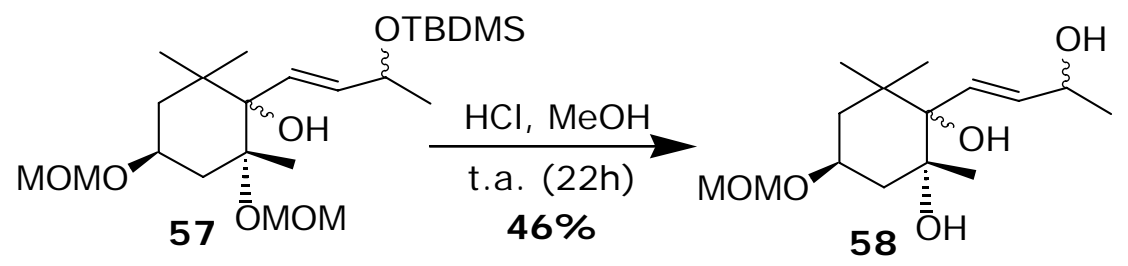

Em um balão de $10 \mathrm{ml}$, munido de agitação magnética, adicionou-se 0,0371 g (0,08 mmol) do composto 57 dissolvido em $2 \mathrm{~mL}$ de $\mathrm{MeOH}$ e 3 gotas de $\mathrm{HCl} 2$ mol/L. Deixou-se a mistura sob agitação durante 22 horas a temperatura ambiente.

Passado esse tempo, evaporou-se o metanol sob pressão reduzida, adicionou-se solução saturada de $\mathrm{NaHCO}_{3}$ e éter etílico. As fases foram separadas e a fase aquosa foi extraída com éter etílico. O extrato orgânico foi lavado com água destilada e secado com $\mathrm{MgSO}_{4}$ anidro, filtrado e o solvente foi evaporado sob pressão reduzida.

O resíduo foi purificado por cromatografia em coluna de sílica gel, utilizando como eluente uma mistura de $n$-hexano:acetato de etila (1:1), obtendo-se o composto 58 com rendimento de $46 \%$.

O composto 58 demonstrou ser muito instável, tanto puro quanto em solução. Por causa disso, não se conseguiu realizar a separação dos diasteroisômeros do composto 58 e, consequentemente, a análise espectroscópica foi realizada apenas com a mistura.

Rendimento: 0,0110 g (0,038 mmol; 46\%). 


\section{Dados espectroscópicos da mistura de diasteroisômeros do composto 58:}

${ }^{1} \mathrm{H}-\mathrm{RMN}\left(\mathrm{CDCl}_{3}\right) \boldsymbol{\delta}$ (ppm): 5,80 (1H, d, J= 15,7); 5,79 (1H, d, J= 15,7); 5,75 $\left(1 \mathrm{H}, \mathrm{dd}, J_{1}=15,7, J_{2}=6,3\right) ; 5,74\left(1 \mathrm{H}, \mathrm{dd}, J_{1}=15,7, J_{2}=6,3\right) ; 4,63(1 \mathrm{H}, \mathrm{d}, J=6,8 \mathrm{~Hz})$; 4,60 (1H, d, J=6,8 Hz); 4,31 (1H, quin, $J=6,3) ; 4,30(1 \mathrm{H}$, quin, $J=6,3) ; 4,00(1 \mathrm{H}, \mathrm{tt}$, $\left.J_{1}=11,1 \mathrm{~Hz}, J_{2}=4,5 \mathrm{~Hz}\right) ; 3,31(3 \mathrm{H}, \mathrm{s}) ; 2,07\left(1 \mathrm{H}, \mathrm{ddd}, J_{1}=13,6 \mathrm{~Hz}, J_{2}=4,5 \mathrm{~Hz}, J_{3}=2,5\right.$ $\mathrm{Hz}) ; 2,06\left(1 \mathrm{H}, \mathrm{ddd}, J_{1}=13,6 \mathrm{~Hz}, J_{2}=4,5 \mathrm{~Hz}, J_{3}=2,5 \mathrm{~Hz}\right) ; 1,90(\mathrm{OH}, \mathrm{sl}) ; 1,72(1 \mathrm{H}$, $\left.\operatorname{ddd}, J_{1}=13,4 \mathrm{~Hz}, J_{2}=4,5 \mathrm{~Hz}, J_{3}=2,5 \mathrm{~Hz}\right) ; 1,71\left(1 \mathrm{H}, \mathrm{ddd}, J_{1}=13,4 \mathrm{~Hz}, J_{2}=4,5 \mathrm{~Hz}\right.$, $\left.J_{3}=2,5 \mathrm{~Hz}\right) ; 1,53\left(1 \mathrm{H}, \mathrm{dd}, J_{1}=13,6 \mathrm{~Hz}, J_{2}=11,1 \mathrm{~Hz}\right) ; 1,52\left(1 \mathrm{H}, \mathrm{dd}, J_{1}=13,6 \mathrm{~Hz}, J_{2}=\right.$ $11,1 \mathrm{~Hz}) ; 1,47-1,36(1 \mathrm{H}, \mathrm{m}) ; 1,22(3 \mathrm{H}, \mathrm{d}, J=6,3 \mathrm{~Hz}) ; 1,21(3 \mathrm{H}, \mathrm{d}, J=6,3 \mathrm{~Hz}) ; 1,17$ $(3 \mathrm{H}, \mathrm{s}) ; 1,16(3 \mathrm{H}, \mathrm{s}) ; 1,06(3 \mathrm{H}, \mathrm{s}) ; 1,01(3 \mathrm{H}, \mathrm{s}) ; 0,77(3 \mathrm{H}, \mathrm{s}) ; 0,74(3 \mathrm{H}, \mathrm{s})$. 


\section{4) Preparação do 1-(3-hidroxi-but-1-enil)-2,6,6-trimetil-ciclo-hexano-1,2,4-triol} (30a e 30b):

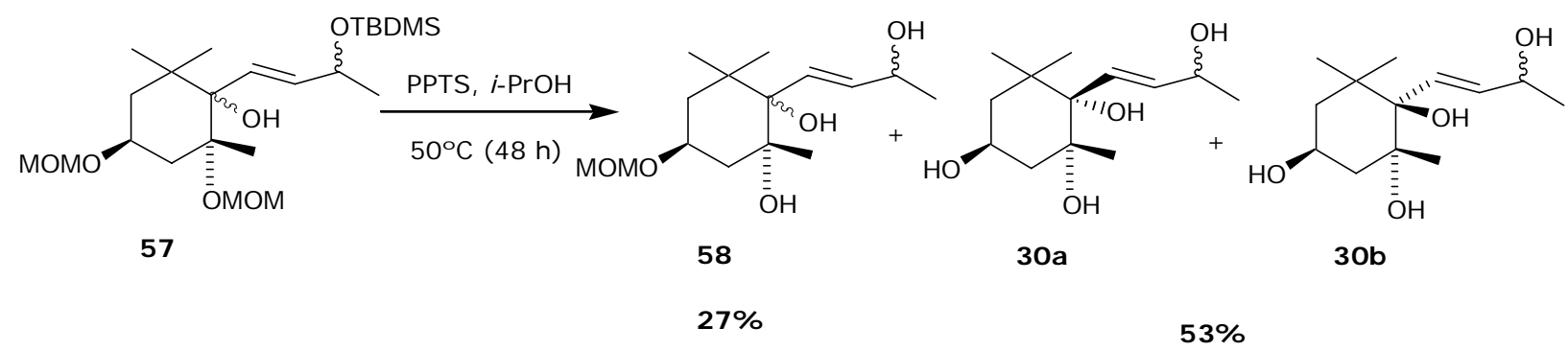

Em um balão de $10 \mathrm{~mL}$, munido de agitação magnética e condensador de refluxo, adicionou-se 0,02404 g (0,054 mmol) do composto 57 dissolvido em $1 \mathrm{~mL}$ de isopropanol e 0,0272 $\mathrm{g}(0,11 \mathrm{mmol})$ de PPTS (para-toluenossulfonato de piridínio).

A mistura reacional foi aquecida a $50^{\circ} \mathrm{C}$ e deixada sob agitação durante 48 horas. Depois disso, evaporou-se o isopropanol sob pressão reduzida, obtendo-se um resíduo sólido composto pela mistura do PPTS e dois produtos.

Esse resíduo foi purificado por cromatografia em coluna de sílica gel, utilizando como eluente uma mistura de $n$-hexano:acetato de etila (1:1), obtendo-se o composto 58 com rendimento de $27 \%$ e o composto 30 desejado com $53 \%$ de rendimento.

Como o produto natural 30 obtido encontra-se na forma de quatro pares de diasteroisômeros, a análise de seus espectros de ${ }^{1} \mathrm{H}-\mathrm{RMN}$ e ${ }^{13} \mathrm{C}-\mathrm{RMN}$ foram bastante dificultadas devido a sobreposição dos sinais. Porém, pela análise do espectro de ${ }^{1} \mathrm{H}-\mathrm{RMN}$ da mistura pôde-se determinar que a proporção entre esses diasteroisômeros é de 1:1:1:1.

Para fins analíticos, uma pequena quantidade de dois pares dos diasteroisômeros do produto natural $\mathbf{3 0}$ foi separada por cromatografia em coluna de sílica gel, utilizando como eluente uma mistura de $n$-hexano:acetato de etila (2:8). Ambos estereoisômeros permaneceram na forma de óleo incolor. 
Através da técnica de NOE-diff, pôde-se verificar que a estereoquímica relativa entre as duas hidroxilas vizinhas no composto 30a $(3 S, 5 R, 6 S)$ é cis, enquanto que no composto $30 \mathrm{~b}(3 S, 5 R, 6 R)$ é trans. Neste caso, pôde verificar que o centro assimétrico referente ao carbono da cadeia lateral não influenciou no deslocamento químico desses diasteroisômeros.

Rendimento (composto 58): 0,0042 g (0,015mmol; 27\%).

Rendimento (composto 30): 0,0069 g (0,028 mmol; 53\%).

Rendimento total: $80 \%$

Dados espectroscópicos do composto 30a $(3 S, 5 R, 6 S)$ :

${ }^{1} \mathbf{H}-\mathbf{R M N}\left(\mathrm{CDCl}_{3}\right) \delta$ (ppm): 5,75 (1H, d, J= 15,5 Hz); 5,68 (1H, dd, $J_{1}=15,5 \mathrm{~Hz}$, $\left.J_{2}=6,5 \mathrm{~Hz}\right) ; 4,20(1 \mathrm{H}$, quin, $J=6,5 \mathrm{~Hz}) ; 4,02\left(1 \mathrm{H}, \mathrm{tt}, J_{1}=11,6 \mathrm{~Hz}, J_{2}=4,6 \mathrm{~Hz}\right) ; 1,88(1 \mathrm{H}$, ddd, $\left.J_{1}=13,5 \mathrm{~Hz}, J_{2}=4,6 \mathrm{~Hz}, J_{3}=2,6 \mathrm{~Hz}\right) ; 1,55\left(1 \mathrm{H}, \mathrm{ddd}, J_{1}=12,5 \mathrm{~Hz}, J_{2}=4,6 \mathrm{~Hz}, J_{3}=\right.$ 2,6 Hz); 1,39 (1H, dd, $\left.J_{1}=12,5 \mathrm{~Hz}, J_{2}=11,6 \mathrm{~Hz}\right) ; 1,19(\mathrm{OH}, \mathrm{sl}) ; 1,14(9 \mathrm{H}, \mathrm{s}) ; 1,12(3 \mathrm{H}, \mathrm{d}$, $\left.J_{1}=6,5\right) ; 0,94(3 \mathrm{H}, \mathrm{s}) ; 0,72(3 \mathrm{H}, \mathrm{s})$.

${ }^{13} \mathrm{C}-\mathrm{RMN}\left(\mathrm{CDCl}_{3}\right) \delta$ (ppm): 134,1 (HC=); 131,4 (HC=); 79,9 (C-OH); 77,1 (C$\mathrm{OH}) ; 69,3$ (CH-OH); 65,1 (CH-OH); 48,1 ( $\left.\mathrm{CH}_{2}\right) ; 46,9\left(\mathrm{CH}_{2}\right) ; 40,3(\mathrm{C}) ; 29,4\left(\mathrm{CH}_{3}\right) ; 27,6$ $\left(\mathrm{CH}_{3}\right) ; 25,4\left(\mathrm{CH}_{3}\right) ; 24,0\left(\mathrm{CH}_{3}\right)$.

Dados espectroscópicos do composto $30 \mathrm{~b}(3 S, 5 R, 6 R)$ :

${ }^{1} \mathbf{H}-\mathbf{R M N}\left(\mathrm{CDCl}_{3}\right) \delta$ (ppm): 5,75 (1H, d, J= 15,7 Hz); 5,66 (1H, dd, $J_{1}=15,7 \mathrm{~Hz}$, $\left.J_{2}=6,5 \mathrm{~Hz}\right) ; 4,20(1 \mathrm{H}$, quin, $J=6,5 \mathrm{~Hz}) ; 4,01\left(1 \mathrm{H}, \mathrm{tt}, J_{1}=11,6 \mathrm{~Hz}, J_{2}=4,5 \mathrm{~Hz}\right) ; 1,88(1 \mathrm{H}$, ddd, $\left.J_{1}=13,5 \mathrm{~Hz}, J_{2}=4,5 \mathrm{~Hz}, J_{3}=2,5 \mathrm{~Hz}\right) ; 1,55\left(1 \mathrm{H}, \mathrm{ddd}, J_{1}=12,5 \mathrm{~Hz}, J_{2}=4,5 \mathrm{~Hz}, J_{3}=2,5\right.$ $\mathrm{Hz}) ; 1,44\left(1 \mathrm{H}, \mathrm{dd}, J_{1}=13,5 \mathrm{~Hz}, J_{2}=11,6 \mathrm{~Hz}\right) ; 1,37\left(1 \mathrm{H}, \mathrm{dd}, J_{1}=12,5 \mathrm{~Hz}, J_{2}=11,6 \mathrm{~Hz}\right)$; $1,14(9 \mathrm{H}, \mathrm{s}) ; 1,12\left(3 \mathrm{H}, \mathrm{d}, J_{1}=6,5\right) ; 0,98(3 \mathrm{H}, \mathrm{s}) ; 0,68(3 \mathrm{H}, \mathrm{s})$. 
${ }^{13} \mathrm{C}-\mathrm{RMN}\left(\mathrm{CDCl}_{3}\right) \delta$ (ppm): 134,1 (HC=); 131,6 (HC=); 79,9 (C-OH); 77,1 (C$\mathrm{OH}) ; 69,3(\mathrm{CH}-\mathrm{OH}) ; 65,1(\mathrm{CH}-\mathrm{OH}) ; 48,1\left(\mathrm{CH}_{2}\right) ; 46,9\left(\mathrm{CH}_{2}\right) ; 40,4(\mathrm{C}) ; 29,3\left(\mathrm{CH}_{3}\right) ; 27,6$ $\left(\mathrm{CH}_{3}\right) ; 25,4\left(\mathrm{CH}_{3}\right) ; 24,1\left(\mathrm{CH}_{3}\right)$.

Dados de IV da mistura dos compostos 30a e 30b:

IV (cm-1): 3395 (OH); 1699 (C=C); 1229 (C-O) álcool; $1368(\mathrm{OH}) ; 981$ (C-H)dupla ligação. 


\section{5) Preparação do 1-(3-metoxi-but-1-enil)-2,6,6-trimetil-ciclo-hexano-1,2,4-triol} (59a e 59b):

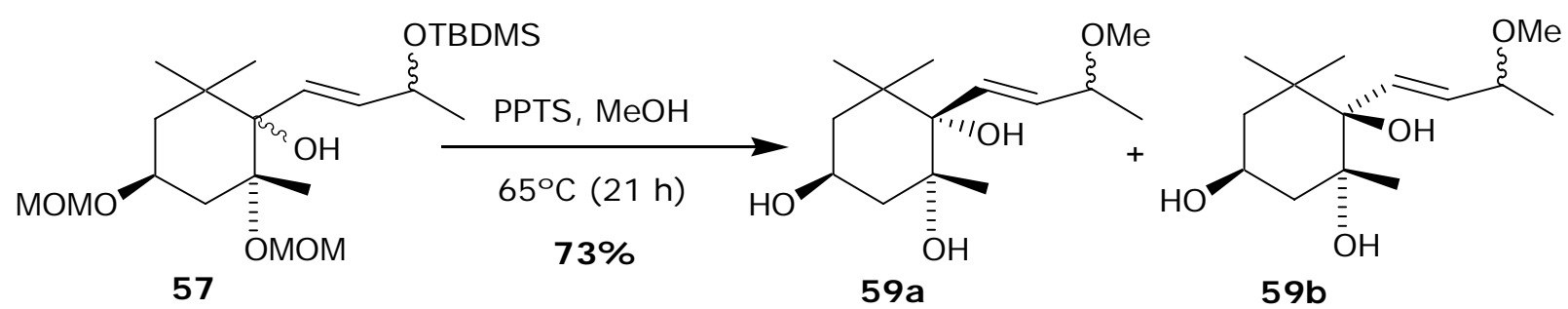

Em um balão de $10 \mathrm{~mL}$, munido de agitação magnética e condensador de refluxo, adicionou-se 0,1451 g (0,32 $\mathrm{mmol})$ do composto 57 diluído em $5 \mathrm{~mL}$ de MeOH e 0,1608 g (0,64 mmol) de PPTS (para-toluenossulfonato de piridínio).

A mistura reacional foi aquecida a temperatura de refluxo do metanol $\left(65^{\circ} \mathrm{C}\right)$ e deixada sob agitação por 21 horas. Depois disso, evaporou-se o metanol e o resíduo sólido obtido foi uma mistura do PPTS e do produto.

O resíduo foi purificado por cromatografia em coluna de sílica gel, utilizando como eluente uma mistura de $n$-hexano:acetato de etila (2:8), obtendo-se o produto 59 com rendimento de $73 \%$.

Como o produto 59 obtido também se encontra na forma de quatro pares de diasteroisômeros, pelo espectro de ${ }^{1} \mathrm{H}-\mathrm{RMN}$ da mistura verificou-se que os sinais dos deslocamentos químicos estavam duplicados e pôde-se determinar que a proporção entre eles é de 1:1:1:1.

Para fins analíticos, uma pequena quantidade dos dois pares de diasteroisômeros do composto 59 foi separada por cromatografia em coluna de sílica gel, utilizando como eluente uma mistura de n-hexano:acetato de etila (2:8). Ambos estereoisômeros permaneceram na forma de óleo amarelo claro.

Através da técnica de NOE-diff, pôde-se verificar que a estereoquímica relativa entre as duas hidroxilas vizinhas no composto 59 a $(3 S, 5 R, 6 S)$ é cis, 
enquanto que no composto $59 \mathrm{~b}(3 S, 5 R, 6 R)$ é trans. Isso demonstra claramente que o centro assimétrico do carbono metoxilado não interfere significativamente no deslocamento químico desses diastereoisômeros.

Rendimento: 0,0611 g (0,24 mmol; 73\%).

Dados espectroscópicos do composto 59a $(3 S, 5 R, 6 S)$ :

${ }^{1} \mathbf{H}-\mathbf{R M N}\left(\mathrm{CDCl}_{3}\right) \delta$ (ppm): 5,84 (1H, d, J= 15,4 Hz); 5,66 (1H, dd, $J_{1}=15,4 \mathrm{~Hz}$, $\left.J_{2}=6,5 \mathrm{~Hz}\right) ; 4,24\left(1 \mathrm{H}, \mathrm{tt}, J_{1}=11,6 \mathrm{~Hz}, J_{2}=4,6 \mathrm{~Hz}\right) ; 3,80(1 \mathrm{H}$, quin, $J=6,5 \mathrm{~Hz}) ; 3,27(3 \mathrm{H}$, s); 2,10 (1H, ddd, $\left.J_{1}=13,6 \mathrm{~Hz}, J_{2}=4,6 \mathrm{~Hz}, J_{3}=2,8 \mathrm{~Hz}\right) ; 1,76\left(1 \mathrm{H}, \mathrm{ddd}, J_{1}=12,5 \mathrm{~Hz}, J_{2}=\right.$ $\left.4,6 \mathrm{~Hz}, J_{3}=2,8 \mathrm{~Hz}\right) ; 1,54\left(1 \mathrm{H}, \mathrm{dd}, J_{1}=13,6 \mathrm{~Hz}, J_{2}=11,6 \mathrm{~Hz}\right) ; 1,50\left(1 \mathrm{H}, \mathrm{dd}, J_{1}=12,5 \mathrm{~Hz}\right.$, $\left.J_{2}=11,6 \mathrm{~Hz}\right) ; 1,25(3 \mathrm{H}, \mathrm{s}) ; 1,24\left(3 \mathrm{H}, \mathrm{d}, J_{1}=6,5\right) ; 1,08(3 \mathrm{H}, \mathrm{s}) ; 0,86(3 \mathrm{H}, \mathrm{s})$.

${ }^{13} \mathrm{C}-\mathrm{RMN}\left(\mathrm{CDCl}_{3}\right) \delta$ (ppm): 132,3 (HC=); 131,1 (HC=); 78,6 (C-OH); 77,9 (C$\left.\mathrm{OCH}_{3}\right) ; 76,1(\mathrm{CH}-\mathrm{OH}) ; 64,1(\mathrm{CH}-\mathrm{OH}) ; 56,3\left(\mathrm{CH}_{3}-\mathrm{O}\right) ; 46,7\left(\mathrm{CH}_{2}\right) ; 45,7\left(\mathrm{CH}_{2}\right) ; 39,0(\mathrm{C})$; $28,7\left(\mathrm{CH}_{3}\right) ; 27,5\left(\mathrm{CH}_{3}\right) ; 24,6\left(\mathrm{CH}_{3}\right) ; 21,5\left(\mathrm{CH}_{3}\right)$.

\section{Dados espectroscópicos do composto $59 \mathrm{~b}(3 S, 5 R, 6 R)$ :}

${ }^{1} \mathrm{H}-\mathrm{RMN}\left(\mathrm{CDCl}_{3}\right) \boldsymbol{\delta}$ (ppm): 5,82 (1H, d, J= 15,6 Hz); 5,65 (1H, dd, $J_{1}=15,6 \mathrm{~Hz}$, $\left.J_{2}=6,5 \mathrm{~Hz}\right) ; 4,22\left(1 \mathrm{H}, \mathrm{tt}, J_{1}=11,6 \mathrm{~Hz}, J_{2}=4,6 \mathrm{~Hz}\right) ; 3,79(1 \mathrm{H}$, quin, $J=6,5 \mathrm{~Hz}) ; 3,30(3 \mathrm{H}$, s); 2,09 (1H, ddd, $\left.J_{1}=13,6 \mathrm{~Hz}, J_{2}=4,6 \mathrm{~Hz}, J_{3}=2,8 \mathrm{~Hz}\right) ; 1,95(\mathrm{OH}, \mathrm{sl}) ; 1,73\left(1 \mathrm{H}, \mathrm{ddd}, J_{1}=\right.$ $\left.12,5 \mathrm{~Hz}, J_{2}=4,6 \mathrm{~Hz}, J_{3}=2,8 \mathrm{~Hz}\right) ; 1,56\left(1 \mathrm{H}, \mathrm{dd}, J_{1}=13,6 \mathrm{~Hz}, J_{2}=11,6 \mathrm{~Hz}\right) ; 1,45(1 \mathrm{H}, \mathrm{dd}$, $\left.J_{1}=12,5 \mathrm{~Hz}, J_{2}=11,6 \mathrm{~Hz}\right) ; 1,23(3 \mathrm{H}, \mathrm{s}) ; 1,22\left(3 \mathrm{H}, \mathrm{d}, J_{1}=6,5\right) ; 1,13(3 \mathrm{H}, \mathrm{s}) ; 0,79(3 \mathrm{H}, \mathrm{s})$.

${ }^{13} \mathrm{C}-\mathrm{RMN}\left(\mathrm{CDCl}_{3}\right) \delta$ (ppm): 132,2 (HC=); 131,3 (HC=); 78,6 (C-OH); 77,9 (C$\left.\mathrm{OCH}_{3}\right) ; 76,1(\mathrm{CH}-\mathrm{OH}) ; 64,2(\mathrm{CH}-\mathrm{OH}) ; 56,3\left(\mathrm{CH}_{3}-\mathrm{O}\right) ; 46,9\left(\mathrm{CH}_{2}\right) ; 45,7\left(\mathrm{CH}_{2}\right) ; 39,2(\mathrm{C})$; $28,5\left(\mathrm{CH}_{3}\right) ; 27,6\left(\mathrm{CH}_{3}\right) ; 24,6\left(\mathrm{CH}_{3}\right) ; 21,6\left(\mathrm{CH}_{3}\right)$. 


\section{SEÇÃO DE ESPECTROS}


A numeração dos átomos de carbono dos compostos não segue nenhuma norma ou recomendação oficial. O objetivo da numeração dos compostos é facilitar a identificação dos átomos de hidrogênio nas atribuições realizadas em cada espectro.

Existem compostos descritos nesta seção que se apresentam na forma de mistura de quatro pares de diasteroisômeros e outros como dois pares de diasteroisômeros. Em alguns casos, não se conseguiu separá-los e, por causa disso, são apresentados e discutidos os dados espectroscópicos da mistura.

A proporção entre os diasteroisômeros (geralmente de 1:1) foi determinada pelas integrais dos espectros de ${ }^{1} \mathrm{H}-\mathrm{RMN}$ da mistura dos dois isômeros. 
6.1. ${ }^{1} \mathrm{H}-\mathrm{RMN},{ }^{13} \mathrm{C}-\mathrm{RMN}$ e IV. 


\section{Composto 36}

Espectro de ${ }^{1} \mathrm{H}-\mathrm{RMN}\left(\mathrm{CDCl}_{3}, 400 \mathrm{MHz}\right)$ :
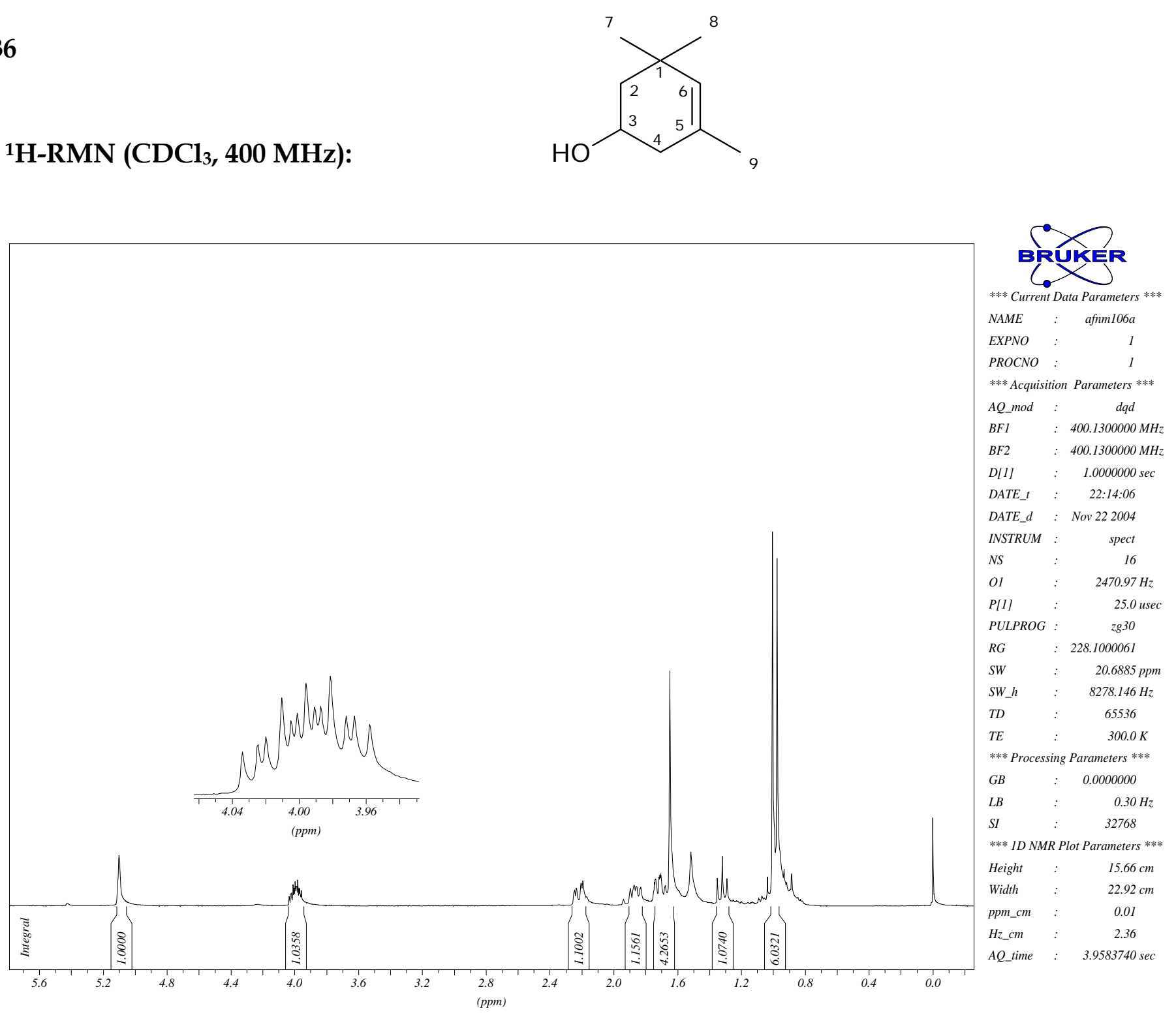
Tabela 2 - Dados espectrais de ${ }^{1} \mathrm{H}-\mathrm{RMN}$ do composto 36.

\begin{tabular}{cccc}
\hline$\delta$ (ppm) & Atribuição & Sinal & $J \mathbf{H z})$ \\
\hline 5,10 & $\mathrm{H}_{6}$ & $\mathrm{~s}$ & \\
4,00 & $\mathrm{H}_{3}$ & $\mathrm{dddd}$ & $J_{3,2}=11,9 ; J_{3,4}=9,3 ; J_{3,4^{\prime}}=5,6 ; J_{3,2^{\prime}}=3,5$ \\
2,22 & $\mathrm{H}_{4^{\prime}}$ & $\mathrm{dd}$ & $J_{4^{\prime}, 4}=16,4 ; J_{4^{\prime}, 3}=5,6$ \\
1,87 & $\mathrm{H}_{4}$ & $\mathrm{ddq}$ & $J_{4,4^{\prime}}=16,4 ; J_{4,3}=9,3 ; J_{4,2^{\prime}}=1,3$ \\
1,72 & $\mathrm{H}_{2^{\prime}}$ & $\mathrm{ddt}$ & $J_{2^{\prime}, 2}=11,9 ; J_{2^{\prime}, 3}=3,5 ; J_{2^{\prime}, 4}=1,3$ \\
1,65 & $\mathrm{H}_{9}$ & $\mathrm{~s}$ & \\
1,52 & $\mathrm{OH}$ & $\mathrm{sl}$ & \\
1,32 & $\mathrm{H}_{2}$ & $\mathrm{t}$ & $J_{2,2^{\prime}}=J_{2,3}=11,9$ \\
1,00 & $\mathrm{H}_{8^{*}}$ & $\mathrm{~s}$ & \\
0,98 & $\mathrm{H}_{7^{*}}$ & $\mathrm{~s}$ & \\
\hline
\end{tabular}

* podem estar trocados 
Espectro de ${ }^{13} \mathrm{C}-\mathrm{RMN}\left\{{ }^{1} \mathrm{H}\right\}\left(\mathrm{CDCl}_{3}, 100 \mathrm{MHz}\right)$ do composto 36:

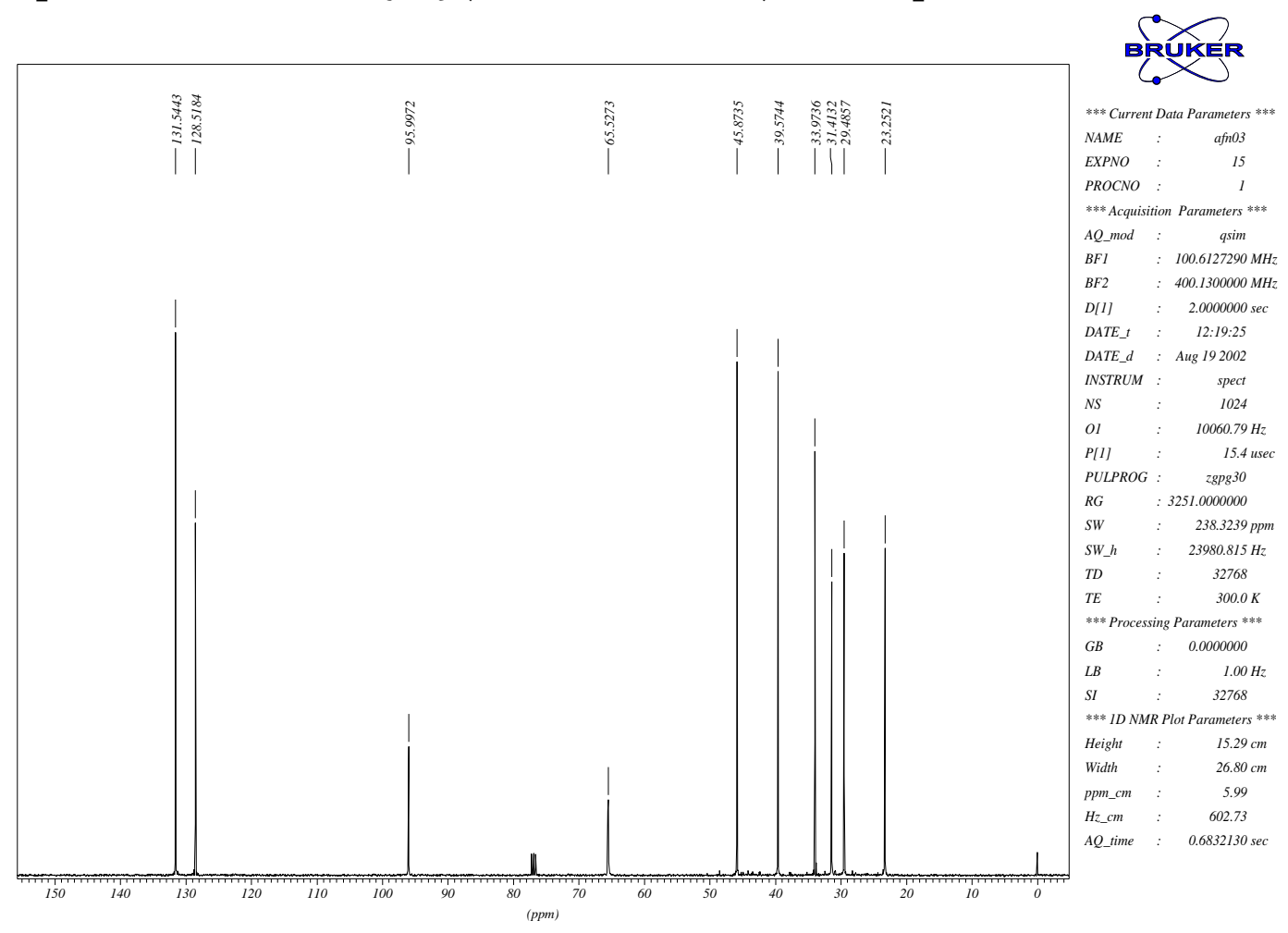

Espectro de ${ }^{13} \mathrm{C}-\mathrm{RMN}(\mathrm{DEPT}-135)\left(\mathrm{CDCl}_{3}, 100 \mathrm{MHz}\right)$ do composto 36:

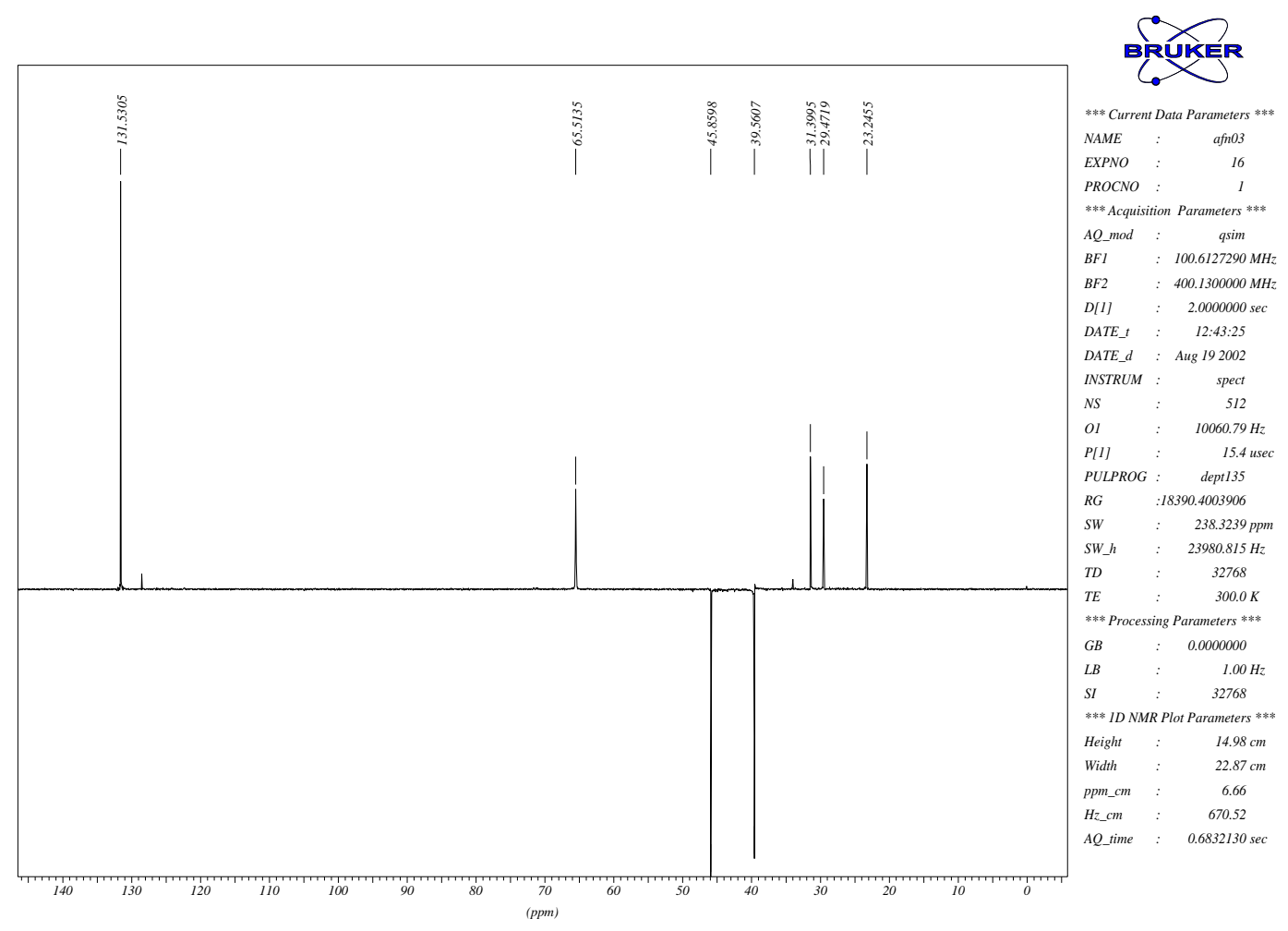


Tabela 3 - Dados espectrais de ${ }^{13} \mathrm{C}-\mathrm{RMN}\left\{{ }^{1} \mathrm{H}\right\}$ do composto 36.

\begin{tabular}{cc}
\hline $\boldsymbol{\delta}(\mathbf{p p m})$ & Atribuição* $^{*}$ \\
\hline 131,5 & $\mathrm{C}_{6}$ \\
128,5 & $\mathrm{C}_{5}$ \\
95,6 & $\mathrm{CCl}_{4}$ \\
65,5 & $\mathrm{C}_{3}$ \\
45,9 & $\mathrm{C}_{2}$ \\
39,6 & $\mathrm{C}_{4}$ \\
33,9 & $\mathrm{C}_{1}$ \\
31,4 & $\mathrm{C}_{7}^{* *}$ \\
29,5 & $\mathrm{C}_{8}^{* *}$ \\
23,2 & $\mathrm{C}_{9}$ \\
\hline
\end{tabular}

* os carbonos foram atribuídos utilizando HMQC

** podem estar trocados 


\section{Espectro de IV do composto 36:}

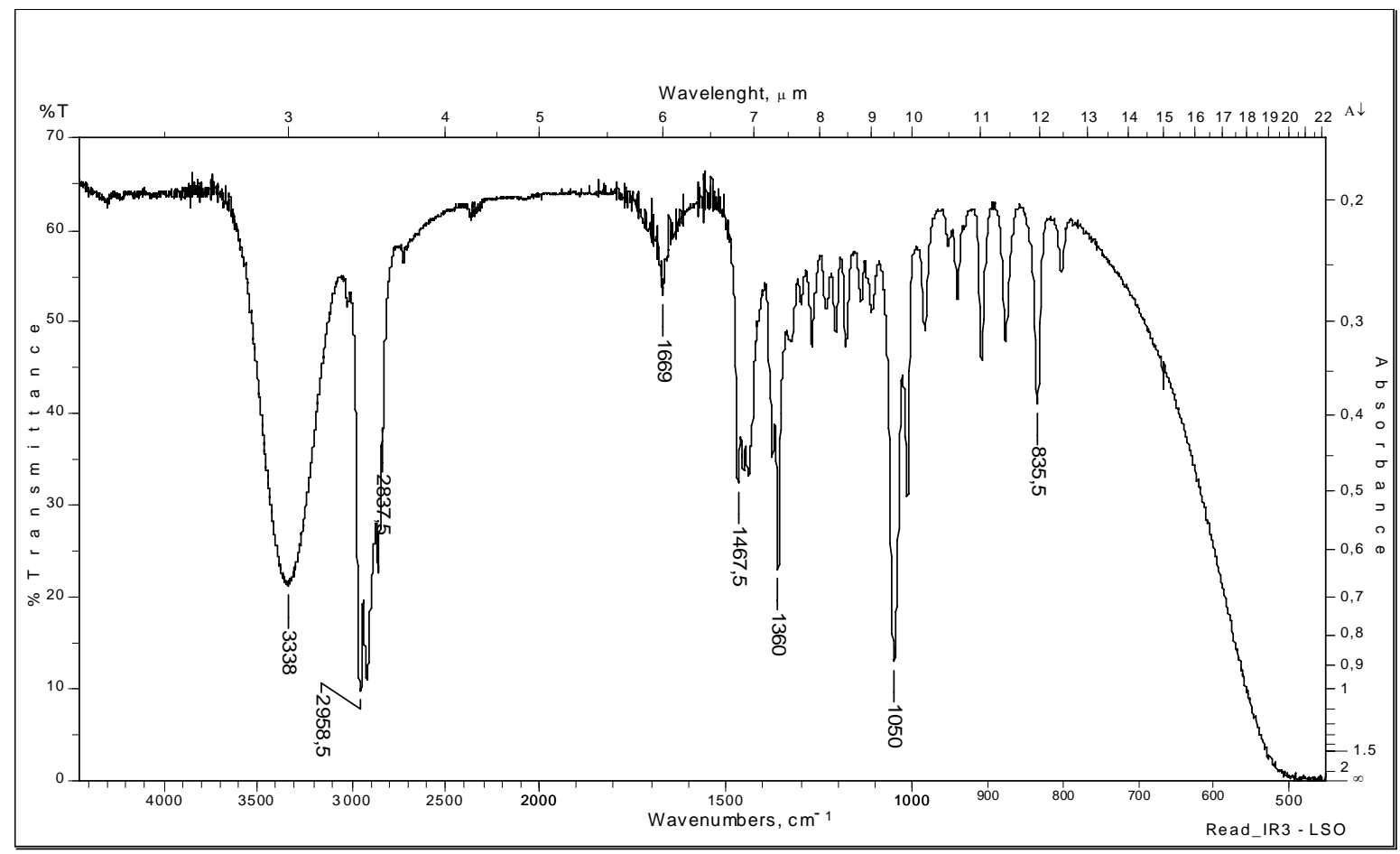

Tabela 4 - Dados espectrais de IV do composto 36.

\begin{tabular}{cl}
\hline$v\left(\mathbf{c m}^{-1}\right)$ & \multicolumn{1}{c}{ Atribuição } \\
\hline 3338 & Deformação axial de $\mathrm{OH}$ \\
1669 & Deformação axial de $\mathrm{C}=\mathrm{C}$ \\
1360 & Deformação angular no plano de OH \\
1050 & Deformação axial de C-O \\
835 & Deformação angular fora do plano de C-H da dupla ligação \\
\hline
\end{tabular}




\section{Composto 41}

Espectro de ${ }^{1} \mathrm{H}-\mathrm{RMN}\left(\mathrm{CDCl}_{3}, 400 \mathrm{MHz}\right)$ :
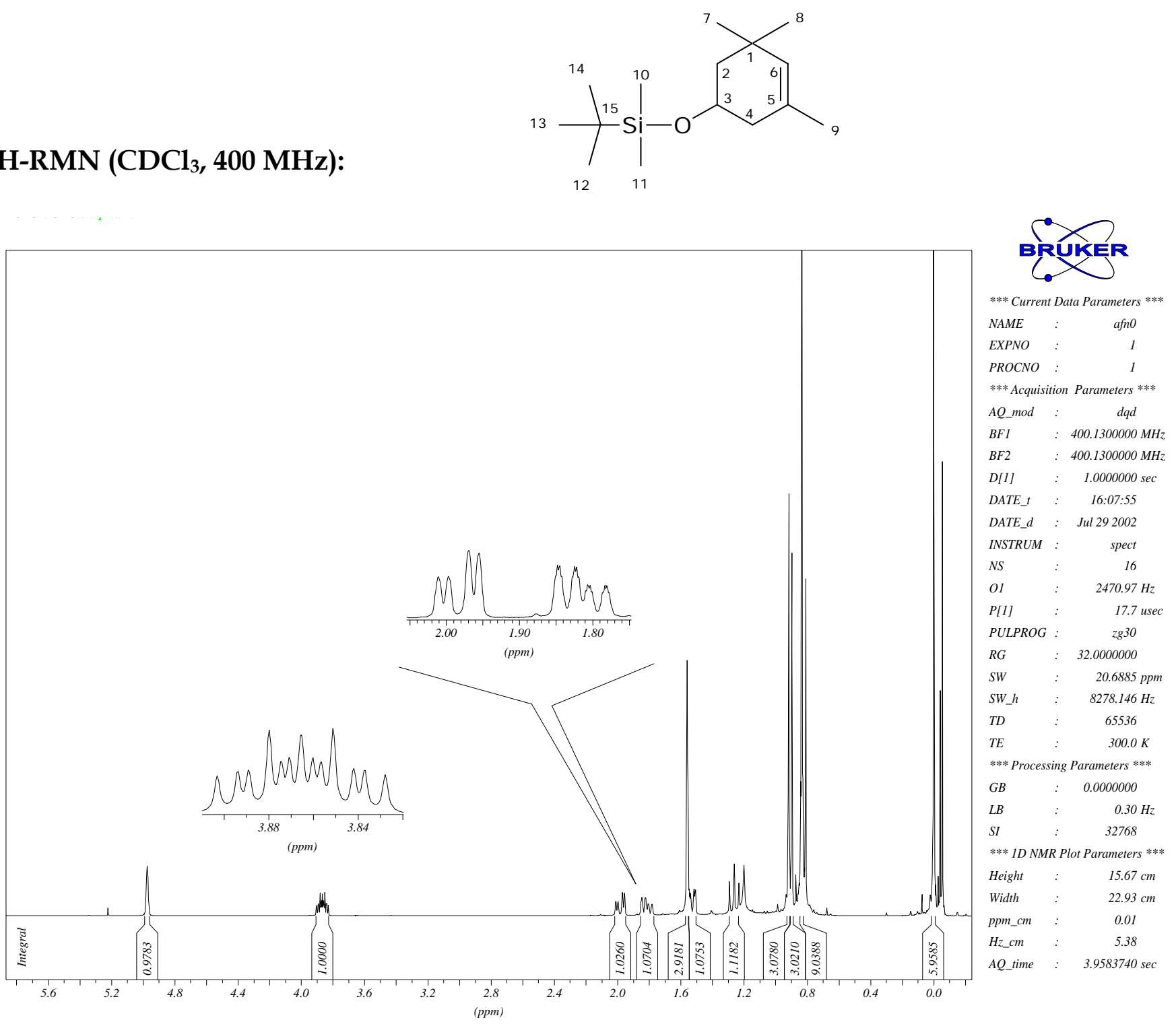
Tabela 5 - Dados espectrais de ${ }^{1} \mathrm{H}-\mathrm{RMN}$ do composto 41.

\begin{tabular}{cccc}
\hline$\delta(\mathbf{p p m})$ & Atribuição & Sinal & $J(\mathbf{H z})$ \\
\hline 5,03 & $\mathrm{H}_{6}$ & $\mathrm{~s}$ & \\
3,92 & $\mathrm{H}_{3}$ & dddd & $J_{3,2}=12,0 ; J_{3,4}=9,3 ; J_{3,4^{\prime}}=5,5 ; J_{3,2^{\prime}}=3,6$ \\
2,04 & $\mathrm{H}_{4^{\prime}}$ & $\mathrm{dd}$ & $J_{4^{\prime}, 4}=16,6 ; J_{4^{\prime}, 3}=5,5$ \\
1,87 & $\mathrm{H}_{4}$ & $\mathrm{ddq}$ & $J_{4,4^{\prime}}=16,6 ; J_{4,3}=9,3 ; J_{4,2^{\prime}}=1,3$ \\
1,61 & $\mathrm{H}_{9}$ & $\mathrm{~s}$ & \\
1,58 & $\mathrm{H}_{2^{\prime}}$ & $\mathrm{ddt}$ & $J_{2^{\prime}, 2}=12,0 ; J_{2^{\prime}, 3}=3,6 ; J_{2^{\prime}, 4}=1,3$ \\
1,32 & $\mathrm{H}_{2}$ & $\mathrm{t}$ & $J_{2,2^{\prime}}=12,0 ; J_{2,3}=12,0$ \\
0,97 & $\mathrm{H}_{7^{*}}$ & $\mathrm{~s}$ & \\
0,95 & $\mathrm{H}_{8^{*}}$ & $\mathrm{~s}$ & \\
0,88 & $\mathrm{H}_{12,} \mathrm{H}_{13}, \mathrm{H}_{14}$ & $\mathrm{~s}$ & \\
0,06 & $\mathrm{H}_{10, \mathrm{H}_{11}}$ & $\mathrm{~s}$ & \\
\hline
\end{tabular}

* podem estar trocados 


\section{Espectro de ${ }^{13} \mathrm{C}-\mathrm{RMN}\left\{{ }^{1} \mathrm{H}\right\}\left(\mathrm{CDCl}_{3}, 100 \mathrm{MHz}\right)$ do composto 41:}

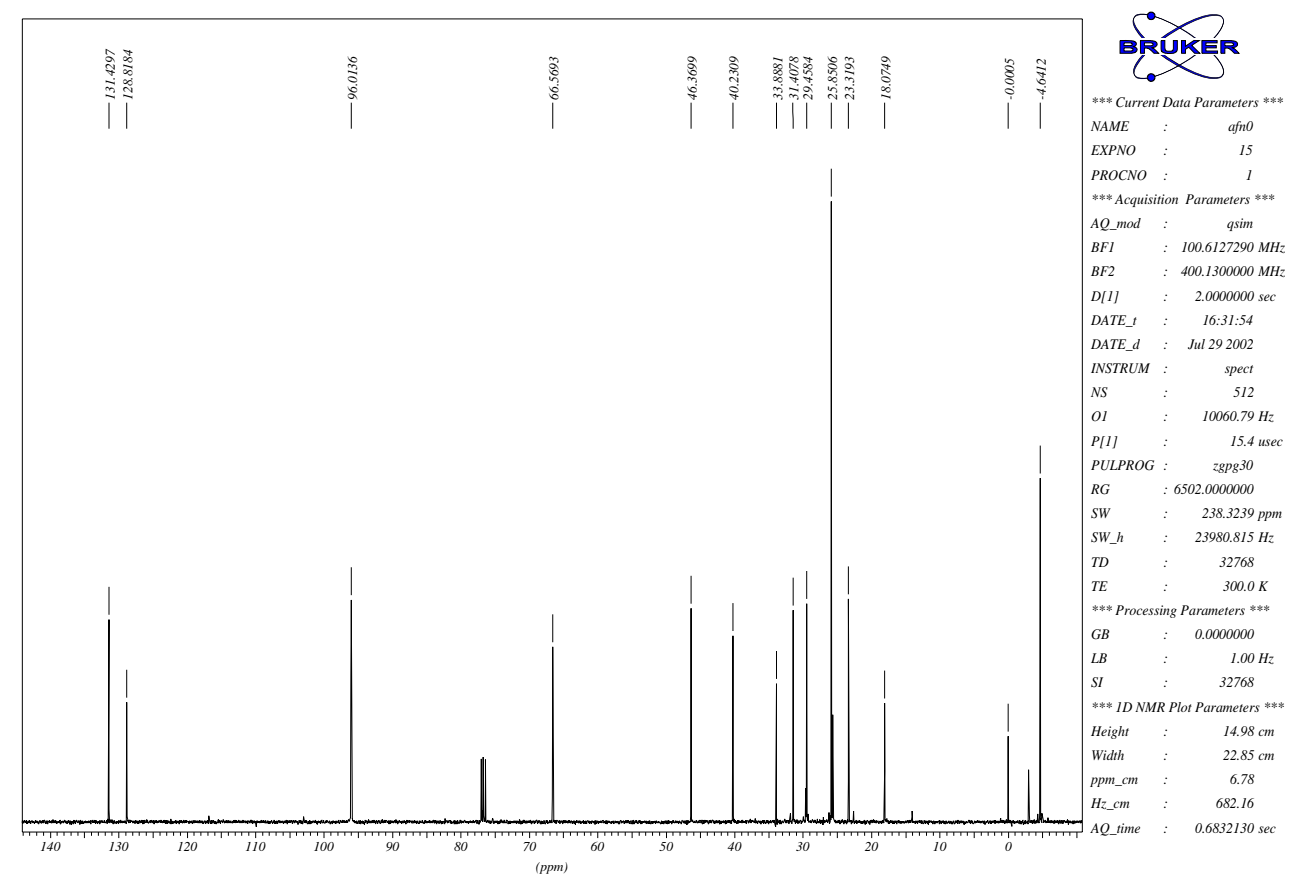

Espectro de ${ }^{13} \mathrm{C}-\mathrm{RMN}(\mathrm{DEPT}-135)\left(\mathrm{CDCl}_{3}, 100 \mathrm{MHz}\right)$ do composto 41:

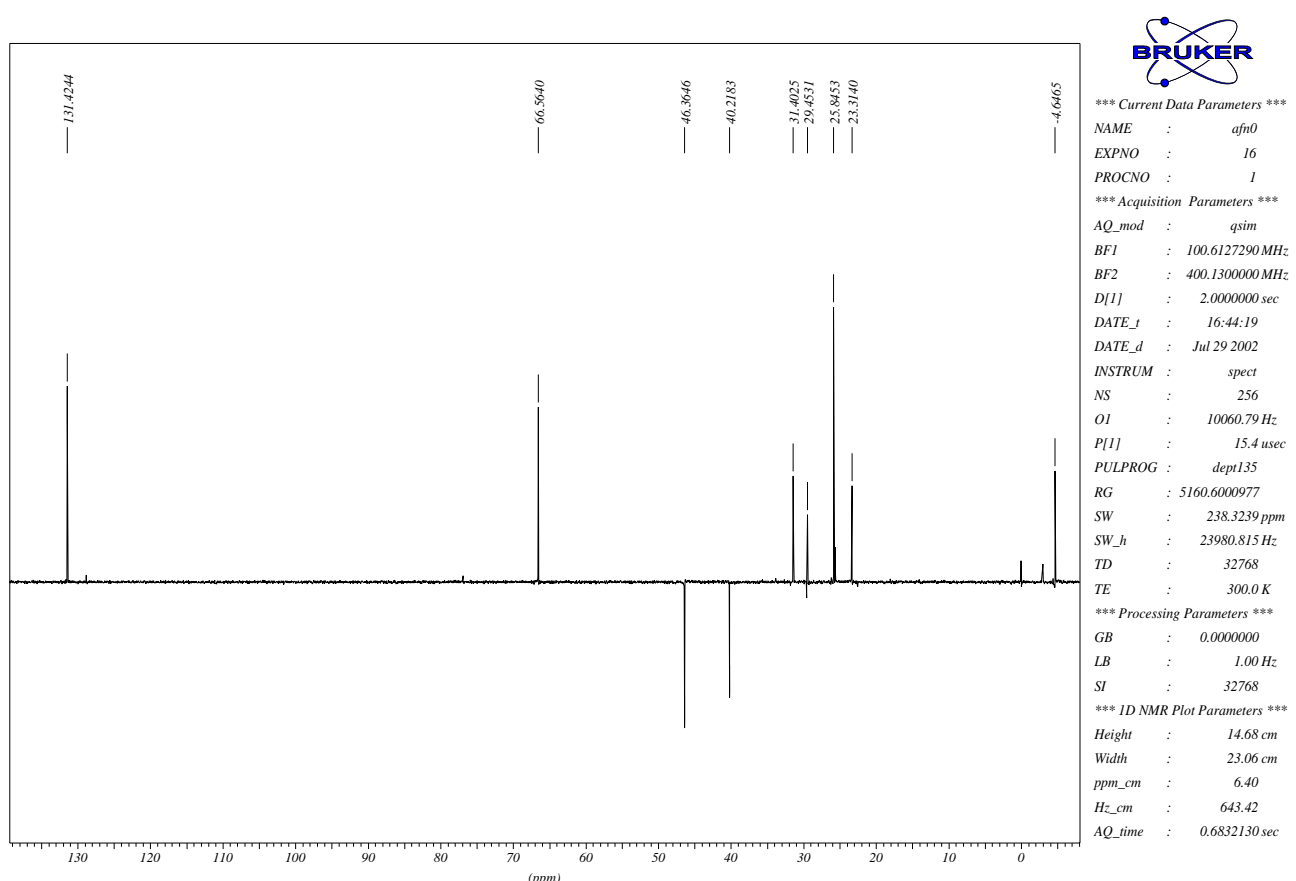


Tabela 6 - Dados espectrais de ${ }^{13} \mathrm{C}-\mathrm{RMN}\left\{{ }^{1} \mathrm{H}\right\}$ do composto 41.

\begin{tabular}{cc}
\hline $\boldsymbol{\delta}(\mathbf{p p m})$ & Atribuição \\
\hline 131,4 & $\mathrm{C}_{6}$ \\
128,8 & $\mathrm{C}_{5}$ \\
96,0 & $\mathrm{CC}_{4}$ \\
66,6 & $\mathrm{C}_{3}$ \\
46,4 & $\mathrm{C}_{2}$ \\
40,2 & $\mathrm{C}_{4}$ \\
33,9 & $\mathrm{C}_{1}$ \\
31,4 & $\mathrm{C}_{7^{*}}$ \\
29,5 & $\mathrm{C}_{8^{*}}$ \\
25,8 & $\mathrm{C}_{12}, \mathrm{C}_{13}, \mathrm{C}_{14}$ \\
23,3 & $\mathrm{C}_{9}$ \\
18,1 & $\mathrm{C}_{15}$ \\
$-4,6$ & $\mathrm{C}_{10}, \mathrm{C}_{11}$ \\
\hline
\end{tabular}

* podem estar trocados 


\section{Espectro de IV do composto 41:}

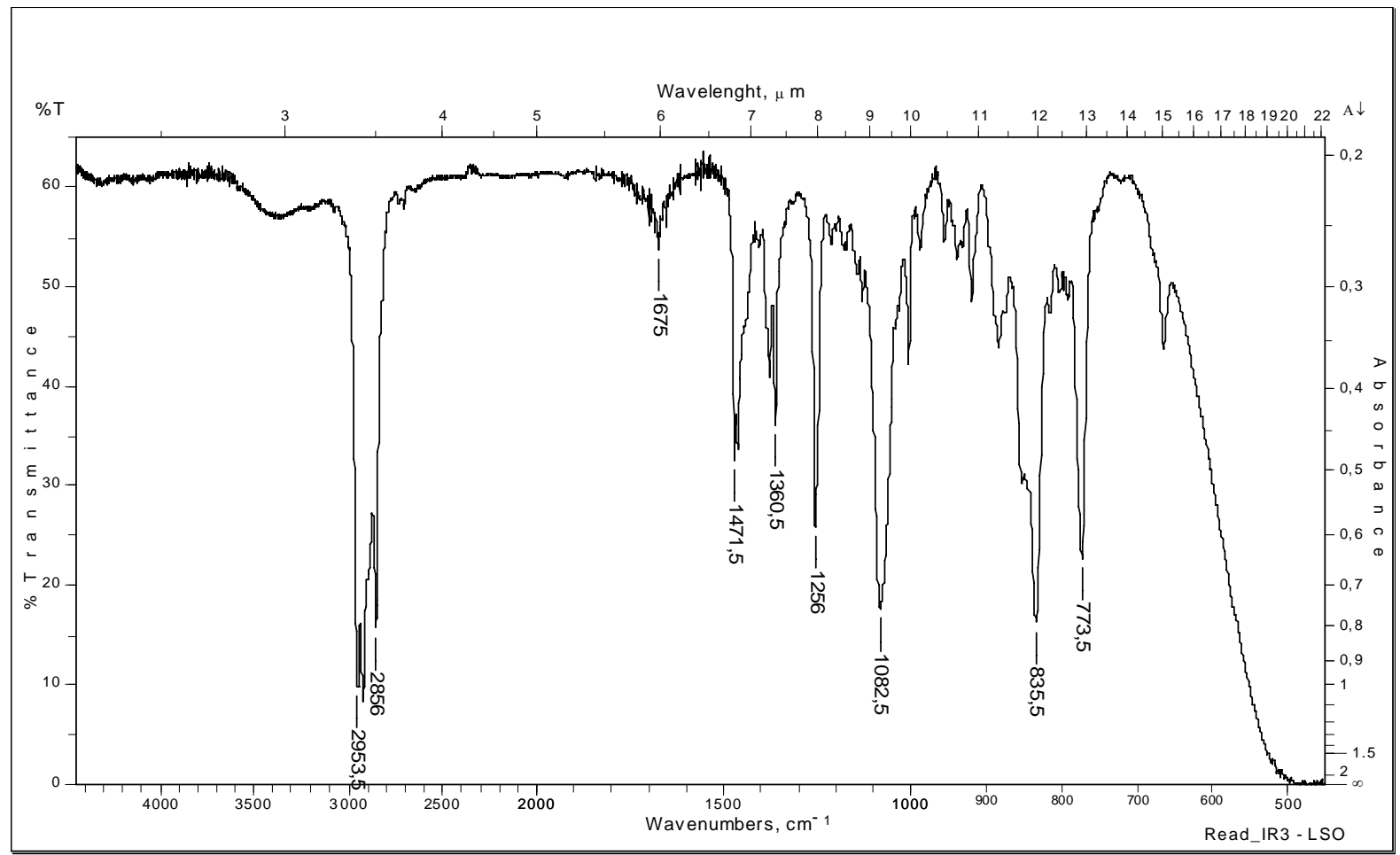

Tabela 7 - Dados espectrais de IV do composto 41.

\begin{tabular}{cl}
\hline$v\left(\mathbf{c m}^{-1}\right)$ & \multicolumn{1}{c}{ Atribuição } \\
\hline 1675 & Deformação axial de $\mathrm{C}=\mathrm{C}$ \\
1256 & Deformação axial de $\mathrm{Si}-\mathrm{CH}_{3}$ \\
1082 & Deformação axial simétrica de Si-C-O \\
835 & Deformação angular fora do plano de C-H da dupla ligação \\
\hline
\end{tabular}




\section{Composto 47}

Espectro de ${ }^{1} \mathrm{H}-\mathrm{RMN}\left(\mathrm{CDCl}_{3}, 400 \mathrm{MHz}\right)$ :
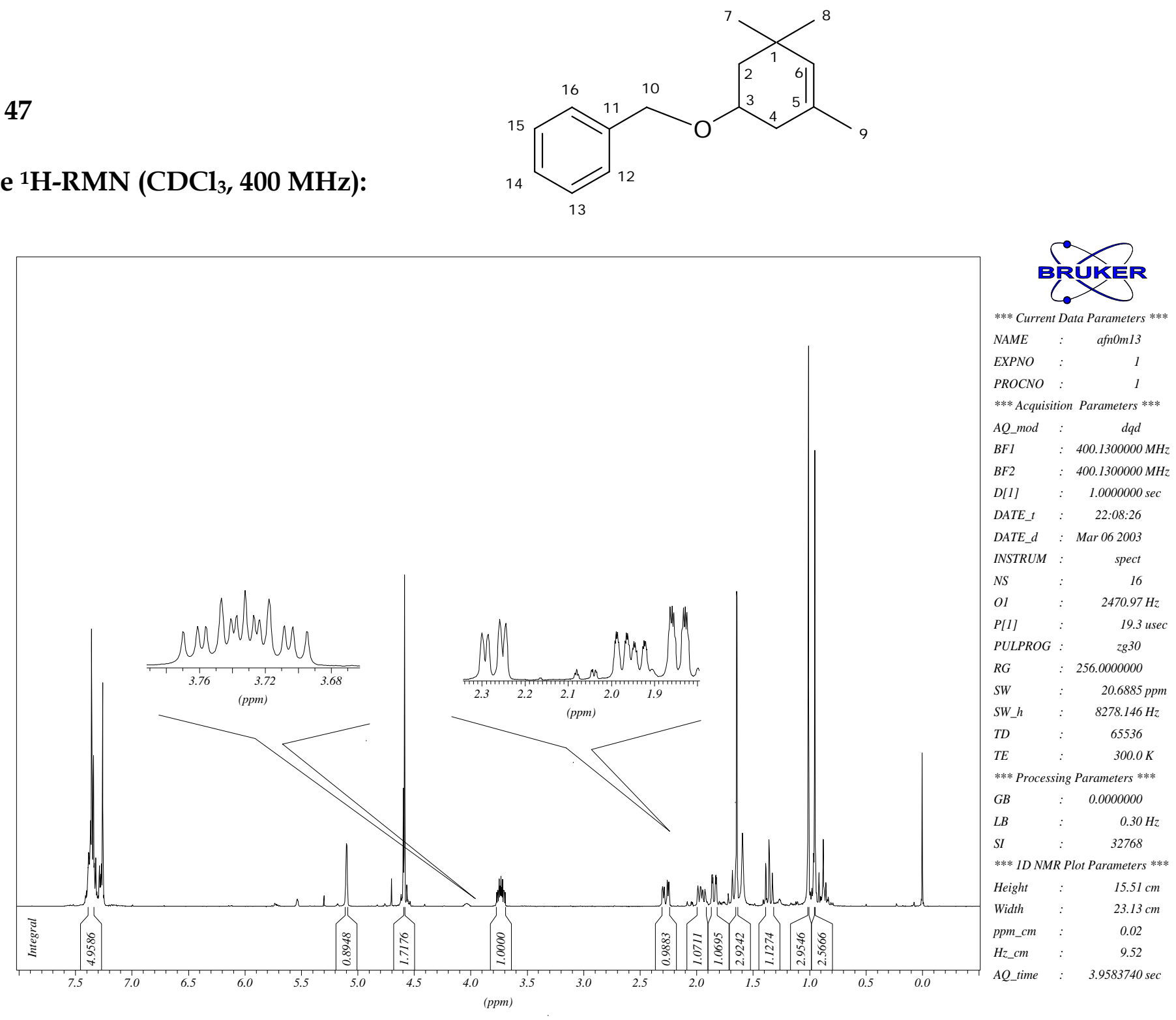
Tabela 8 - Dados espectrais de ${ }^{1} \mathrm{H}-\mathrm{RMN}$ do composto 47.

\begin{tabular}{cccc}
\hline$\delta(\mathbf{p p m})$ & Atribuição & Sinal & $J(\mathbf{H z})$ \\
\hline 7,36 & $\mathrm{H}_{\text {arom }}$ & $\mathrm{m}$ & \\
5,10 & $\mathrm{H}_{6}$ & $\mathrm{~s}$ & \\
4,58 & $\mathrm{H}_{10}$ & $\mathrm{~s}$ & $J_{3,2}=11,9 ; J_{3,4}=9,4 ; J_{3,4^{\prime}}=5,6 ; J_{3,2^{\prime}}=3,3$ \\
3,73 & $\mathrm{H}_{3}$ & $\mathrm{dddd}$ & $J_{4^{\prime}, 4}=16,4 ; J_{4^{\prime}, 3}=5,6$ \\
2,27 & $\mathrm{H}_{4^{\prime}}$ & $\mathrm{dd}$ & $J_{4,4^{\prime}}=16,4 ; J_{4,3}=9,4 ; J_{4,2^{\prime}}=1,5$ \\
1,96 & $\mathrm{H}_{4}$ & $\mathrm{ddq}$ & $J_{2^{\prime}, 2}=11,9 ; J_{2^{\prime}, 3}=3,3 ; J_{2^{\prime}, 4}=1,5$ \\
1,84 & $\mathrm{H}_{2^{\prime}}$ & $\mathrm{ddt}$ & \\
1,64 & $\mathrm{H}_{9}$ & $\mathrm{~s}$ & $J_{2,2^{\prime}}=J_{2,3}=11,9$ \\
1,36 & $\mathrm{H}_{2}$ & $\mathrm{t}$ & \\
1,01 & $\mathrm{H}_{7^{*}}$ & $\mathrm{~s}$ & \\
0,95 & $\mathrm{H}_{8^{*}}$ & $\mathrm{~s}$ & \\
\hline
\end{tabular}

*podem estar trocados 
Espectro de ${ }^{13} \mathrm{C}-\mathrm{RMN}\left\{{ }^{1} \mathrm{H}\right\}\left(\mathrm{CDCl}_{3}, 100 \mathrm{MHz}\right)$ do composto 47:

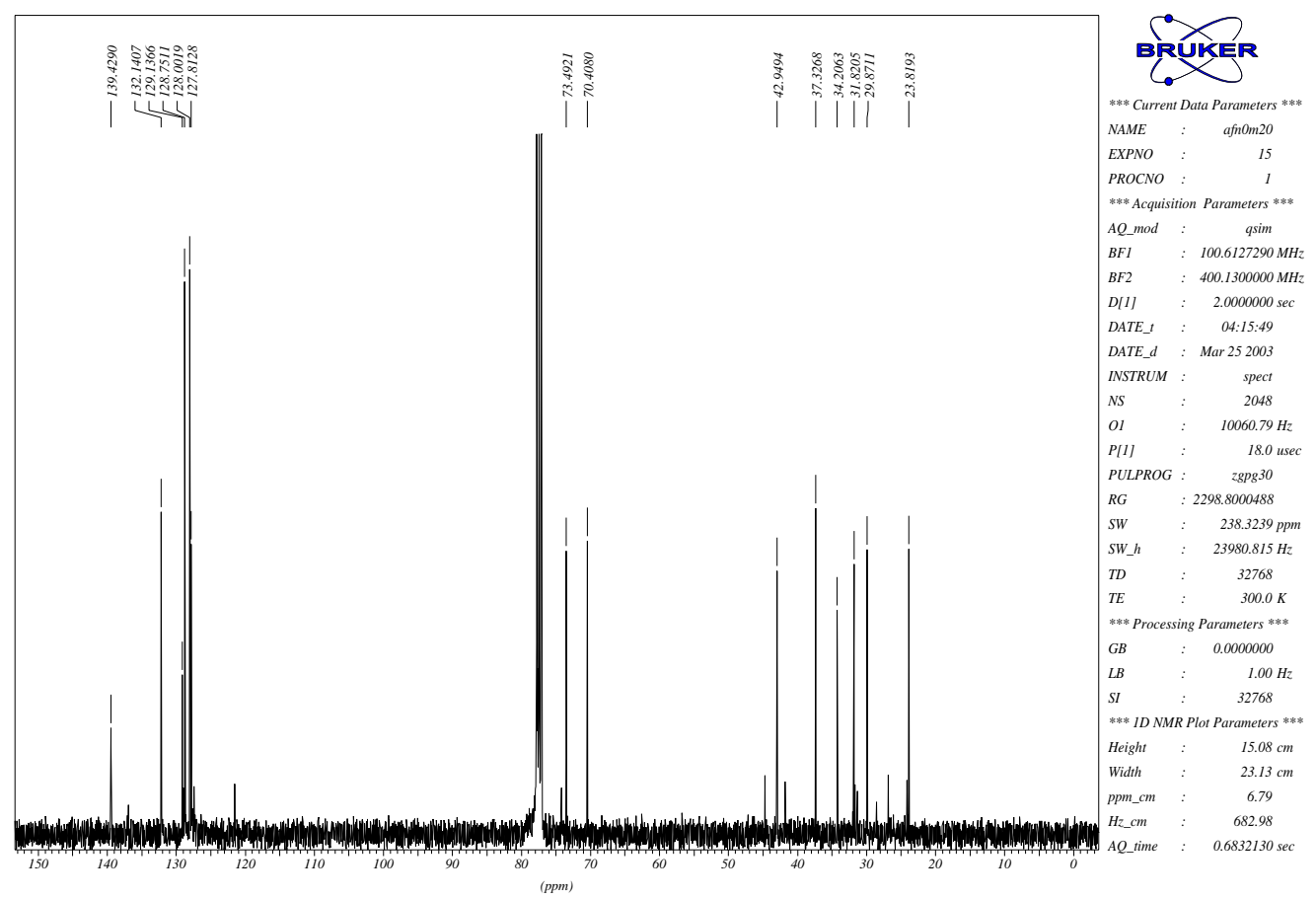

Espectro de ${ }^{13} \mathrm{C}-\mathrm{RMN}(\mathrm{DEPT}-135)\left(\mathrm{CDCl}_{3}, 100 \mathrm{MHz}\right)$ do composto 47:

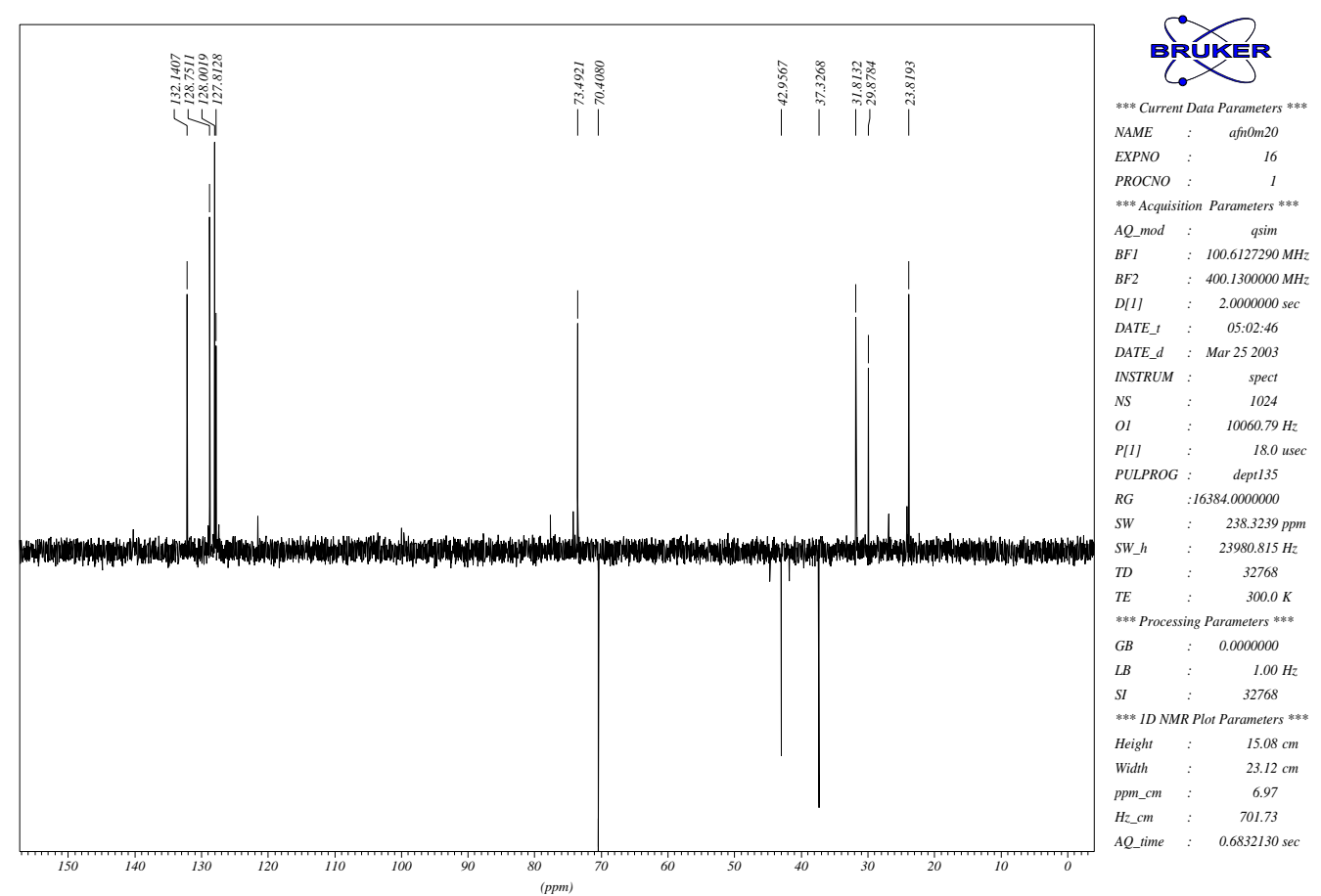


Tabela 9 - Dados espectrais de ${ }^{13} \mathrm{C}-\mathrm{RMN}\left\{{ }^{1} \mathrm{H}\right\}$ do composto 47.

\begin{tabular}{cc}
\hline $\boldsymbol{\delta}(\mathbf{p p m})$ & Atribuição \\
\hline 139,4 & $\mathrm{C}_{11}$ \\
132,1 & $\mathrm{C}_{6}$ \\
129,1 & $\mathrm{C}_{5}$ \\
128,7 & $\mathrm{C}_{13}, \mathrm{C}_{15}$ \\
128,0 & $\mathrm{C}_{12}, \mathrm{C}_{16}$ \\
127,8 & $\mathrm{C}_{14}$ \\
73,5 & $\mathrm{C}_{10}$ \\
70,4 & $\mathrm{C}_{3}$ \\
42,9 & $\mathrm{C}_{2}$ \\
37,3 & $\mathrm{C}_{4}$ \\
34,2 & $\mathrm{C}_{1}$ \\
31,8 & $\mathrm{C}_{7}{ }^{*}$ \\
29,9 & $\mathrm{C}_{8}{ }^{*}$ \\
23,8 & $\mathrm{C}_{9}$ \\
\hline 0
\end{tabular}

*podem estar trocados 


\section{Espectro de IV do composto 47:}

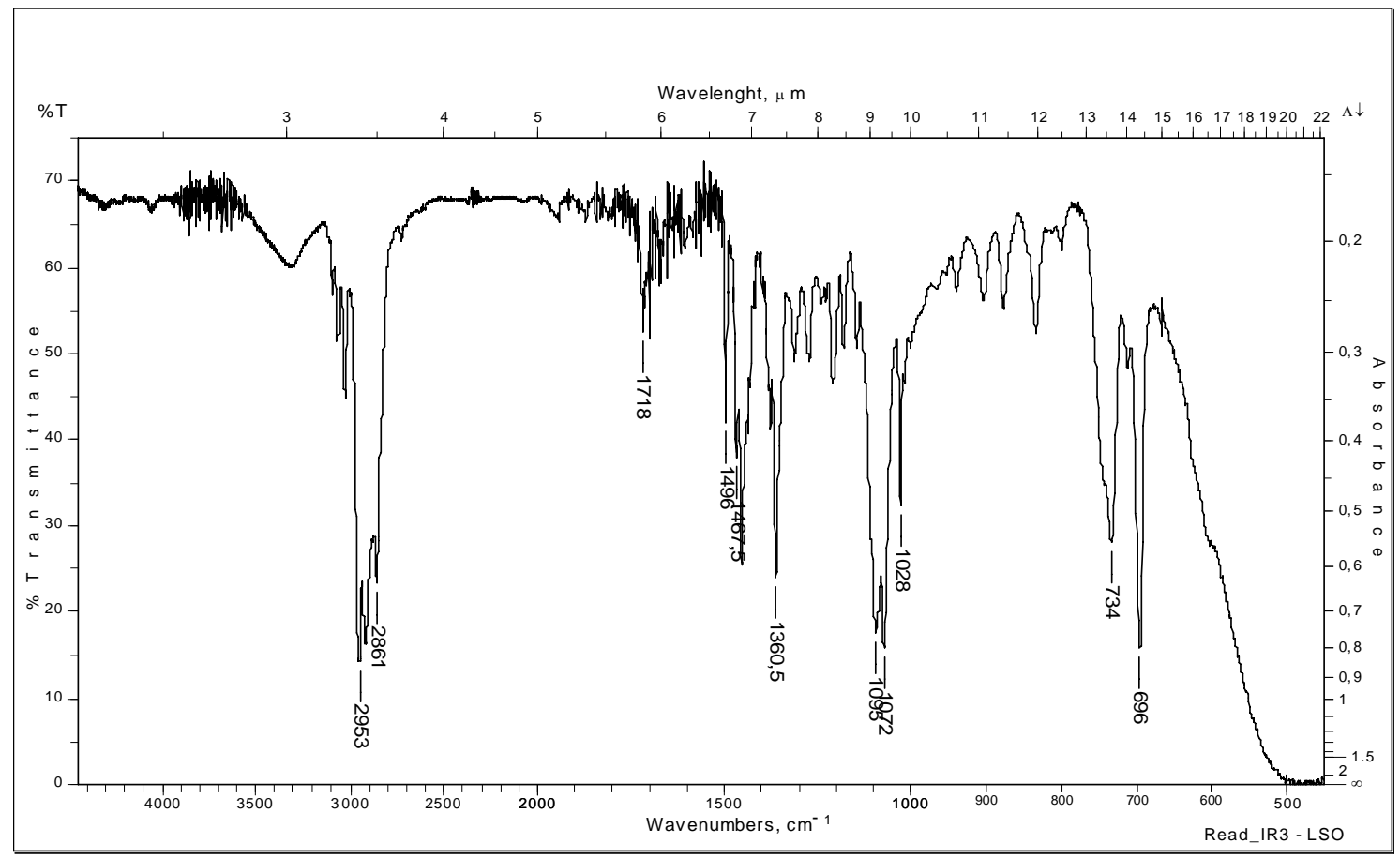

Tabela 10 - Dados espectrais de IV do composto 47.

\begin{tabular}{cl}
\hline $\boldsymbol{v}\left(\mathbf{c m}^{-1}\right)$ & \multicolumn{1}{c}{ Atribuição } \\
\hline 1496 & Deformação axial de C=C aromático \\
1099 & Deformação axial assimétrica de C-O-C \\
1072 & Deformação axial simétrica de C-O-C \\
734 & Deformação angular fora do plano de C-H aromático \\
696 & Deformação angular fora do plano de C-H aromático \\
\hline
\end{tabular}




\section{Composto 48}

Espectro de ${ }^{1} \mathrm{H}-\mathrm{RMN}\left(\mathrm{CDCl}_{3}, 400 \mathrm{MHz}\right)$ :
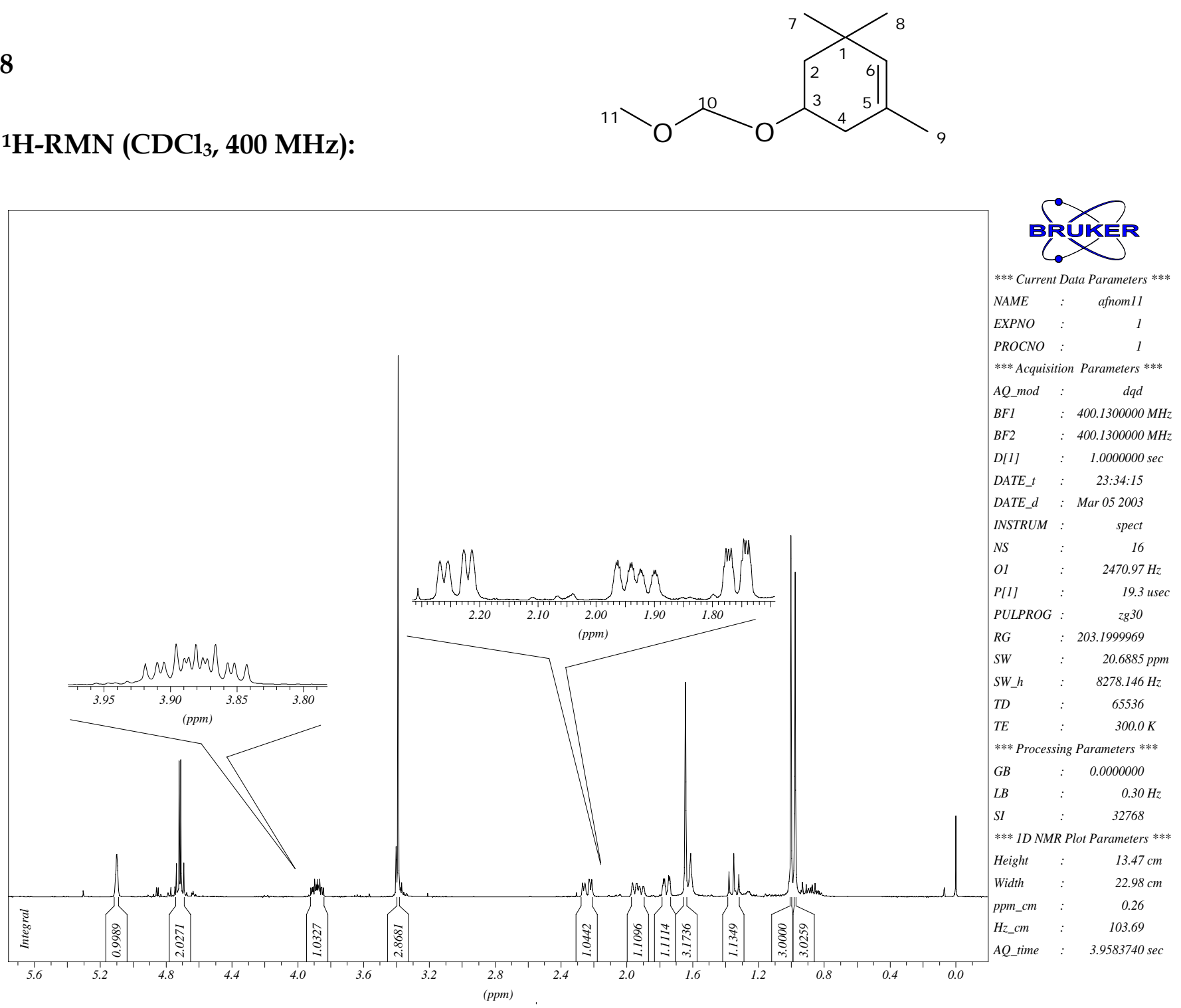
Tabela 11 - Dados espectrais de ${ }^{1} \mathrm{H}-\mathrm{RMN}$ do composto 48.

\begin{tabular}{cccc}
\hline$\delta(\mathbf{p p m})$ & Atribuição & Sinal & $J \mathbf{( H z})$ \\
\hline 5,10 & $\mathrm{H}_{6}$ & $\mathrm{~s}$ & $J_{10,10^{\prime}}=6,8$ \\
4,73 & $\mathrm{H}_{10}$ & $\mathrm{~d}$ & $J_{10^{\prime}, 10}=6,8$ \\
4,70 & $\mathrm{H}_{10^{\prime}}$ & $\mathrm{d}$ & $J_{3,2}=12,1 ; J_{3,4}=9,5 ; J_{3,4^{\prime}}=5,6 ; J_{3,2^{\prime}}=3,5$ \\
3,88 & $\mathrm{H}_{3}$ & dddd & $J_{4^{\prime}, 4}=16,4 ; J_{4^{\prime}, 3}=5,6$ \\
3,39 & $\mathrm{H}_{11}$ & $\mathrm{~s}$ & $J_{4,4^{\prime}}=16,4 ; J_{4,3}=9,5 ; J_{4,2^{\prime}}=1,3$ \\
2,24 & $\mathrm{H}_{4^{\prime}}$ & $\mathrm{dd}$ & $J_{2^{\prime}, 2}=12,1 ; J_{2^{\prime}, 3}=3,5 ; J_{2^{\prime}, 4}=1,3$ \\
1,93 & $\mathrm{H}_{4}$ & $\mathrm{ddq}$ & \\
1,76 & $\mathrm{H}_{2^{\prime}}$ & $\mathrm{ddt}$ & $J_{2,2^{\prime}}=J_{2,3}=12,1$ \\
1,64 & $\mathrm{H}_{9}$ & $\mathrm{~s}$ & \\
1,35 & $\mathrm{H}_{2}$ & $\mathrm{t}$ & \\
1,00 & $\mathrm{H}_{7^{*}}$ & $\mathrm{~s}$ & $\mathrm{~s}$
\end{tabular}

* podem estar trocados 
Espectro de ${ }^{13} \mathrm{C}-\mathrm{RMN}\left\{{ }^{1} \mathrm{H}\right\}\left(\mathrm{CDCl}_{3}, 100 \mathrm{MHz}\right)$ do composto 48:

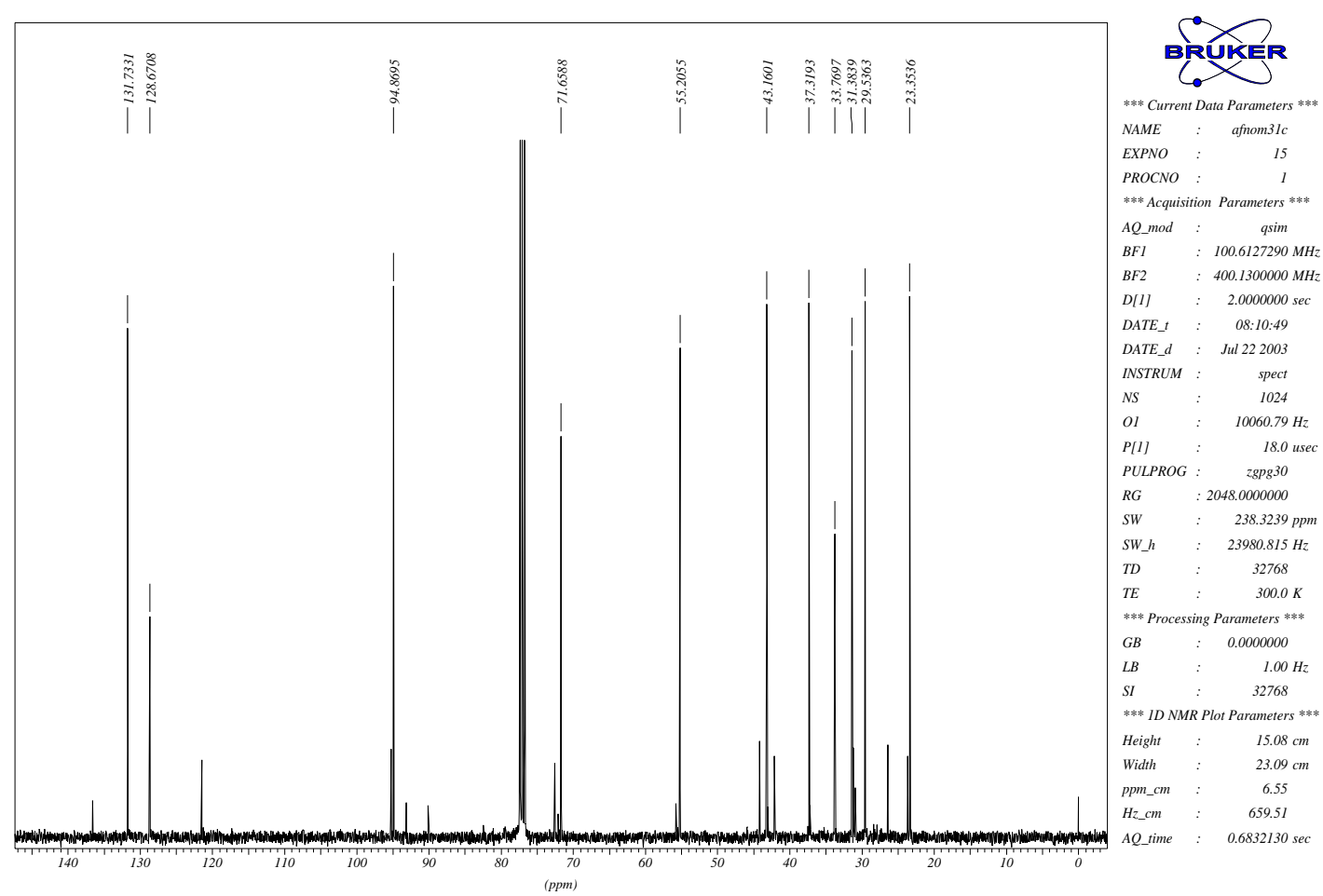

Espectro de ${ }^{13} \mathrm{C}-\mathrm{RMN}(\mathrm{DEPT}-135)\left(\mathrm{CDCl}_{3}, 100 \mathrm{MHz}\right)$ do composto 48:

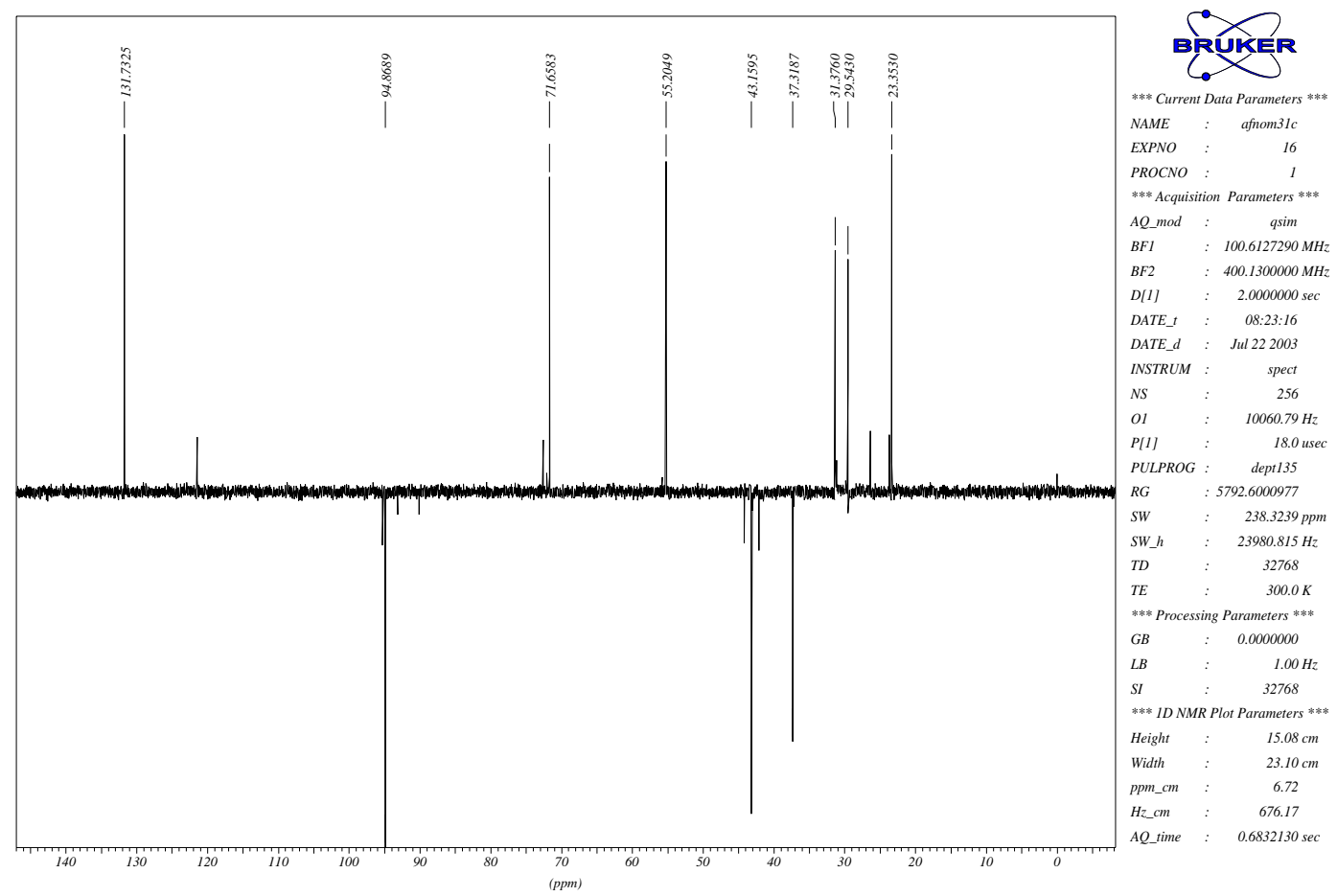


Tabela 12 - Dados espectrais de ${ }^{13} \mathrm{C}-\mathrm{RMN}\left\{{ }^{1} \mathrm{H}\right\}$ do composto 48.

\begin{tabular}{cc}
\hline$\delta(\mathbf{p p m})$ & Atribuição \\
\hline 131,7 & $\mathrm{C}_{6}$ \\
128,7 & $\mathrm{C}_{5}$ \\
94,9 & $\mathrm{C}_{10}$ \\
71,7 & $\mathrm{C}_{3}$ \\
55,2 & $\mathrm{C}_{11}$ \\
43,2 & $\mathrm{C}_{2}$ \\
37,3 & $\mathrm{C}_{4}$ \\
33,8 & $\mathrm{C}_{1}$ \\
31,4 & $\mathrm{C}_{7^{*}}$ \\
29,5 & $\mathrm{C}_{8^{*}}$ \\
23,3 & $\mathrm{C}_{9}$ \\
\hline
\end{tabular}

*podem estar trocados 


\section{Espectro de IV do composto 48:}

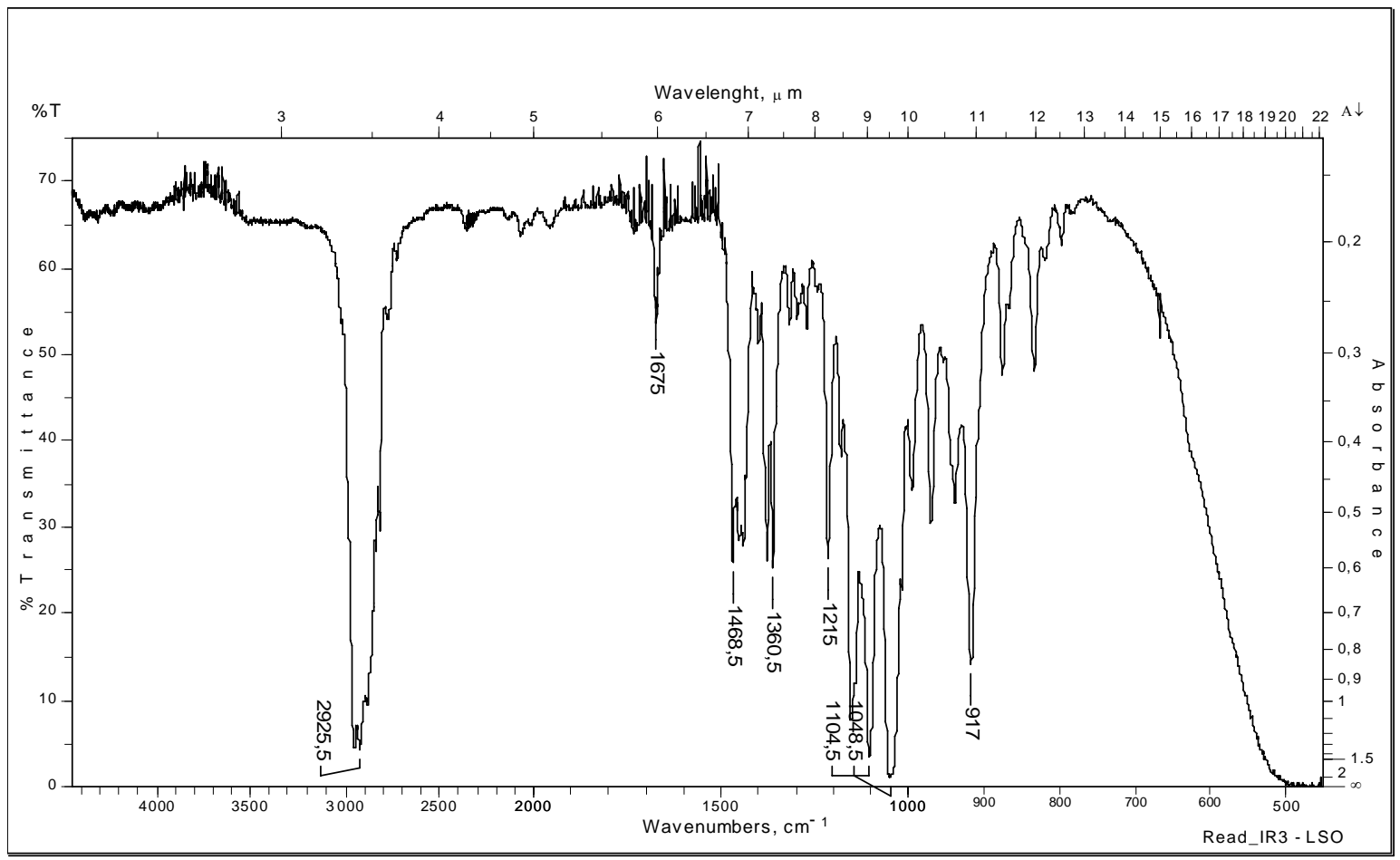

Tabela 13 - Dados espectrais de IV do composto 48.

\begin{tabular}{cl}
\hline$v\left(\mathbf{c m}^{-1}\right)$ & \multicolumn{1}{c}{ Atribuição } \\
\hline 1675 & Deformação axial de C=C \\
1104 & Deformação axial assimétrica de C-O-C \\
1048 & Deformação axial simétrica de C-O-C \\
917 & Deformação angular fora do plano de C-H da dupla ligação \\
\hline
\end{tabular}




\section{Composto 49}

\section{Espectro de ${ }^{1} \mathrm{H}-\mathrm{RMN}\left(\mathrm{CDCl}_{3}, 400 \mathrm{MHz}\right)$ :}
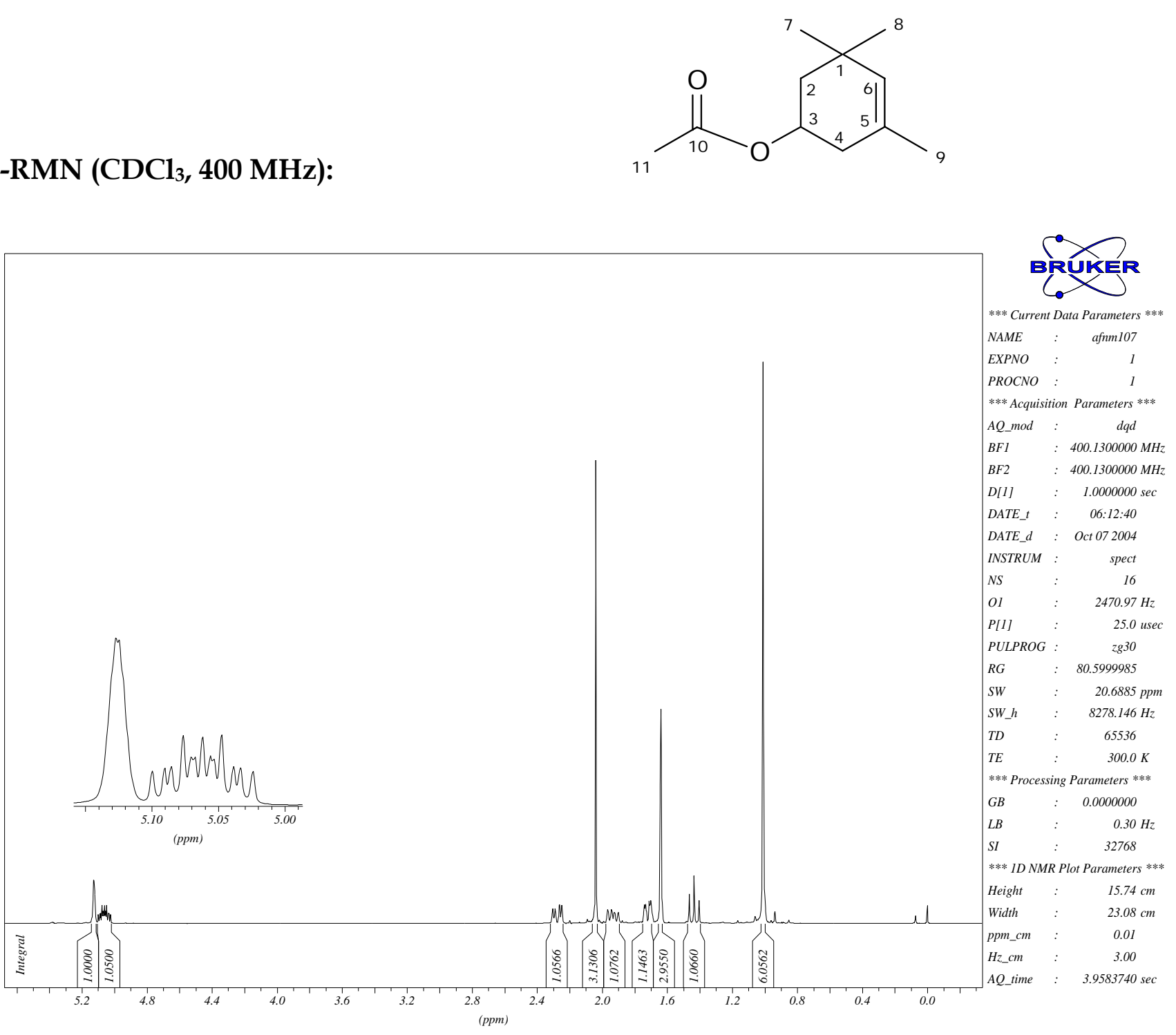
Tabela 14 - Dados espectrais de ${ }^{1} \mathrm{H}-\mathrm{RMN}$ do composto 49.

\begin{tabular}{cccc}
\hline$\delta$ (ppm) & Atribuição & Sinal & $J \mathbf{( H z})$ \\
\hline 5,12 & $\mathrm{H}_{6}$ & $\mathrm{~s}$ & \\
5,07 & $\mathrm{H}_{3}$ & dddd & $J_{3,2}=11,9 ; J_{3,4}=9,1 ; J_{3,4^{\prime}}=5,8 ; J_{3,2^{\prime}}=3,8$ \\
2,28 & $\mathrm{H}_{4^{\prime}}$ & $\mathrm{dd}$ & $J_{4^{\prime}, 4}=16,4 ; J_{4^{\prime}, 3}=5,8$ \\
2,04 & $\mathrm{H}_{11}$ & $\mathrm{~s}$ & \\
1,93 & $\mathrm{H}_{4}$ & $\mathrm{ddq}$ & $J_{4,4^{\prime}}=16,4 ; J_{4,3}=9,1 ; J_{4,2^{\prime}}=1,3$ \\
1,72 & $\mathrm{H}_{2^{\prime}}$ & $\mathrm{ddt}$ & $J_{2^{\prime}, 2}=11,9 ; J_{2^{\prime}, 3}=3,8 ; J_{2^{\prime}, 4}=1,3$ \\
1,64 & $\mathrm{H}_{9}$ & $\mathrm{~s}$ & \\
1,44 & $\mathrm{H}_{2}$ & $\mathrm{t}$ & $J_{2,2^{\prime}}=J_{2,3}=11,9$ \\
1,01 & $\mathrm{H}_{7,8}$ & $\mathrm{~s}$ & \\
\hline
\end{tabular}


Espectro de ${ }^{13} \mathrm{C}-\mathrm{RMN}\left\{{ }^{1} \mathrm{H}\right\}\left(\mathrm{CDCl}_{3}, 100 \mathrm{MHz}\right)$ do composto 49:

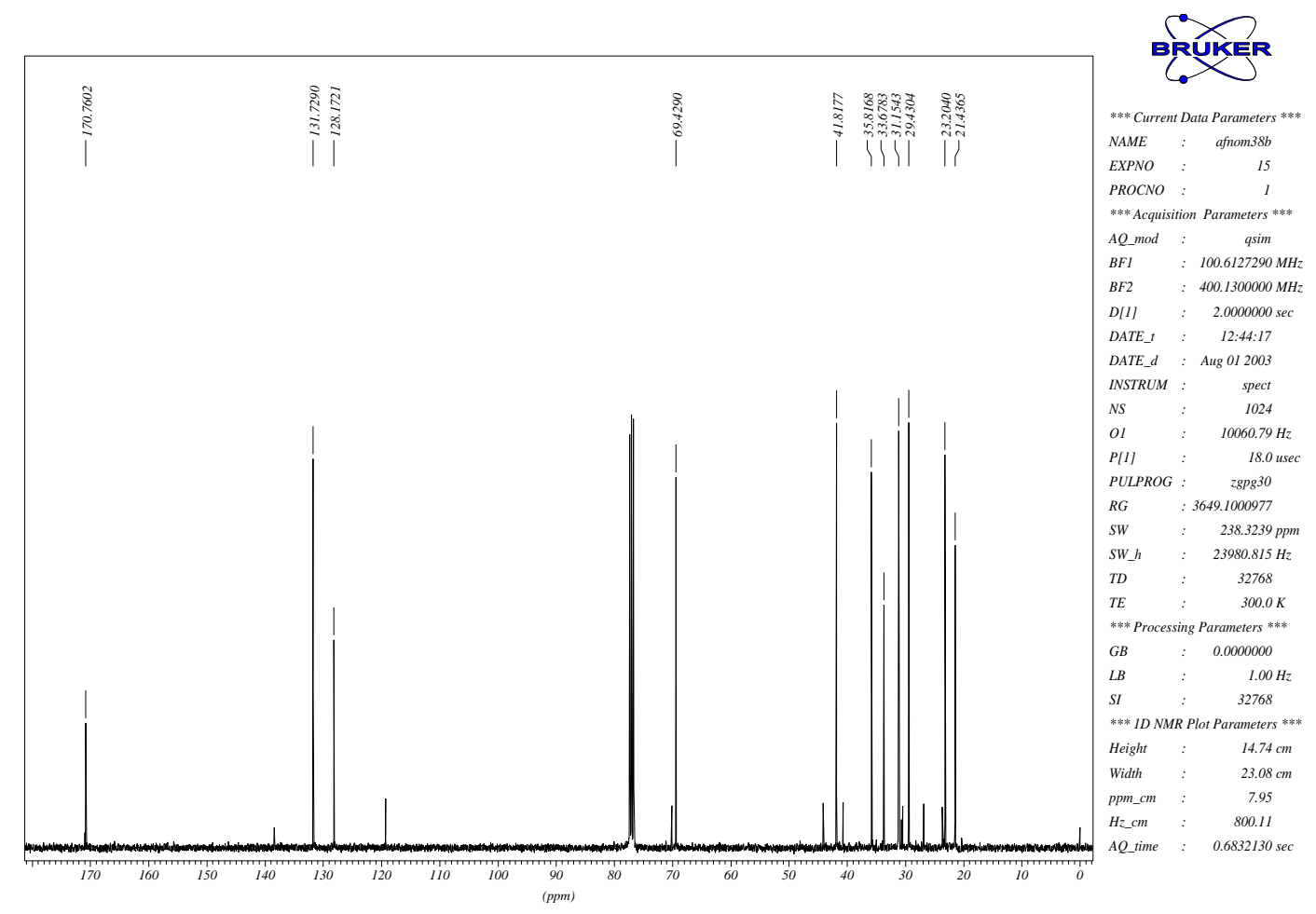

Espectro de ${ }^{13} \mathrm{C}-\mathrm{RMN}(\mathrm{DEPT}-135)\left(\mathrm{CDCl}_{3}, 100 \mathrm{MHz}\right)$ do composto 49:

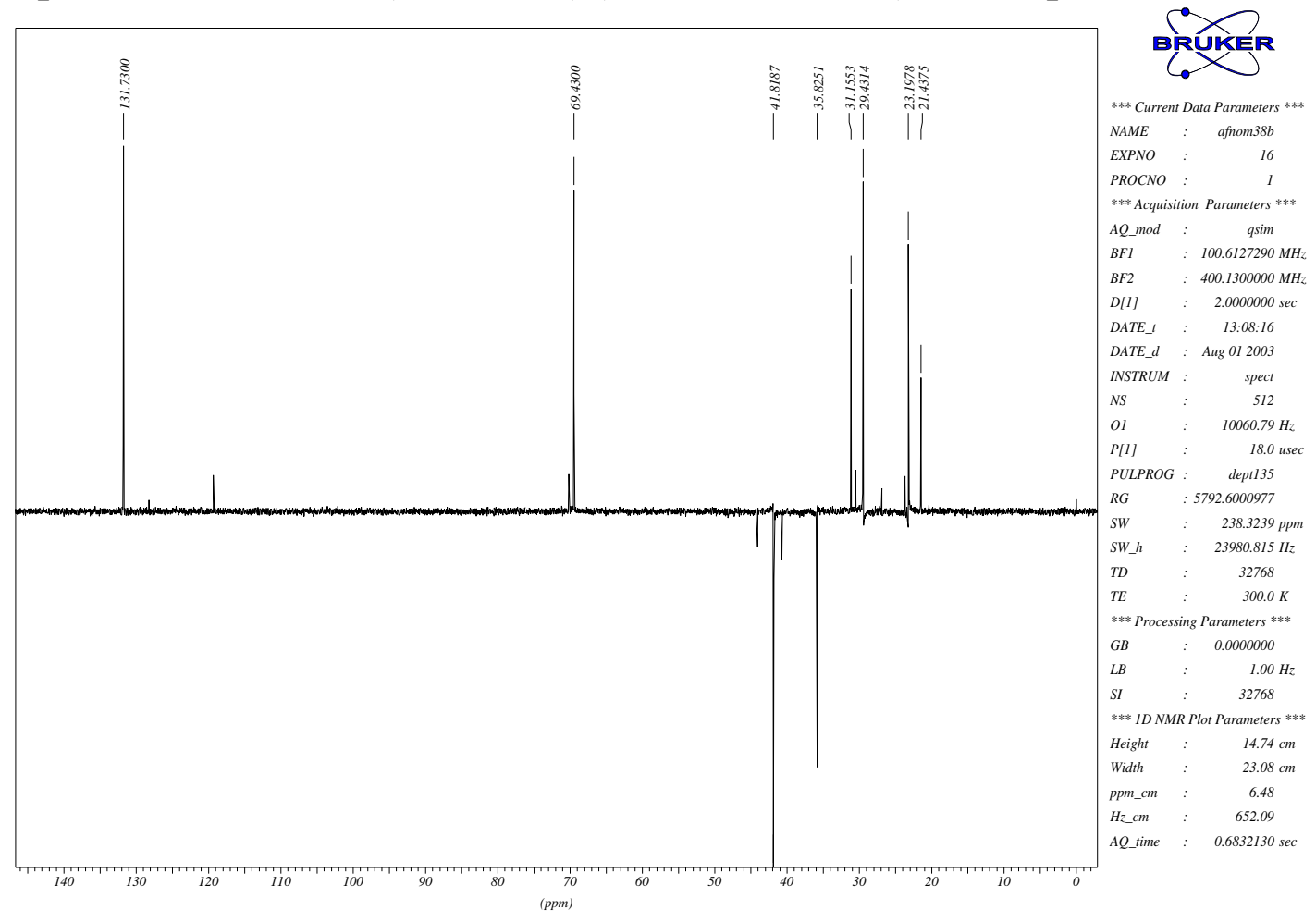


Tabela 15 - Dados espectrais de ${ }^{13} \mathrm{C}-\mathrm{RMN}\left\{{ }^{1} \mathrm{H}\right\}$ do composto 49.

\begin{tabular}{cc}
\hline$\delta(\mathbf{p p m})$ & Atribuição \\
\hline 170,8 & $\mathrm{C}_{10}$ \\
131,7 & $\mathrm{C}_{6}$ \\
128,2 & $\mathrm{C}_{5}$ \\
69,4 & $\mathrm{C}_{3}$ \\
41,8 & $\mathrm{C}_{2}$ \\
35,8 & $\mathrm{C}_{4}$ \\
33,7 & $\mathrm{C}_{8}{ }^{*}$ \\
31,1 & $\mathrm{C}_{7}^{*}$ \\
29,4 & $\mathrm{C}_{1}$ \\
23,2 & $\mathrm{C}_{9}$ \\
21,4 & $\mathrm{C}_{11}$ \\
\hline
\end{tabular}

*podem estar trocados 


\section{Espectro de IV do composto 49:}

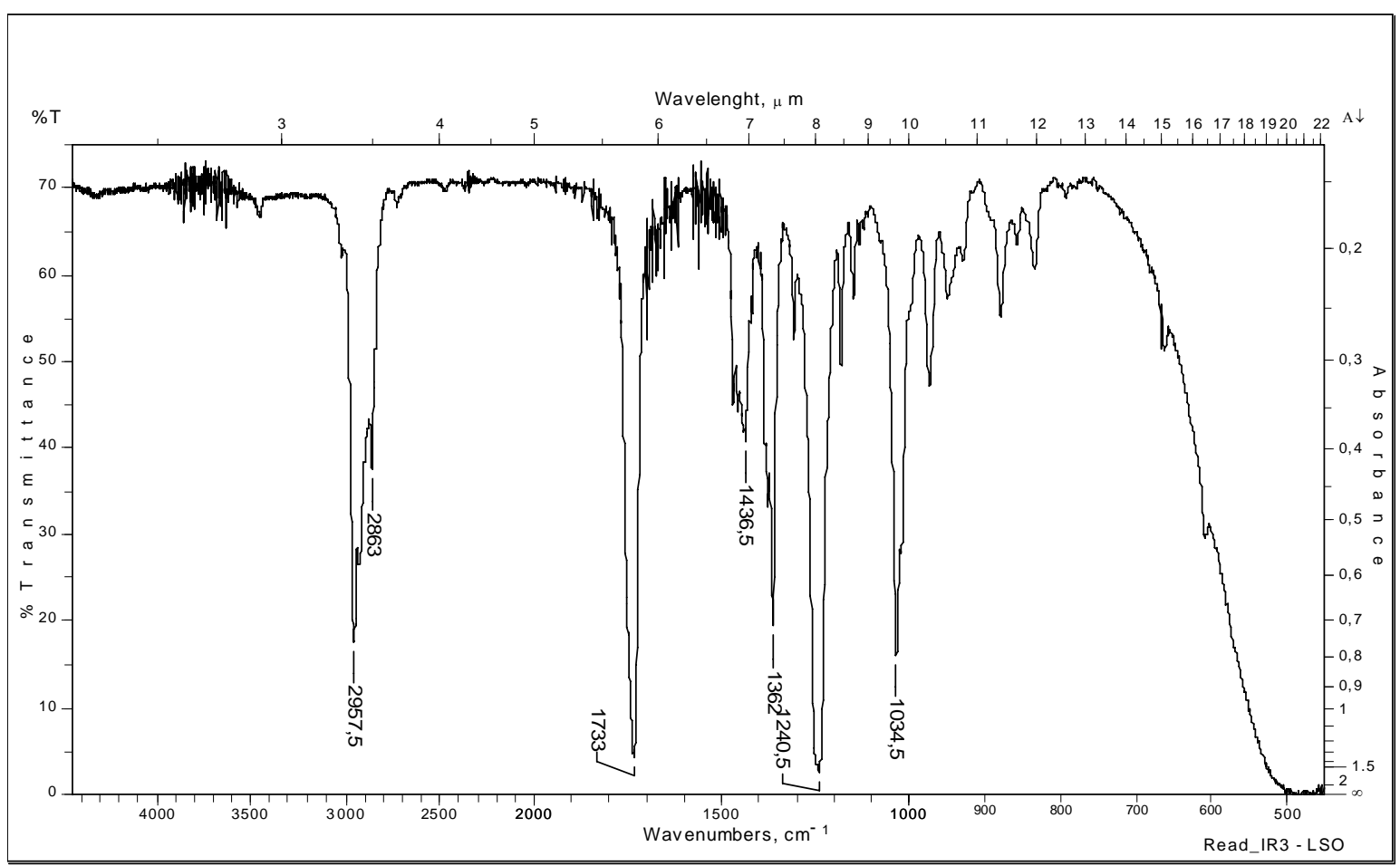

Tabela 16 - Dados espectrais de IV do composto 49.

\begin{tabular}{cl}
\hline$v\left(\mathbf{c m}^{-1}\right)$ & \multicolumn{1}{c}{ Atribuição* $^{*}$} \\
\hline 1733 & Deformação axial de C=O \\
1240 & Deformação axial assimétrica de C-C-(=O)-O \\
1034 & Deformação angular fora do plano de C-H da dupla ligação \\
\hline
\end{tabular}




\section{Composto 50a (3S, 5R)}

\section{Espectro de ${ }^{1} \mathrm{H}-\mathrm{RMN}\left(\mathrm{CDCl}_{3}, 400 \mathrm{MHz}\right)$ :}
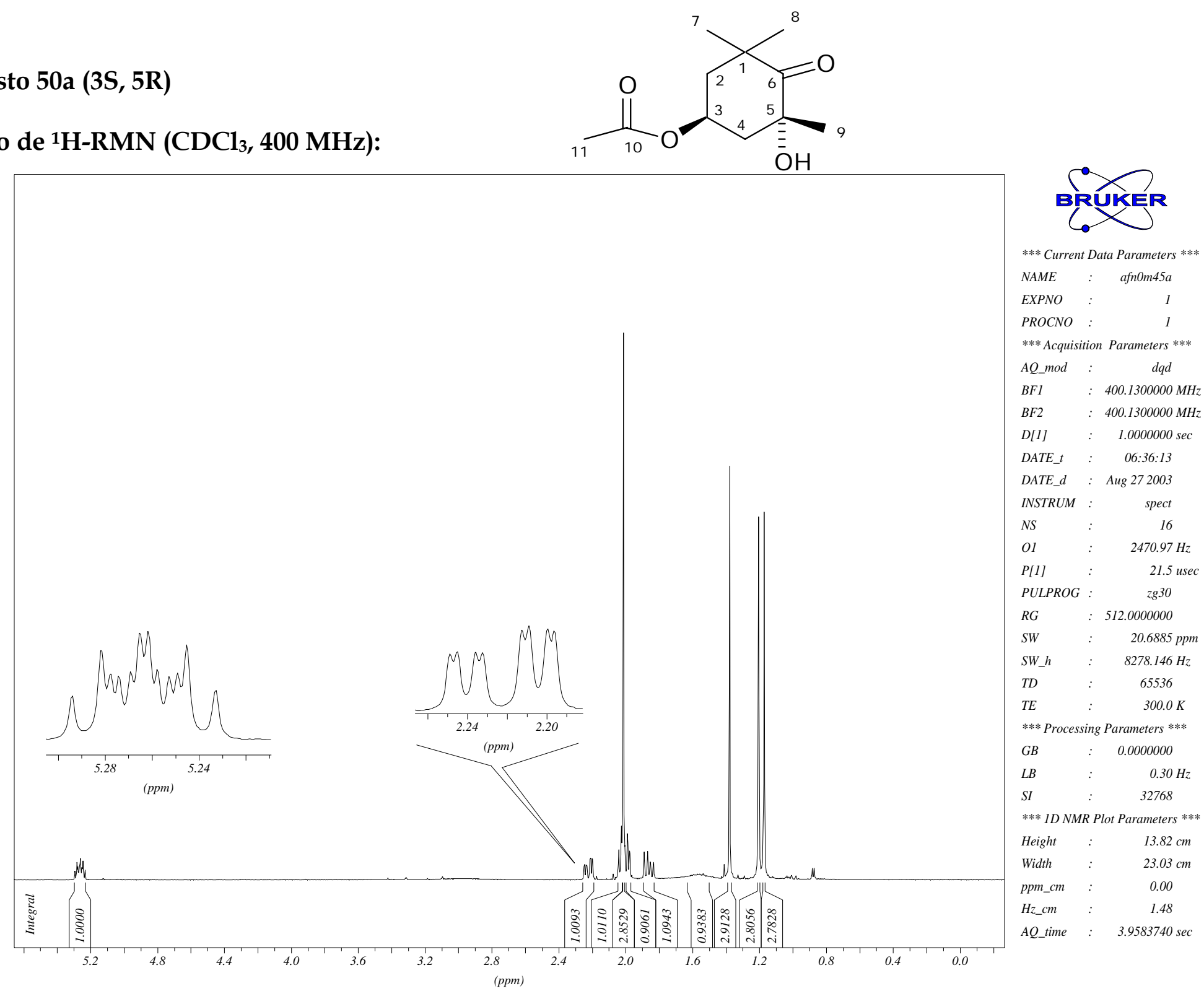
Tabela 17 - Dados espectrais de ${ }^{1} \mathrm{H}-\mathrm{RMN}$ do composto $50 \mathrm{a}$.

\begin{tabular}{cccc}
\hline$\delta$ (ppm) & Atribuição & Sinal & $J(\mathbf{H z})$ \\
\hline 5,26 & $\mathrm{H}_{3}$ & $\mathrm{ddt}$ & $J_{3,2 a x}=7,8 ; J_{3,4 a x}=6,6 ; J_{3,4 e q}=J_{3,2 e q}=4,8$ \\
2,22 & $\mathrm{H}_{4 \mathrm{eq}}$ & $\mathrm{ddd}$ & $J_{4 e q, 4 a x}=14,4 ; J_{4 e q, 3}=4,8 ; J_{4 e q, 2 e q}=1,5$ \\
$2,11-2,05$ & $\mathrm{H}_{2 \mathrm{eq}}, \mathrm{H}_{4 \mathrm{ax}}$ & $\mathrm{m}$ & \\
2,01 & $\mathrm{H}_{11}$ & $\mathrm{~s}$ & $J_{2 a x, 2 e q}=13,1 ; J_{2 a x, 3}=7,8$ \\
1,86 & $\mathrm{H}_{2 \mathrm{ax}}$ & $\mathrm{dd}$ & \\
1,38 & $\mathrm{H}_{9}$ & $\mathrm{~s}$ & \\
1,21 & $\mathrm{H}_{7}{ }^{*}$ & $\mathrm{~s}$ & \\
1,17 & $\mathrm{H}_{8}{ }^{*}$ & $\mathrm{~s}$ & \\
\hline
\end{tabular}

*podem estar trocadops

Tabela 18 - Interação NOE observada no experimento de NOE-diff ${ }^{1} \mathrm{H}-\mathrm{RMN}$ do composto 50a.

\begin{tabular}{ccc}
\hline$\delta$ (ppm) irradiado & Atribuição & Efeito NOE observado \\
\hline 5,26 & $\mathrm{H}_{3}$ & $\mathrm{H}_{2 \mathrm{eq}}, \mathrm{H}_{4 \mathrm{eq}}$ \\
1,38 & $\mathrm{H}_{9}$ & $\mathrm{H}_{4 \mathrm{ax}}, \mathrm{H}_{4 \mathrm{eq}}$ \\
\hline
\end{tabular}


Espectro de ${ }^{13} \mathrm{C}-\mathrm{RMN}\left\{{ }^{1} \mathrm{H}\right\}\left(\mathrm{CDCl}_{3}, 100 \mathrm{MHz}\right)$ do composto 50a:

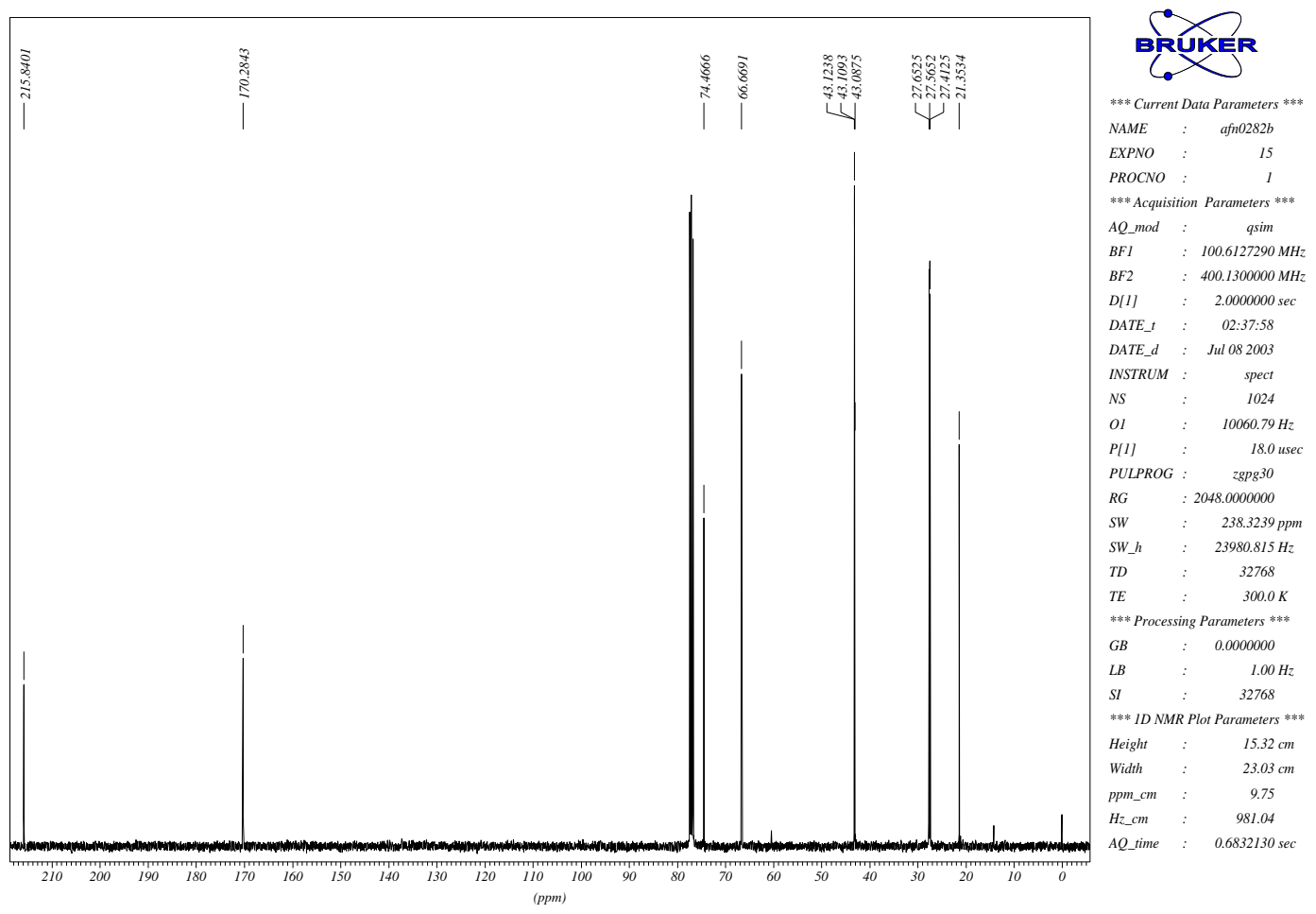

Espectro de ${ }^{13} \mathrm{C}-\mathrm{RMN}$ (DEPT-135) do composto 50a:

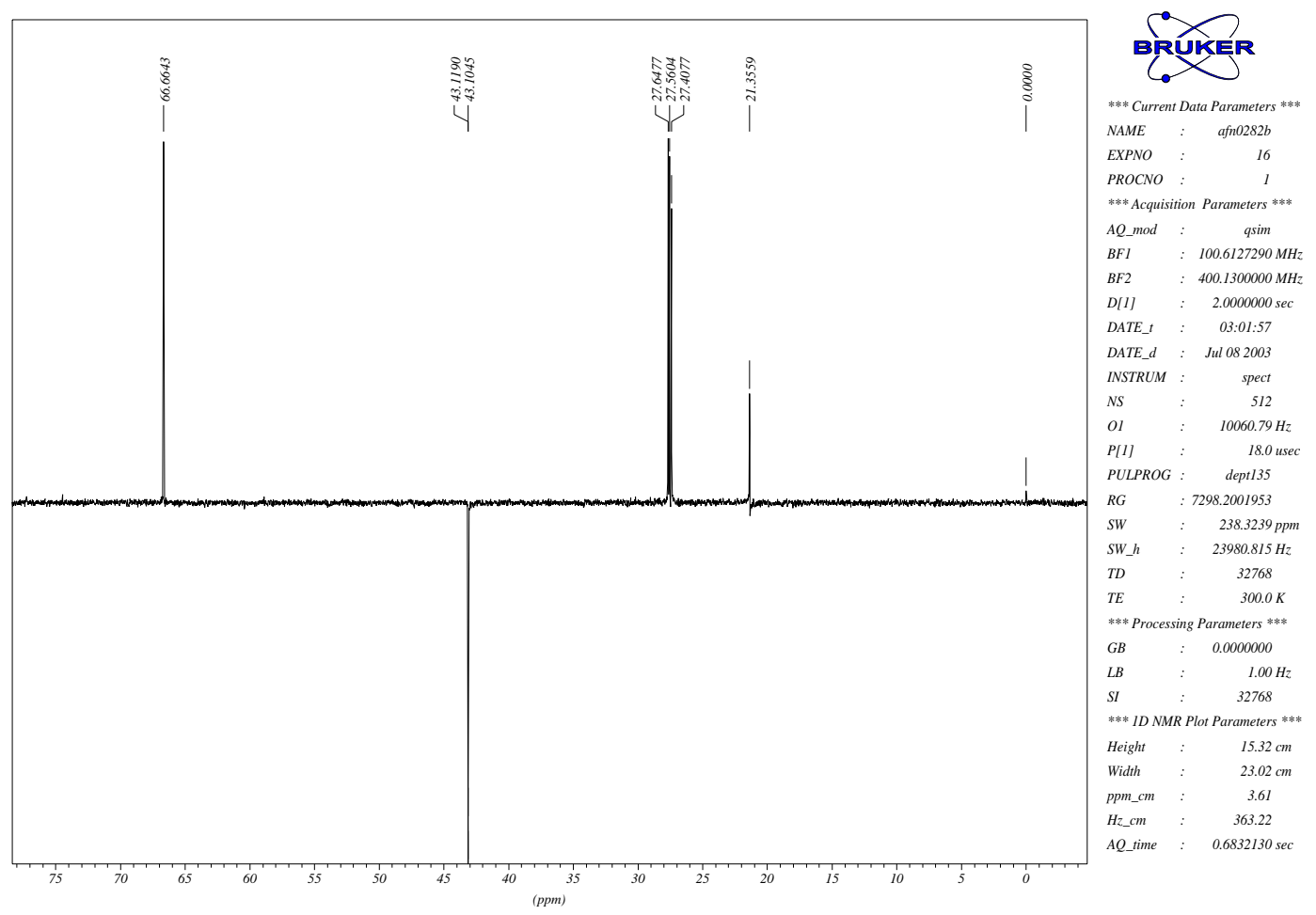


Tabela 19 - Dados espectrais de ${ }^{13} \mathrm{C}-\mathrm{RMN}\left\{{ }^{1} \mathrm{H}\right\}$ do composto 50a.

\begin{tabular}{cc}
\hline $\boldsymbol{\delta}$ (ppm) & Atribuição* $^{*}$ \\
\hline 215,8 & $\mathrm{C}_{6}$ \\
170,3 & $\mathrm{C}_{10}$ \\
74,5 & $\mathrm{C}_{5}$ \\
66,7 & $\mathrm{C}_{3}$ \\
43,1 & $\mathrm{C}_{4}, \mathrm{C}_{2}, \mathrm{C}_{1}$ \\
27,7 & $\mathrm{C}_{7}{ }^{* *}$ \\
27,6 & $\mathrm{C}_{8}^{* *}$ \\
27,4 & $\mathrm{C}_{9}$ \\
21,3 & $\mathrm{C}_{11}$
\end{tabular}

* os carbonos foram atribuídos utilizando HMQC

** podem estar trocados 


\section{Espectro de IV do composto 50a:}

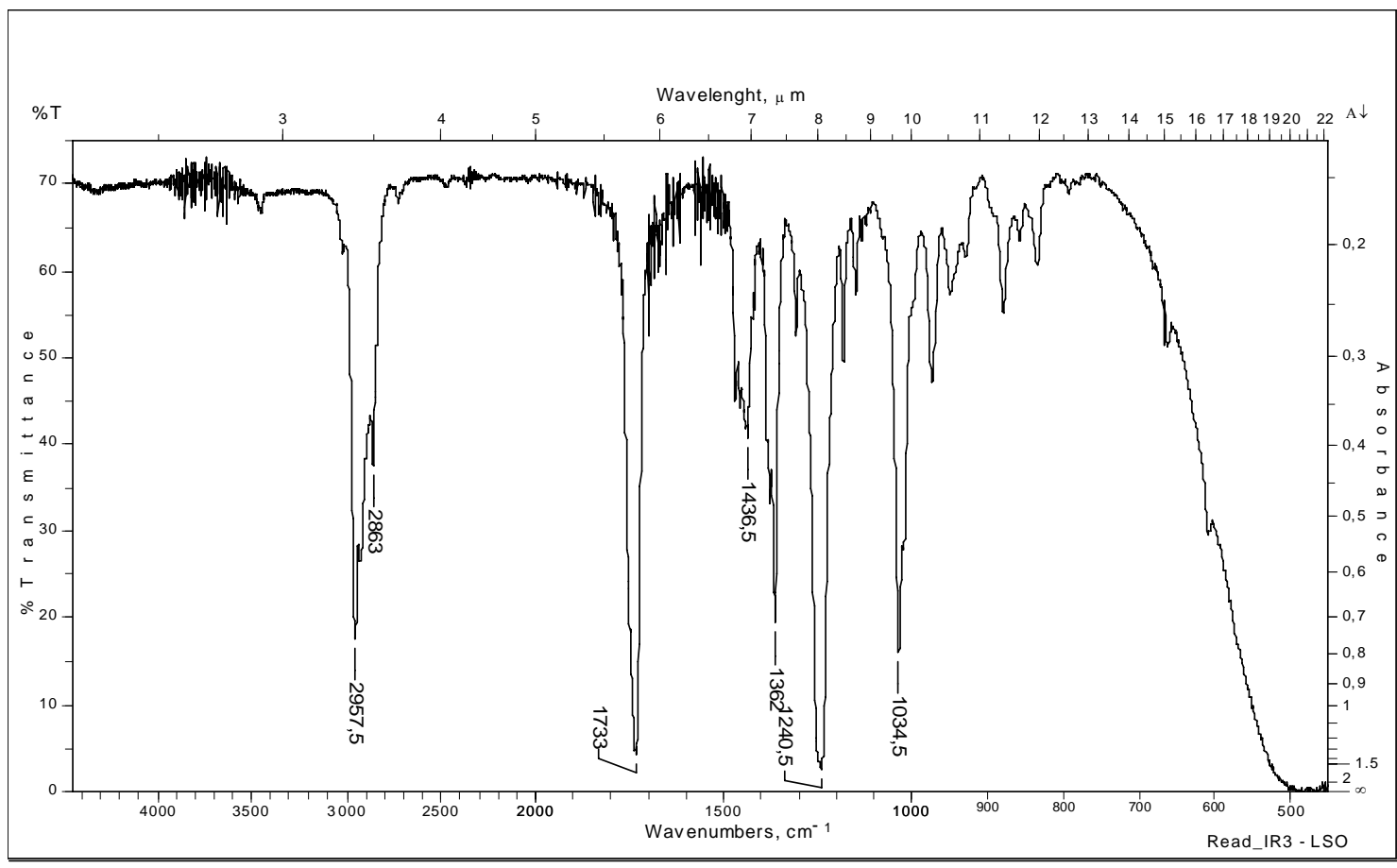

Tabela 20 - Dados espectrais de IV do composto 50a.

\begin{tabular}{ll}
\hline $\boldsymbol{v}\left(\mathbf{c m}^{-1}\right)$ & \multicolumn{1}{c}{ Atribuição } \\
\hline 3447 & Deformação axial de $\mathrm{OH}$ \\
1745 & Deformação axial de C=O do éster \\
1718 & Deformação axial de C=O da cetona \\
1368 & Deformação angular no plano de OH \\
1247 & Deformação axial assimétrica de C-C(=O)-O \\
1167 & Deformação axial assimétrica de O-C-C \\
1030 & Deformação axial de C-O do álcool \\
\hline
\end{tabular}




\section{Composto 50b (3S, 5S)}

\section{Espectro de ${ }^{1} \mathrm{H}-\mathrm{RMN}\left(\mathrm{CDCl}_{3}, 400 \mathrm{MHz}\right)$ :}
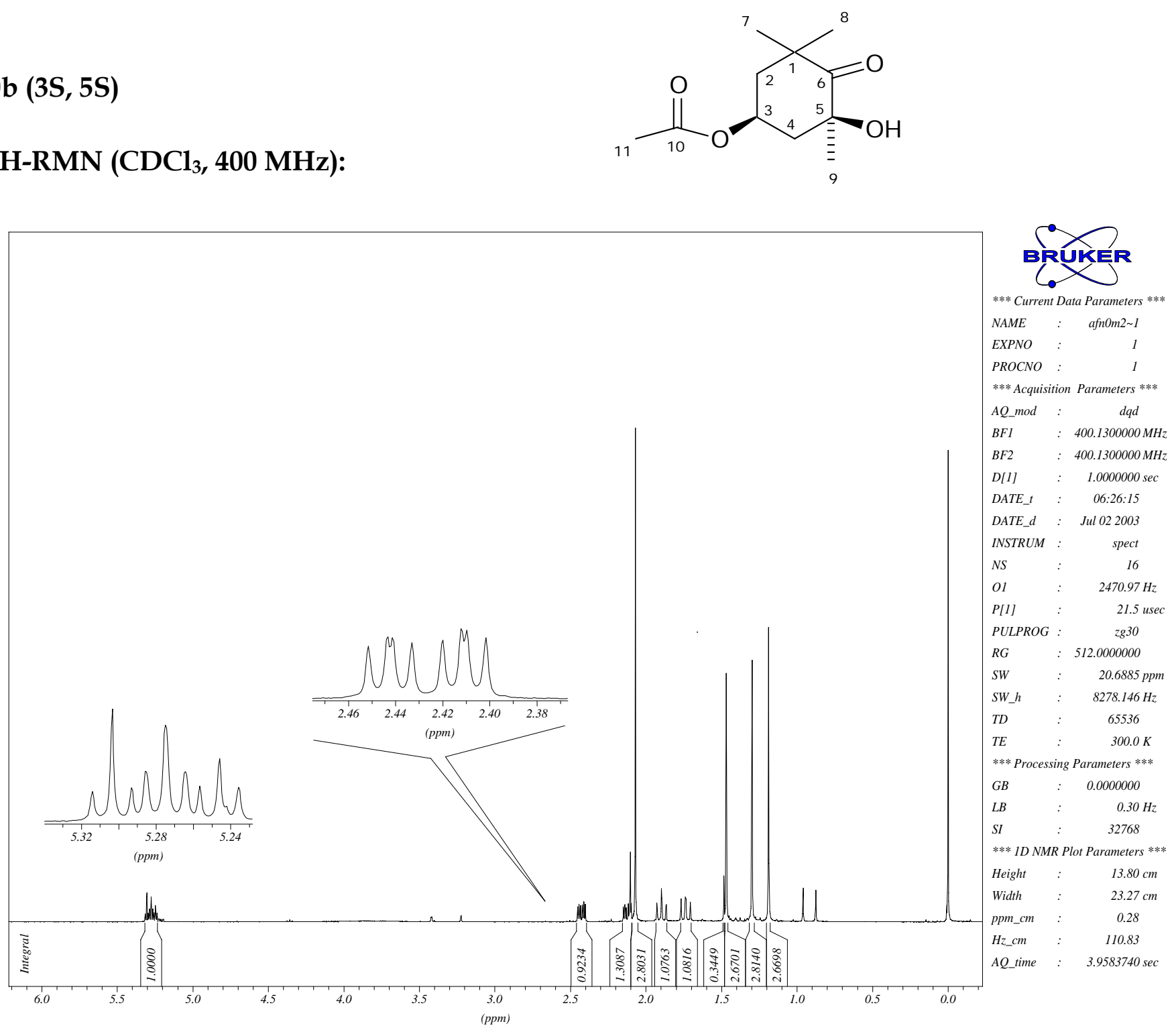
Tabela 21 - Dados espectrais de ${ }^{1} \mathrm{H}-\mathrm{RMN}$ do composto $50 \mathrm{~b}$.

\begin{tabular}{cccc}
\hline$\delta$ (ppm) & Atribuição & Sinal & $J(\mathbf{H z})$ \\
\hline 5,27 & $\mathrm{H}_{3}$ & $\mathrm{tt}$ & $J_{3,2 a x}=J_{3,4 a x}=11,6 ; J_{3,4 e q}=J_{3,2 e q}=4,2$ \\
2,43 & $\mathrm{H}_{4 \mathrm{eq}}$ & $\mathrm{ddd}$ & $J_{4 e q, 4 a x}=12,3 ; J_{4 e q, 3}=4,2 ; J_{4 e q, 2 e q}=3,3$ \\
2,12 & $\mathrm{H}_{2 \mathrm{eq}}$ & $\mathrm{ddd}$ & $J_{2 e q, 2 a x}=13,1 ; J_{2 e q, 3}=4,2 ; J_{2 e q, 4 e q}=3,3$ \\
2,07 & $\mathrm{H}_{11}$ & $\mathrm{~s}$ & \\
1,89 & $\mathrm{H}_{4 \mathrm{ax}}$ & $\mathrm{dd}$ & $J_{4 a x, 4 e q}=12,3 ; J_{4 a x, 3}=11,6$ \\
1,74 & $\mathrm{H}_{2 \mathrm{ax}}$ & $\mathrm{dd}$ & $J_{2 a x, 2 e q}=13,1 ; J_{2 a x, 3}=11,6$ \\
1,47 & $\mathrm{H}_{9}$ & $\mathrm{sl}$ & \\
1,29 & $\mathrm{H}_{7}{ }^{*}$ & $\mathrm{~s}$ & \\
1,19 & $\mathrm{H}_{8}{ }^{*}$ & $\mathrm{~s}$ & \\
\hline
\end{tabular}

Tabela 22 - Interação NOE observada no experimento de NOE-diff ${ }^{1} \mathrm{H}-\mathrm{RMN}$ do composto $\mathbf{5 0 b}$.

\begin{tabular}{ccc}
\hline$\delta(\mathbf{p p m})$ irradiado & Atribuição & Efeito NOE observado \\
\hline 5,27 & $\mathrm{H}_{3}$ & $\mathrm{H}_{4 \mathrm{eq}}, \mathrm{H}_{2 \mathrm{eq}}, \mathrm{H}_{9}$ \\
1,47 & $\mathrm{H}_{9}$ & $\mathrm{H}_{4 \mathrm{eq}}, \mathrm{H}_{3}$ \\
\hline
\end{tabular}


Espectro de ${ }^{13} \mathrm{C}-\mathrm{RMN}\left\{{ }^{1} \mathrm{H}\right\}\left(\mathrm{CDCl}_{3}, 100 \mathrm{MHz}\right)$ do composto $50 \mathrm{~b}$ :

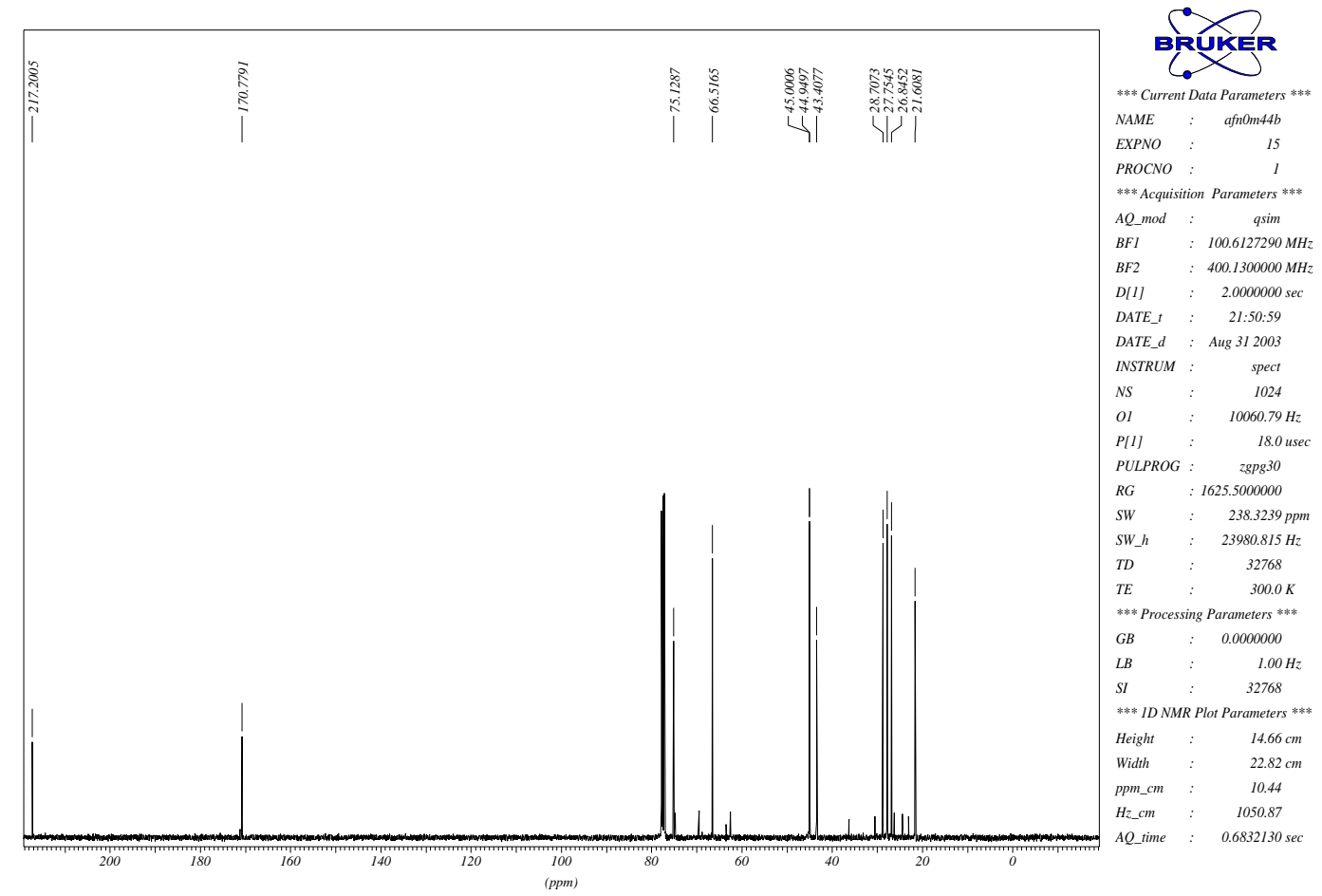

Espectro de ${ }^{13} \mathrm{C}-\mathrm{RMN}(\mathrm{DEPT}-135)\left(\mathrm{CDCl}_{3}, 100 \mathrm{MHz}\right)$ do composto 50b:

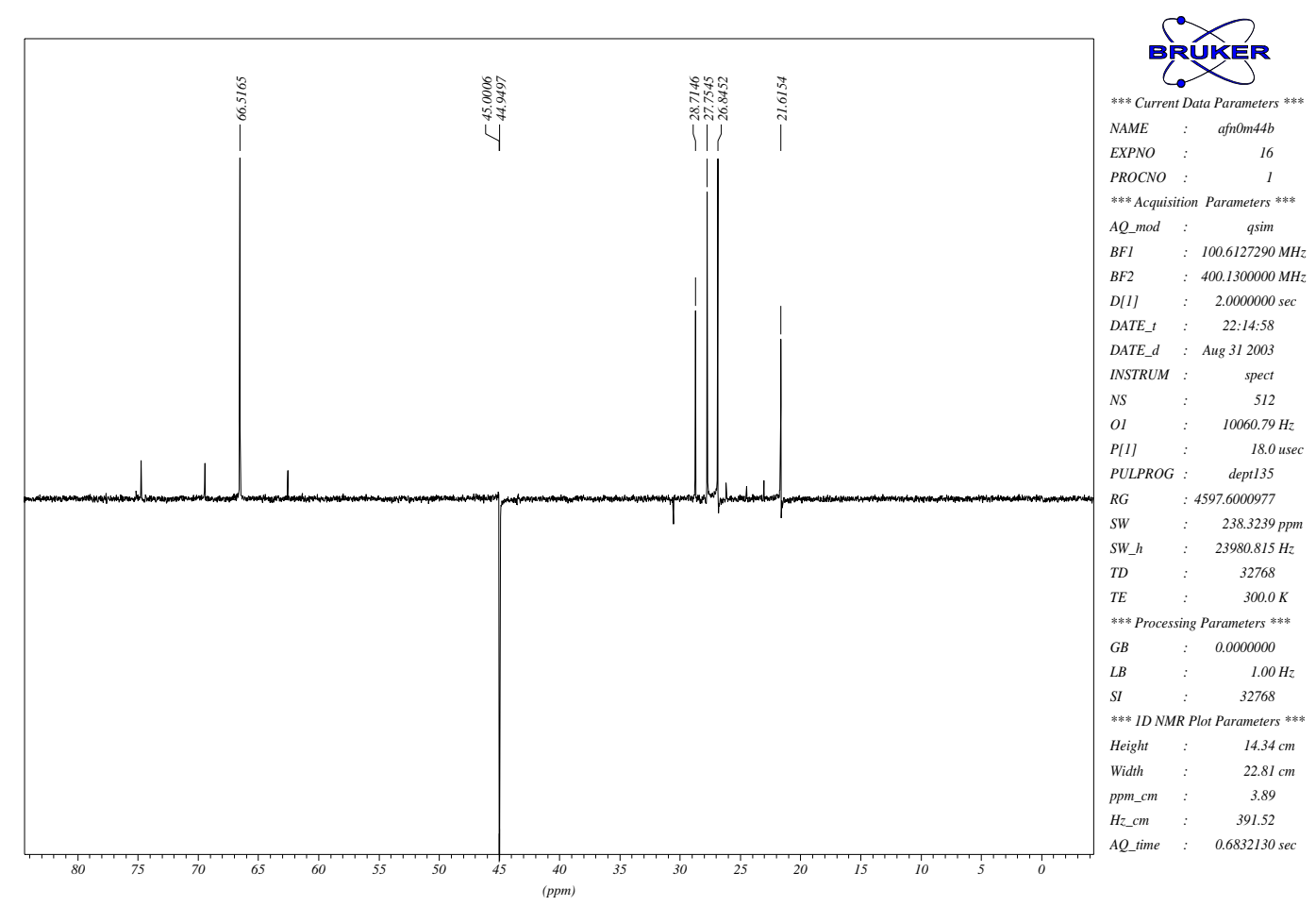


Tabela 23 - Dados espectrais de ${ }^{13} \mathrm{C}-\mathrm{RMN}\left\{{ }^{1} \mathrm{H}\right\}$ do composto 50b.

\begin{tabular}{cc}
\hline$\delta($ ppm $)$ & Atribuição* $^{*}$ \\
\hline 217,2 & $\mathrm{C}_{6}$ \\
170,8 & $\mathrm{C}_{10}$ \\
75,1 & $\mathrm{C}_{5}$ \\
66,5 & $\mathrm{C}_{3}$ \\
45,0 & $\mathrm{C}_{2}$ \\
44,9 & $\mathrm{C}_{4}$ \\
43,3 & $\mathrm{C}_{1}$ \\
28,7 & $\mathrm{C}_{9}$ \\
27,8 & $\mathrm{C}_{8}^{* *}$ \\
26,8 & $\mathrm{C}_{7}^{* *}$ \\
21,6 & $\mathrm{C}_{11}$
\end{tabular}

* os carbonos foram atribuídos utilizando HMQC

** podem estar trocados 
Espectro de IV do composto 50b:

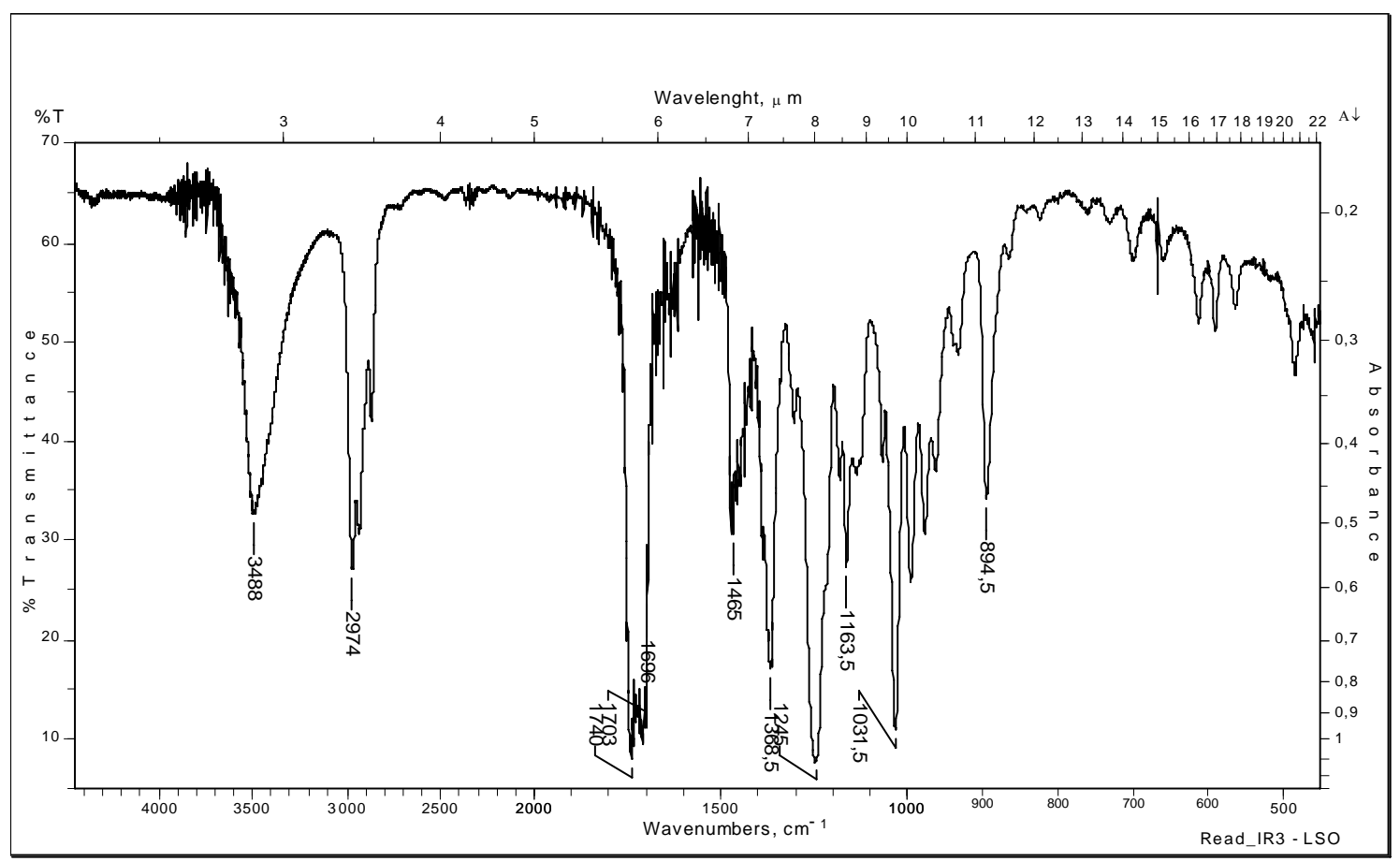

Tabela 24 - Dados espectrais de IV do composto 50b.

\begin{tabular}{cl}
\hline$v\left(\mathbf{c m}^{-1}\right)$ & \multicolumn{1}{c}{ Atribuição } \\
\hline 3488 & Deformação axial de OH \\
1740 & Deformação axial de C=O do éster \\
1703 & Deformação axial de C=O da cetona \\
1368 & Deformação angular no plano de OH \\
1250 & Deformação axial assimétrica de C-C $(=\mathrm{O})-\mathrm{O}$ \\
1163 & Deformação axial assimétrica de O-C-C \\
1031 & Deformação axial de C-O do álcool \\
\hline
\end{tabular}




\section{Composto 51a (3S, 5R)}

\section{Espectro de ${ }^{1} \mathrm{H}-\mathrm{RMN}\left(\mathrm{CDCl}_{3}, 400 \mathrm{MHz}\right)$ :}
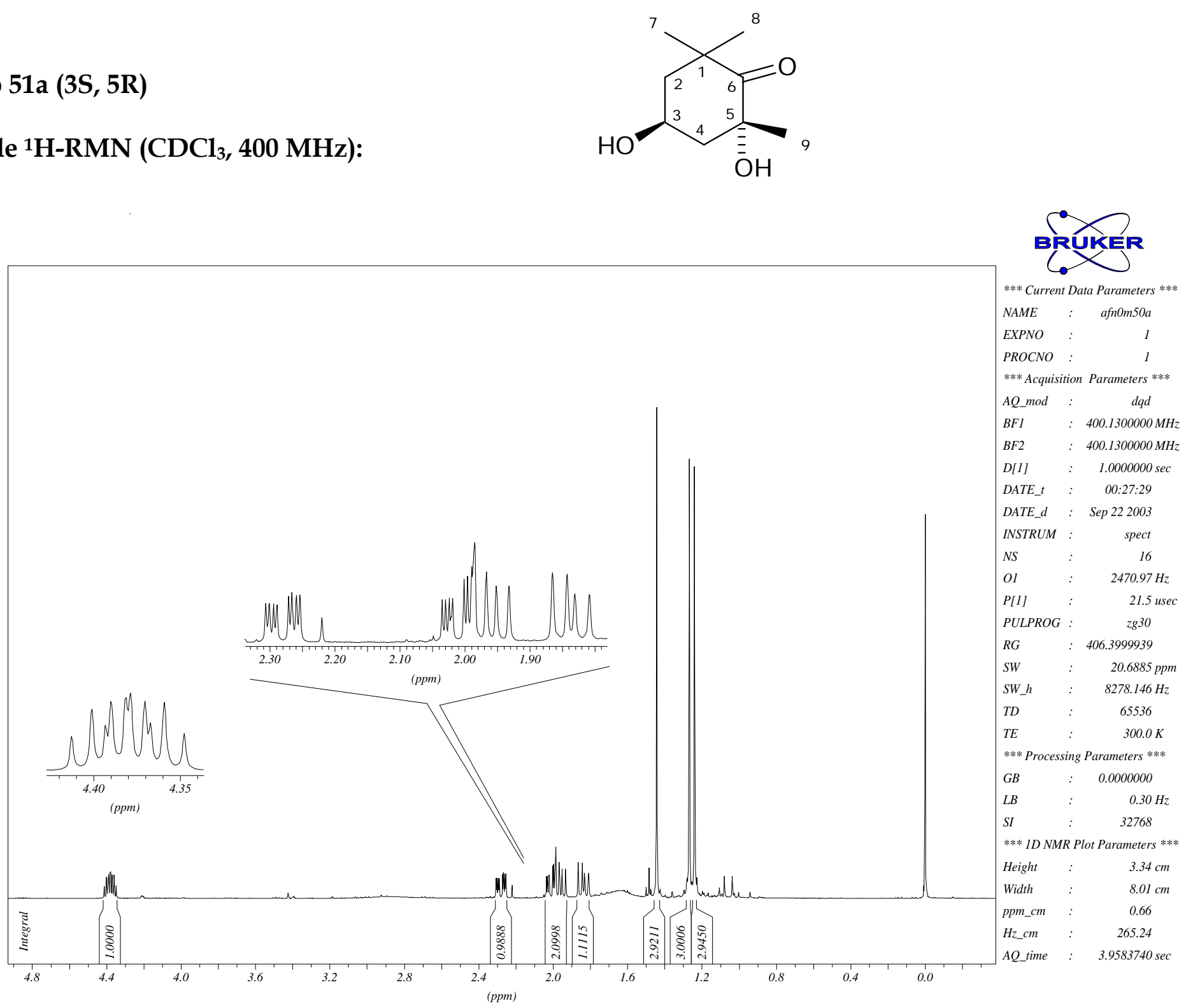
Tabela 25 - Dados espectrais de ${ }^{1} \mathrm{H}-\mathrm{RMN}$ do composto $51 \mathrm{a}$.

\begin{tabular}{cccc}
\hline$\delta$ (ppm) & Atribuição & \multicolumn{1}{c}{ Sinal } & $J(\mathbf{H z})$ \\
\hline 4,38 & $\mathrm{H}_{3}$ & $\mathrm{ddt}$ & $J_{3,2 a x}=9,1 ; J_{3,4 a x}=7,8 ; J_{3,4 e q}=J_{3,2 e q}=4,7$ \\
2,28 & $\mathrm{H}_{4 \mathrm{eq}}$ & $\mathrm{ddd}$ & $J_{4 e q, 4 a x}=14,0 ; J_{4 e q, 3}=4,7 ; J_{4 e q, 2 e q}=2,3$ \\
2,01 & $\mathrm{H}_{2 \mathrm{eq}}$ & $\mathrm{ddd}$ & $J_{2 e q, 2 a x}=13,6 ; J_{2 e q, 3}=4,7 ; J_{2 e q, 4 e q}=2,3$ \\
1,96 & $\mathrm{H}_{4 \mathrm{ax}}$ & $\mathrm{dd}$ & $J_{4 a x, 4 e q}=14,0 ; J_{4 a x, 3}=7,8$ \\
1,84 & $\mathrm{H}_{2 \mathrm{ax}}$ & $\mathrm{dd}$ & $J_{2 a x, 2 e q}=13,6 ; J_{2 a x, 3}=9,1$ \\
1,64 & $\mathrm{OH}$ & $\mathrm{sl}$ & \\
1,44 & $\mathrm{H}_{9}$ & $\mathrm{~s}$ & \\
1,27 & $\mathrm{H}_{7}{ }^{*}$ & $\mathrm{~s}$ & \\
1,24 & $\mathrm{H}_{8}{ }^{*}$ & $\mathrm{~s}$ & \\
\hline
\end{tabular}

*podem estar trocados

Tabela 26 - Interação NOE observada no experimento de NOE-diff ${ }^{1} \mathrm{H}-\mathrm{RMN}$ do composto 51 .

\begin{tabular}{ccc}
\hline $\boldsymbol{\delta}(\mathbf{p p m})$ irradiado & Atribuição & Efeito NOE observado \\
\hline 4,18 & $\mathrm{H}_{3}$ & $\mathrm{H}_{4 \mathrm{eq}}, \mathrm{H}_{2 \mathrm{eq}}$ \\
1,43 & $\mathrm{H}_{9}$ & $\mathrm{H}_{4 \mathrm{eq}}, \mathrm{H}_{4 \mathrm{ax}}$ \\
\hline
\end{tabular}


Espectro de ${ }^{13} \mathrm{C}-\mathrm{RMN}\left\{{ }^{1} \mathrm{H}\right\}\left(\mathrm{CDCl}_{3}, 100 \mathrm{MHz}\right)$ do composto 51a:

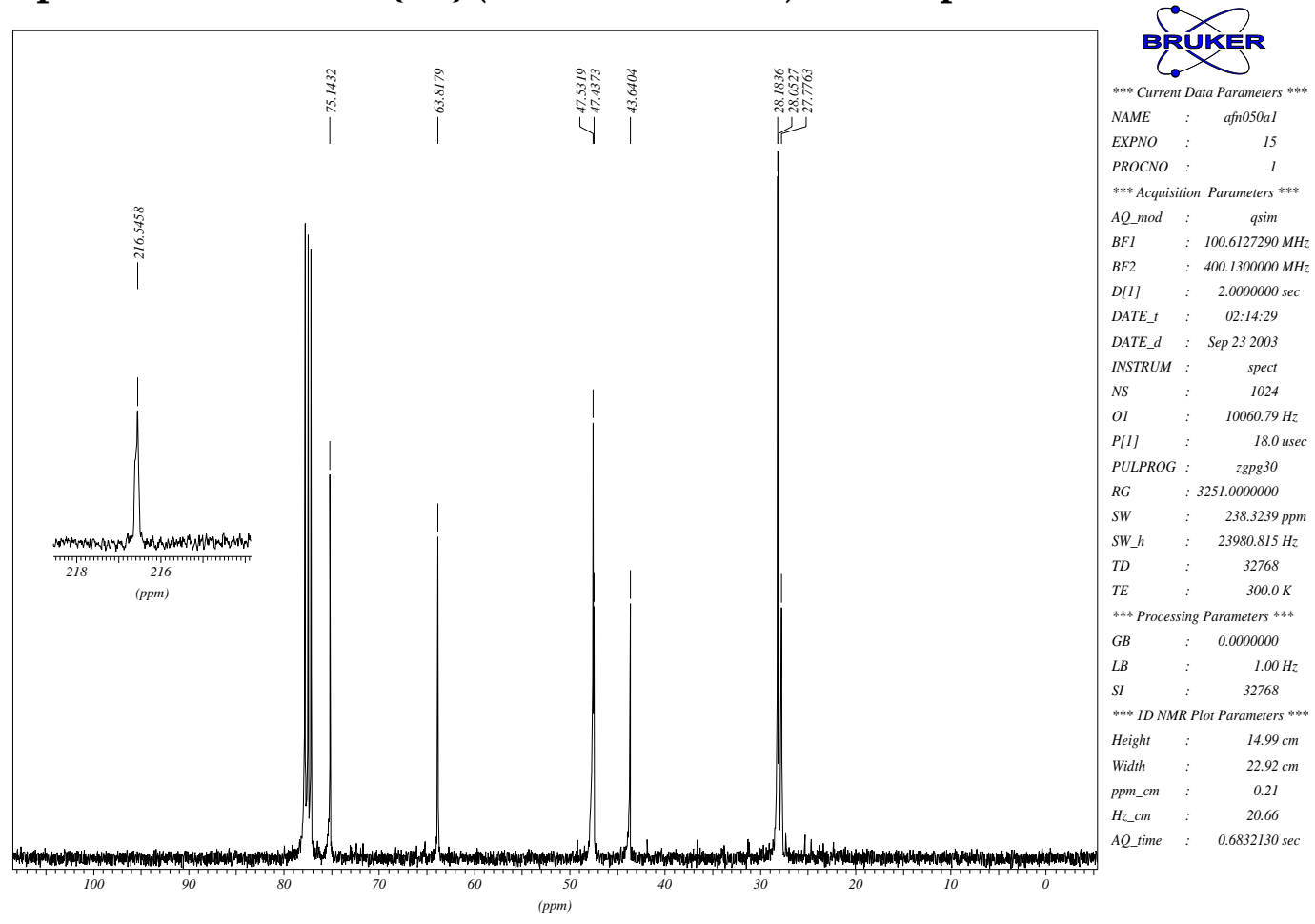

Espectro de ${ }^{13} \mathrm{C}-\mathrm{RMN}$ (DEPT-135) $\left(\mathrm{CDCl}_{3}, 100 \mathrm{MHz}\right)$ do composto 51a:

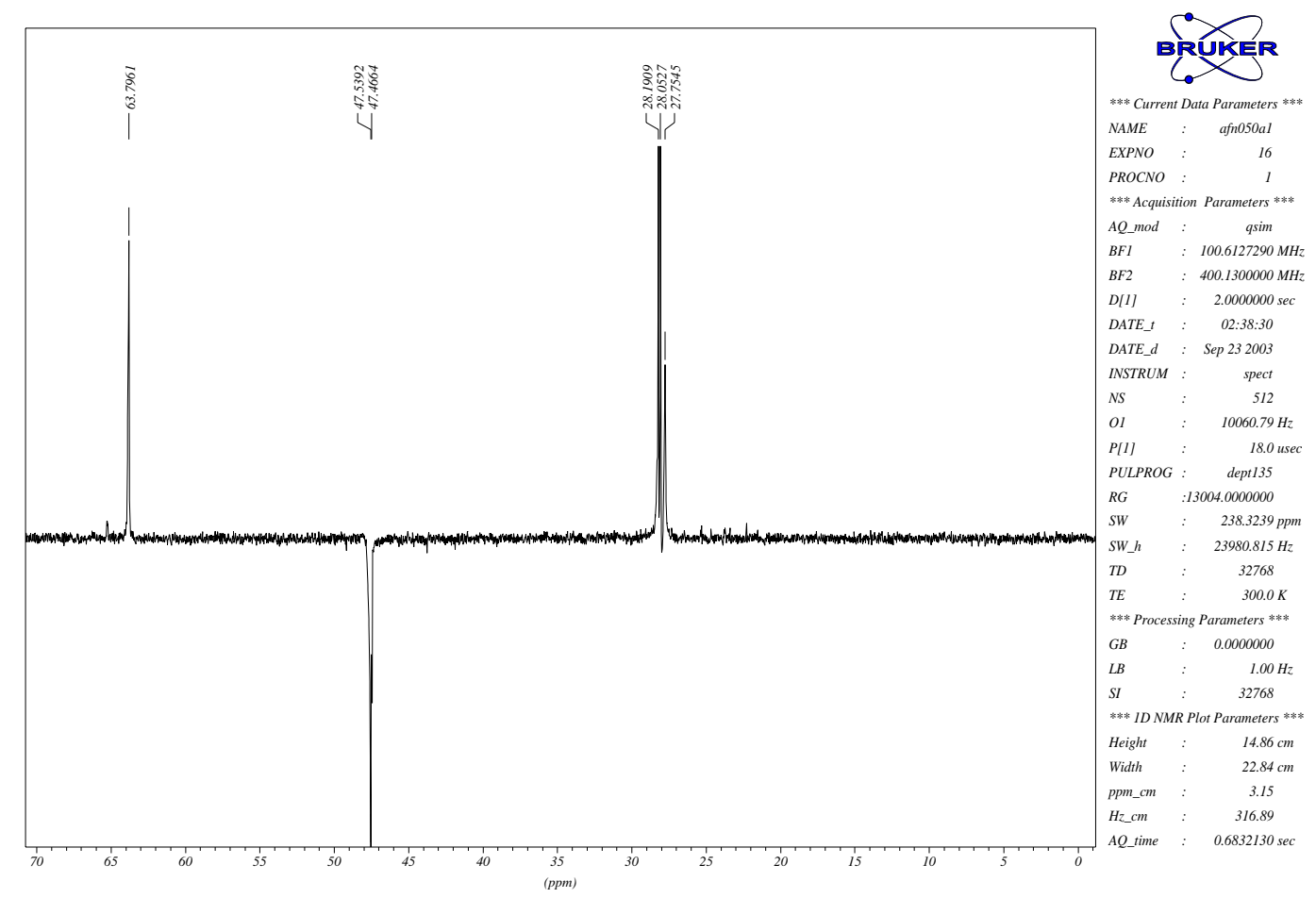


Tabela 27 - Dados espectrais de ${ }^{13} \mathrm{C}-\mathrm{RMN}\left\{{ }^{1} \mathrm{H}\right\}$ do composto 51a.

\begin{tabular}{cc}
\hline$\delta($ ppm $)$ & Atribuição* $^{*}$ \\
\hline 216,5 & $\mathrm{C}_{6}$ \\
75,1 & $\mathrm{C}_{5}$ \\
63,5 & $\mathrm{C}_{3}$ \\
47,5 & $\mathrm{C}_{2}$ \\
47,4 & $\mathrm{C}_{4}$ \\
43,6 & $\mathrm{C}_{1}$ \\
28,2 & $\mathrm{C}_{7}^{* *}$ \\
28,1 & $\mathrm{C}_{8}^{* *}$ \\
27,8 & $\mathrm{C}_{9}$ \\
\hline
\end{tabular}

* os carbonos foram atribuídos utilizando HMQC

** podem estar trocados 


\section{Espectro de IV do composto 51a:}

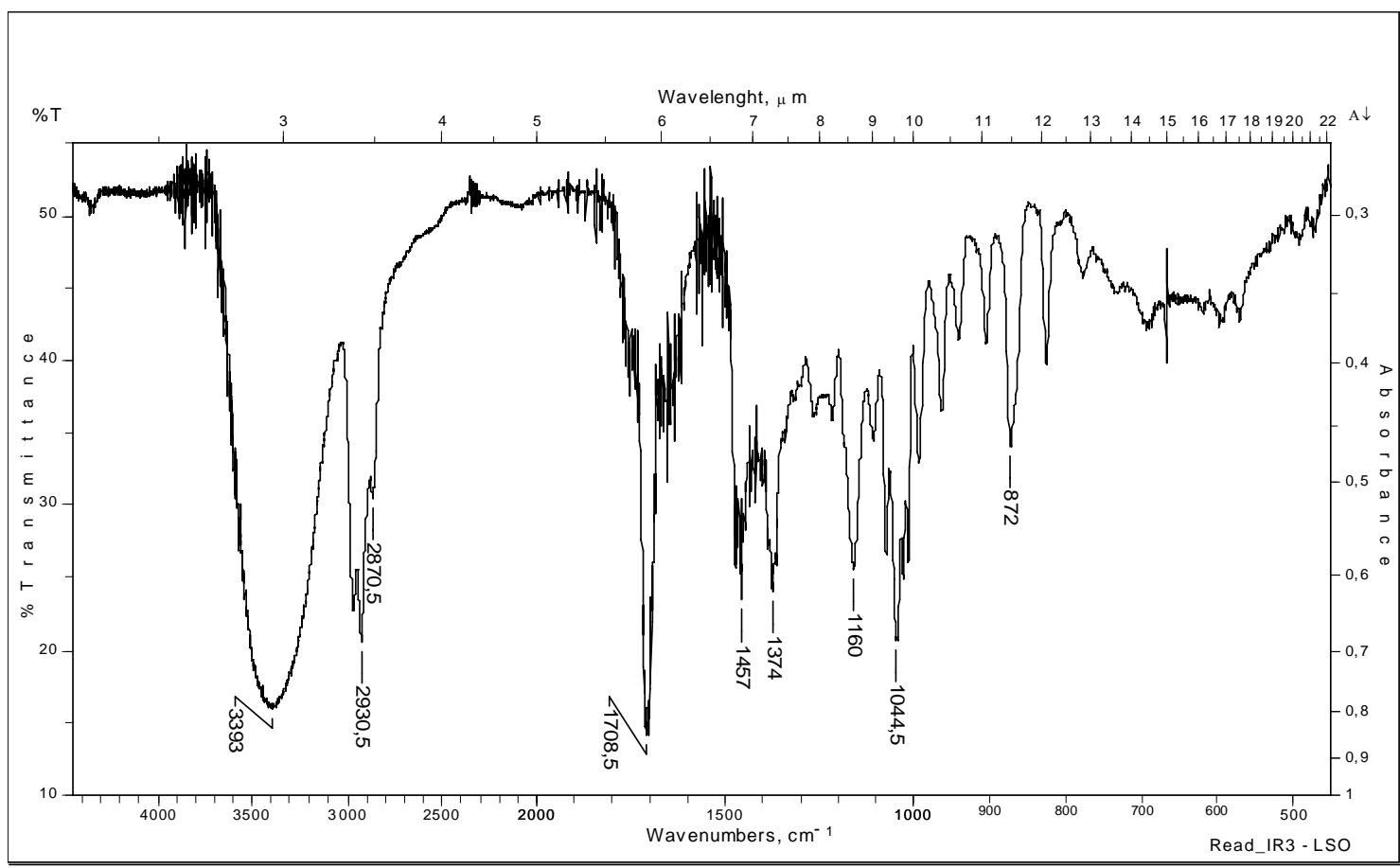

Tabela 28 - Dados espectrais de IV do composto 51a.

\begin{tabular}{cl}
\hline$v\left(\mathbf{c m}^{-1}\right)$ & \multicolumn{1}{c}{ Atribuição } \\
\hline 3393 & Deformação axial de $\mathrm{OH}$ \\
1708 & Deformação axial de $\mathrm{C}=\mathrm{O}$ \\
1374 & Deformação angular no plano de OH \\
1044 & Deformação axial de C-O do álcool \\
\hline
\end{tabular}




\section{Composto 51b (3S, 5S)}

\section{Espectro de ${ }^{1} \mathrm{H}-\mathrm{RMN}\left(\mathrm{CDCl}_{3}, 400 \mathrm{MHz}\right)$ :}

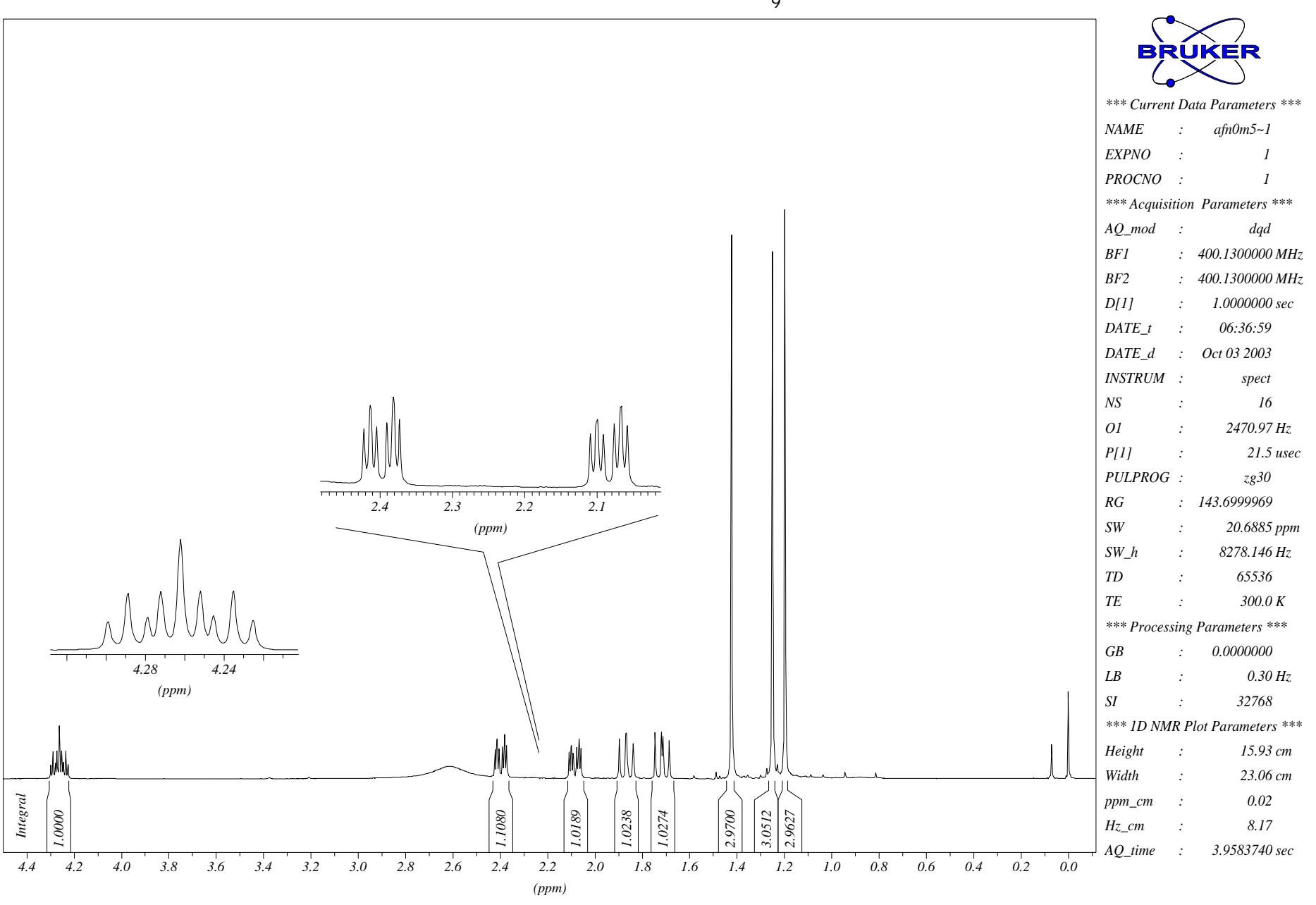


Tabela 29 - Dados espectrais de ${ }^{1} \mathrm{H}-\mathrm{RMN}$ do composto $\mathbf{5 1 b}$.

\begin{tabular}{cccc}
\hline$\delta$ (ppm) & Atribuição & Sinal & $J \mathbf{~ ( H z )}$ \\
\hline 4,26 & $\mathrm{H}_{3}$ & $\mathrm{ddt}$ & $J_{3,2 a x}=9,1 ; J_{3,4 a x}=7,8 ; J_{3,4 e q}=J_{3,2 e q}=4,7$ \\
2,62 & $\mathrm{OH}$ & $\mathrm{sl}$ & \\
2,40 & $\mathrm{H}_{4 \mathrm{eq}}$ & $\mathrm{ddd}$ & $J_{4 e q, 4 a x}=12,6 ; J_{4 e q, 3}=4,0 ; \mathrm{J}_{4 \mathrm{eq}, 2 \mathrm{eq}}=3,3$ \\
2,08 & $\mathrm{H}_{2 \mathrm{eq}}$ & $\mathrm{ddd}$ & $J_{2 e q, 2 a x}=13,1 ; J_{2 e q, 3}=4,0 ; J_{2 e q, 4 e q}=3,3$ \\
1,87 & $\mathrm{H}_{4 \mathrm{ax}}$ & $\mathrm{dd}$ & $J_{4 a x, 4 e q}=12,6 ; J_{4 a x, 3}=10,6$ \\
1,72 & $\mathrm{H}_{2 \mathrm{ax}}$ & $\mathrm{dd}$ & $J_{2 a x, 2 e q}=13,1 ; J_{2 a x, 3}=10,6$ \\
1,42 & $\mathrm{H}_{9}$ & $\mathrm{~s}$ & \\
1,25 & $\mathrm{H}_{7}{ }^{*}$ & $\mathrm{~s}$ & \\
1,20 & $\mathrm{H}_{8}{ }^{*}$ & $\mathrm{~s}$ & \\
\hline
\end{tabular}

Tabela 30 - Interação NOE observada no experimento de NOE-diff ${ }^{1} \mathrm{H}-\mathrm{RMN}$ do composto $\mathbf{5 1 b}$.

\begin{tabular}{ccc}
\hline $\boldsymbol{\delta}(\mathbf{p p m})$ irradiado & Atribuição & Efeito NOE observado \\
\hline 4,26 & $\mathrm{H}_{3}$ & $\mathrm{H}_{4 \mathrm{eq}}, \mathrm{H}_{2 \mathrm{eq}}$ \\
1,42 & $\mathrm{H}_{9}$ & $\mathrm{H}_{4 \mathrm{eq}}, \mathrm{H}_{3}$ \\
\hline
\end{tabular}


Espectro de ${ }^{13} \mathrm{C}-\mathrm{RMN}\left\{{ }^{1} \mathrm{H}\right\}\left(\mathrm{CDCl}_{3}, 100 \mathrm{MHz}\right)$ do composto $51 \mathrm{~b}$ :

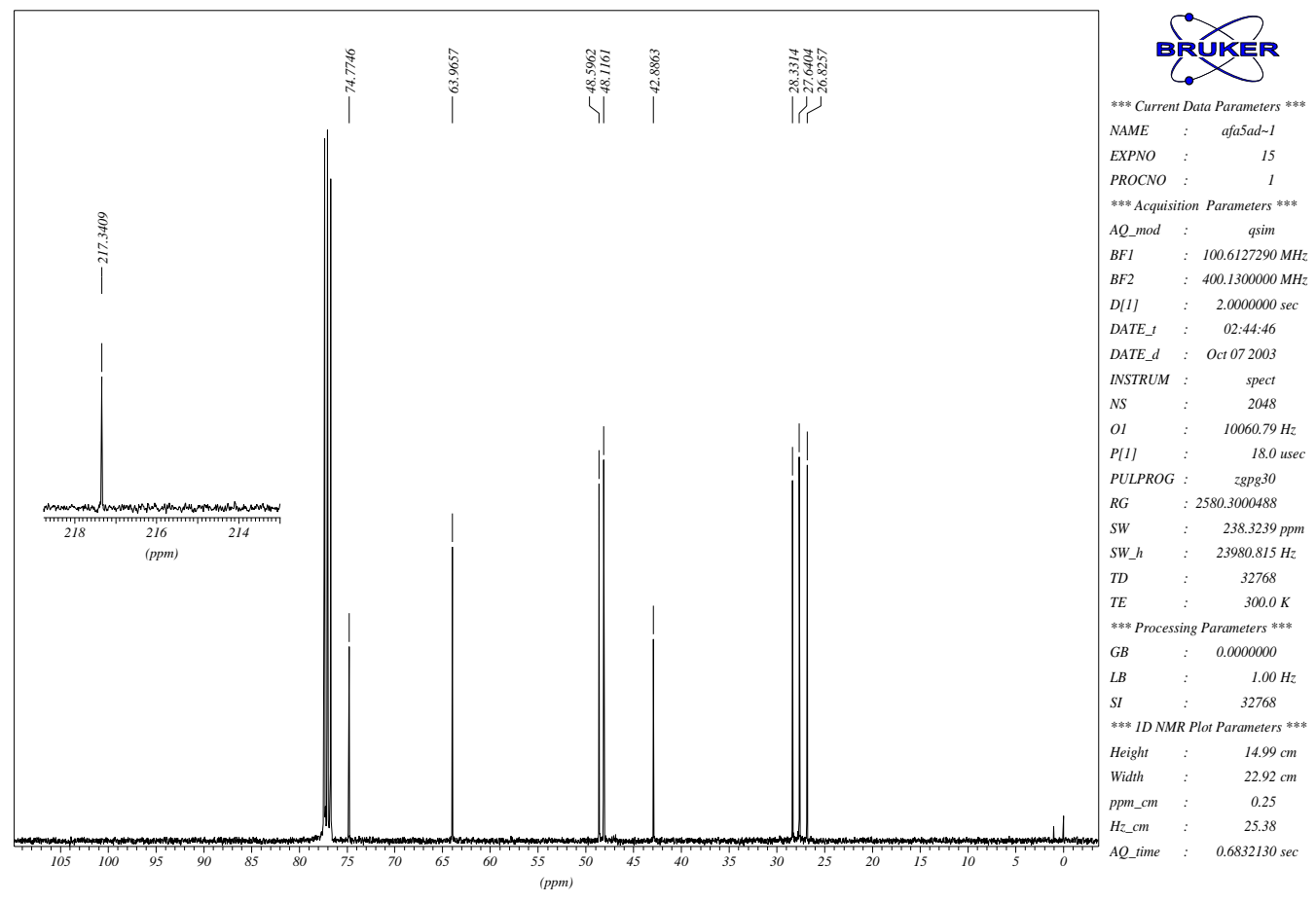

Espectro de ${ }^{13} \mathrm{C}-\mathrm{RMN}(\mathrm{DEPT}-135)\left(\mathrm{CDCl}_{3}, 100 \mathrm{MHz}\right)$ do composto $51 \mathrm{~b}$ :

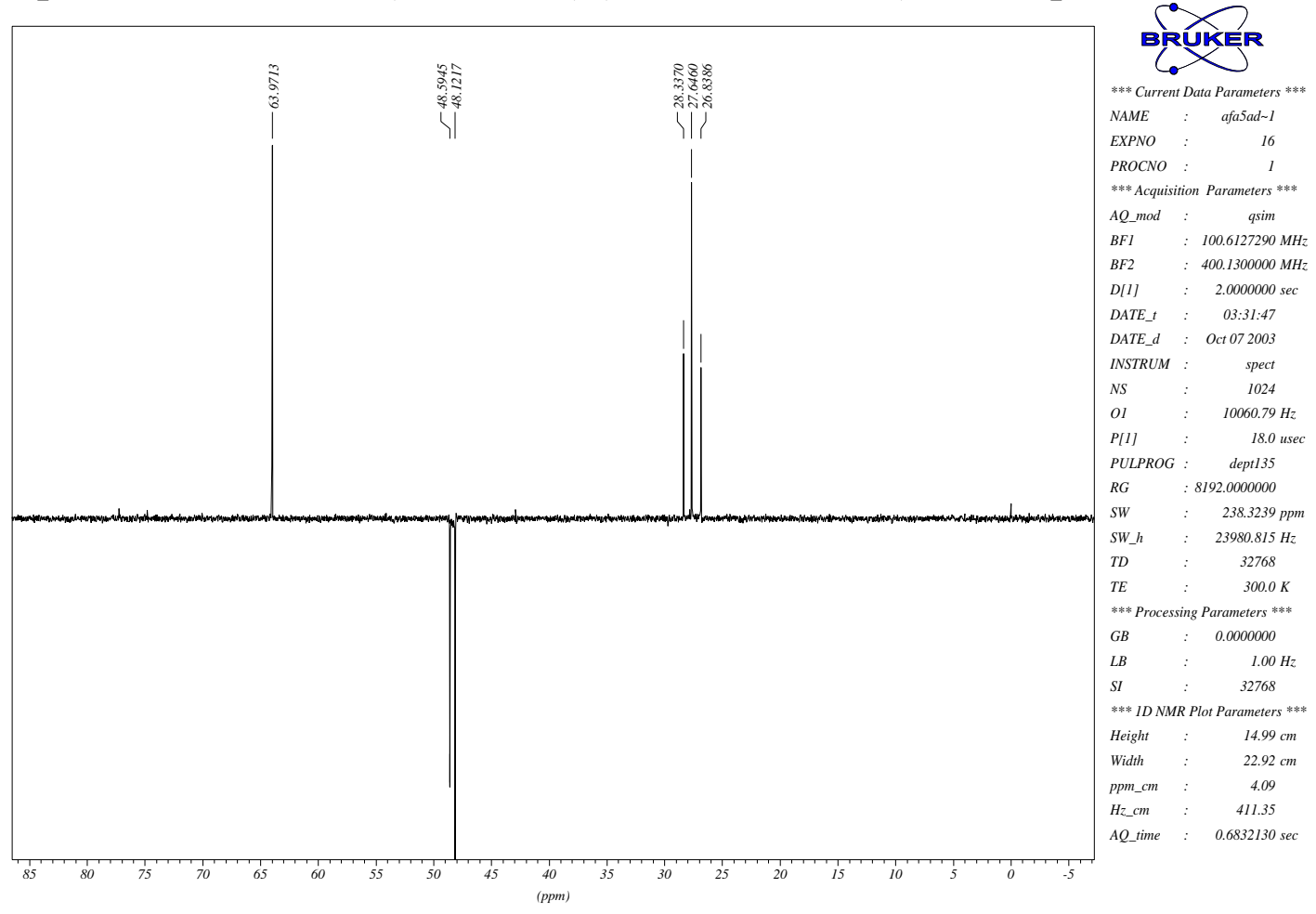


Tabela 31 - Dados espectrais de ${ }^{13} \mathrm{C}-\mathrm{RMN}\left\{{ }^{1} \mathrm{H}\right\}$ do composto $\mathbf{5 1 b}$.

\begin{tabular}{cc}
\hline$\delta$ (ppm) & Atribuição* \\
\hline 217,3 & $\mathrm{C}_{6}$ \\
74,8 & $\mathrm{C}_{5}$ \\
64,0 & $\mathrm{C}_{3}$ \\
48,6 & $\mathrm{C}_{2}$ \\
48,1 & $\mathrm{C}_{4}$ \\
42,9 & $\mathrm{C}_{1}$ \\
28,3 & $\mathrm{C}_{9}$ \\
27,6 & $\mathrm{C}_{7}^{* *}$ \\
26,8 & $\mathrm{C}_{8}^{* *}$ \\
\hline
\end{tabular}

* os carbonos foram atribuídos utilizando HMQC

** podem estar trocados 


\section{Espectro de IV do composto 51b:}

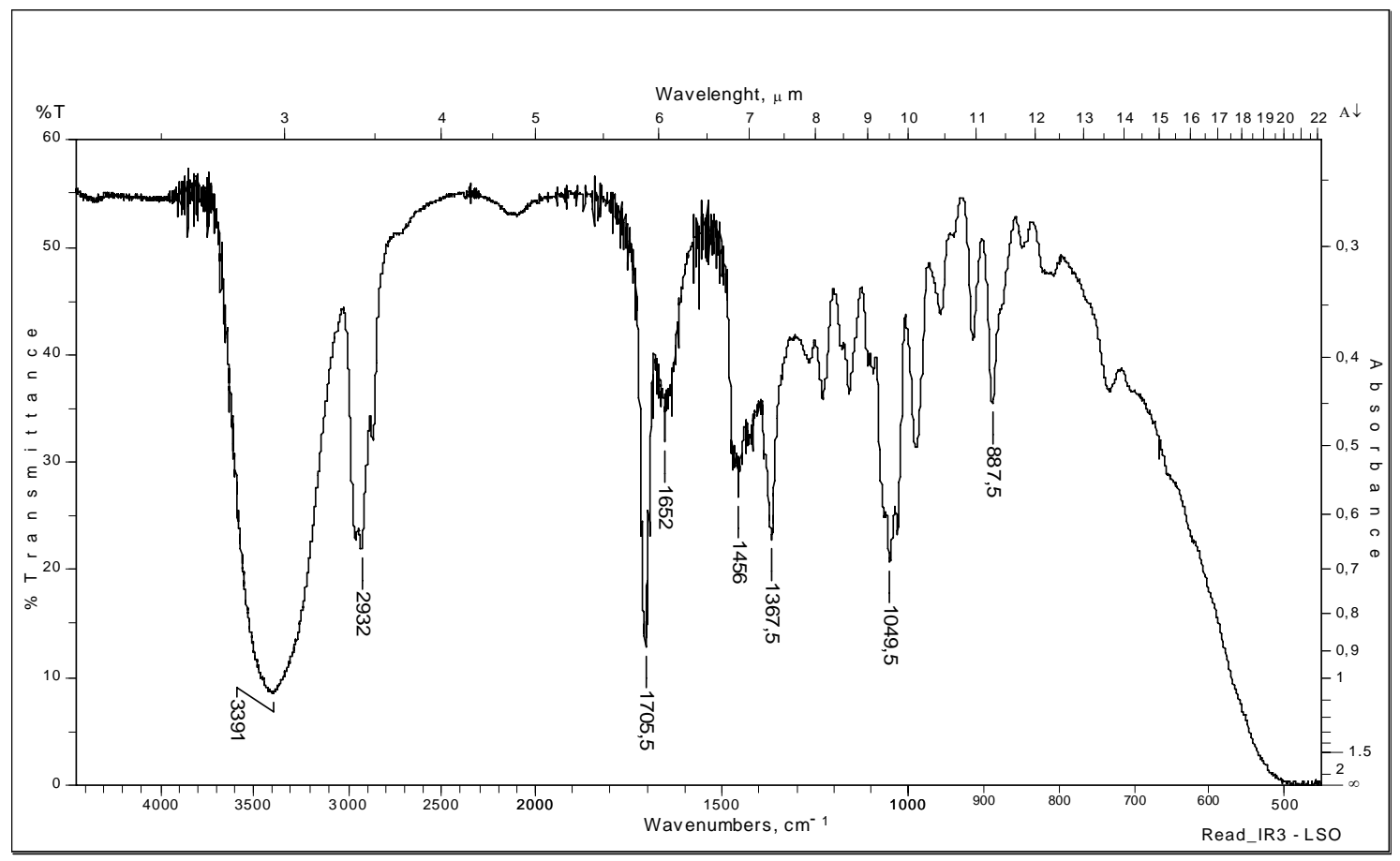

Tabela 32 - Dados espectrais de IV do composto $\mathbf{5 1 b .}$

\begin{tabular}{cl}
\hline$v\left(\mathbf{c m}^{-1}\right)$ & \multicolumn{1}{c}{ Atribuição } \\
\hline 3391 & Deformação axial de OH \\
1705 & Deformação axial de C=O \\
1367 & Deformação angular no plano de OH \\
1049 & Deformação axial de C-O do álcool \\
\hline
\end{tabular}




\section{Composto 52}

\section{Espectro de ${ }^{1} \mathrm{H}-\mathrm{RMN}\left(\mathrm{CDCl}_{3}, 400 \mathrm{MHz}\right)$ :}
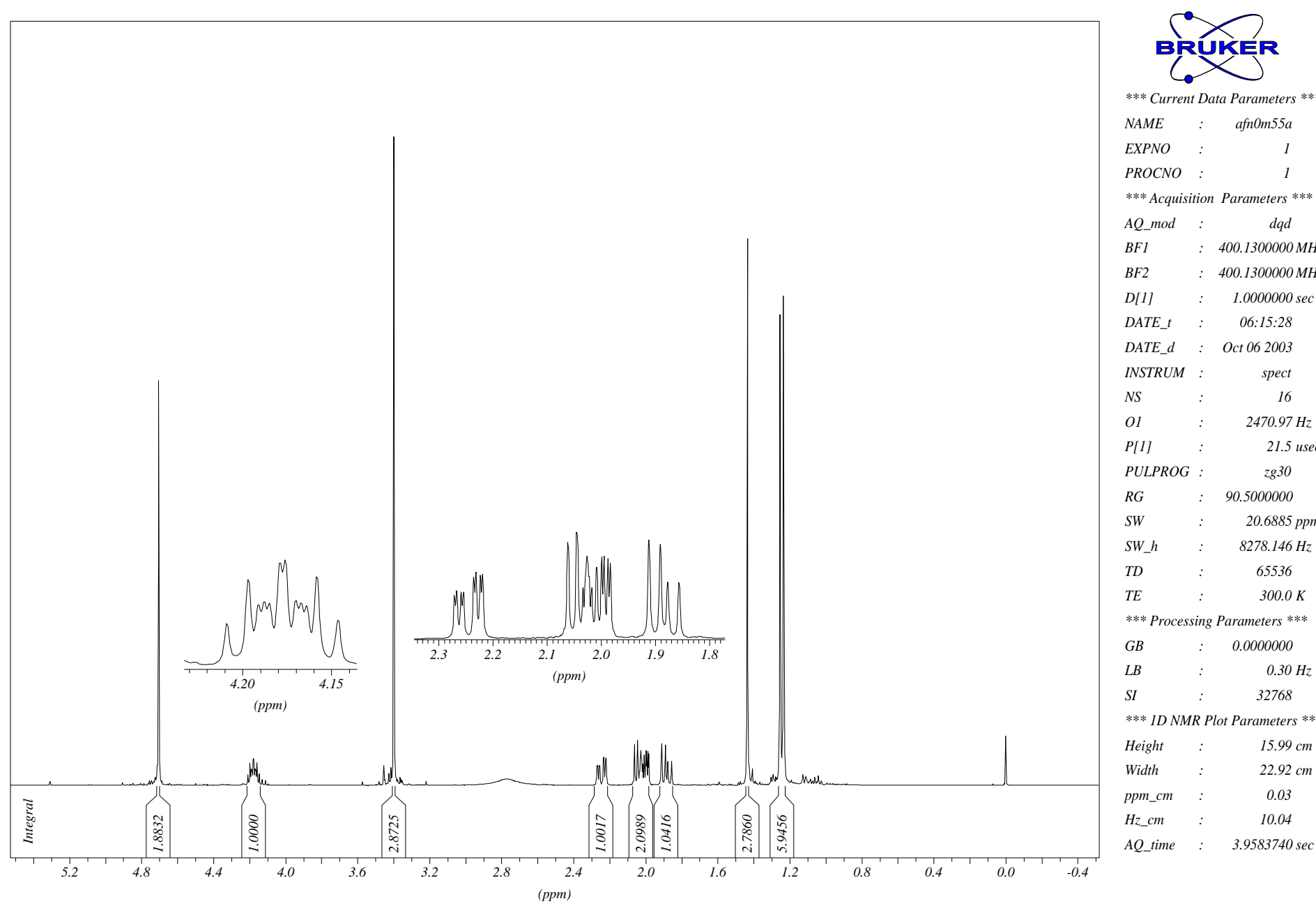

NAME : afnOm55a

EXPNO

PROCNO :

*** Acquisition Parameters **

$A Q \_$mod : $\quad d q d$

$B F 1 \quad: \quad 400.1300000 \mathrm{MHz}$

$\begin{array}{lll}B F 1 & : & 400.1300000 \mathrm{MHz} \\ B F 2 & : & 400.1300000 \mathrm{MHz}\end{array}$

D[1] : $1.0000000 \mathrm{sec}$

DATE_t : $\quad 06: 15: 28$

DATE_d : Oct 062003

INSTRUM : spect

NS : $\quad 16$

O1 : $\quad 2470.97 \mathrm{~Hz}$

P[1] : $\quad 21.5$ usec

PULPROG : $\quad$ zg30

$R G \quad: \quad 90.5000000$

SW $\quad: \quad 20.6885 \mathrm{ppm}$

SW_h : $\quad 8278.146 \mathrm{~Hz}$

TD : $\quad 65536$

TE : $\quad 300.0 \mathrm{~K}$

*** Processing Parameters ***

GB : 0.0000000

$L B \quad: \quad 0.30 \mathrm{~Hz}$

SI : 32768

***1D NMR Plot Parameters ***

Height : $\quad 15.99 \mathrm{~cm}$

Width : $\quad 22.92 \mathrm{~cm}$

ppm_cm : $\quad 0.03$

Hz_cm : 10.04

AQ_time : $\quad 3.9583740 \mathrm{sec}$ 
Tabela 33 - Dados espectrais de ${ }^{1} \mathrm{H}-\mathrm{RMN}$ do composto 52.

\begin{tabular}{cccc}
\hline$\delta$ (ppm) & Atribuição & Sinal & $J \mathbf{~ H z})$ \\
\hline 4,70 & $\mathrm{H}_{10,} \mathrm{H}_{10^{\prime}}$ & $\mathrm{s}$ & \\
4,18 & $\mathrm{H}_{3}$ & $\mathrm{dt}$ & $J_{3,2 a x}=8,3 ; J_{3,4 a x}=7,1 ; J_{3,2 e q}=J_{3,4 e q}=4,8$ \\
3,40 & $\mathrm{H}_{11}$ & $\mathrm{~s}$ & \\
2,77 & $\mathrm{OH}$ & $\mathrm{sl}$ & $J_{4 e q, 4 a x}=14,2 ; J_{4 e q, 3}=4,8 ; J_{4 e q, 2 e q}=1,8$ \\
2,24 & $\mathrm{H}_{4 \mathrm{eq}}$ & $\mathrm{ddd}$ & $J_{4 a x, 4 e q}=14,2 ; J_{4 a x, 3}=7,1$ \\
2,04 & $\mathrm{H}_{4 a x}$ & $\mathrm{dd}$ & $J_{2 e q, 2 a x}=13,9 ; J_{2 e q, 3}=4,8 ; J_{2 e q, 4 e q}=1,8$ \\
2,01 & $\mathrm{H}_{2 \mathrm{eq}}$ & $\mathrm{ddd}$ & $J_{2 a x, 2 e q}=13,9 ; J_{2 a x, 3}=8,3$ \\
1,88 & $\mathrm{H}_{2 \mathrm{ax}}$ & $\mathrm{dd}$ & \\
1,43 & $\mathrm{H}_{9}$ & $\mathrm{~s}$ & \\
1,25 & $\mathrm{H}_{7}{ }^{*}$ & $\mathrm{~s}$ & \\
1,23 & $\mathrm{H}_{8}{ }^{*}$ & $\mathrm{~s}$ & \\
\hline
\end{tabular}


Espectro de ${ }^{13} \mathrm{C}-\mathrm{RMN}\left\{{ }^{1} \mathrm{H}\right\}\left(\mathrm{CDCl}_{3}, 100 \mathrm{MHz}\right)$ do composto 52:

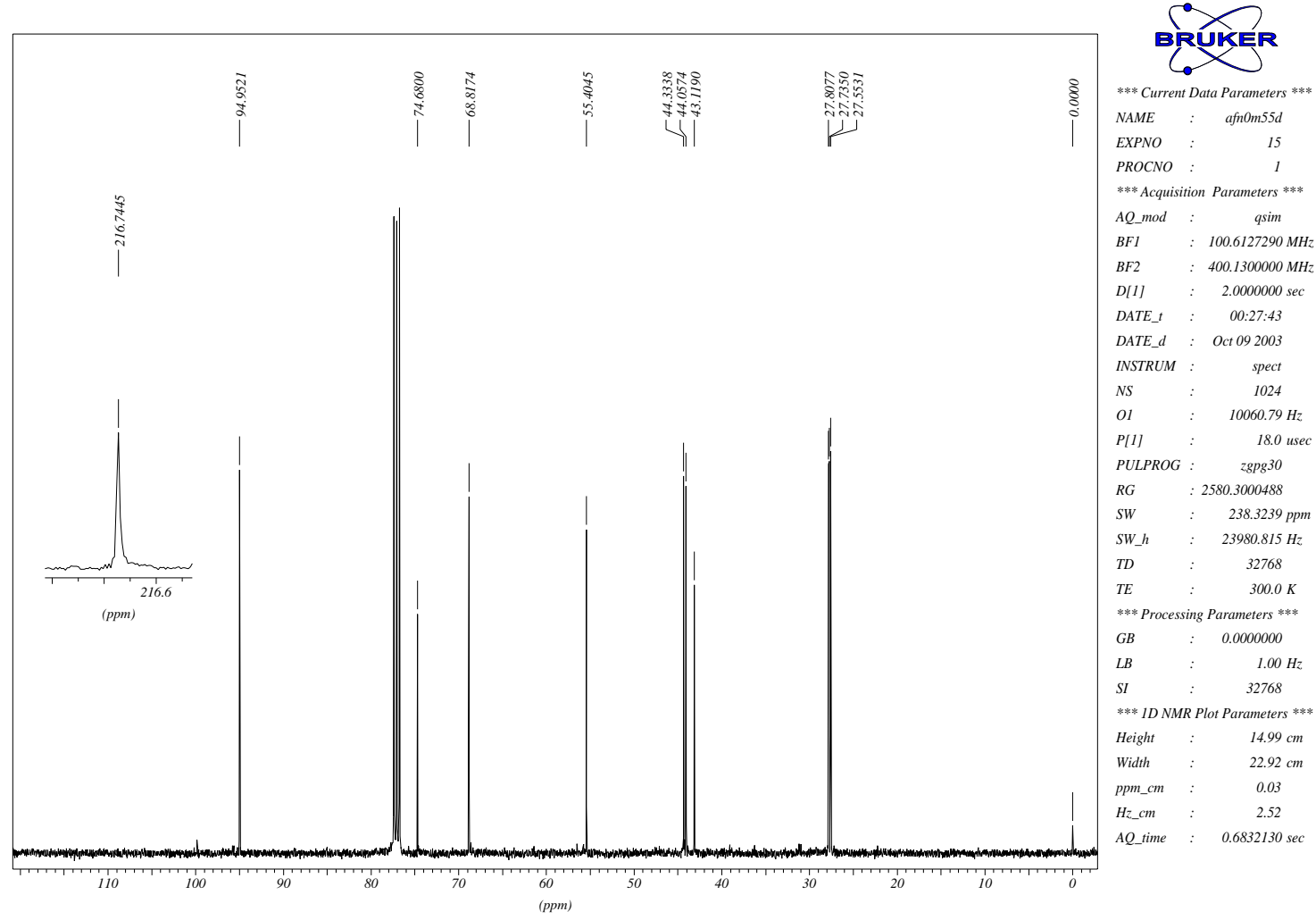

Espectro de ${ }^{13} \mathrm{C}-\mathrm{RMN}(\mathrm{DEPT}-135)\left(\mathrm{CDCl}_{3}, 100 \mathrm{MHz}\right)$ do composto 52:
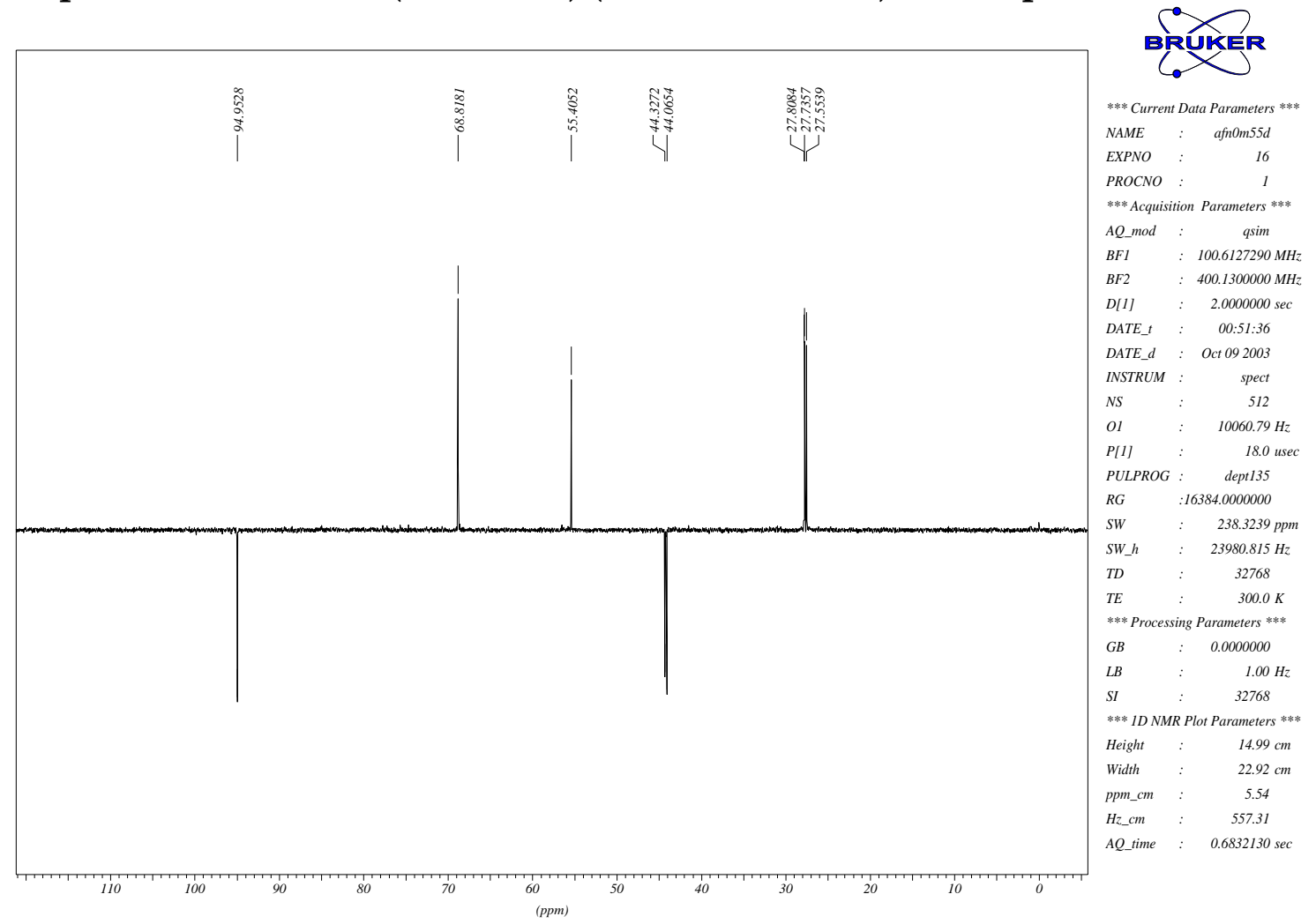
Tabela 34 - Dados espectrais de ${ }^{13} \mathrm{C}-\mathrm{RMN}\left\{{ }^{1} \mathrm{H}\right\}$ do composto 52.

\begin{tabular}{cc}
\hline$\delta($ ppm $)$ & Atribuição* $^{*}$ \\
\hline 216,7 & $\mathrm{C}_{6}$ \\
94,9 & $\mathrm{C}_{10}$ \\
74,7 & $\mathrm{C}_{5}$ \\
68,8 & $\mathrm{C}_{3}$ \\
55,4 & $\mathrm{C}_{11}$ \\
44,3 & $\mathrm{C}_{2}$ \\
44,0 & $\mathrm{C}_{4}$ \\
43,1 & $\mathrm{C}_{1}$ \\
27,8 & $\mathrm{C}_{9}$ \\
27,7 & $\mathrm{C}_{7}^{* *}$ \\
27,5 & $\mathrm{C}_{8}^{* *}$
\end{tabular}

* Os carbonos foram atribuídos utilizando HMQC

** Podem estar trocados 
Espectro de IV do composto 52:

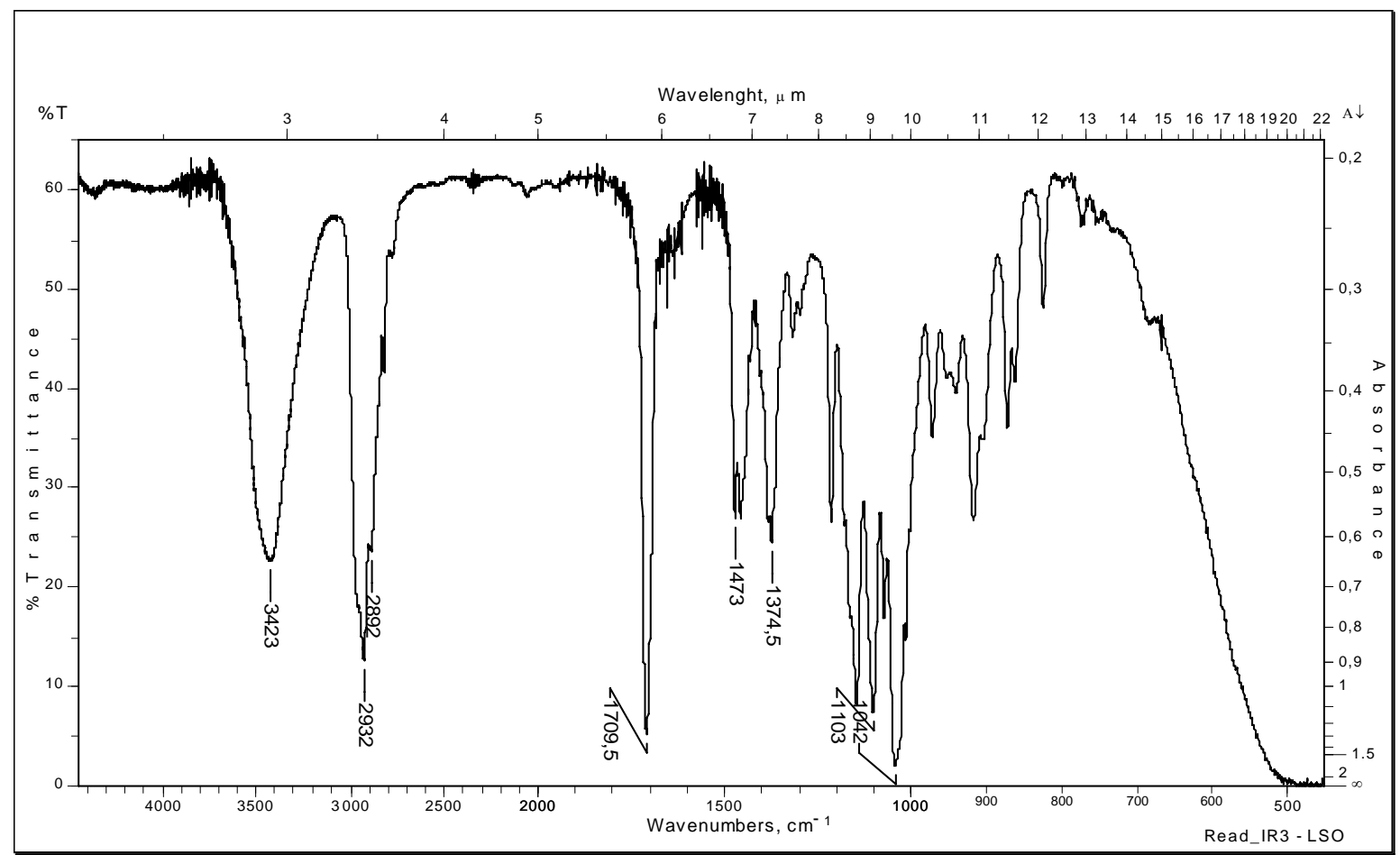

Tabela 35 - Dados espectrais de IV do composto 52.

\begin{tabular}{cl}
\hline$v\left(\mathbf{c m}^{-1}\right)$ & \multicolumn{1}{c}{ Atribuição } \\
\hline 3423 & Deformação axial de OH \\
1709 & Deformação axial de C=O \\
1374 & Deformação angular no plano de OH \\
1103 & Deformação axial assimétrica de C-O-C \\
1042 & Deformação axial simétrica de C-O-C \\
\hline
\end{tabular}




\section{Composto 53}

Espectro de ${ }^{1} \mathrm{H}-\mathrm{RMN}\left(\mathrm{CDCl}_{3}, 400 \mathrm{MHz}\right)$ :
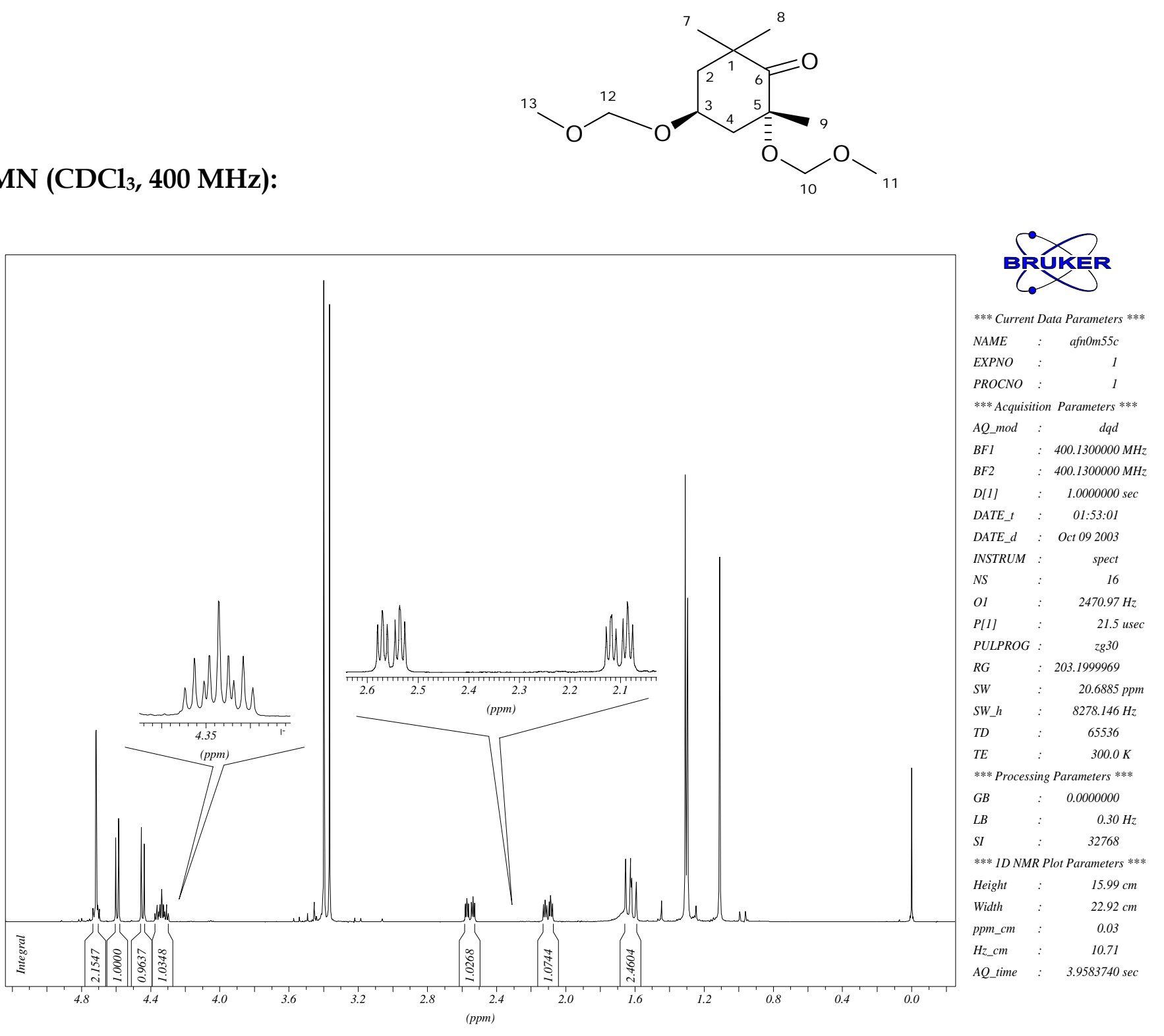
Tabela 36 - Dados espectrais de ${ }^{1} \mathrm{H}-\mathrm{RMN}$ do composto 53.

\begin{tabular}{|c|c|c|c|}
\hline$\delta(\mathrm{ppm})$ & Atribuição & Sinal & $J(\mathrm{~Hz})$ \\
\hline 4,72 & $\mathrm{H}_{12}{ }^{*}$ & $\mathrm{~d}$ & $J_{12,12^{\prime}}=7,1$ \\
\hline 4,70 & $\mathrm{H}_{12^{\prime}}{ }^{*}$ & d & $J_{12^{\prime}, 12}=7,1$ \\
\hline 4,59 & $\mathrm{H}_{10}$ ** & d & $J_{10,10^{\prime}}=7,1$ \\
\hline 4,45 & $\mathrm{H}_{10^{\prime}}^{* *}$ & $\mathrm{~d}$ & $J_{10^{\prime}, 10}=7,1$ \\
\hline 4,33 & $\mathrm{H}_{3}$ & $\mathrm{tt}$ & $J_{3,2 a x}=J_{3,4 a x}=11,1 ; J_{3,2 e q}=J_{3,4 e q}=4,3$ \\
\hline 3,40 & $\mathrm{H}_{13}{ }^{\#}$ & $\mathrm{~s}$ & \\
\hline 3,36 & $\mathrm{H}_{11} \#$ & s & \\
\hline 2,55 & $\mathrm{H}_{4 \mathrm{eq}}$ & ddd & $J_{4 e q, 4 a x}=13,9 ; J_{4 e q, 3}=4,3 ; J_{4 e q, 2 e q}=3,5$ \\
\hline 2,10 & $\mathrm{H}_{2 \mathrm{eq}}$ & ddd & $J_{2 e q, 2 a x}=13,1 ; J_{2 e q, 3}=4,3 ; J_{2 e q, 4}, 4 e q=3,5$ \\
\hline 1,63 & $\mathrm{H}_{2 \mathrm{ax}}$ & $\mathrm{dd}$ & $J_{2 a x, 2 e q}=13,1 ; J_{2 a x, 3}=11,1$ \\
\hline 1,62 & $\mathrm{H}_{4 \mathrm{ax}}$ & $\mathrm{dd}$ & $J_{4 a x, 4 e q}=13,9 ; J_{4 a x, 3}=11,1$ \\
\hline 1,31 & $\mathrm{H}_{7}^{\# \#}$ & $\mathrm{~s}$ & \\
\hline 1,29 & $\mathrm{H}_{8}^{\# \#}$ & $\mathrm{~s}$ & \\
\hline 1,11 & $\mathrm{H}_{9}$ & $\mathrm{~s}$ & \\
\hline
\end{tabular}


Espectro de ${ }^{13} \mathrm{C}-\mathrm{RMN}\left\{{ }^{1} \mathrm{H}\right\}\left(\mathrm{CDCl}_{3}, 100 \mathrm{MHz}\right)$ do composto 53:

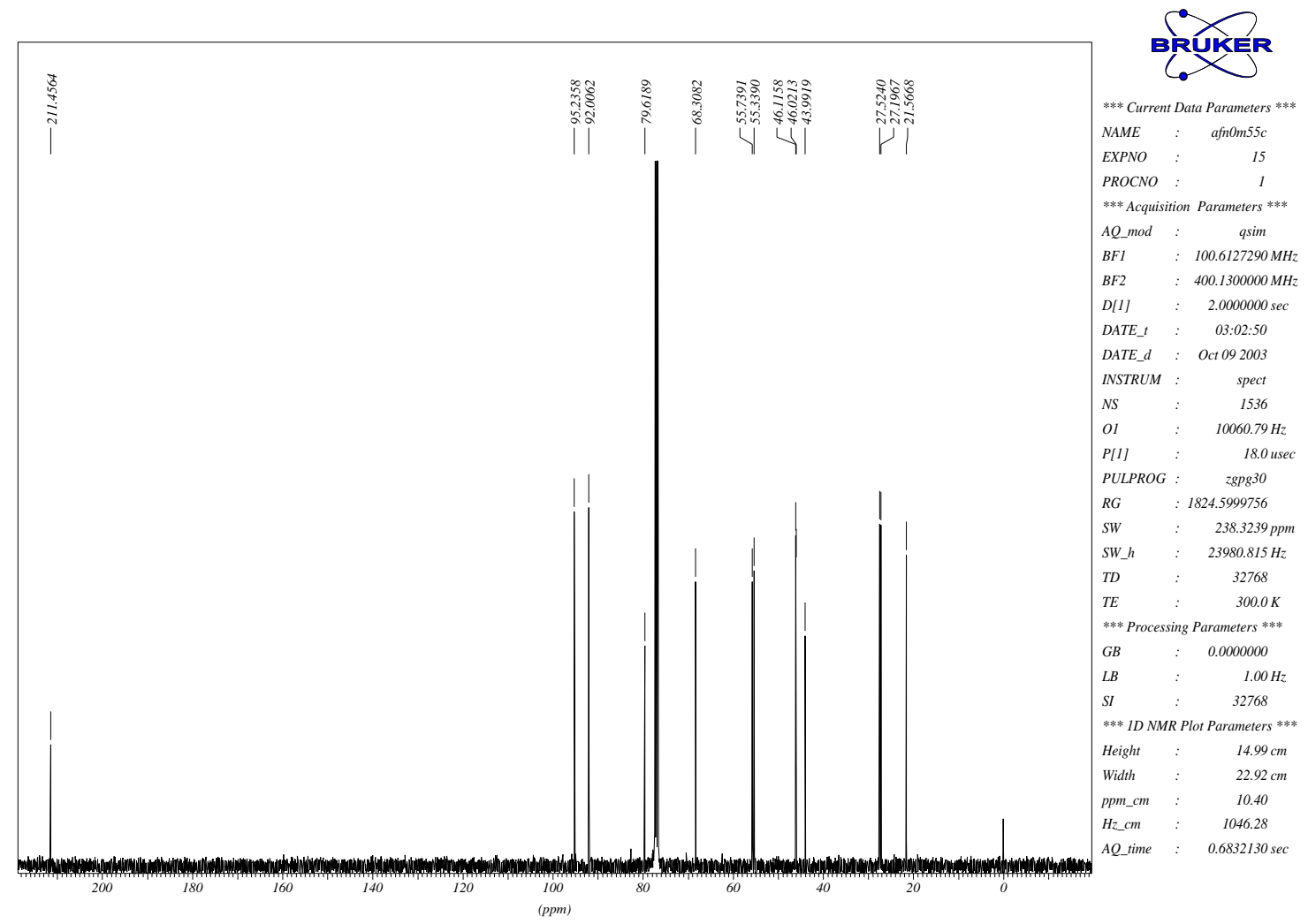

Espectro de ${ }^{13} \mathrm{C}-\mathrm{RMN}(\mathrm{DEPT}-135)\left(\mathrm{CDCl}_{3}, 100 \mathrm{MHz}\right)$ do composto 53:

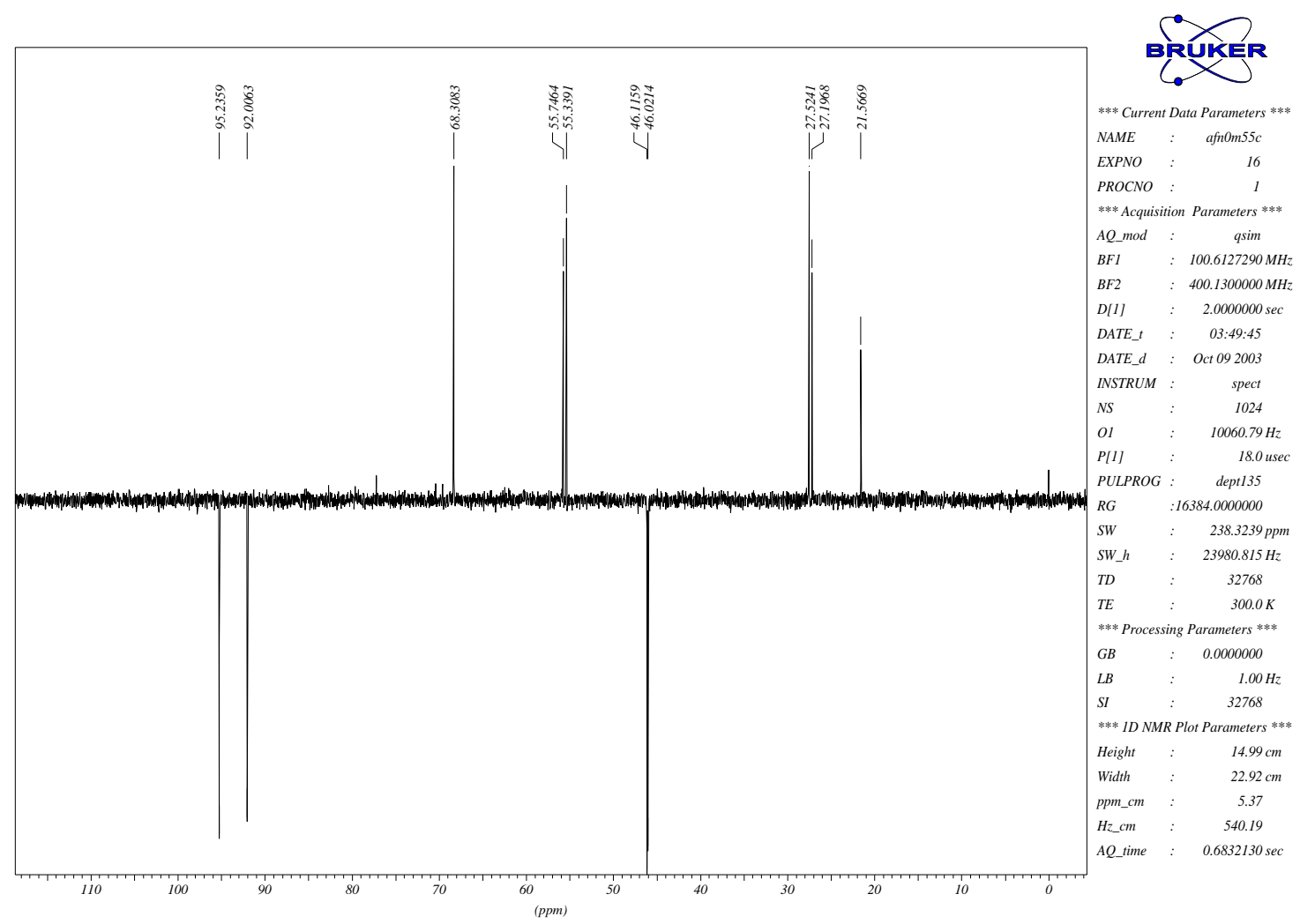


Tabela 37 - Dados espectrais de ${ }^{13} \mathrm{C}-\mathrm{RMN}\left\{{ }^{1} \mathrm{H}\right\}$ do composto 53.

\begin{tabular}{cc}
\hline$\delta(\mathbf{p p m})$ & Atribuiçãö $^{\#}$ \\
\hline 211,4 & $\mathrm{C}_{6}$ \\
95,2 & $\mathrm{C}_{12}$ \\
92,0 & $\mathrm{C}_{10}$ \\
79,6 & $\mathrm{C}_{5}$ \\
68,3 & $\mathrm{C}_{3}$ \\
55,7 & $\mathrm{C}_{11}{ }^{*}$ \\
55,3 & $\mathrm{C}_{13}{ }^{*}$ \\
46,1 & $\mathrm{C}_{2}$ \\
46,0 & $\mathrm{C}_{4}$ \\
44,0 & $\mathrm{C}_{1}$ \\
27,5 & $\mathrm{C}_{9}$ \\
27,2 & $\mathrm{C}_{7}^{* *}$ \\
21,6 & $\mathrm{C}_{8}^{* *}$
\end{tabular}

\# os carbonos foram atribuídos utilizando HMQC

$*, * *$ podem estar trocados 
Espectro de IV do composto 53:

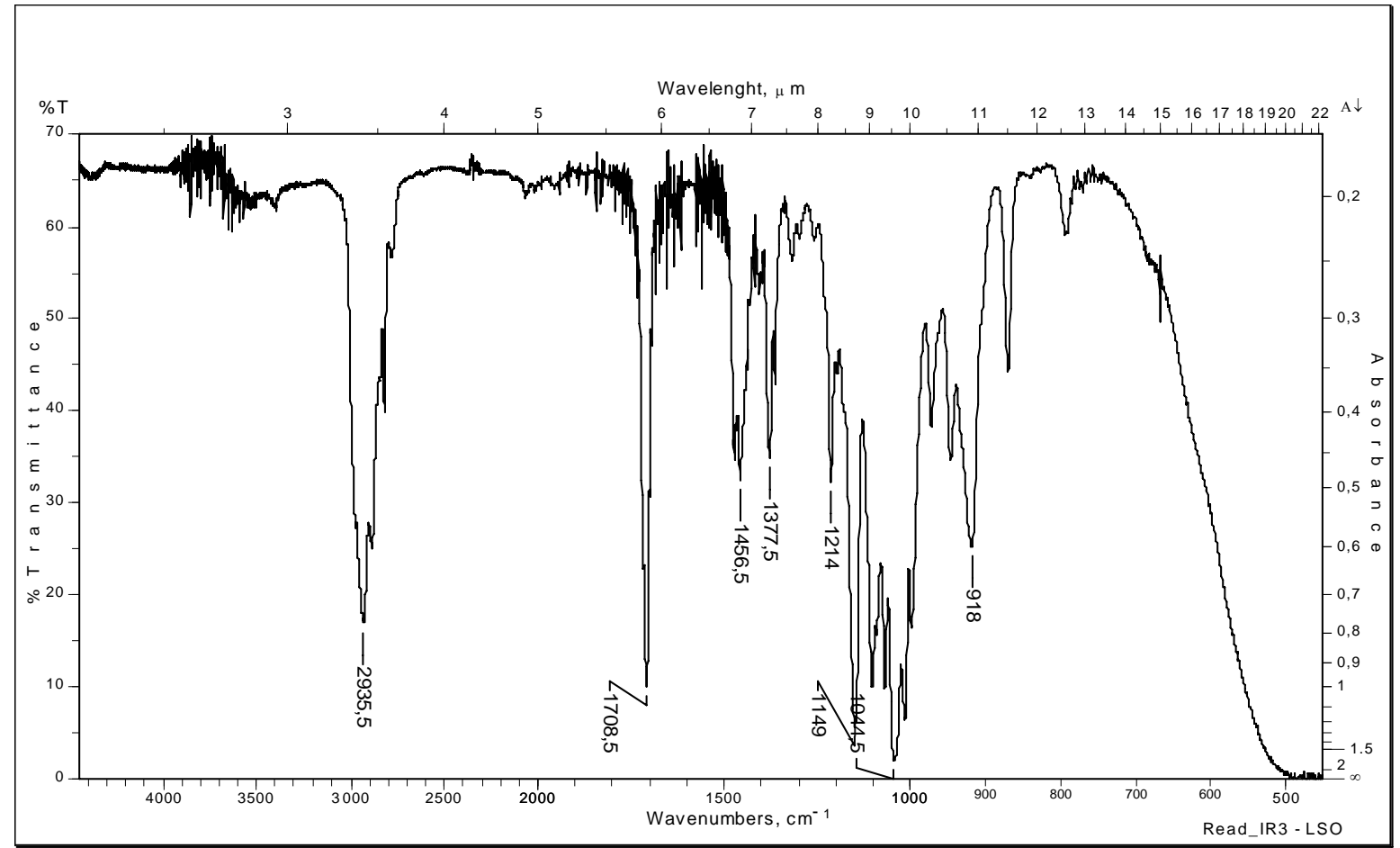

Tabela 38 - Dados espectrais de IV do composto 53.

\begin{tabular}{cl}
\hline$v\left(\mathbf{c m}^{-1}\right)$ & \multicolumn{1}{c}{ Atribuição* $^{*}$} \\
\hline 1708 & Deformação axial de C=O \\
1149 & Deformação axial assimétrica de C-O-C \\
1102 & Deformação axial assimétrica de C-O-C \\
1044 & Deformação axial simétrica de C-O-C \\
\hline
\end{tabular}




\section{Composto 55}

\section{Espectro de ${ }^{1} \mathrm{H}-\mathrm{RMN}\left(\mathrm{CDCl}_{3}, 400 \mathrm{MHz}\right)$ :}
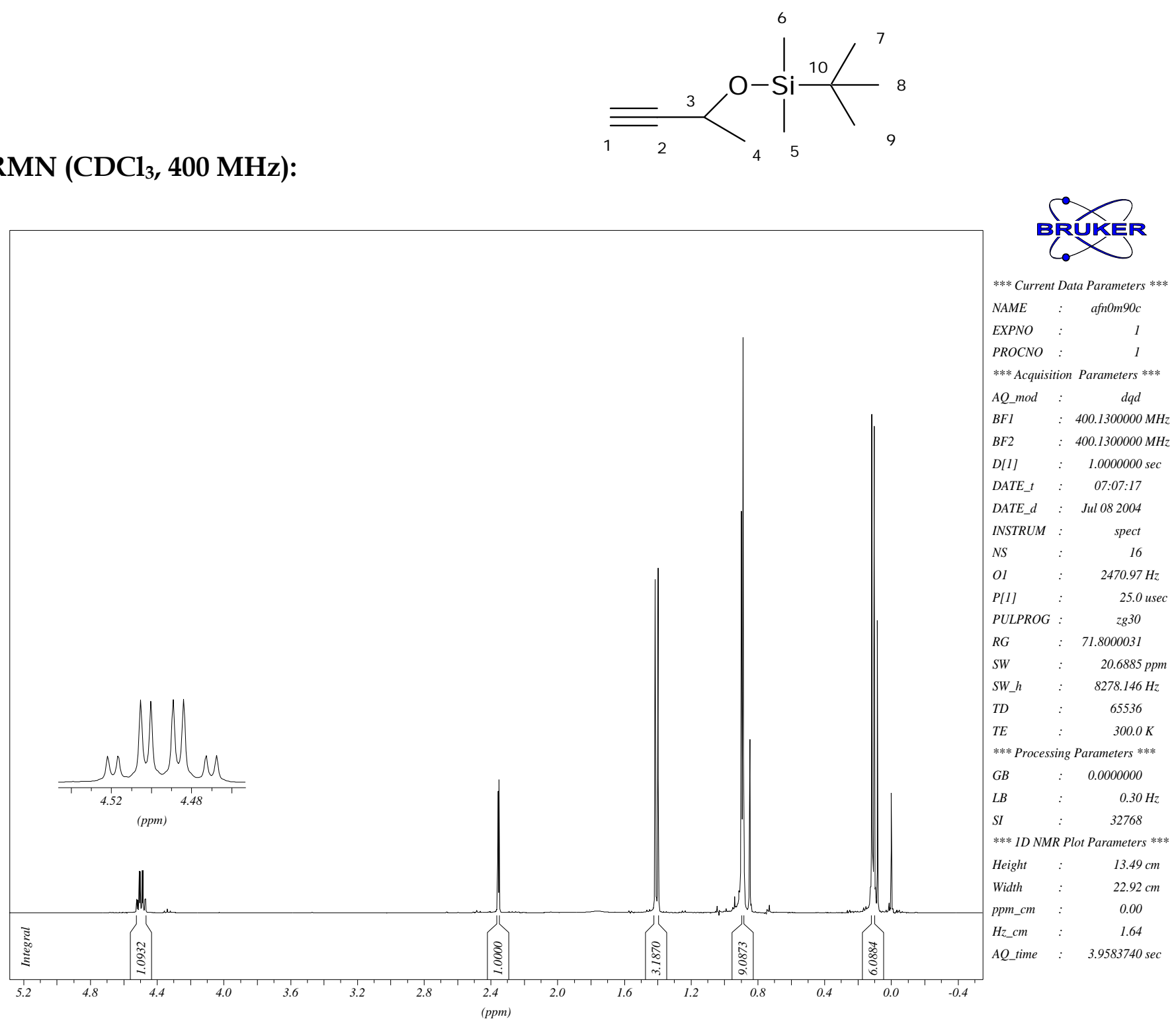
Tabela 39 - Dados espectrais de ${ }^{1} \mathrm{H}-\mathrm{RMN}$ do composto 55.

\begin{tabular}{cccc}
\hline$\delta$ (ppm) & Atribuição & Sinal & $J \mathbf{~ H z})$ \\
\hline 4,50 & $\mathrm{H}_{3}$ & $\mathrm{qd}$ & $J_{3,4}=6,6 ; J_{3,1}=2,0$ \\
2,36 & $\mathrm{H}_{1}$ & $\mathrm{~d}$ & $J_{1,3}=2,0$ \\
1,41 & $\mathrm{H}_{4}$ & $\mathrm{~d}$ & $J_{4,3}=6,6$ \\
0,89 & $\mathrm{H}_{7}, \mathrm{H}_{8}, \mathrm{H}_{9}$ & $\mathrm{~s}$ & \\
0,12 & $\mathrm{H}_{5}{ }^{*}$ & $\mathrm{~s}$ & \\
0,10 & $\mathrm{H}_{6}{ }^{*}$ & $\mathrm{~s}$ & \\
\hline * podem estar trocado & &
\end{tabular}


Espectro de ${ }^{13} \mathrm{C}-\mathrm{RMN}\left\{{ }^{1} \mathrm{H}\right\}\left(\mathrm{CDCl}_{3}, 100 \mathrm{MHz}\right)$ do composto 55:

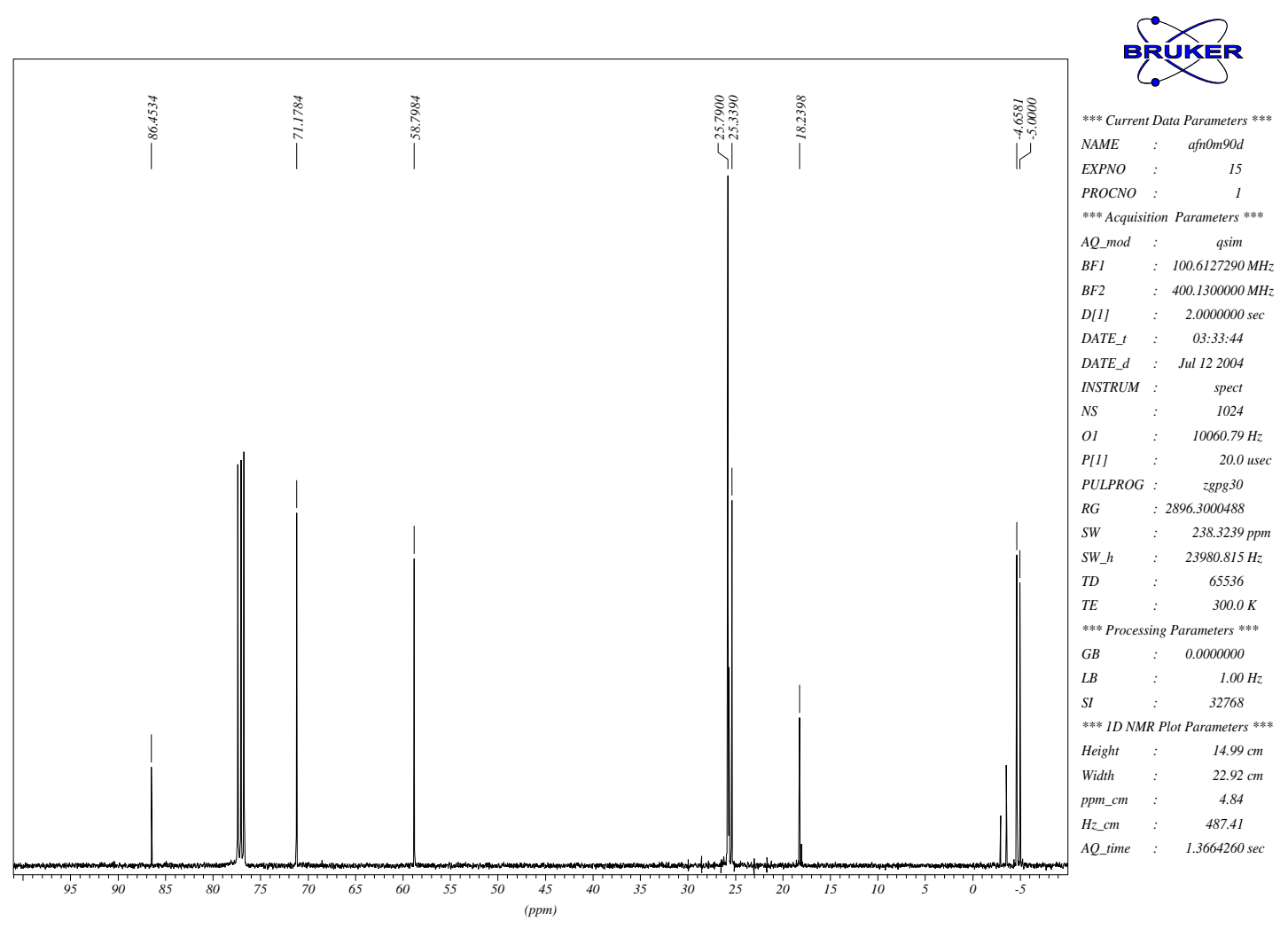

Espectro de ${ }^{13} \mathrm{C}-\mathrm{RMN}(\mathrm{DEPT}-135)\left(\mathrm{CDCl}_{3}, 100 \mathrm{MHz}\right)$ do composto 55:

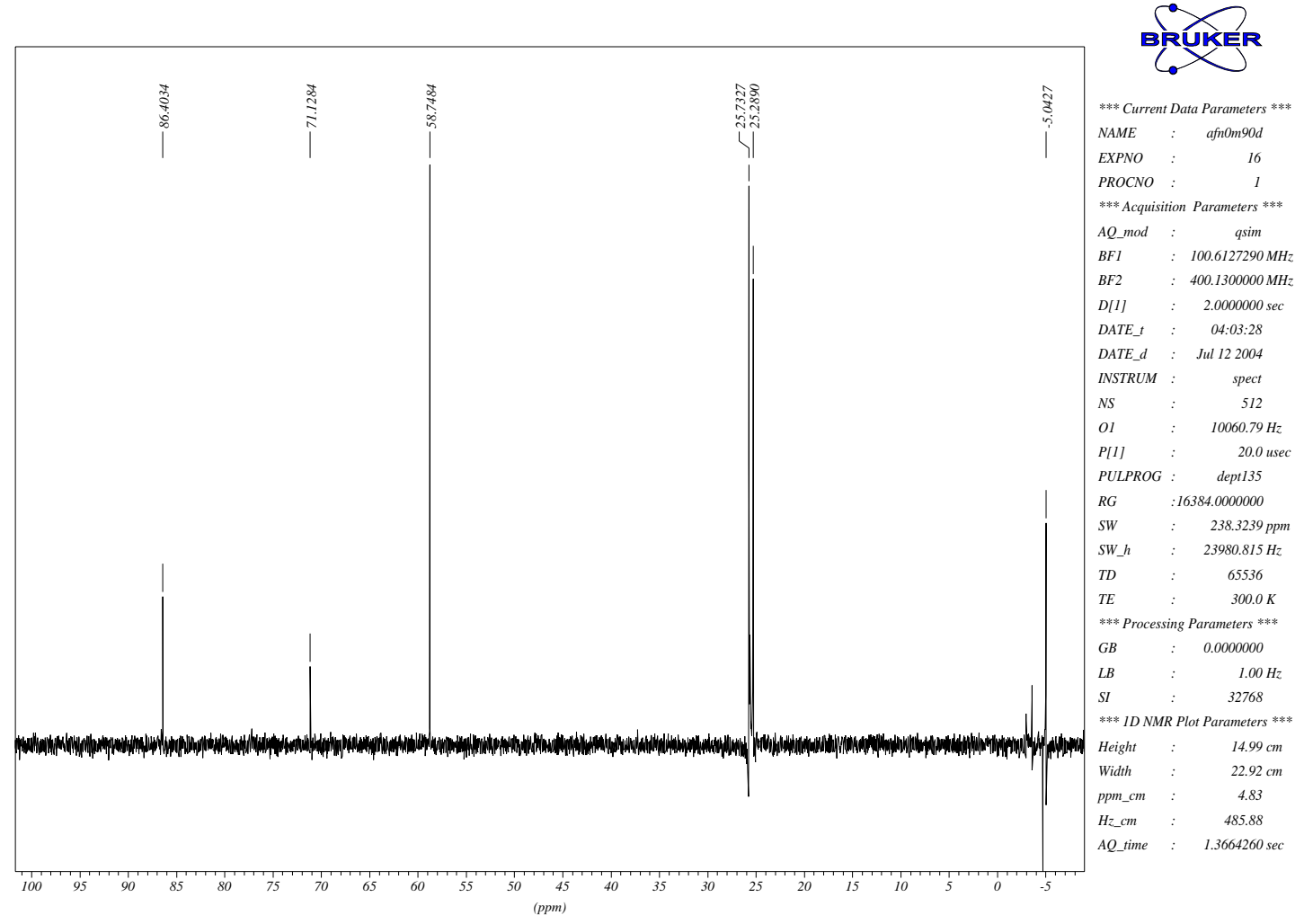


Tabela 40 - Dados espectrais de ${ }^{13} \mathrm{C}-\mathrm{RMN}\left\{{ }^{1} \mathrm{H}\right\}$ do composto 55.

\begin{tabular}{cc}
\hline$\delta($ ppm) & Atribuição \\
\hline 86,4 & $C_{2}$ \\
71,1 & $C_{1}$ \\
58,7 & $C_{3}$ \\
25,7 & $C_{7}, C_{8}, C_{9}$ \\
25,3 & $C_{4}$ \\
18,2 & $C_{10}$ \\
$-5,0$ & $C_{6}{ }^{*}$ \\
$-4,7$ & $C_{5}{ }^{*}$ \\
\hline
\end{tabular}

* podem estar trocados 
Espectro de IV do composto 55:

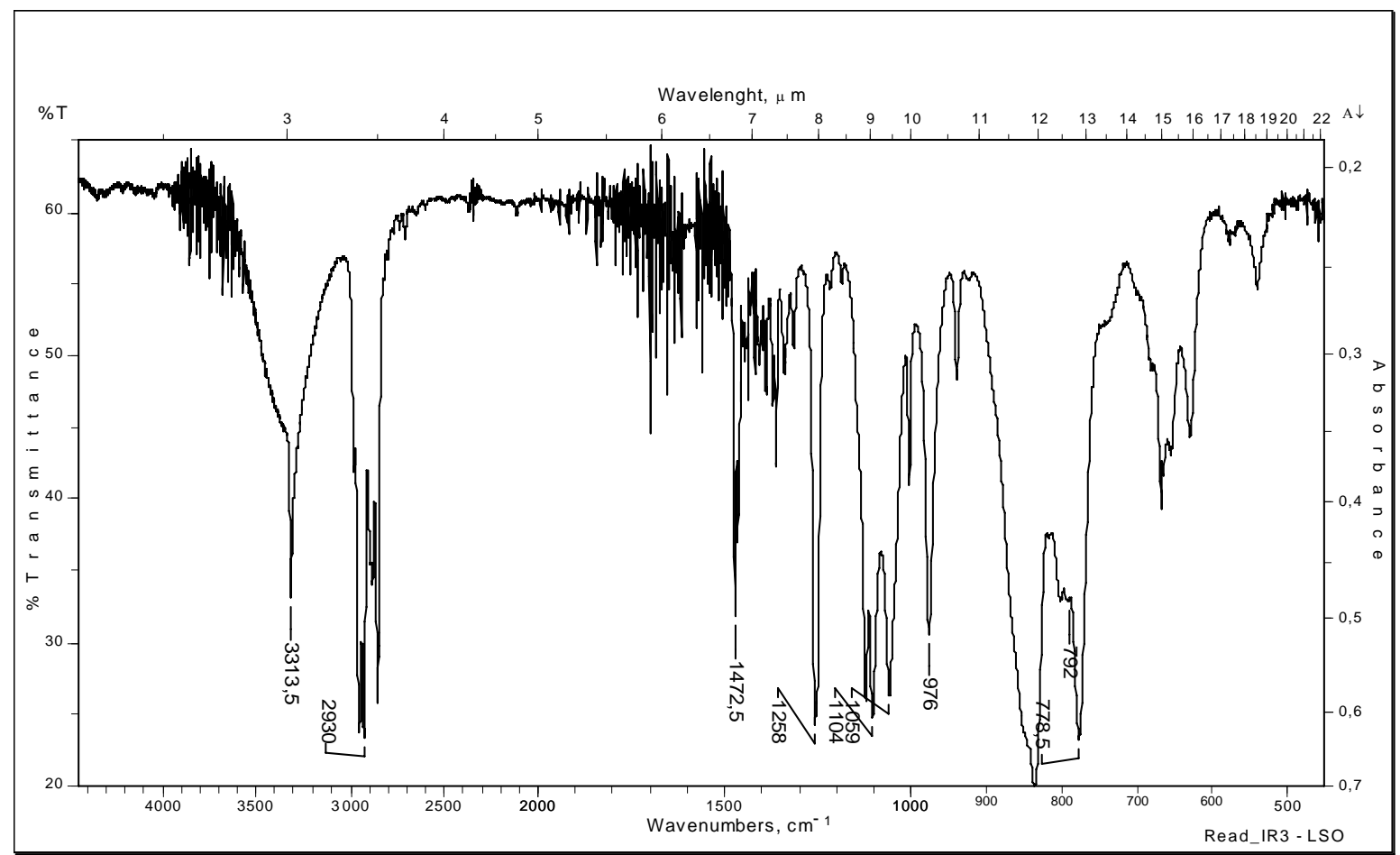

Tabela 41 - Dados espectrais de IV do composto 55.

\begin{tabular}{cl}
\hline$v\left(\mathbf{c m}^{-1}\right)$ & \multicolumn{1}{c}{ Atribuição } \\
\hline 3313 & Deformação axial de C-H da tripla ligação \\
1258 & Deformação axial de CH3-Si \\
1104 & Deformação axial assimétrica de Si-O-C \\
1052 & Deformação axial simétrica de Si-O-C \\
778 & Deformação angular de C-H da tripla ligação. \\
\hline
\end{tabular}




\section{Composto 56}

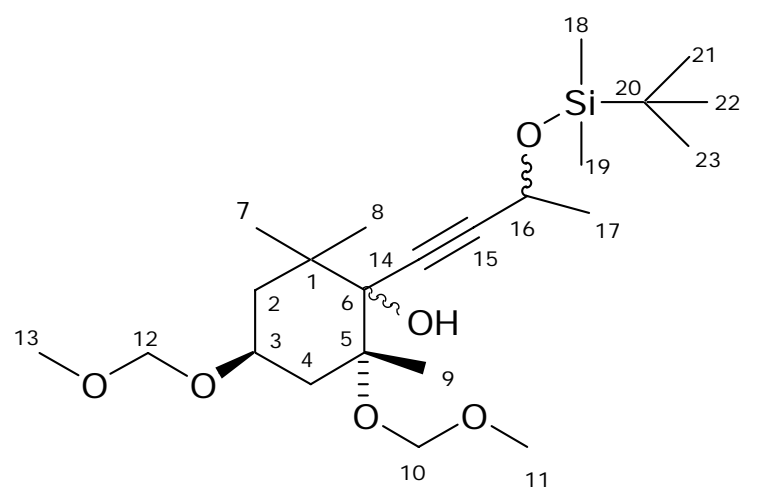

Os espectros de ${ }^{1} \mathrm{H}-\mathrm{RMN}$ e ${ }^{13} \mathrm{C}-\mathrm{RMN}$ apresentados a seguir são de uma mistura de quatro pares de diasteroisômeros do composto 56, onde, todos os sinais aparecem sobrepostos.

A proporção desta mistura é de 1:1:1:1, calculada pelos valores das integrais. 


\section{Espectro de ${ }^{1} \mathrm{H}-\mathrm{RMN}\left(\mathrm{CDCl}_{3}, 400 \mathrm{MHz}\right)$ do composto 56:}

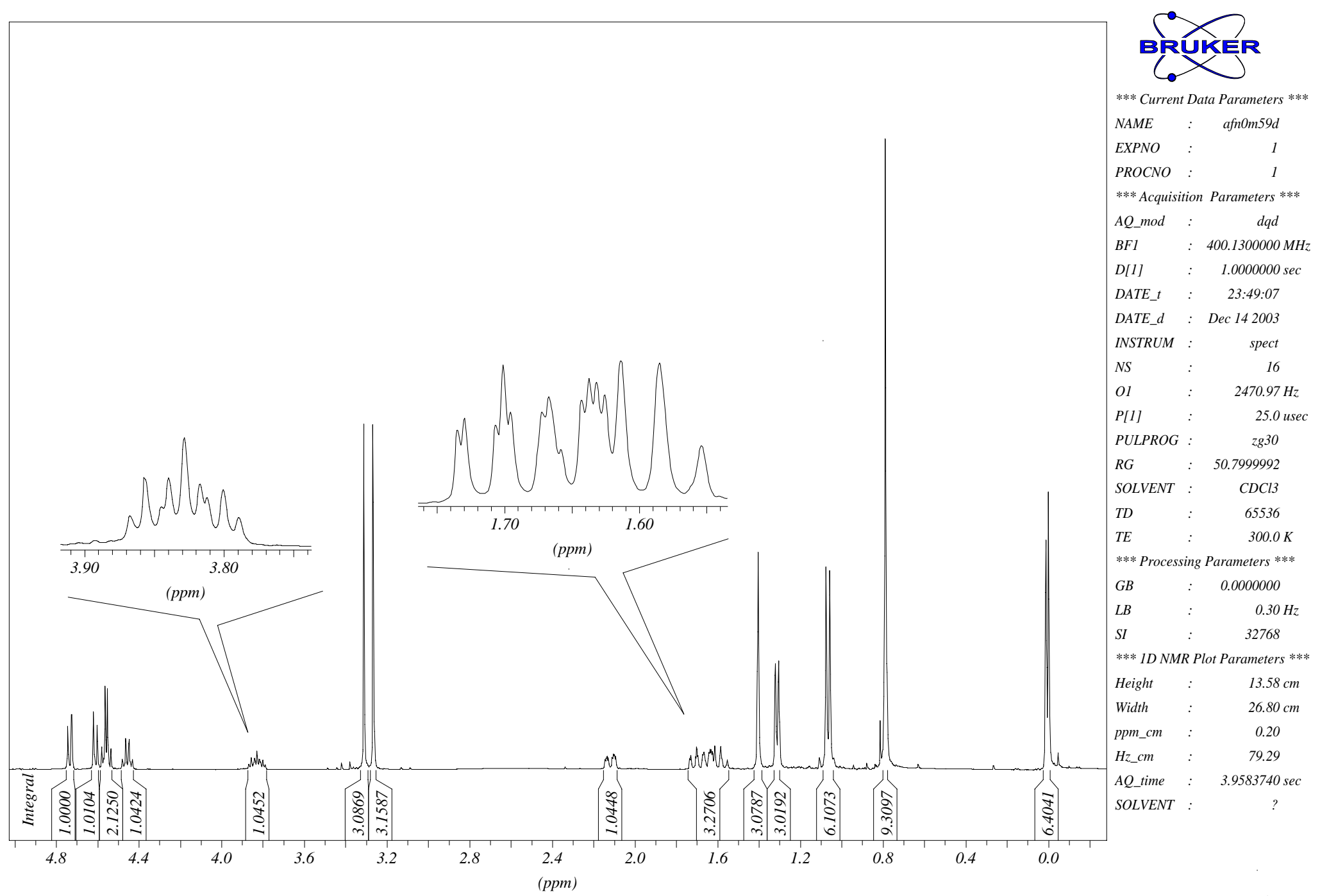


Tabela 42 - Dados espectrais de ${ }^{1} \mathrm{H}-\mathrm{RMN}$ do composto 56.

\begin{tabular}{|c|c|c|c|}
\hline$\delta(\mathrm{ppm})$ & Atribuição & Sinal & $J(\mathrm{~Hz})$ \\
\hline 4,81 & $\mathrm{H}_{10}^{*}$ & d & $J_{10,10^{\prime}}=7,3$ \\
\hline 4,69 & $\mathrm{H}_{10^{*}}{ }^{*}$ & d & $J_{10^{\prime}, 10}=7,3$ \\
\hline 4,65 & $\mathrm{H}_{12}{ }^{* *}$ & d & $J_{12,12^{\prime}}=6,8$ \\
\hline 4,62 & $\mathrm{H}_{12^{* * *}}$ & d & $J_{12^{\prime}, 12}=6,8$ \\
\hline 4,54 & $\mathrm{H}_{16}$ & $q$ & $J_{16,17}=6,6$ \\
\hline 4,53 & $\mathrm{H}_{16}$ & $q$ & $J_{16,17}=6,6$ \\
\hline 3,91 & $\mathrm{H}_{3}$ & $\mathrm{tt}$ & $J_{3,4 a x}=J_{3,2 a x}=11,1 ; J_{3,4 e q}=J_{3,2 e q}=4,3$ \\
\hline 3,38 & $\mathrm{H}_{13}{ }^{* * *}$ & $\mathrm{~s}$ & \\
\hline 3,34 & $\mathrm{H}_{11}^{* * *}$ & $\mathrm{~s}$ & \\
\hline 2,20 & $\mathrm{H}_{4 \mathrm{eq}}$ & ddd & $J_{4 e q, 4 a x}=13,9 ; J_{4 e q, 3}=4,3 ; J_{4 e q, 2 e q}=2,3$ \\
\hline $1,82-1,63$ & $\mathrm{H}_{2 \mathrm{eq}}, \mathrm{H}_{4 \mathrm{ax}}, \mathrm{H}_{2 \mathrm{ax}}$ & $\mathrm{m}$ & \\
\hline 1,47 & $\mathrm{H}_{9}$ & $\mathrm{~s}$ & \\
\hline 1,40 & $\mathrm{H}_{17}$ & $d$ & $J_{17,16}=6,6$ \\
\hline 1,39 & $\mathrm{H}_{17}$ & d & $J_{17,16}=6,6$ \\
\hline 1,14 & $\mathrm{H}_{7}^{\#}$ & $\mathrm{~s}$ & \\
\hline 1,12 & $\mathrm{H}_{8}^{\#}$ & $\mathrm{~s}$ & \\
\hline 0,86 & $\mathrm{H}_{21}, \mathrm{H}_{22}, \mathrm{H}_{23}$ & $\mathrm{~s}$ & \\
\hline 0,08 & $\mathrm{H}_{19}^{\# \#}$ & $\mathrm{~s}$ & \\
\hline 0,07 & $\mathrm{H}_{18} \# \#$ & $\mathrm{~s}$ & \\
\hline
\end{tabular}


Espectro de ${ }^{13} \mathrm{C}-\mathrm{RMN}\left\{{ }^{1} \mathrm{H}\right\}\left(\mathrm{CDCl}_{3}, 100 \mathrm{MHz}\right)$ do composto 56:

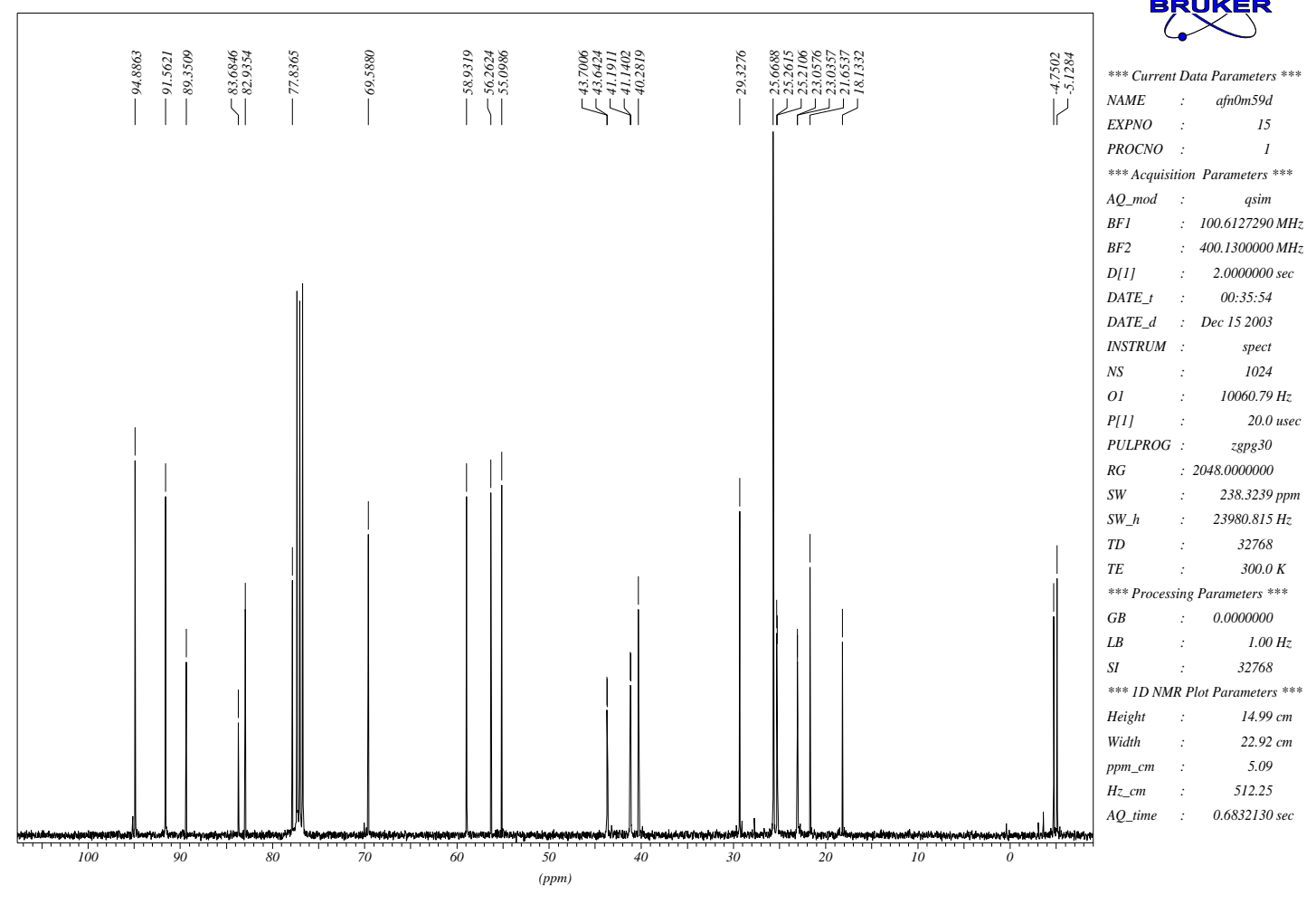

Espectro de ${ }^{13} \mathrm{C}-\mathrm{RMN}(\mathrm{DEPT}-135)\left(\mathrm{CDCl}_{3}, 100 \mathrm{MHz}\right)$ do composto 56:

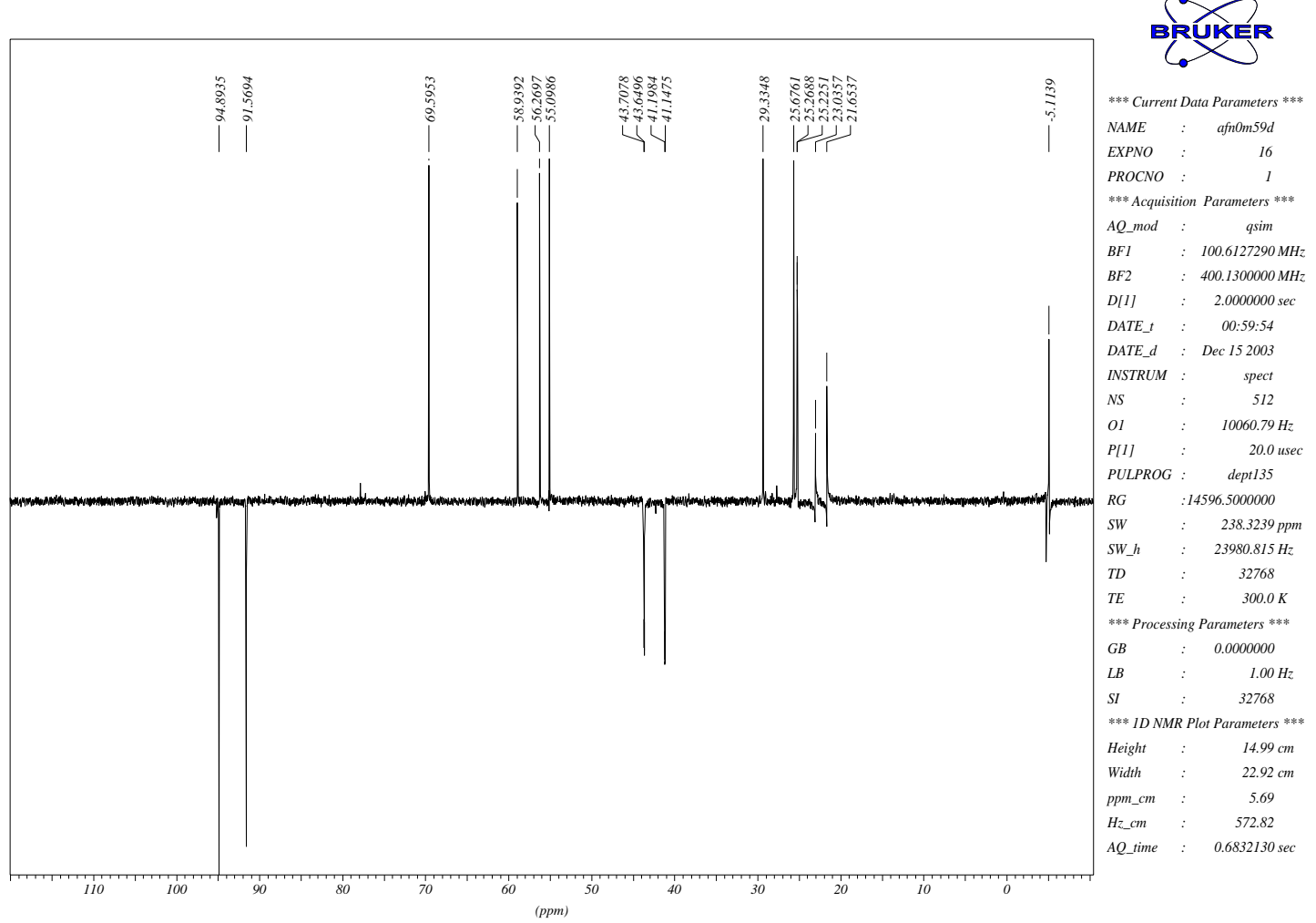


Tabela 43 - Dados espectrais de ${ }^{13} \mathrm{C}-\mathrm{RMN}\left\{{ }^{1} \mathrm{H}\right\}$ do composto 56.

\begin{tabular}{|c|c|}
\hline$\delta(\mathrm{ppm})$ & Atribuição" \\
\hline 94,9 & $\mathrm{C}_{12}$ \\
\hline 91,5 & $\mathrm{C}_{10}$ \\
\hline 89,3 & $\mathrm{C}_{6}$ \\
\hline 83,7 & $\mathrm{C}_{14}$ \\
\hline 82,9 & $\mathrm{C}_{15}$ \\
\hline 77,8 & $\mathrm{C}_{5}$ \\
\hline 69,6 & $\mathrm{C}_{3}$ \\
\hline 58,9 & $\mathrm{C}_{16}$ \\
\hline 56,3 & $\mathrm{C}_{13}{ }^{*}$ \\
\hline 55,1 & $\mathrm{C}_{11}^{*}$ \\
\hline 43,7 & $\mathrm{C}_{2}$ \\
\hline 43,6 & $\mathrm{C}_{2}$ \\
\hline 41,2 & $\mathrm{C}_{4}$ \\
\hline 41,1 & $\mathrm{C}_{4}$ \\
\hline 40,3 & $\mathrm{C}_{1}$ \\
\hline 29,3 & $\mathrm{C}_{8}^{* *}$ \\
\hline 25,7 & $\mathrm{C}_{21}, \mathrm{C}_{22}, \mathrm{C}_{23}$ \\
\hline 25,3 & $\mathrm{C}_{17}$ \\
\hline 25,2 & $\mathrm{C}_{17}$ \\
\hline 23,1 & $\mathrm{C}_{7}^{* *}$ \\
\hline 21,7 & $\mathrm{C}_{9}$ \\
\hline 18,1 & $\mathrm{C}_{20}$ \\
\hline$-5,1$ & $\mathrm{C}_{19}{ }^{* * *}$ \\
\hline$-4,8$ & $\mathrm{C}_{18}{ }^{* * *}$ \\
\hline
\end{tabular}

\# os carbonos foram atribuídos utilizando HMQC

$*, * *, * * *$ podem estar trocados 


\section{Espectro de IV do composto 56:}

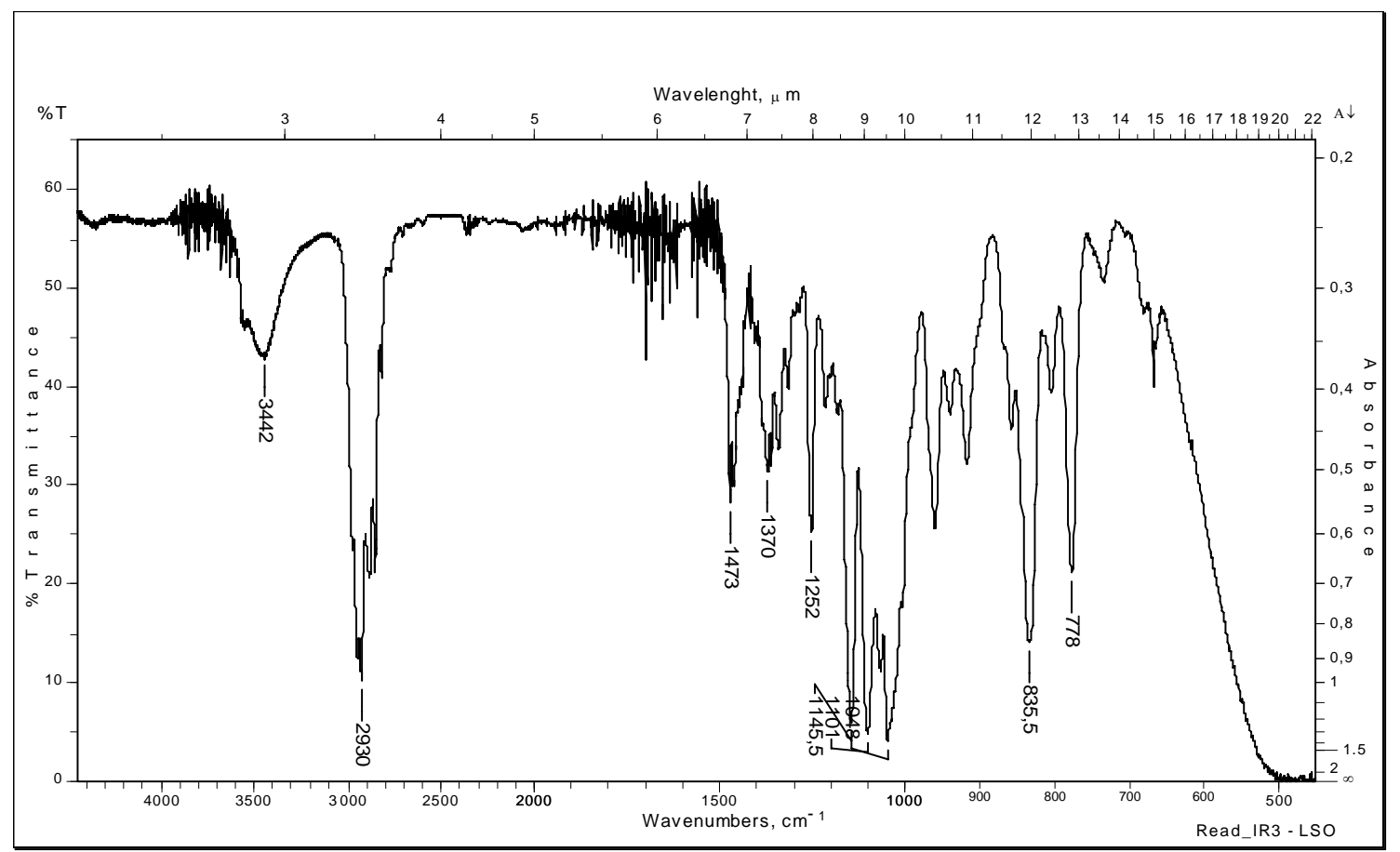

Tabela 44 - Dados espectrais de IV do composto 56.

\begin{tabular}{cl}
\hline$v\left(\mathbf{c m}^{-1}\right)$ & \multicolumn{1}{c}{ Atribuição } \\
\hline 3442 & Deformação axial de OH \\
1252 & Deformação axial de Si- $\mathrm{CH}_{3}$ \\
1145 & Deformação axial assimétrica de C-O-C \\
1101 & Deformação axial assimétrica de Si-O-C \\
1048 & Deformação axial de C-O do álcool \\
778 & Deformação angular fora do plano de OH \\
\hline
\end{tabular}




\section{Composto 57}

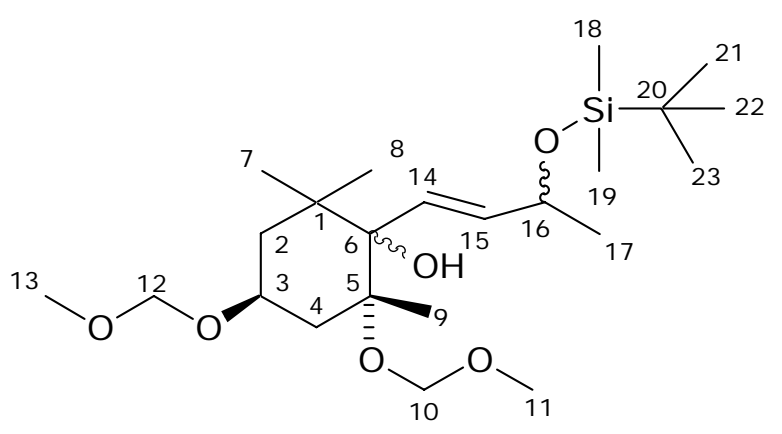

Os espectros de ${ }^{1} \mathrm{H}-\mathrm{RMN}$ e ${ }^{13} \mathrm{C}-\mathrm{RMN}$ apresentados a seguir são de uma mistura de quatro pares de diasteroisômeros do composto 57, onde, alguns sinais aparecem duplicados e outros sobrepostos.

A proporção desta mistura é de 1:1:1:1, calculada pelos valores das integrais. 


\section{Espectro de ${ }^{1} \mathrm{H}-\mathrm{RMN}\left(\mathrm{CDCl}_{3}, 400 \mathrm{MHz}\right)$ do composto 57:}

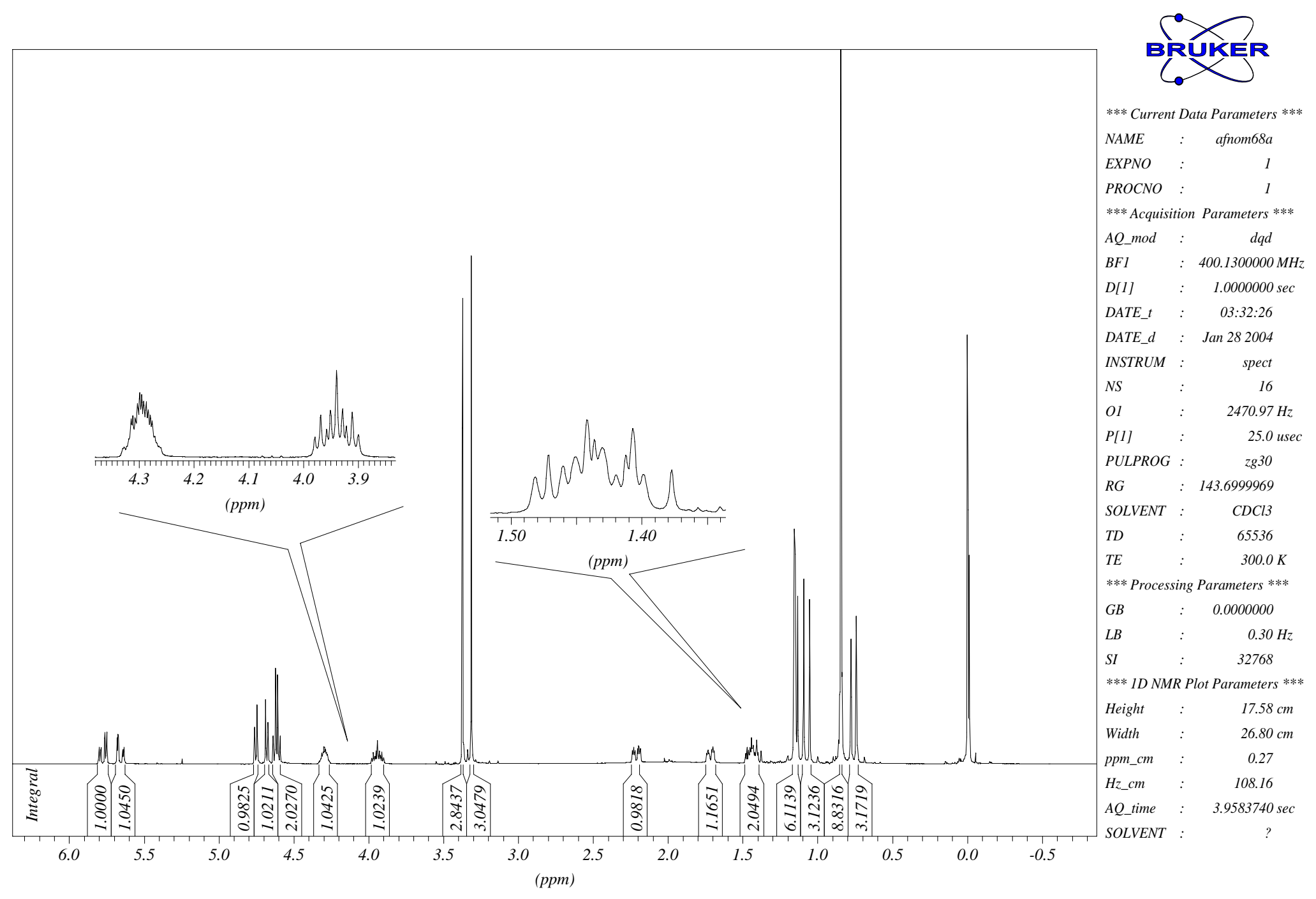


Tabela 45 - Dados espectrais de ${ }^{1} \mathrm{H}-\mathrm{RMN}$ do composto 57.

\begin{tabular}{|c|c|c|c|}
\hline$\delta(\mathrm{ppm})$ & Atribuição & Sinal & $J(\mathrm{~Hz})$ \\
\hline 5,83 & $\mathrm{H}_{15}$ & $\mathrm{dd}$ & $J_{15,14}=15,2 ; J_{15,16}=4,5$ \\
\hline 5,82 & $\mathrm{H}_{15}$ & $\mathrm{dd}$ & $J_{15,14}=15,2 ; J_{15,16}=4,5$ \\
\hline 5,71 & $\mathrm{H}_{14}$ & $\mathrm{dd}$ & $J_{14,15}=15,2 ; J_{14,16}=3,0$ \\
\hline 5,70 & $\mathrm{H}_{14}$ & $\mathrm{dd}$ & $J_{14,15}=15,2 ; J_{14,16}=3,0$ \\
\hline 4,80 & $\mathrm{H}_{10}{ }^{*}$ & d & $J_{10,10^{\prime}}=7,3$ \\
\hline 4,73 & $\mathrm{H}_{10^{*}}{ }^{*}$ & d & $J_{10^{\prime}, 10}=7,3$ \\
\hline 4,68 & $\mathrm{H}_{12}{ }^{* *}$ & $\mathrm{~d}$ & $J_{12,12^{\prime}}=6,8$ \\
\hline 4,65 & $\mathrm{H}_{12}{ }^{* * *}$ & d & $J_{12}, 12=6,8$ \\
\hline 4,30 & $\mathrm{H}_{16}$ & qdd & $J_{16,17}=6,5 ; J_{16,15}=4,5 ; J_{16,14}=3,0$ \\
\hline 4,29 & $\mathrm{H}_{16}$ & qdd & $J_{16,17}=6,5 ; J_{16,15}=4,5 ; J_{16,14}=3,0$ \\
\hline 3,99 & $\mathrm{H}_{3}$ & $\mathrm{tt}$ & $J_{3,2 a x}=J_{3,4 a x}=11,6 ; J_{3,2 e q}=J_{3,4 e q}=4,5$ \\
\hline 3,42 & $\mathrm{H}_{13}^{* * *}$ & s & \\
\hline 3,36 & $\mathrm{H}_{11}^{* * *}$ & s & \\
\hline 2,26 & $\mathrm{H}_{4 \mathrm{eq}}$ & ddd & $J_{4 e q, 4 a x}=13,9 ; J_{4 e q, 3}=4,5 ; J_{4 e q, 2 e q}=2,8$ \\
\hline 1,77 & $\mathrm{H}_{2 \mathrm{eq}}$ & ddd & $J_{2 e q, 2 a x}=13,4 ; J_{2 e q, 3}=4,5 ; J_{2 e q, 4 e q}=2,8$ \\
\hline 1,76 & $\mathrm{H}_{2 \mathrm{eq}}$ & ddd & $J_{2 e q, 2 a x}=13,4 ; J_{2 e q, 3}=4,5 ; J_{2 e q, 4 e q}=2,8$ \\
\hline $1,49-1,37$ & $\mathrm{H}_{2 \mathrm{ax}}, \mathrm{H}_{4 \mathrm{ax}}$ & $\mathrm{m}$ & \\
\hline 1,16 & $\mathrm{H}_{9}$ & s & \\
\hline 1,14 & $\mathrm{H}_{17}$ & d & $\mathrm{J}_{17,16}=6,5$ \\
\hline 1,10 & $\mathrm{H}_{7}{ }^{\#}$ & s & \\
\hline 1,05 & $\mathrm{H}_{7}^{\#}$ & $\mathrm{~s}$ & \\
\hline 0,89 & $\mathrm{H}_{21}, \mathrm{H}_{22}, \mathrm{H}_{23}$ & s & \\
\hline 0,83 & $\mathrm{H}_{8} \#$ & $\mathrm{~s}$ & \\
\hline 0,79 & $\mathrm{H}_{8}^{\#}$ & $\mathrm{~s}$ & \\
\hline 0,05 & $\mathrm{H}_{18}^{\# \#}$ & $\mathrm{~s}$ & \\
\hline 0,04 & $\mathrm{H}_{19} \# \#$ & $\mathrm{~s}$ & \\
\hline 0,03 & $\mathrm{H}_{19} \# \#$ & $\mathrm{~s}$ & \\
\hline
\end{tabular}


Espectro de ${ }^{13} \mathrm{C}-\mathrm{RMN}\left\{{ }^{1} \mathrm{H}\right\}\left(\mathrm{CDCl}_{3}, 100 \mathrm{MHz}\right)$ do composto 57:

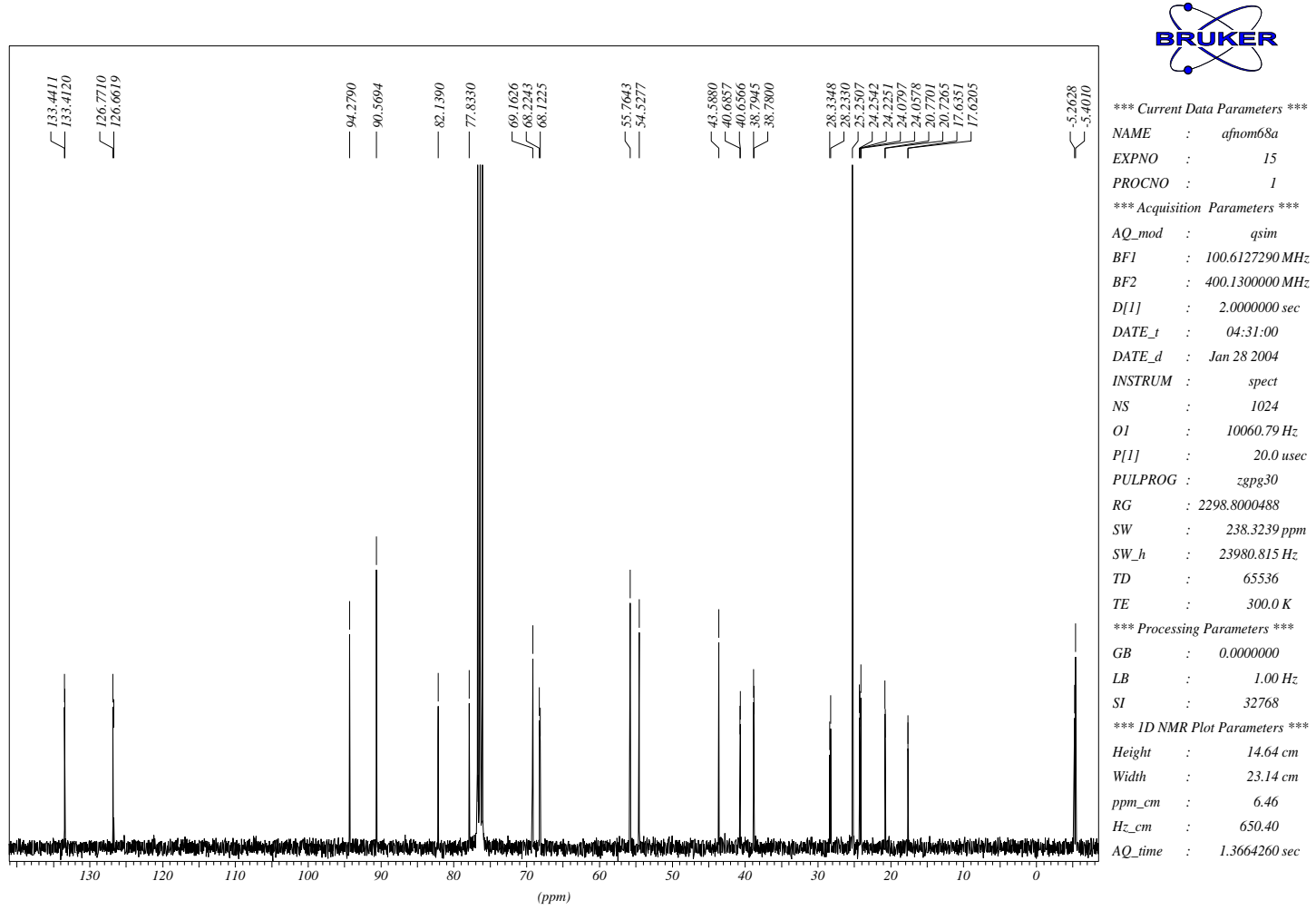

Espectro de ${ }^{13} \mathrm{C}-\mathrm{RMN}(\mathrm{DEPT}-135)\left(\mathrm{CDCl}_{3}, 100 \mathrm{MHz}\right)$ do composto 57:

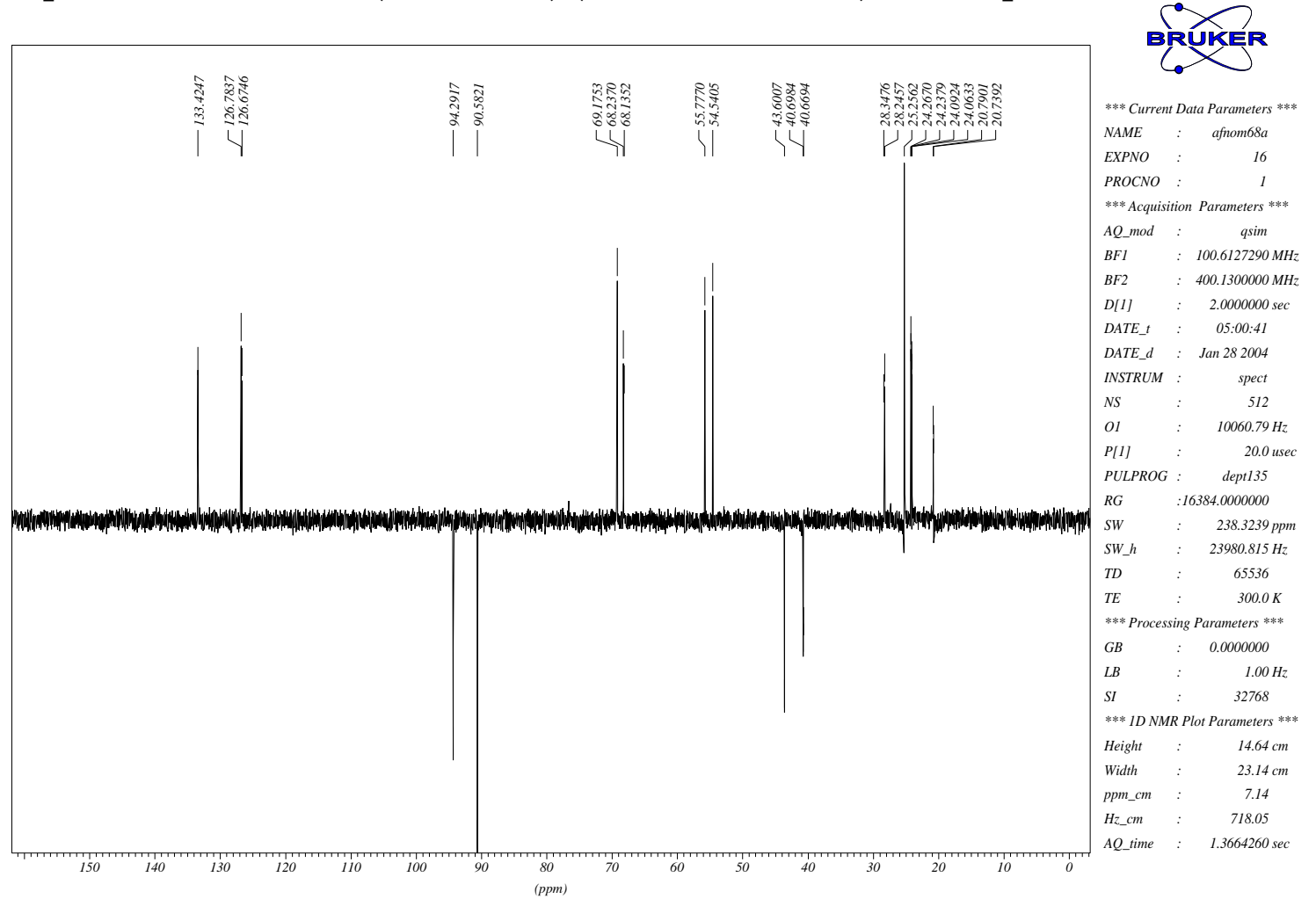


Tabela 46 - Dados espectrais de ${ }^{13} \mathrm{C}-\mathrm{RMN}\left\{{ }^{1} \mathrm{H}\right\}$ do composto 57.

\begin{tabular}{|c|c|}
\hline$\delta(\mathrm{ppm})$ & Atribuição\# \\
\hline 133,4 & $\mathrm{C}_{15}$ \\
\hline 126,8 & $\mathrm{C}_{14}$ \\
\hline 126,7 & $\mathrm{C}_{14}$ \\
\hline 94,3 & $\mathrm{C}_{12}$ \\
\hline 90,6 & $\mathrm{C}_{10}$ \\
\hline 82,1 & $\mathrm{C}_{6}$ \\
\hline 77,8 & $\mathrm{C}_{5}$ \\
\hline 69,2 & $\mathrm{C}_{3}$ \\
\hline 68,2 & $\mathrm{C}_{16}$ \\
\hline 68,1 & $\mathrm{C}_{16}$ \\
\hline 55,8 & $\mathrm{C}_{13}{ }^{*}$ \\
\hline 54,5 & $\mathrm{C}_{11}{ }^{*}$ \\
\hline 43,6 & $\mathrm{C}_{2}$ \\
\hline 40,7 & $\mathrm{C}_{4}$ \\
\hline 40,6 & $\mathrm{C}_{4}$ \\
\hline 38,8 & $\mathrm{C}_{1}$ \\
\hline 28,3 & $\mathrm{C}_{8}^{* *}$ \\
\hline 28,2 & $\mathrm{C}_{8}^{* *}$ \\
\hline 25,2 & $\mathrm{C}_{21}, \mathrm{C}_{22}, \mathrm{C}_{23}$ \\
\hline 24,2 & $\mathrm{C}_{17}$ \\
\hline 24,1 & $\mathrm{C}_{9}$ \\
\hline 20,8 & $\mathrm{C}_{7}^{* *}$ \\
\hline 20,7 & $\mathrm{C}_{7}^{* *}$ \\
\hline 17,6 & $\mathrm{C}_{20}$ \\
\hline$-5,4$ & $\mathrm{C}_{19^{* * *}}$ \\
\hline$-5,3$ & $\mathrm{C}_{18}^{* * *}$ \\
\hline
\end{tabular}


Espectro de IV do composto 57:

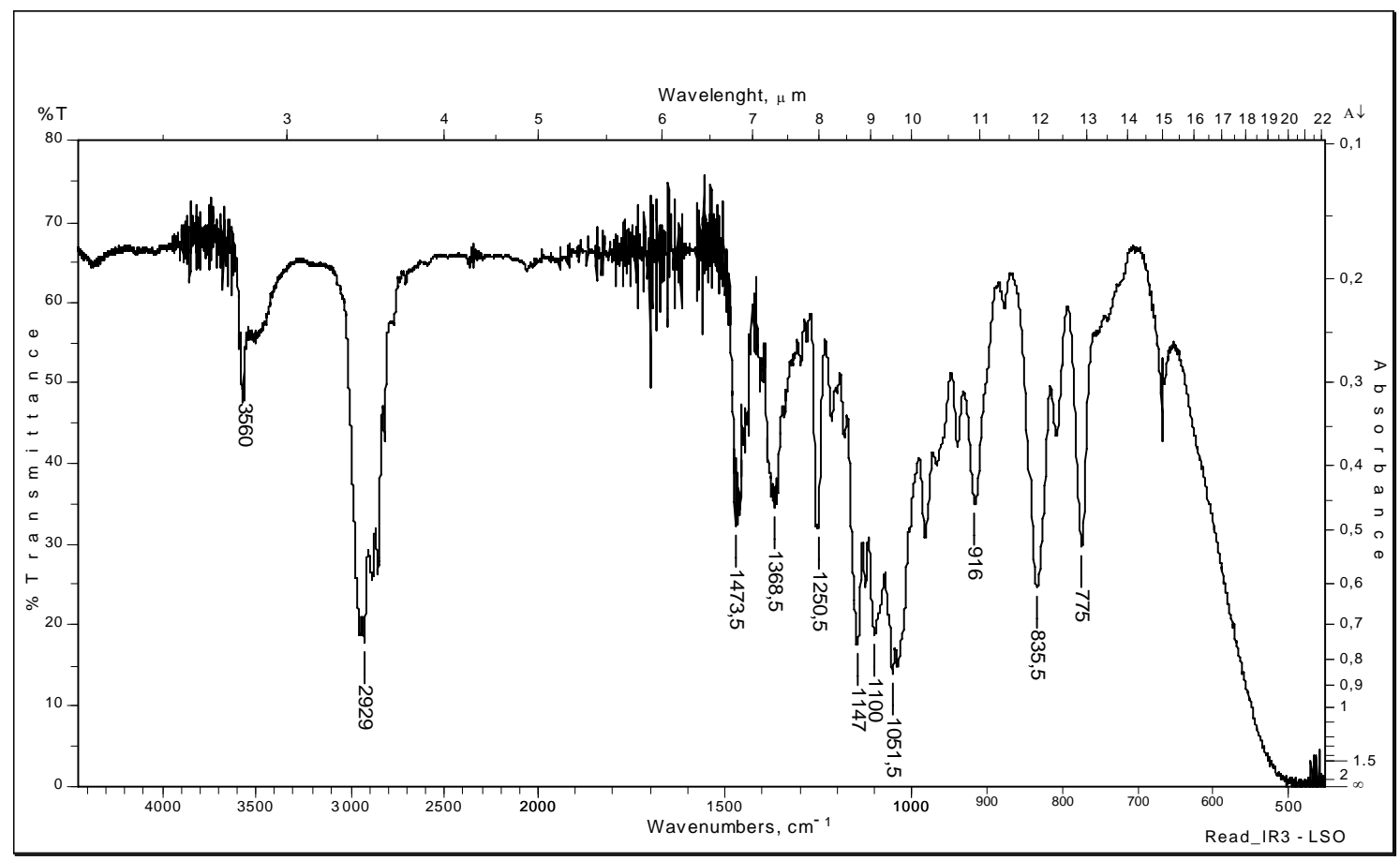

Tabela 47 - Dados espectrais de IV do composto 57.

\begin{tabular}{cl}
\hline $\boldsymbol{v}\left(\mathbf{c m}^{-1}\right)$ & \multicolumn{1}{c}{ Atribuição } \\
\hline 3560 & Deformação axial de OH \\
1250 & Deformação axial de Si-CH3 \\
1147 & Deformação axial assimétrica de C-O-C \\
1099 & Deformação axial assimétrica de Si-O-C \\
1051 & Deformação axial de C-O do álcool \\
835 & Deformação angular fora do plano de C-H da dupla ligação \\
775 & Deformação angular fora do plano de OH \\
\hline
\end{tabular}




\section{Composto 58}

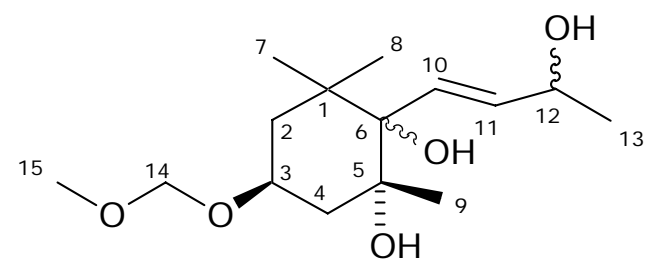

Os espectros de ${ }^{1} \mathrm{H}-\mathrm{RMN}$ e ${ }^{13} \mathrm{C}-\mathrm{RMN}$ apresentados a seguir são de uma mistura de quatro pares de diasteroisômeros do composto 58, alguns sinais aparecem duplicados e outros sobrepostos.

A proporção desta mistura é de 1:1:1:1, calculada pelos valores das integrais. 


\section{Espectro de ${ }^{1} \mathrm{H}-\mathrm{RMN}\left(\mathrm{CDCl}_{3}, 400 \mathrm{MHz}\right)$ do composto 58:}

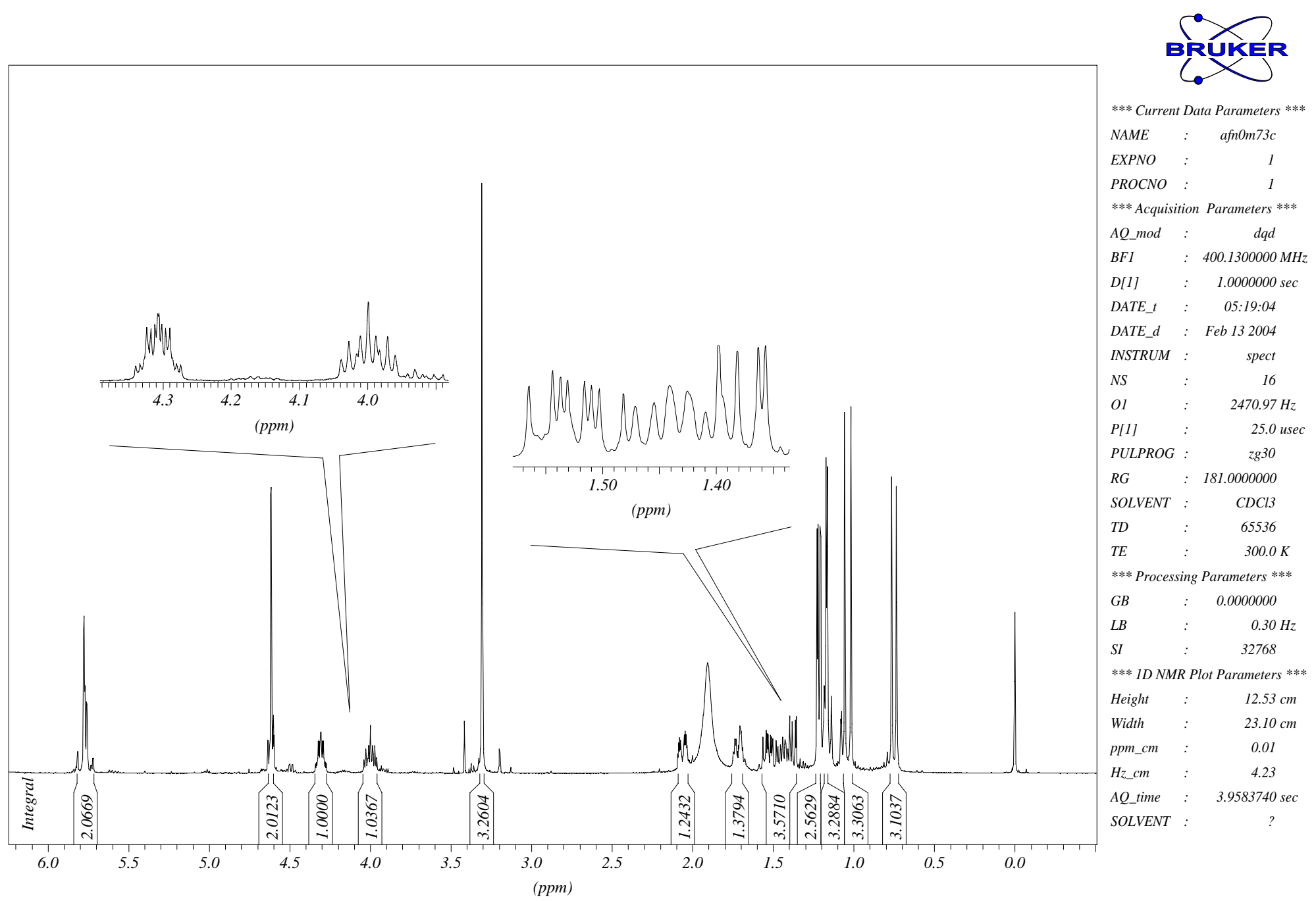


Tabela 48 - Dados espectrais de ${ }^{1} \mathrm{H}-\mathrm{RMN}$ do composto 58.

\begin{tabular}{|c|c|c|c|}
\hline$\delta(\mathrm{ppm})$ & Atribuição & Sinal & $J(\mathrm{~Hz})$ \\
\hline 5,80 & $\mathrm{H}_{10}$ & $\mathrm{~d}$ & $J_{10,11}=15,7$ \\
\hline 5,79 & $\mathrm{H}_{10}$ & d & $J_{10,11}=15,7$ \\
\hline 5,75 & $\mathrm{H}_{11}$ & dd & $J_{11,10}=15,7 ; J_{11,12}=6,3$ \\
\hline 5,74 & $\mathrm{H}_{11}$ & $\mathrm{dd}$ & $J_{11,10}=15,7 ; J_{11,12}=6,3$ \\
\hline 4,63 & $\mathrm{H}_{14}^{*}$ & $\mathrm{~d}$ & $J_{14,14^{\prime}}=6,8$ \\
\hline 4,60 & $\mathrm{H}_{14}{ }^{*}$ & $\mathrm{~d}$ & $J_{14^{\prime}, 14}=6,8$ \\
\hline 4,31 & $\mathrm{H}_{12}$ & quin & $J_{12,13}=6,3$ \\
\hline 4,30 & $\mathrm{H}_{12}$ & quin & $J_{12,13}=6,3$ \\
\hline 4,00 & $\mathrm{H}_{3}$ & $\mathrm{tt}$ & $J_{3,2 a x}=J_{3,4 a x}=11,1 ; J_{3,2 e q}=J_{3,4 e q}=4,5$ \\
\hline 3,31 & $\mathrm{H}_{15}$ & $\mathrm{~s}$ & \\
\hline 2,07 & $\mathrm{H}_{4 \mathrm{eq}}$ & ddd & $J_{4 e q, 4 a x}=13,6 ; J_{4 e q, 3}=4,5 ; J_{4 e q,, 2 e q}=2,5$ \\
\hline 2,06 & $\mathrm{H}_{4 \mathrm{eq}}$ & ddd & $J_{4 e q, 4 a x}=3,6 ; J_{4 e q, 3}=4,5 ; J_{4 e q, 2 e q}=2,5$ \\
\hline 1,90 & $\mathrm{OH}$ & sl & \\
\hline 1,72 & $\mathrm{H}_{2 \mathrm{eq}}$ & ddd & $J_{2 e q, 2 a x}=13,4 ; J_{2 e q, 3}=4,5 ; J_{2 e q, 4 e q}=2,5$ \\
\hline 1,71 & $\mathrm{H}_{2 \mathrm{eq}}$ & ddd & $J_{2 e q, 2 a x}=13,4 ; J_{2 e q, 3}=4,5 ; J_{2 e q, 4 e q}=2,5$ \\
\hline 1,53 & $\mathrm{H}_{4 a x}$ & dd & $J_{4 a x, 4 e q}=13,6 ; J_{4 a x, 3}=11,1$ \\
\hline 1,52 & $\mathrm{H}_{4 \mathrm{ax}}$ & $\mathrm{dd}$ & $J_{4 a x, 4 e q}=13,6 ; J_{4 a x, 3}=11,1$ \\
\hline $1,47-1,36$ & $\mathrm{H}_{2 \mathrm{ax}}$ & $\mathrm{m}$ & \\
\hline 1,22 & $\mathrm{H}_{13}$ & $\mathrm{~d}$ & $J_{13,12}=6,3$ \\
\hline 1,21 & $\mathrm{H}_{13}$ & d & $J_{13,12}=6,3$ \\
\hline 1,17 & $\mathrm{H}_{9}$ & $\mathrm{~s}$ & \\
\hline 1,16 & $\mathrm{H}_{9}$ & $\mathrm{~s}$ & \\
\hline 1,06 & $\mathrm{H}_{7}^{* *}$ & $\mathrm{~s}$ & \\
\hline 1,01 & $\mathrm{H}_{7}^{* *}$ & $\mathrm{~s}$ & \\
\hline 0,77 & $\mathrm{H}_{8}^{* *}$ & $\mathrm{~s}$ & \\
\hline 0,74 & $\mathrm{H}_{8}^{* *}$ & $\mathrm{~s}$ & \\
\hline
\end{tabular}


Composto 59a $(3 S, 5 R, 6 S)$

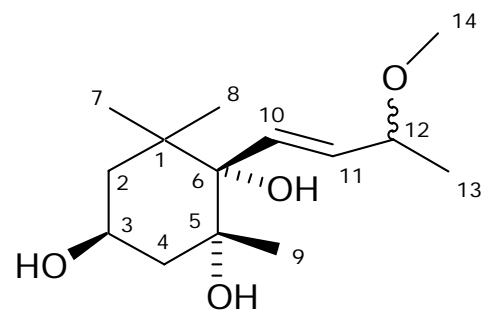

Os espectros de ${ }^{1} \mathrm{H}-\mathrm{RMN}$ e ${ }^{13} \mathrm{C}-\mathrm{RMN}$ apresentados a seguir são de uma mistura de dois pares de diasteroisômeros do composto 59a $(3 S, 5 R, 6 S)$, onde todos os sinais aparecem sobrepostos.

A proporção desta mistura é de 1:1, calculada pelos valores das integrais. 
Espectro de ${ }^{1} \mathrm{H}-\mathrm{RMN}\left(\mathrm{CDCl}_{3}, 400 \mathrm{MHz}\right)$ do composto 59a:

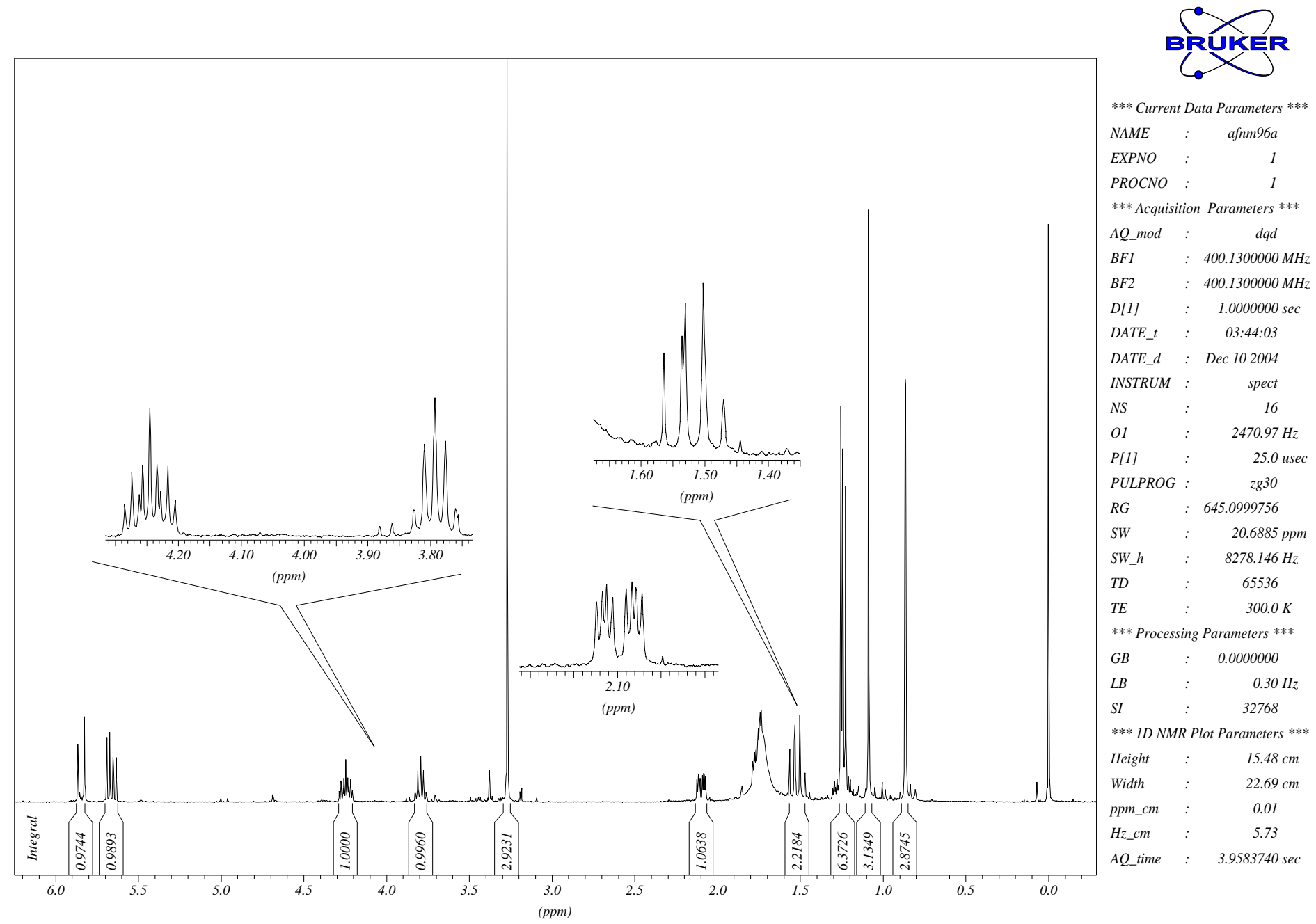


Tabela 49 - Dados espectrais de ${ }^{1} \mathrm{H}-\mathrm{RMN}$ do composto $59 \mathrm{a}$.

\begin{tabular}{cccc}
\hline$\delta$ (ppm) & Atribuição & Sinal & $J(\mathbf{H z})$ \\
\hline 5,84 & $\mathrm{H}_{10}$ & $\mathrm{~d}$ & $J_{10,11}=15,4$ \\
5,66 & $\mathrm{H}_{11}$ & $\mathrm{dd}$ & $J_{11,10}=15,4 ; J_{11,12}=6,5$ \\
4,24 & $\mathrm{H}_{3}$ & $\mathrm{tt}$ & $J_{3,2 a x}=J_{3,4 a x}=11,6 ; J_{3,2 e q}=J_{3,4 e q}=4,6$ \\
3,80 & $\mathrm{H}_{12}$ & quin & $J_{12,13}=J_{12,11}=6,5$ \\
3,27 & $\mathrm{H}_{14}$ & $\mathrm{~s}$ & \\
2,10 & $\mathrm{H}_{4 \mathrm{eq}}$ & $\mathrm{ddd}$ & $J_{4 e q, 4 a x}=13,6 ; J_{4 e q, 3}=4,6 ; J_{4 e q, 2 e q}=2,8$ \\
1,76 & $\mathrm{H}_{2 \mathrm{eq}}$ & $\mathrm{ddd}$ & $J_{2 e q, 2 a x}=12,5 ; J_{2 e q, 3}=4,6 ; J_{2 e q, 4 e q}=2,8$ \\
1,54 & $\mathrm{H}_{4 \mathrm{ax}}$ & $\mathrm{dd}$ & $J_{4 a x, 4 e q}=13,6 ; J_{4 a x, 3}=11,6$ \\
1,50 & $\mathrm{H}_{2 \mathrm{ax}}$ & $\mathrm{dd}$ & $J_{2 a x, 2 e q}=12,5 ; J_{2 a x, 3}=11,6$ \\
1,25 & $\mathrm{H}_{9}$ & $\mathrm{~s}$ & \\
1,24 & $\mathrm{H}_{13}$ & $\mathrm{~d}$ & $J_{13,12}=6,5$ \\
1,08 & $\mathrm{H}_{7}^{*}$ & $\mathrm{~s}$ & \\
0,86 & $\mathrm{H}_{8}^{*}$ & $\mathrm{~s}$ & \\
\hline
\end{tabular}

* podem estar trocados

Tabela 50 - Interação NOE observada no experimento de NOE-diff ${ }^{1} \mathrm{H}-$ RMN do composto 59a.

\begin{tabular}{ccc}
\hline$\delta$ (ppm) irradiado & Atribuição & Efeito NOE observado \\
\hline 5,84 & $\mathrm{H}_{10}$ & $\mathrm{H}_{2 \mathrm{ax}}, \mathrm{H}_{4 \mathrm{ax}}, \mathrm{H}_{12}$ \\
\hline
\end{tabular}


Espectro de ${ }^{13} \mathrm{C}-\mathrm{RMN}\left\{{ }^{1} \mathrm{H}\right\}\left(\mathrm{CDCl}_{3}, 125 \mathrm{MHz}\right)$ do composto 59a:

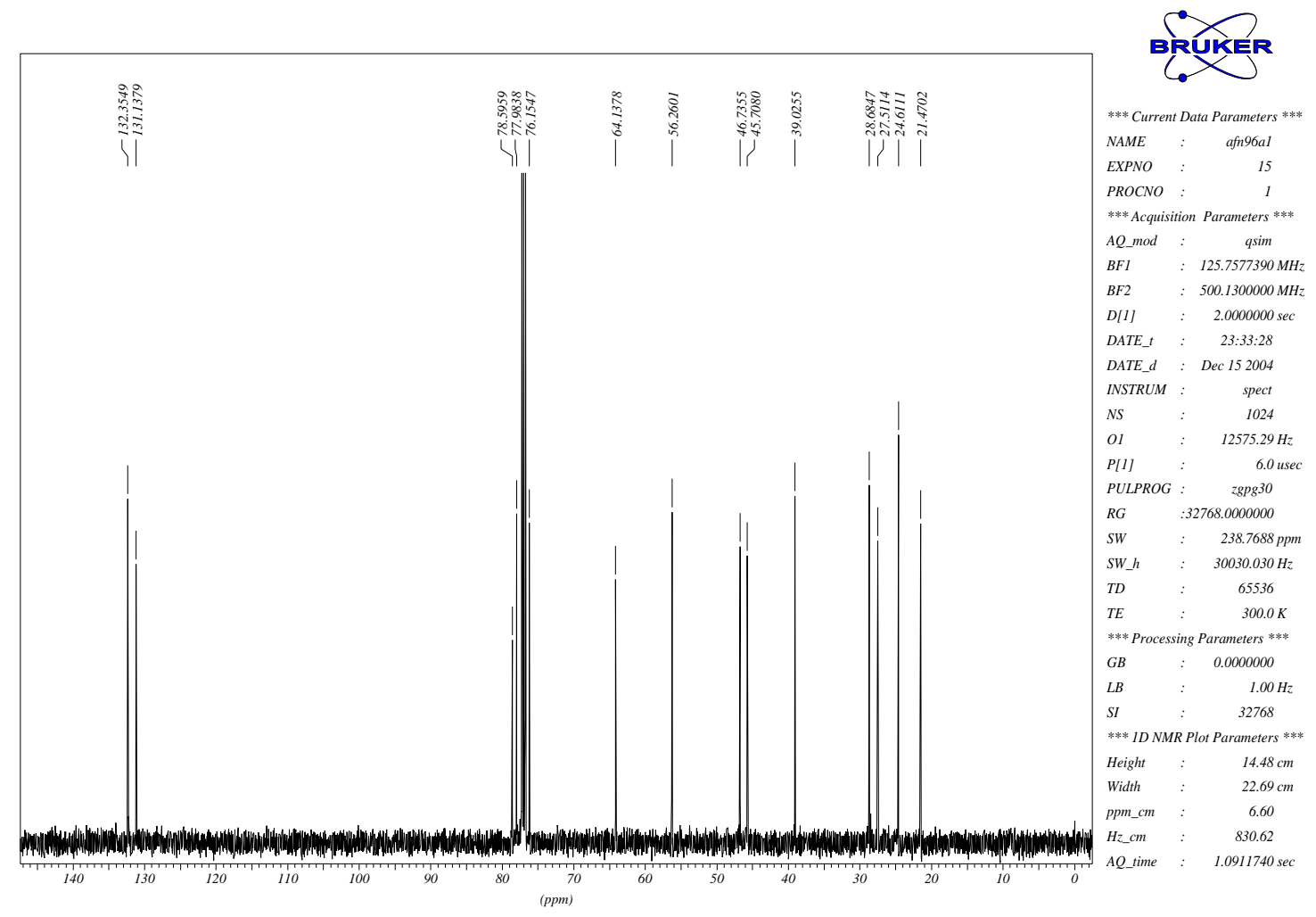

Espectro de ${ }^{13} \mathrm{C}-\mathrm{RMN}(\mathrm{DEPT}-135)\left(\mathrm{CDCl}_{3}, 125 \mathrm{MHz}\right)$ do composto 59a:

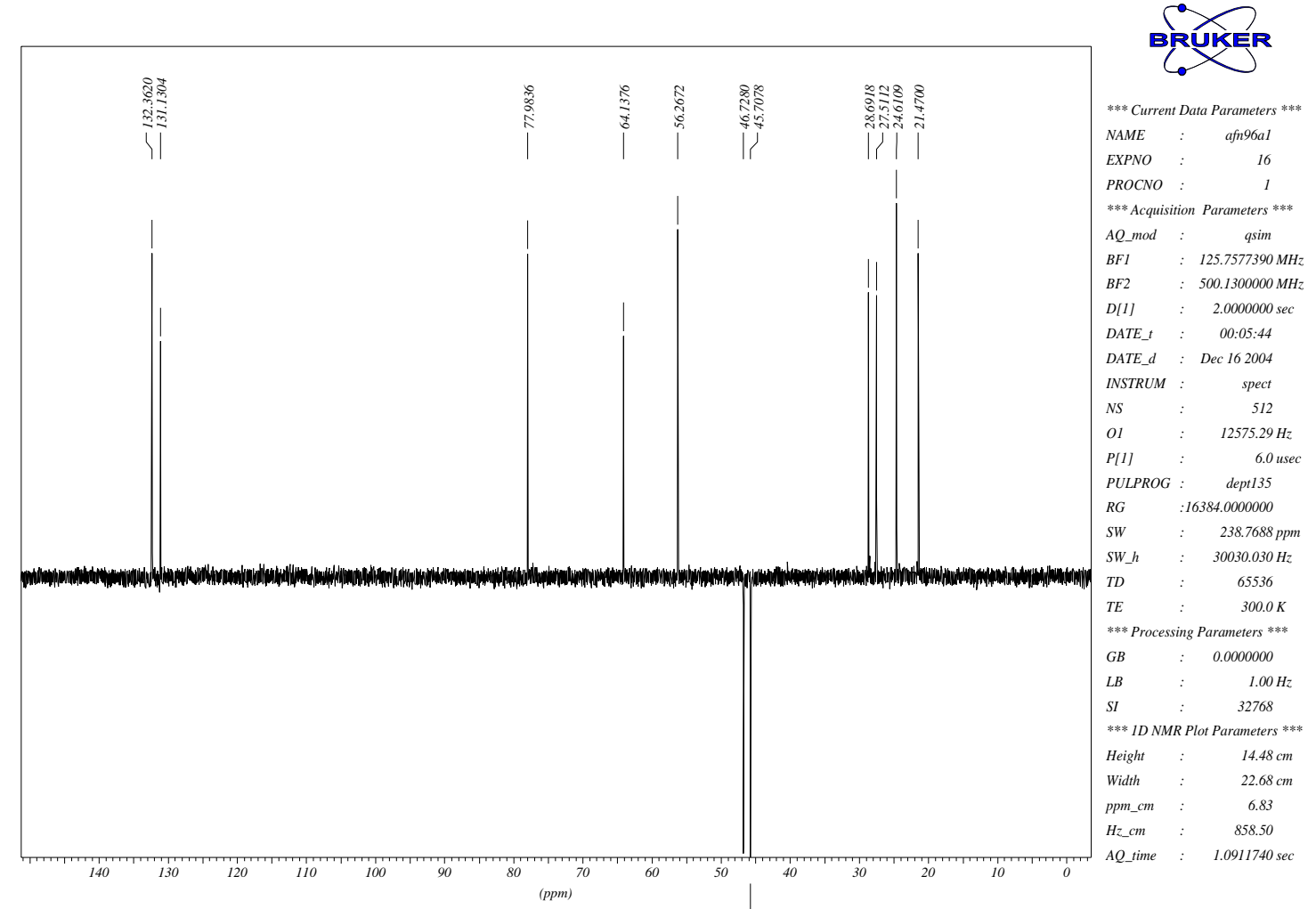


Tabela 51 - Dados espectrais de ${ }^{13} \mathrm{C}-\mathrm{RMN}\left\{{ }^{1} \mathrm{H}\right\}$ do composto 59a.

\begin{tabular}{cc}
$\delta($ ppm $)$ & Atribuição \\
\hline 132,3 & $\mathrm{C}_{10}$ \\
131,1 & $\mathrm{C}_{11}$ \\
78,6 & $\mathrm{C}_{6}$ \\
78,0 & $\mathrm{C}_{12}$ \\
76,1 & $\mathrm{C}_{5}$ \\
64,1 & $\mathrm{C}_{3}$ \\
56,3 & $\mathrm{C}_{14}$ \\
46,7 & $\mathrm{C}_{2}$ \\
45,7 & $\mathrm{C}_{4}$ \\
39,0 & $\mathrm{C}_{1}$ \\
28,7 & $\mathrm{C}_{8}{ }^{* *}$ \\
27,5 & $\mathrm{C}_{7}{ }^{* *}$ \\
24,6 & $\mathrm{C}_{9}$ \\
21,5 & $\mathrm{C}_{13}$ \\
\hline
\end{tabular}

\footnotetext{
* os carbonos foram atribuídos utilizando HMQC

** podem estar trocados
} 
Composto 59b (3S, 5R, 6R)

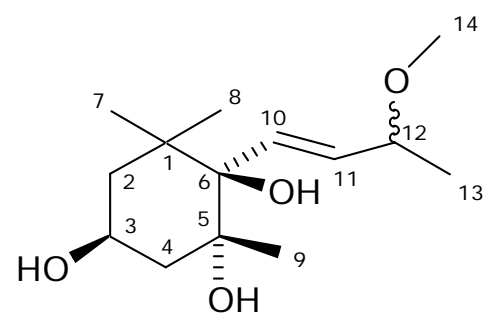

Os espectros de ${ }^{1} \mathrm{H}-\mathrm{RMN}$ e ${ }^{13} \mathrm{C}-\mathrm{RMN}$ apresentados a seguir são de uma mistura de dois pares de diasteroisômeros do composto 59 b $(3 S, 5 R, 6 R)$, onde todos os sinais aparecem sobrepostos.

A proporção desta mistura é de 1:1, calculada pelos valores das integrais. 
Espectro de ${ }^{1} \mathrm{H}-\mathrm{RMN}\left(\mathrm{CDCl}_{3}, 500 \mathrm{MHz}\right)$ do composto $59 \mathrm{~b}$ :

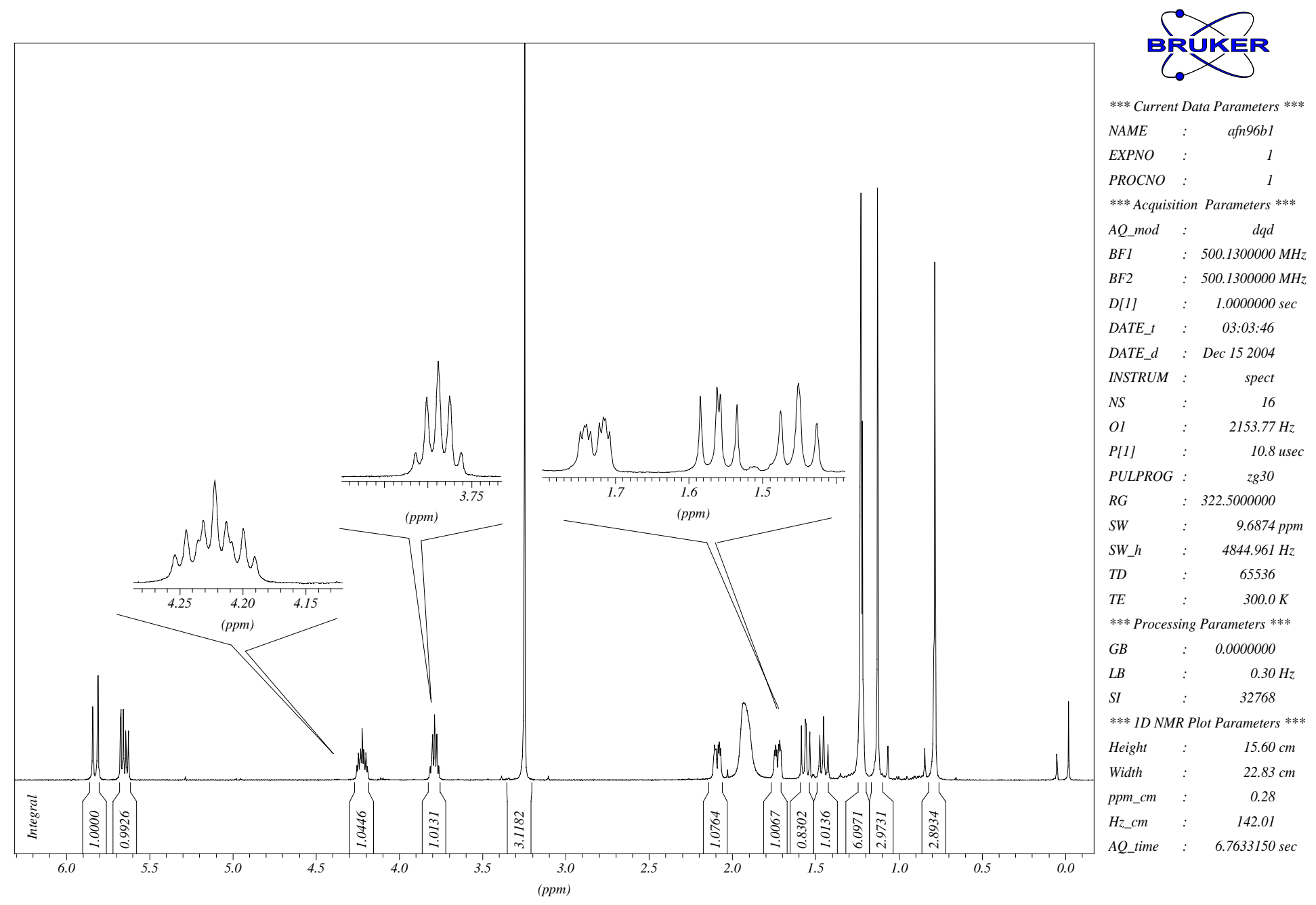


Tabela 52 - Dados espectrais de ${ }^{1} \mathrm{H}-\mathrm{RMN}$ do composto $\mathbf{5 9 b}$.

\begin{tabular}{cccc}
\hline$\delta$ (ppm) & Atribuição & Sinal & $J(\mathbf{H z})$ \\
\hline 5,82 & $\mathrm{H}_{10}$ & $\mathrm{~d}$ & $J_{10,11}=15,6$ \\
5,65 & $\mathrm{H}_{11}$ & $\mathrm{dd}$ & $J_{11,10}=15,6 ; J_{11,12}=6,5$ \\
4,22 & $\mathrm{H}_{3}$ & $\mathrm{tt}$ & $J_{3,2 a x}=J_{3,4 a x}=11,6 ; J_{3,2 e q}=J_{3,4 e q}=4,6$ \\
3,79 & $\mathrm{H}_{12}$ & quin & $J_{12,13}=J_{12,11}=6,5$ \\
3,30 & $\mathrm{H}_{14}$ & $\mathrm{~s}$ & \\
2,09 & $\mathrm{H}_{4 \mathrm{eq}}$ & $\mathrm{ddd}$ & $J_{4 e q, 4 a x}=13,6 ; J_{4 e q, 3}=4,6 ; J_{4 e q, 2 e q}=2,8$ \\
1,95 & $\mathrm{OH}_{1}$ & $\mathrm{sl}$ & \\
1,73 & $\mathrm{H}_{2 \mathrm{eq}}$ & $\mathrm{ddd}$ & $J_{2 e q, 2 a x}=12,5 ; J_{2 e q, 3}=4,6 ; J_{2 e q, 4 e q}=2,8$ \\
1,56 & $\mathrm{H}_{4 \mathrm{ax}}$ & $\mathrm{dd}$ & $J_{4 a x, 4 e q}=13,6 ; J_{4 a x, 3}=11,6$ \\
1,45 & $\mathrm{H}_{2 \mathrm{ax}}$ & $\mathrm{dd}$ & $J_{2 a x, 2 e q}=12,5 ; J_{2 a x, 3}=11,6$ \\
1,23 & $\mathrm{H}_{9}$ & $\mathrm{~s}$ & \\
1,22 & $\mathrm{H}_{13}$ & $\mathrm{~d}$ & $J_{13,12}=6,5$ \\
1,13 & $\mathrm{H}_{7}^{*}$ & $\mathrm{~s}$ & $\mathrm{~s}$ \\
0,79 & $\mathrm{H}_{8}{ }^{*}$ & & \\
\hline$*$ & & &
\end{tabular}

* podem estar trocados

Tabela 53 - Interação NOE observada no experimento de NOE-diff ${ }^{1} \mathrm{H}-$ RMN do composto $59 \mathrm{~b}$.

\begin{tabular}{ccc}
\hline$\delta(\mathbf{p p m})$ irradiado & Atribuição & Efeito NOE observado \\
\hline 5,82 & $\mathrm{H}_{10}$ & $\mathrm{H}_{12}$ \\
\hline
\end{tabular}


Espectro de ${ }^{13} \mathrm{C}-\mathrm{RMN}\left\{{ }^{1} \mathrm{H}\right\}\left(\mathrm{CDCl}_{3}, 125 \mathrm{MHz}\right)$ do composto $59 \mathrm{~b}$ :

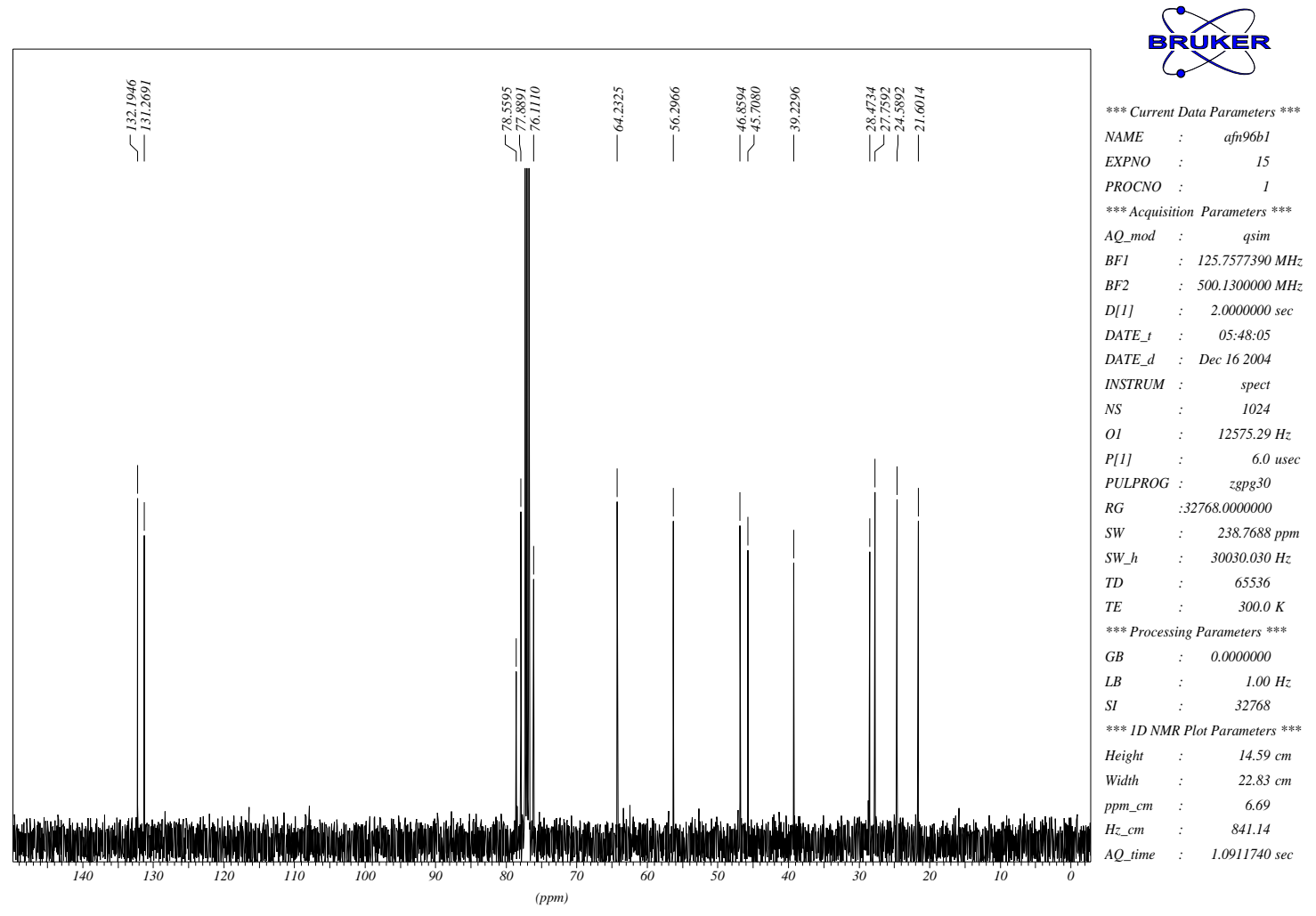

Espectro de ${ }^{13} \mathrm{C}-\mathrm{RMN}(\mathrm{DEPT}-135)\left(\mathrm{CDCl}_{3}, 125 \mathrm{MHz}\right)$ do composto 59b:

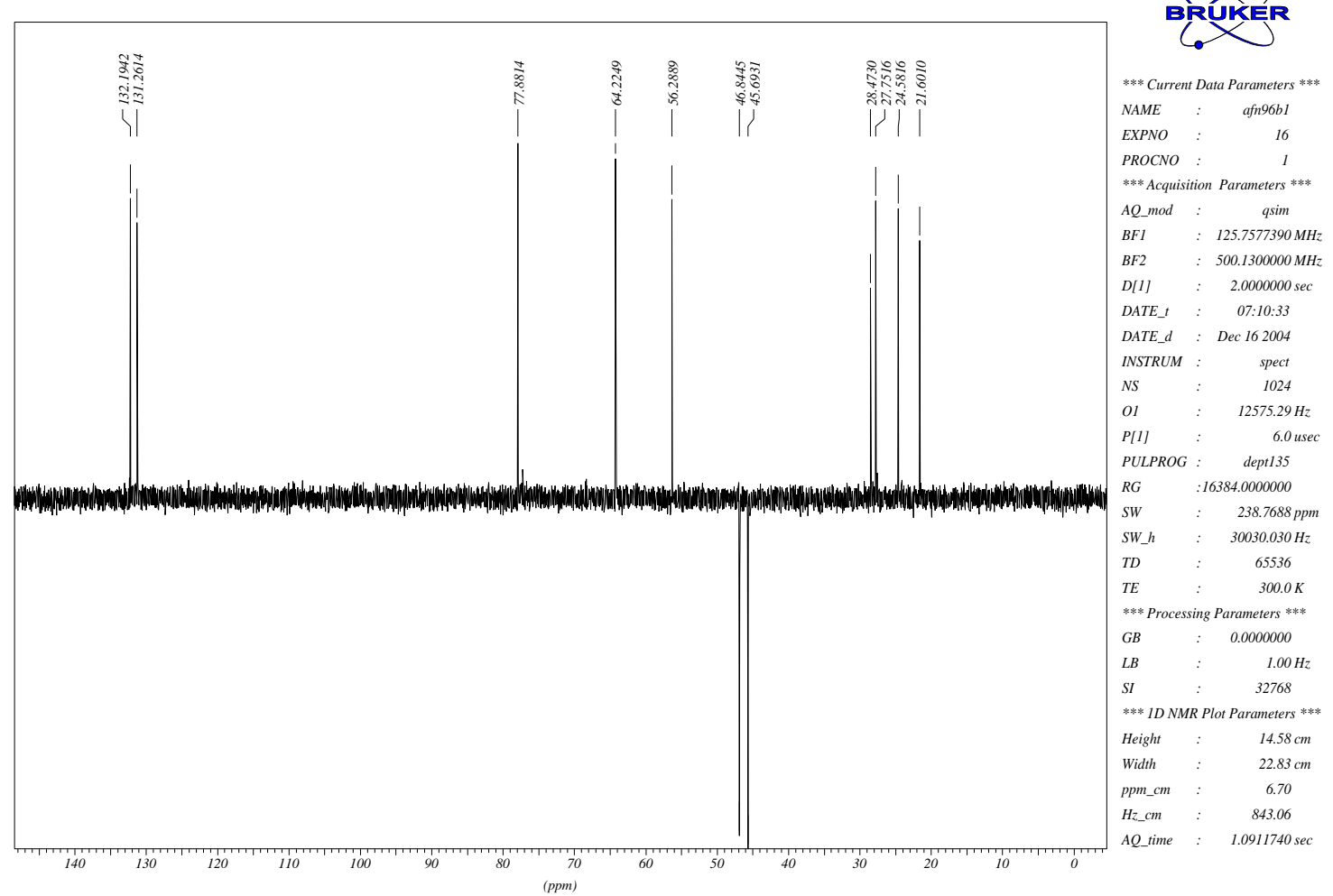


Tabela 54 - Dados espectrais de ${ }^{13} \mathrm{C}-\mathrm{RMN}\left\{{ }^{1} \mathrm{H}\right\}$ do composto $59 \mathrm{~b}$.

\begin{tabular}{cc}
$\delta(\mathbf{p p m})$ & Atribuição $^{*}$ \\
132,2 & $\mathrm{C}_{10}$ \\
131,3 & $\mathrm{C}_{11}$ \\
78,6 & $\mathrm{C}_{6}$ \\
77,9 & $\mathrm{C}_{12}$ \\
76,1 & $\mathrm{C}_{5}$ \\
64,2 & $\mathrm{C}_{3}$ \\
56,3 & $\mathrm{C}_{14}$ \\
46,9 & $\mathrm{C}_{2}$ \\
45,7 & $\mathrm{C}_{4}$ \\
39,2 & $\mathrm{C}_{1}$ \\
28,5 & $\mathrm{C}_{8}{ }^{* *}$ \\
27,6 & $\mathrm{C}_{7}^{* *}$ \\
24,6 & $\mathrm{C}_{9}$ \\
21,6 & $\mathrm{C}_{13}$ \\
\hline
\end{tabular}

* os carbonos foram atribuídos utilizando HMQC

** podem estar trocados 
Composto $30 \mathrm{a}(3 \mathrm{~S}, 5 \mathrm{R}, 6 \mathrm{~S})$

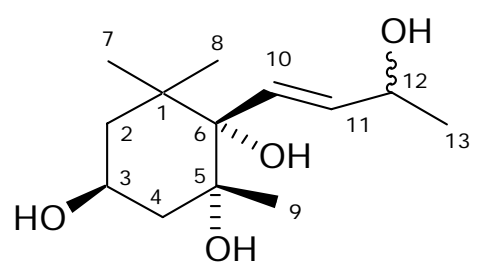

Os espectros de ${ }^{1} \mathrm{H}-\mathrm{RMN}$ e ${ }^{13} \mathrm{C}-\mathrm{RMN}$ apresentados a seguir são de uma mistura de dois pares de diasteroisômeros do composto $30 \mathrm{a}(3 \mathrm{~S}, \mathbf{5 R}, \mathbf{6 S})$, onde todos os sinais aparecem sobrepostos.

A proporção desta mistura é de 1:1, calculada pelos valores das integrais. 
Espectro de ${ }^{1} \mathrm{H}-\mathrm{RMN}\left(\mathrm{CD}_{3} \mathrm{OD}, 500 \mathrm{MHz}\right)$ do composto 30a:

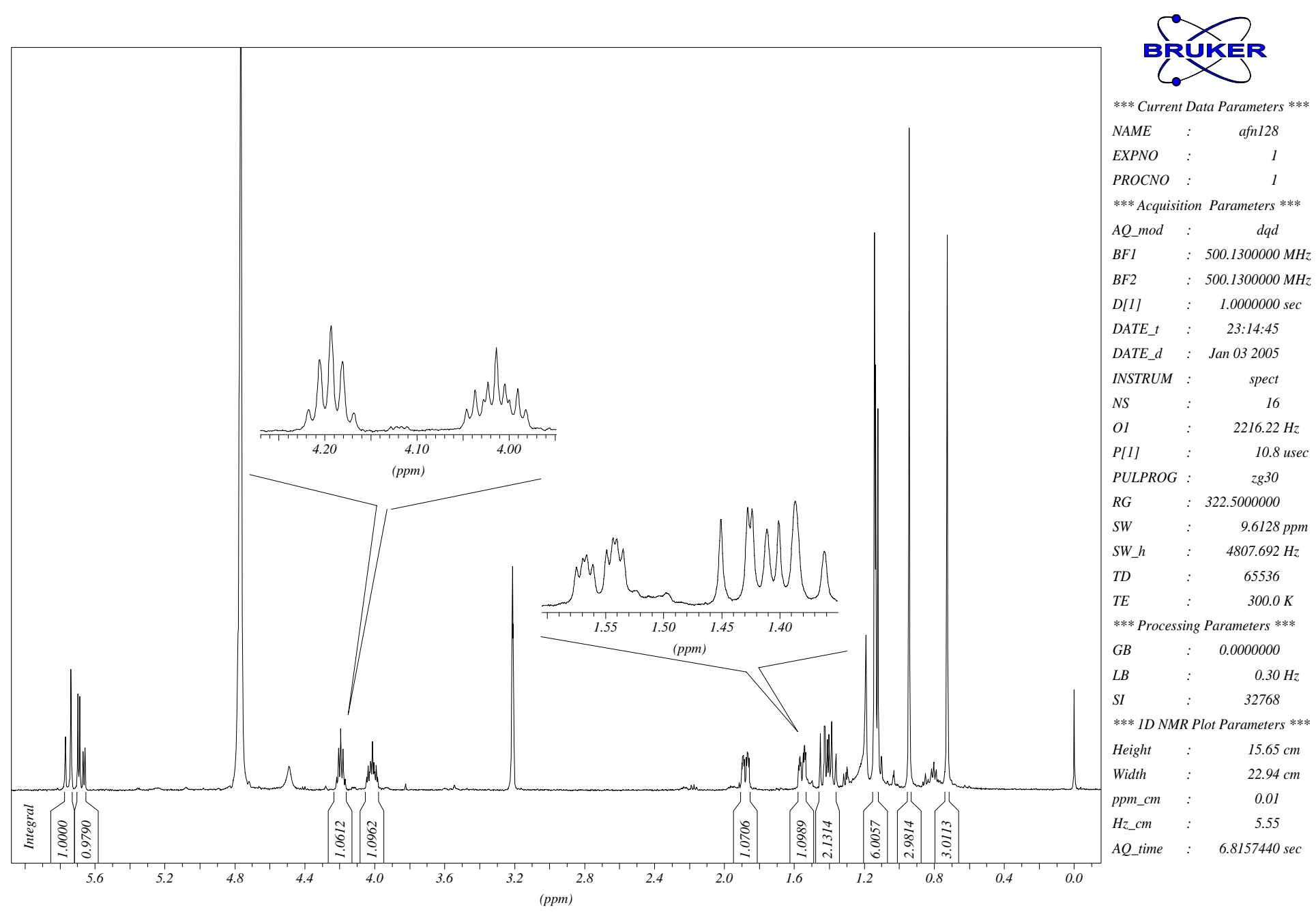


Tabela 55 - Dados espectrais de ${ }^{1} \mathrm{H}-\mathrm{RMN}$ do composto $30 \mathrm{a}$.

\begin{tabular}{cccc}
\hline$\delta(\mathbf{p p m})$ & Atribuição & Sinal & $J(\mathbf{H z})$ \\
\hline 5,75 & $\mathrm{H}_{10}$ & $\mathrm{~d}$ & $J_{10,11}=15,5$ \\
5,68 & $\mathrm{H}_{11}$ & $\mathrm{dd}$ & $J_{11,10}=15,5 ; J_{11,12}=6,5$ \\
4,20 & $\mathrm{H}_{12}$ & quin & $J_{12,13}=J_{12,11}=6,5$ \\
4,02 & $\mathrm{H}_{3}$ & $\mathrm{tt}$ & $J_{3,2 a x}=J_{3,4 a x}=11,6 ; J_{3,2 e q}=J_{3,4 e q}=4,6$ \\
1,88 & $\mathrm{H}_{4 \mathrm{eq}}$ & $\mathrm{ddd}$ & $J_{4 e q, 4 a x}=13,5 ; J_{4 e q, 3}=4,6 ; J_{4 e q, 2 e q}=2,6$ \\
1,55 & $\mathrm{H}_{2 \mathrm{eq}}$ & $\mathrm{ddd}$ & $J_{2 e q, 2 a x}=12,5 ; J_{2 e q, 3}=4,6 ; J_{2 e q, 4 e q}=2,6$ \\
1,43 & $\mathrm{H}_{4 \mathrm{ax}}$ & $\mathrm{dd}$ & $J_{4 a x, 4 e q}=13,5 ; J_{4 a x, 3}=11,6$ \\
1,39 & $\mathrm{H}_{2 \mathrm{ax}}$ & $\mathrm{dd}$ & $J_{2 a x, 2 e q}=12,5 ; J_{2 a x, 3}=11,6$ \\
1,19 & $\mathrm{OH}$ & $\mathrm{sl}$ & \\
1,14 & $\mathrm{H}_{9}$ & $\mathrm{~s}$ & \\
1,12 & $\mathrm{H}_{13}$ & $\mathrm{~d}$ & $J_{13,12}=6,5$ \\
0,94 & $\mathrm{H}_{7}{ }^{*}$ & $\mathrm{~s}$ & \\
0,72 & $\mathrm{H}_{8}{ }^{*}$ & $\mathrm{~s}$ & \\
\hline
\end{tabular}

Tabela 56 - Interação NOE observada no experimento de NOE-diff ${ }^{1} \mathrm{H}-$ RMN do composto 30a.

\begin{tabular}{ccc}
\hline $\boldsymbol{\delta}$ (ppm) irradiado & Atribuição & Efeito NOE observado \\
\hline 5,75 & $\mathrm{H}_{10}$ & $\mathrm{H}_{2 \mathrm{ax}}, \mathrm{H}_{4 a x}, \mathrm{H}_{12}$ \\
\hline
\end{tabular}


Espectro de ${ }^{13} \mathrm{C}-\mathrm{RMN}\left\{{ }^{1} \mathrm{H}\right\}\left(\mathrm{CD}_{3} \mathrm{OD}, 125 \mathrm{MHz}\right)$ do composto 30a:

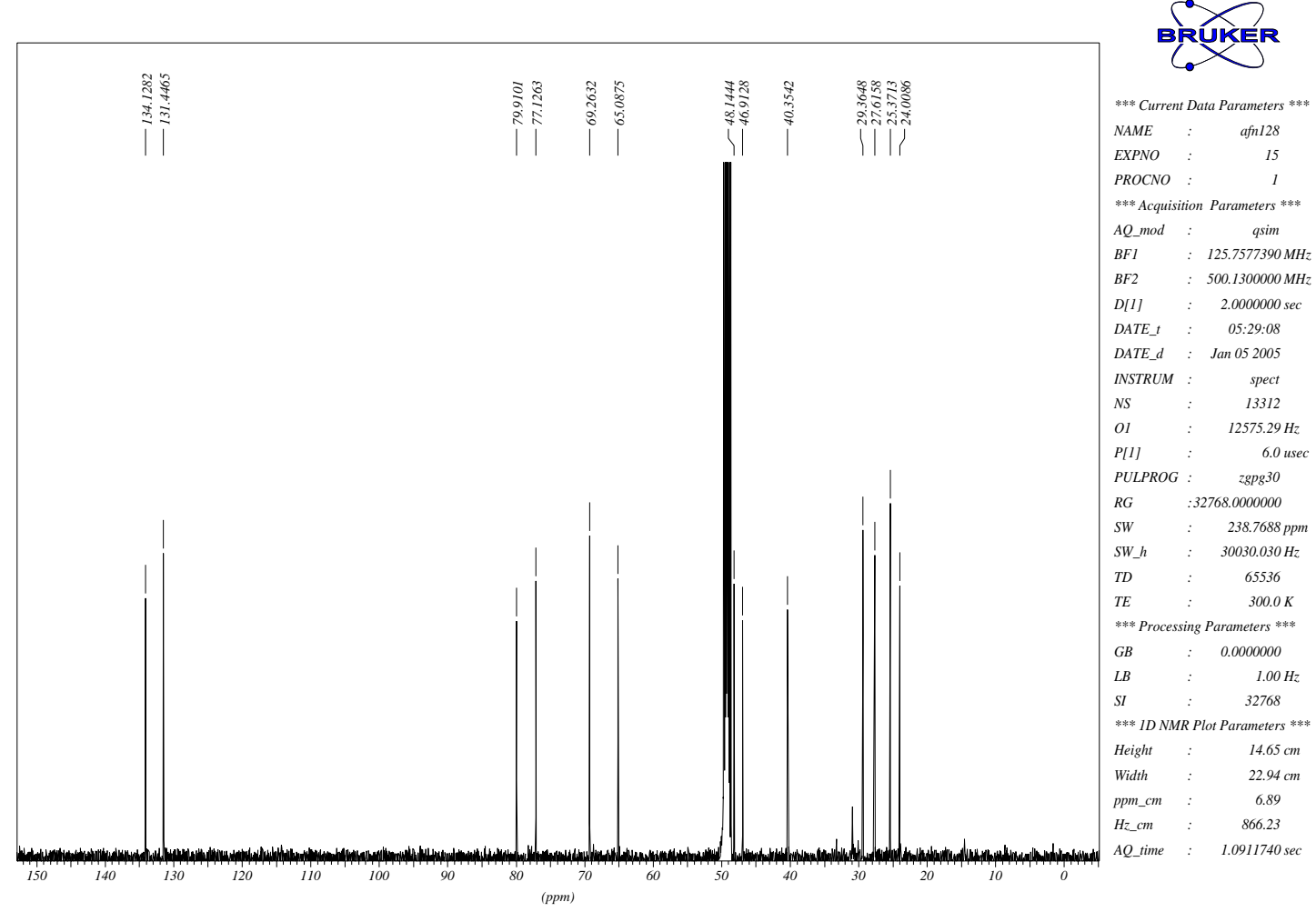

Espectro de ${ }^{13} \mathrm{C}-\mathrm{RMN}(\mathrm{DEPT}-135)\left(\mathrm{CD}_{3} \mathrm{OD}, 125 \mathrm{MHz}\right)$ do composto 30a:

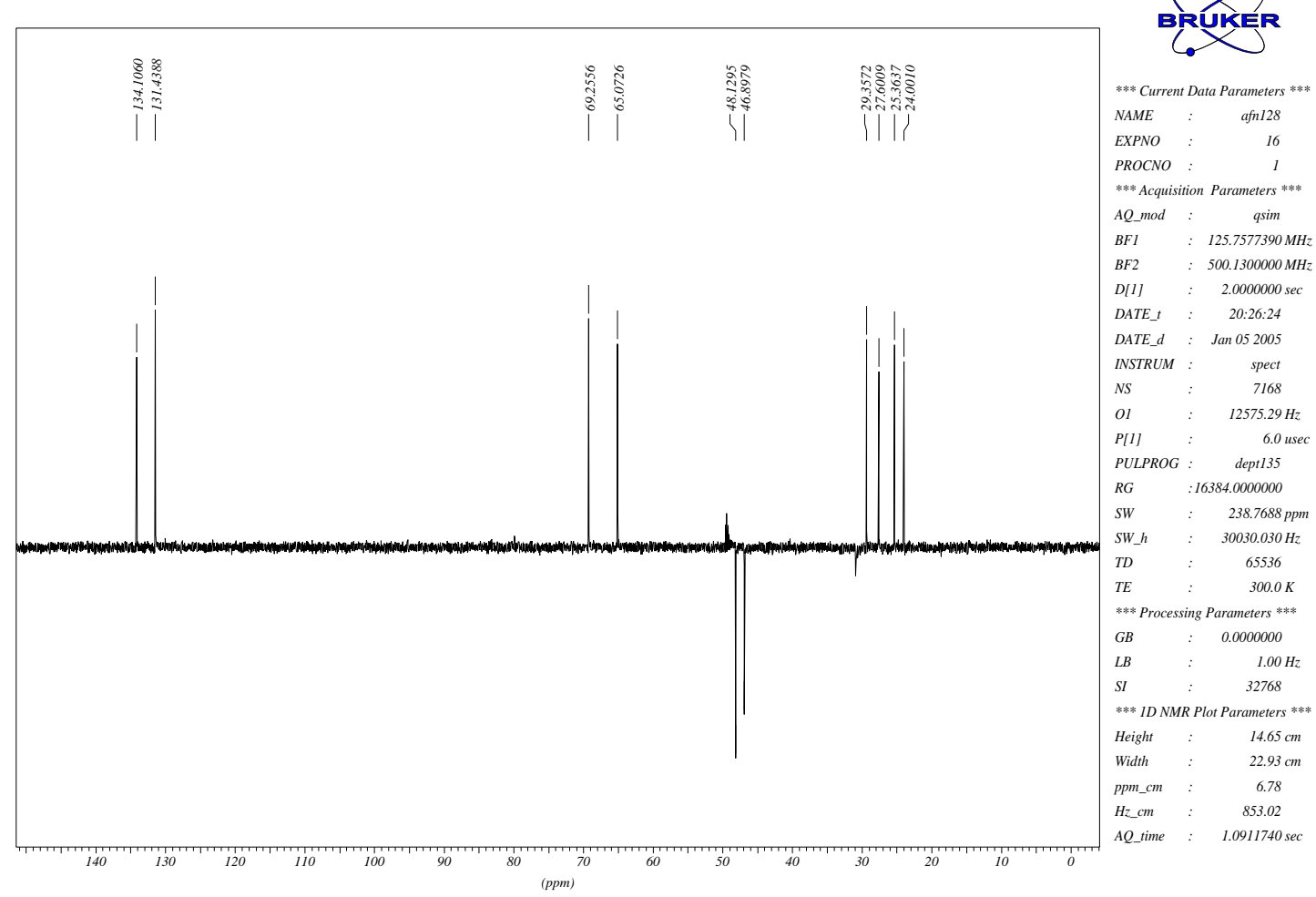


Tabela 57- Dados espectrais de ${ }^{13} \mathrm{C}-\mathrm{RMN}\left\{{ }^{1} \mathrm{H}\right\}$ do composto 30a.

\begin{tabular}{cc}
$\delta(\mathbf{p p m})$ & Atribuição* $^{*}$ \\
\hline 134,1 & $\mathrm{C}_{11}$ \\
131,4 & $\mathrm{C}_{10}$ \\
79,9 & $\mathrm{C}_{6}$ \\
77,1 & $\mathrm{C}_{5}$ \\
69,3 & $\mathrm{C}_{12}$ \\
65,1 & $\mathrm{C}_{3}$ \\
48,1 & $\mathrm{C}_{2}$ \\
46,9 & $\mathrm{C}_{4}$ \\
40,3 & $\mathrm{C}_{1}$ \\
29,4 & $\mathrm{C}_{8}^{* *}$ \\
27,6 & $\mathrm{C}_{7}^{* *}$ \\
25,4 & $\mathrm{C}_{9}$ \\
24,0 & $\mathrm{C}_{13}$ \\
\hline
\end{tabular}

* os carbonos foram atribuídos utilizando HMQC

${ }^{* *}$ podem estar trocados 


\section{Composto $30 \mathrm{~b}(3 \mathrm{~S}, 5 \mathrm{R}, 6 \mathrm{R})$}

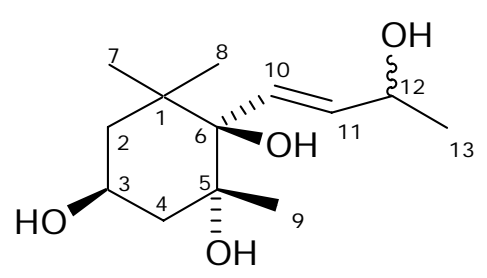

Os espectros de ${ }^{1} \mathrm{H}-\mathrm{RMN}$ e ${ }^{13} \mathrm{C}-\mathrm{RMN}$ apresentados a seguir são de uma mistura de dois pares de diasteroisômeros do composto $30 \mathrm{~b}$ (3S, 5R, 6R), onde todos os sinais aparecem sobrepostos.

A proporção desta mistura é de 1:1, calculada pelos valores das integrais. 
Espectro de ${ }^{1} \mathrm{H}-\mathrm{RMN}\left(\mathrm{CD}_{3} \mathrm{OD}, 400 \mathrm{MHz}\right)$ do composto $30 \mathrm{~b}$ :

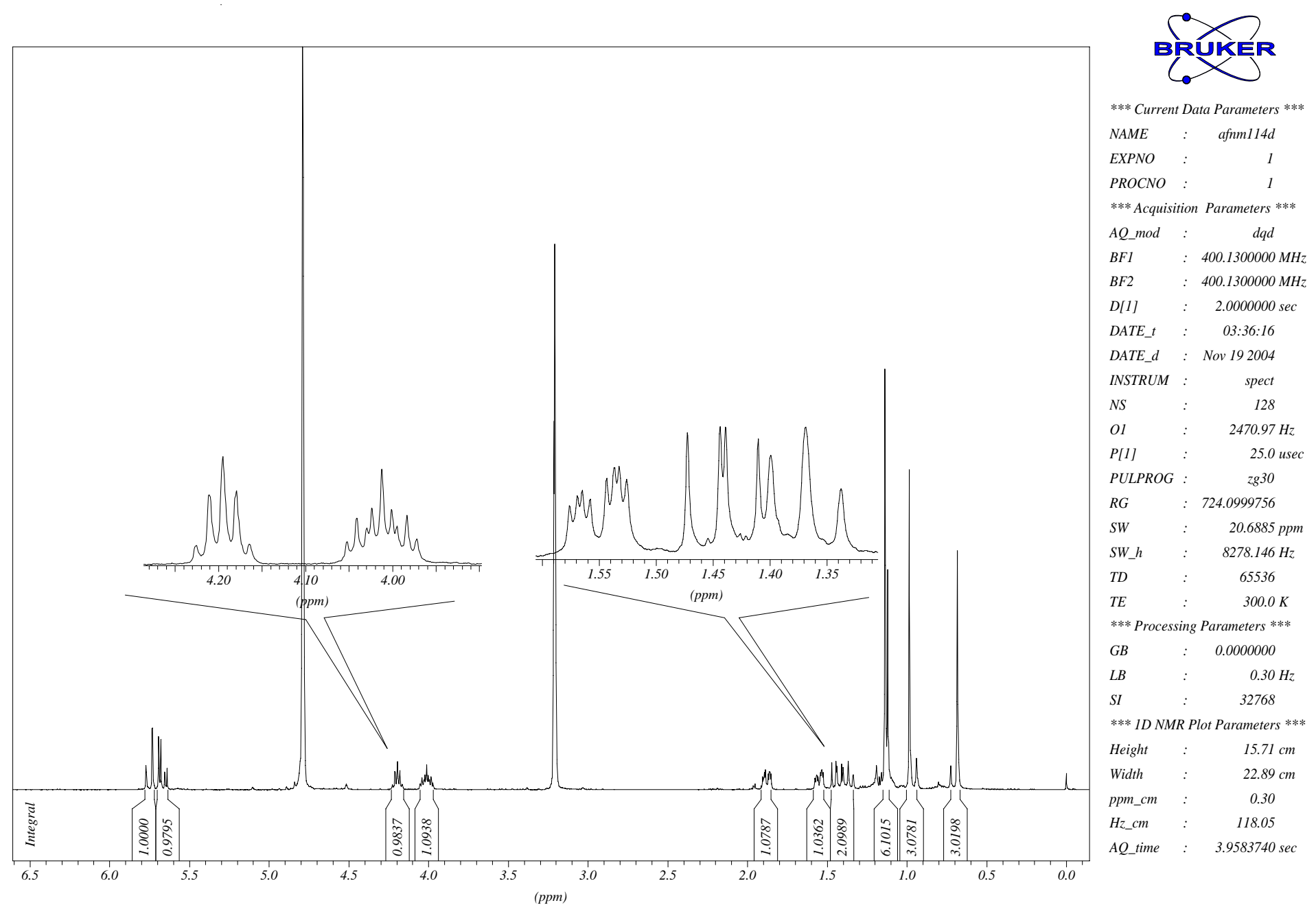


Tabela 58 - Dados espectrais de ${ }^{1} \mathrm{H}-\mathrm{RMN}$ do composto $\mathbf{3 0 b}$.

\begin{tabular}{cccc}
\hline$\delta(\mathbf{p p m})$ & Atribuição & Sinal & $J \mathbf{( H z})$ \\
\hline 5,75 & $\mathrm{H}_{10}$ & $\mathrm{~d}$ & $J_{10,11}=15,7$ \\
5,66 & $\mathrm{H}_{11}$ & $\mathrm{dd}$ & $J_{11,10}=15,7 ; J_{11,12}=6,5$ \\
4,20 & $\mathrm{H}_{12}$ & quin & $J_{12,13}=J_{12,11}=6,5$ \\
4,01 & $\mathrm{H}_{3}$ & $\mathrm{tt}$ & $J_{3,2 a x}=J_{3,4 a x}=11,6 ; J_{3,2 e q}=J_{3,4 e q}=4,5$ \\
1,88 & $\mathrm{H}_{4 \mathrm{eq}}$ & $\mathrm{ddd}$ & $J_{4 e q, 4 a x}=13,5 ; J_{4 e q, 3}=4,5 ; J_{4 e q, 2 e q}=2,5$ \\
1,55 & $\mathrm{H}_{2 \mathrm{eq}}$ & $\mathrm{ddd}$ & $J_{2 e q, 2 a x}=12,5 ; J_{2 e q, 3}=4,5 ; J_{2 e q, 4 e q}=2,5$ \\
1,44 & $\mathrm{H}_{4 \mathrm{ax}}$ & $\mathrm{dd}$ & $J_{4 a x, 4 e q}=13,5 ; J_{4 a x, 3}=11,6$ \\
1,37 & $\mathrm{H}_{2 \mathrm{ax}}$ & $\mathrm{dd}$ & $J_{2 a x, 2 e q}=12,5 ; J_{2 a x, 3}=11,6$ \\
1,14 & $\mathrm{H}_{9}$ & $\mathrm{~s}$ & $J_{13,12}=6,5$ \\
1,12 & $\mathrm{H}_{13}$ & $\mathrm{~d}$ & \\
0,98 & $\mathrm{H}_{7}{ }^{*}$ & $\mathrm{~s}$ & $\mathrm{~s}$ \\
0,68 & $\mathrm{H}_{8}{ }^{*}$ & & \\
\hline
\end{tabular}

* podem estar trocados

Tabela 59 - Interação NOE observada no experimento de NOE-diff ${ }^{1} \mathrm{H}-\mathrm{RMN}$ do composto $\mathbf{3 0 b}$.

\begin{tabular}{ccc}
\hline$\delta(\mathbf{p p m})$ irradiado & Atribuição & Efeito NOE observado \\
\hline 5,75 & $\mathrm{H}_{10}$ & $\mathrm{H}_{12}$ \\
\hline
\end{tabular}




\section{Espectro de ${ }^{13} \mathrm{C}-\mathrm{RMN}\left\{{ }^{1} \mathrm{H}\right\}\left(\mathrm{CD}_{3} \mathrm{OD}, 125 \mathrm{MHz}\right)$ do composto $30 \mathrm{~b}$ :}

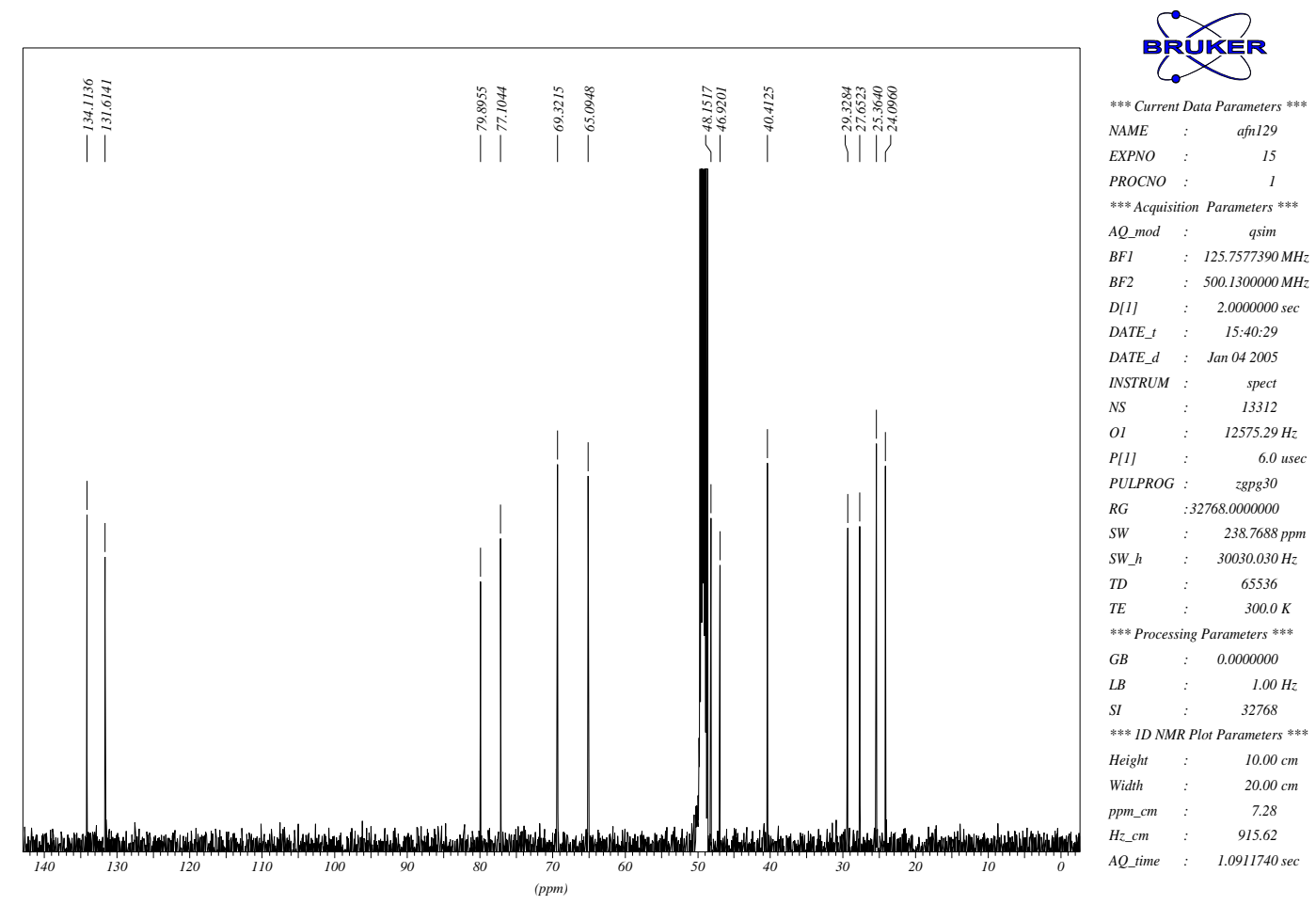

Espectro de ${ }^{13} \mathrm{C}-\mathrm{RMN}(\mathrm{DEPT}-135)\left(\mathrm{CD}_{3} \mathrm{OD}, 125 \mathrm{MHz}\right)$ do composto 30b:

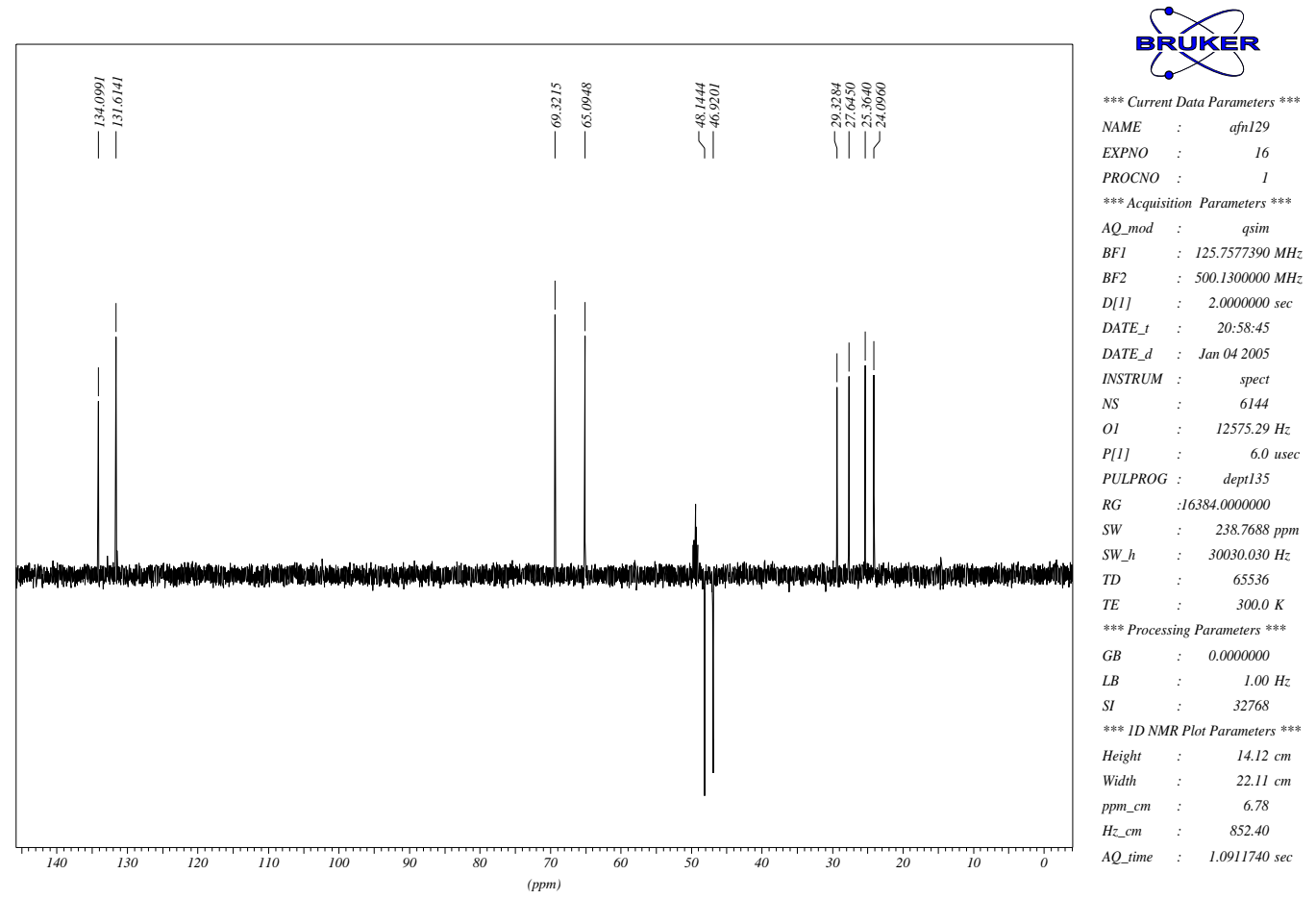


Tabela 60 - Dados espectrais de ${ }^{13} \mathrm{C}-\mathrm{RMN}\left\{{ }^{1} \mathrm{H}\right\}$ do composto $30 \mathrm{~b}$.

\begin{tabular}{cc}
$\delta($ ppm) & Atribuição $^{*}$ \\
\hline 134,1 & $\mathrm{C}_{11}$ \\
131,6 & $\mathrm{C}_{10}$ \\
79,9 & $\mathrm{C}_{6}$ \\
77,1 & $\mathrm{C}_{5}$ \\
69,3 & $\mathrm{C}_{12}$ \\
65,1 & $\mathrm{C}_{3}$ \\
48,1 & $\mathrm{C}_{2}$ \\
46,9 & $\mathrm{C}_{4}$ \\
40,4 & $\mathrm{C}_{1}$ \\
29,3 & $\mathrm{C}_{8}^{* *}$ \\
27,6 & $\mathrm{C}_{7}^{* *}$ \\
25,4 & $\mathrm{C}_{9}$ \\
24,1 & $\mathrm{C}_{13}$ \\
\hline
\end{tabular}

* os carbonos foram atribuídos utilizando HMQC

** podem estar trocados 


\section{Espectro de IV do composto 30b:}

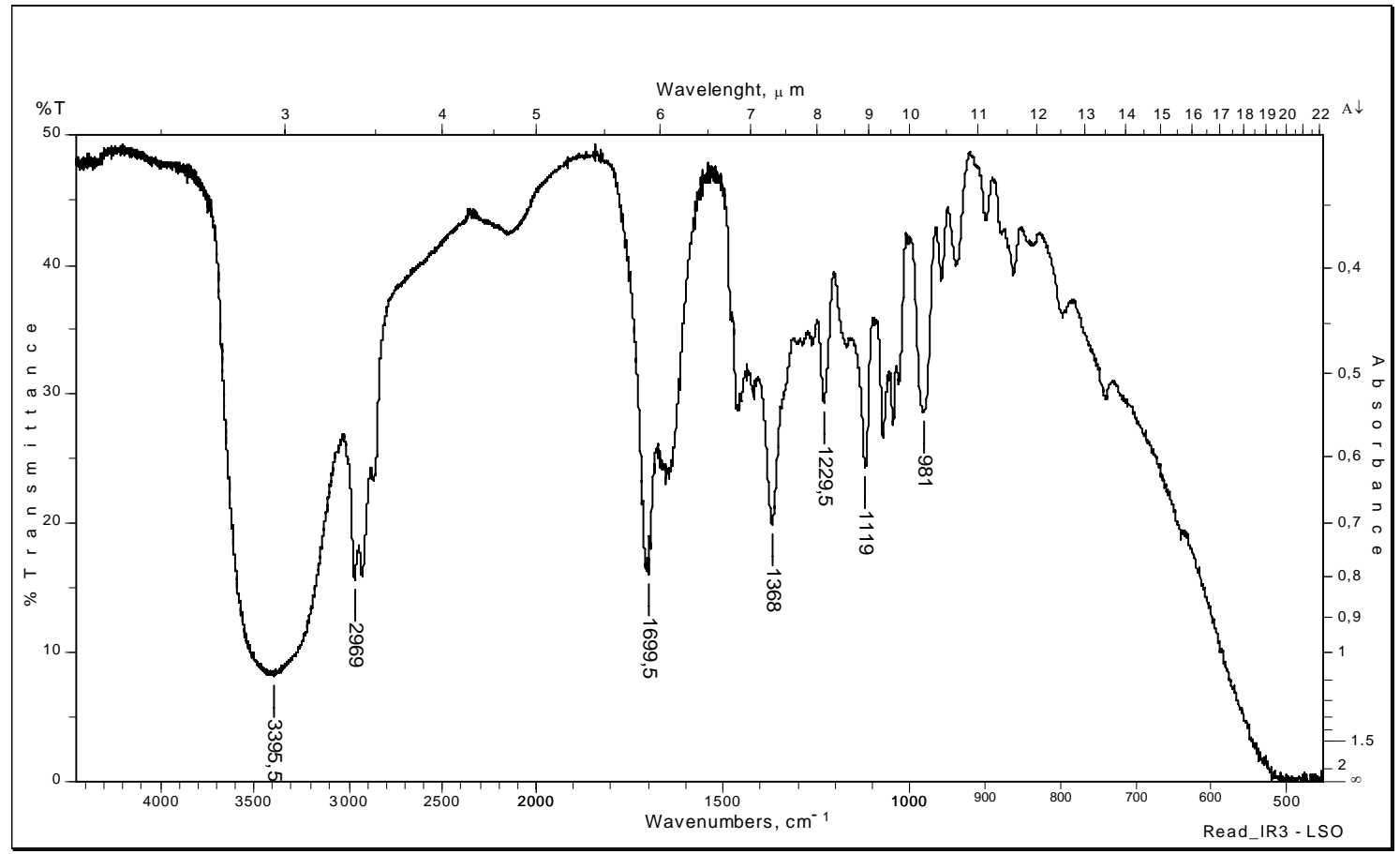

Tabela 61 - Dados espectrais de IV da mistura dos compostos 30a e 30b.

\begin{tabular}{cl}
\hline$v\left(\mathbf{c m}^{-1}\right)$ & \multicolumn{1}{c}{ Atribuição } \\
\hline 3395 & Deformação axial de OH \\
1699 & Deformação axial de C=C \\
1368 & Deformação angular no plano de OH \\
1229 & Deformação axial de C-O do álcool \\
981 & Deformação angular fora do plano de C-H da dupla ligação \\
\hline
\end{tabular}


1. G. Peckolt, Revista da Flora Medicinal, 1942, 9(9), 453.

2. J. P.P. Carauta, Albertoa, 1989, 2, 5.

3. D. Alzugaray, C. Alzugaray, Flora Brasileira, 1984, 204.

4. G. Peckolt, Revista da Flora Medicinal, 1942, 9(7), 333.

5. M. Nascimento, A. C. Arruda, M. S. P. Arruda, A. H. Müller, C. Y. C. Yoshioka, Fitoterapia, 1999, 70, 628.

6. D. Lopes, C. T. Villela, M. A. C. Kaplan, J. P. P. Carauta, Phytochemistry, 1993, $34,279$.

7. B. Baungartner, C. A. J. Erdelmeier, A. D. Wright, T. Rali, O. Sticher, Phytochemistry, 1990, 29, 3327.

8. N. Jain, R. N. Yadava, Fitoterapia, 1994, 65, 94.

9. E. O. Isler, Carotenoids, Birkhauser, Basel, 1971, 3.

10. T.W. Goodwin, Carotenoids, their comparative biochemistry, Chemical Publishing Co. Inc., New York, 1954, 1.

11. J. A. Olson, Journal Nutr., 1989, 119, 94.

12. S. K. Clinton, Nutr. Rev., 1998, 56, 35.

13. T. M. Devlin, "Manual de Bioquímica com Correlações Clínicas", Ed. Edgard Blucher, São Paulo, 4a .edição, 2000, 935.

14. S. B. Kritchevsky, J. Nutr., 1999, 129, 5.

15. C. R. Enzell, I. Wahlberg, A. I. Aasen, "Progress in the Chem. of Org. Nat. Prod.", Eds. Wien-Spinger, Verlag, 1977, 34, 1.

16. M. A. Stevens, J. Amer. Soc. Horticult. Sci., 1970, 95, 461.

17. G. W. Sanderson, J.G. Gonzalez, J. Food Sci., 1971, 36, 231.

18. S. Isoe, S. B. Hyeon, S. Katsumura, T. Sakan, Tetrahedron Lett., 1972, 2517.

19. C. R. Enzell, Pure and Applied Chem. 1969, 20, 497.

20. N. Ito, T. Etoh, H. Hagiwara, M. Kato, J. Chem. Soc. Perkin Trans. 1, 1997, 1571.

21. O. Takazawa, H. Tamura, K. Kogami, K. Hayashi, Bull. Chem. Soc. Jpn, 1982, 55, 1907.

22. J. Wirth, W. Guo, R. Baumes, Z. Gunata, J. Agric. Food Chem. 2001, 49, 2917. 
23. G. Ohloff, "Progress in the Chemistry of Organic Natural Products", Eds. Eds. Wien-Spinger, Verlag, 1978, 35, 431.

24. M. N. da Silva, A. C. Arruda, M. S. P. Arruda, A. H. Müller, C. Y. C. Yoshioka, Aripuanin: Um novo sesquiterpeno megastigmano isolado de Ficus aripuanensis, Livro de Resumos da 23a. Reunião Anual da Sociedade Brasileira de Química, Poços de Caldas, MG, 2000, resumo PN-015.

25. (a) P. M. Donate, "Síntese de Ácido Abscísico e Substâncias Correlatas", Tese de Doutoramento, IQ-USP, São Paulo, 1984. (b) M. G. Constantino, P. M. Donate, N. Petragnani, J. Org. Chem. 1986, 51, 253. (c) M. G. Constantino, P. M. Donate, N. Petragnani, J. Org. Chem. 1986, 51, 387.

26. (a) M. S. Kharasch, P. O. Tawney, J. Am. Chem. Soc. 1941, 63, 2308. (b) J. Meinwald, L. Hendry, J. Org. Chem. 1971, 36, 1446.

27. M. G. Constantino, P. M. Donate, D. Frederico, T. V. Carvalho, L. E. Cardoso, J. Zukerman-Schpector, Synth. Commun. 2000, 30, 3327.

28. T. W. Greene, P. G. M. Wuts, "Protective Groups in Organic Synthesis", John Wiley: N. York, 2a edição, 1991.

29. K. B. Wiberg, K. A. Saegebarth, J. Am. Chem. Soc. 1957, 79, 2822.

30. M. B. Smith, "Organic Synthesis", McGraw-Hill 1994, 281.

31. W. P. Weber, J. P. Shepherd, Tetrahedron Lett. 1972, 48, 4907.

32. S. Czernecki, C. Georgoulis, C. Provelenghiou, Tetrahedron Lett. 1976, 39, 3535.

33. G. Stork, T. Takahashi, J. Am. Chem. Soc. 1977, 99, 1275.

34. G. Hofle, W. Steglich, H. Vorbruggen, Angew. Chem. Inter. Ed. 1978, 17, 569.

35. L. Brandsma, "Preparative Acetylenic Chemistry”, Elsevier: Amsterdam, 1971.

36. J. J. Plattner, R. D. Gless, H. R. Rapoport, J. Am. Chem. Soc. 1972, 94, 8613.

37. H. Wetter, K. Oertle, Tetrahedron Lett. 1985, 26, 5515.

38. P. Nayler, M. C. Whiting, J. Chem. Soc. 1954, 4006.

39. H. J. Mayer, N. Rigassi, U. Schwieter, B. C. L. Weedon, Helv. Chim. Acta 1976, 59,1424 .

40. J. Auerbach, S. M. Weinreb, J. Chem. Soc. Commun. 1974, 298. 
41. N. Miyashita, A. Yoshikoshi, P. A. Grieco, J. Org. Chem. 1977, 42, 3772.

42. H. Monti, G. Leandri, M. Klos-Ringuet, C. Corriol, Synth. Commun. 1983, 13(12), 1021.

43. D. D. Perrin, W. L. F. Armarego, D. R. Perrin, "Purification of Laboratory Chemicals", Pergamon Press: Oxford, 2a edição, 1980. 